Design espacial-perceptivo: uma nova compreensão para representações visuais interativas 


\title{
Design espacial-perceptivo: uma nova compreensão para representações visuais interativas
}

\author{
José Fernando Rodrigues Júnior
}

Orientadora: Profa. Dra. Agma Juci Machado Traina

Tese apresentada ao Instituto de Ciências Matemáticas e de Computação - ICMC-USP, como parte dos requisitos para obtenção do título de Doutor em Ciências - Ciências de Computação e Matemática Computacional.

\section{"VERSÃO REVISADA APÓS A DEFESA"}

Data da Defesa:

$17 / 07 / 2007$

Visto do Orientador:

USP - São Carlos

Maio/2007 

(C) Direitos de cópia a José Fernando Rodrigues Júnior, 2007. Todos os direitos reservados. 



\section{Resumo}

Esta tese apresenta um arcabouço teórico para auxiliar o estudo e o projeto de técnicas de visualização interativa de dados. Tais técnicas, tradicionalmente, têm sido projetadas baseando-se na experiência dos analistas desenvolvedores. Muitos trabalhos, todavia, têm procurado desenvolver um espaço de compreensão coerente para explicar como as visualizações são compostas e para permitir a predição de novas abordagens para técnicas de visualização. No entanto, propostas precursoras apresentam inadequações, não sendo capazes nem de fomentar novas sistematizações nem de explicar a concepção das técnicas mais recentes encontradas na literatura.

Numa etapa inicial, esta tese revê conceitos em visualização, percepção e cognição procurando explicar como a análise visual de dados funciona. A revisão destes trabalhos é sintetizada em um processo de expressividade visual que correlaciona estímulos pré-atentivos, percepção visual analítica e interpretação cognitiva.

Em seguida, após uma extensa revisão de trabalhos relacionados, a discussão prossegue definindo um plano de teorização da constituição dos métodos de representação visual de dados. Este plano impulsiona o desenvolvimento de uma sistematização inicial na forma de uma taxonomia capaz de caracterizar os constituintes pré-atentivos das visualizações. Esta caracterização é orientada à percepção visual analítica, que é parte do processo de expressividade visual. Desta maneira, em uma abordagem orientada a percepções visuais, as técnicas de visualização são classificadas de acordo com um conjunto limitado de características comuns e de processos de espacialização de dados.

O próximo passo da discussão prossegue para a construção de um espaço de design com dimensões de posição, forma e cor. O espaço proposto, denominado Espaço de Design EspacialPerceptivo, considera a possibilidade de múltiplos ciclos de espacialização de dados e também técnicas de interação.

Baseando-se no espaço de design introduzido, a tese apresenta um modelo para a definição de parâmetros para o design de visualizações. Este modelo, que é um primeiro resultado da aplicação dos conceitos apresentados, prevê uma ferramenta para a definição, apresentação automática e avaliação empírica de representações visuais de dados.

O trabalho é encerrado com a descrição de dois sistemas completos para a visualização de grafos e de dados multi variados. Assim, na última parte do texto, os sistemas GMine e VisTree são formalmente apresentados e analisados como estudos de caso à luz da teoria desenvolvida na tese. 



\begin{abstract}
This thesis presents a theoretical framework to assist the study and the design of interactive data visualization techniques. Traditionally, visualization techniques have been designed based on analysts' experience. Many works, though, have sought to develop a coherent comprehension space to explain how visualizations are composed and to allow the prediction of new approaches for visualization techniques. However, precursor proposals present inadequacies and have not been able neither to furnish new systematizations nor to explain late techniques found in literature.

In an initial step, this thesis reviews concepts on visualization, perception and cognition aiming at explaining how visual data analyses work. The revision of these works is synthesized in a process of visual expressivity that interrelates pre-attentive stimuli, analytical visual perception and cognitive interpretation.

Then, after an extensive revision of related works, the discussion proceeds by structuring a plan for theorizing the constitution of methods for data visual representation. This plan furnishes the development of an initial systematization in the form of a taxonomy that characterizes the pre-attentive constituents of visualizations. This characterization considers visual analytical perceptions, which are part of the processes of visual expressivity. Like so, in a perceptions oriented approach, visualization techniques are classified according to a limited set of common characteristics and to data spatialization processes.

The next step in the discussion proceeds to the construction of a space with dimensions position, shape and color. The proposed space is named Spatial/Perceptual Design Space, it considers the possibility of multiple cycles of data spatialization and also interaction techniques.

Based on the design space just introduced, this thesis presents a model for the definition of parameters for visualization design. This model, which is a first result of the application of the presented concepts, foresees a tool for the definition, automatic presentation and empirical evaluation of visual data representations.

The work is finished with the description of two complete systems for the visualization of graphs and multivariate data. Hence, in the last part of the text, systems GMine and VisTree are formally presented and analyzed as study cases under the light of the theory introduced in the thesis.
\end{abstract}





\section{Dedicatória}

À minha esposa Fabíola, minha companheira, meu bem-estar. A pessoa mais importante da minha vida.

À minha orientadora Agma que, com carinho e dedicação, me guiou por novos horizontes.

Aos meus pais Fernando e Ivete, pelo apoio e por sempre acreditarem.

À minha sogra Dona Maria, pelo constante incentivo.

Aos meus co-orientadores Christos Faloutsos e Caetano Traina, provendo suporte e inspiração.

Às minhas queridas irmãs Telma e Eseli, por se orgulharem de mim.

Aos meus amigos Fúlvio de Freitas, André Balan, David Daugherty, Tia Aggie, Jia-Yu Pan (Tim) e Hanhang Tong.

Aos meus bons amigos do Grupo de Bases de Dados e Imagens do ICMC-USP (Humberto, Fábio, Enzo, Marcão, Joaquim, Camila, Mônica, Marcela, Ana Paula e Joseane), e a todos os meus amigos de Araraquara e de São Carlos.

A toda minha Família. 



\section{Sumário}

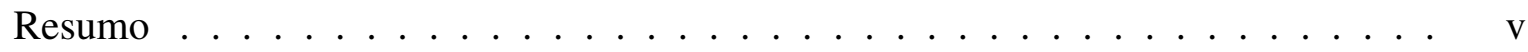

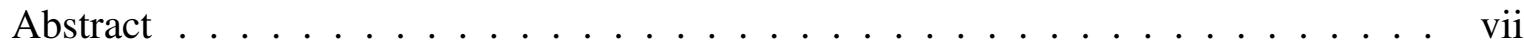

$\begin{array}{ll}\text { Lista de Figuras } & 1\end{array}$

$\begin{array}{ll}\text { Lista de Tabelas } & 5\end{array}$

Glossário de Termos 6

1 Introdução 9

1.1 Considerações Iniciais $\ldots \ldots \ldots$. . . . . . . . . . . . . . . . 9

1.2 Motivação . . . . . . . . . . . . . . . . . . . . . 11

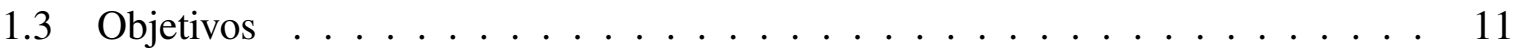

1.4 Desafios . . . . . . . . . . . . . . . . . . . . . 13

1.5 Resultados Obtidos . . . . . . . . . . . . . . . . . . . . 13

1.6 Organização do Trabalho . . . . . . . . . . . . . . . . . . . . . 14

I Conceitos, Embasamento e Estratégia de Racionalização 17

2 Análise Visual Interativa de Dados 19

2.1 Considerações Iniciais ． . . . . . . . . . . . . . . . . . . . . . . 19

2.2 O Processo de Análise . . . . . . . . . . . . . . . . . . . . 20

2.3 Visualização de Dados e Análise . . . . . . . . . . . . . . . . . . 21

2.4 Técnicas de Visualização de Dados . . . . . . . . . . . . . . . . . . . . . . . . . . 22

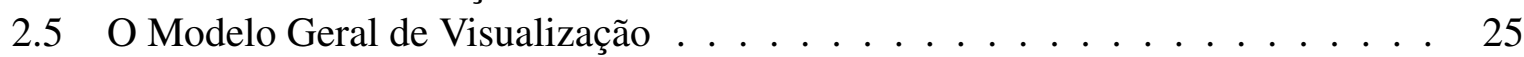

2.6 Interação em Análise Visual de Dados . . . . . . . . . . . . . . . . . . . 27

2.7 Considerações Gerais . . . . . . . . . . . . . . . . . . . . . . . . . . 29

3 Expressividade Visual $\quad 31$

3.1 Considerações Iniciais $\ldots \ldots \ldots$. . . . . . . . . . . . . . . . . . . . . . . . . . . . .

3.2 Estímulos Pré-atentivos . . . . . . . . . . . . . . . . . 31

3.3 Percepção Posicional e Espacialização . . . . . . . . . . . . . . . . . 33

3.4 O Processo de Expressividade Visual . . . . . . . . . . . . . . . . . . . . . . 34

3.5 Considerações Gerais . . . . . . . . . . . . . . . . . . . . . . 39

4 Taxonomias e Espaços de Design 4

4.1 Considerações Iniciais ． . . . . . . . . . . . . . . . . . . . 41

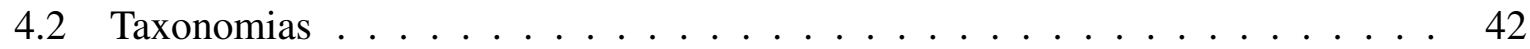


4.2.1 A Taxonomia de Shneiderman . . . . . . . . . . . . . . . . . . . 42

4.2 .2 A Taxonomia de Keim . . . . . . . . . . . . . . . . . . . . . . . . . . . . . . 43

4.2 .3 O trabalho de Bugajska . . . . . . . . . . . . . . . . . 46

4.2 .4 O trabalho de Tweedie . . . . . . . . . . . . . . . . . . . . 47

4.2 .5 A Taxonomia de Tory e Möller . . . . . . . . . . . . . . . . . . . . . . . . . . . . . . 48

4.2 .6 A Taxonomina de Chi . . . . . . . . . . . . . . . . . . 48

4.2 .7 Outros trabalhos . . . . . . . . . . . . . . . . 50

4.3 Espaços de Design . . . . . . . . . . . . . . . . . . 51

4.3.1 O Trabalho de Bertin . . . . . . . . . . . . . . . . 51

4.3 .2 Cleveland e McGill . . . . . . . . . . . . . . . . . . . 53

4.3 .3 O Trabalho de Mackinlay . . . . . . . . . . . . . . . . . . . 54

4.3.4 O Trabalho de Card e Mackinlay . . . . . . . . . . . . . . . . . 55

4.4 Diretrizes de Design . . . . . . . . . . . . . . . . . . . . . . . . . . . . . . . . . . 57

4.5 Considerações Gerais . . . . . . . . . . . . . . . . . . . . . . 59

5 Uma Nova Organização Abstrata 61

5.1 Considerações Iniciais . . . . . . . . . . . . . . . . . . . . 61

5.2 Raciocínio Abstrato . . . . . . . . . . . . . . . . . . . 61

5.3 Abstração em Trabalhos Prévios . . . . . . . . . . . . . . . . . . 63

5.4 Proposta de Organização Abstrata . . . . . . . . . . . . . . . . . . . . . 66

5.5 Considerações Gerais . . . . . . . . . . . . . . . . . . . 68

II Compreensão Espacial-Perceptiva 69

6 A Taxonomia Espacial-Perceptiva $\quad \mathbf{7 1}$

6.1 Considerações Iniciais . . . . . . . . . . . . . . . . . . . . . . . . . . . . . . . . . . . .

6.2 Espacialização . . . . . . . . . . . . . . . . . . . . . . . . . . . . . . . . . 72

6.3 Forma . . . . . . . . . . . . . . . . . . . . . 77

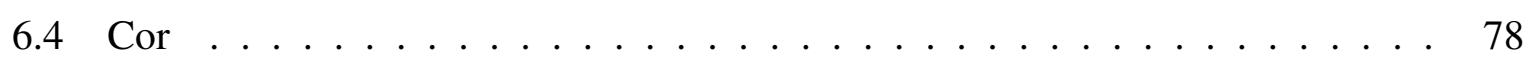

6.5 Exemplos Analíticos . . . . . . . . . . . . . . . . . . . 79

6.6 Espacializações Múltiplas . . . . . . . . . . . . . . . . . . . . . . . . . . . . . . . . 81

6.7 Considerações Gerais . . . . . . . . . . . . . . . . . . . . . 83

7 Um Novo Espaço de Design $\quad 85$

7.1 Considerações Iniciais $\ldots \ldots \ldots \ldots$. . . . . . . . . . . . . . . . . . . . . . . . . . . . . .

7.2 Design Espacial-Perceptivo . . . . . . . . . . . . . . . . . . . . . . . . . 85

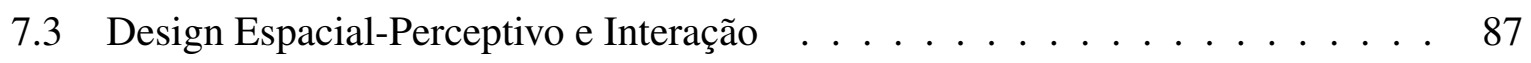

7.4 Considerações Gerais . . . . . . . . . . . . . . . . . . . . . . 90

8 Design Automatizado de Visualizações 91

8.1 Considerações Iniciais . . . . . . . . . . . . . . . . . . . . . . . . . . . . . . . . . . . . . . . . .

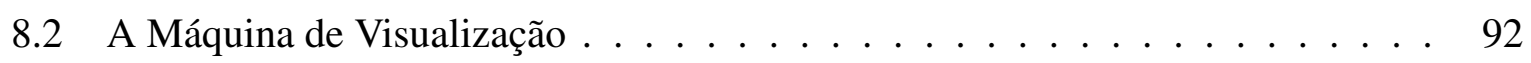

8.3 Considerações Gerais . . . . . . . . . . . . . . . . . . . . . . 95 


\section{Outras Contribuições e Conclusão}

9 Ampliação do Espaço de Visualização 99

9.1 Considerações Iniciais . . . . . . . . . . . . . . . . . . . . . . . . . . . . . . 99

9.2 Multi-resolução no Sistema GMine . . . . . . . . . . . . . . . . . . . . . . 100

9.2.1 Terminologia . . . . . . . . . . . . . . . . 101

9.2.2 Estendendo o conceito de SuperGrafo . . . . . . . . . . . . . . . . . 105

9.2.3 Conectividade entre SuperVértices . . . . . . . . . . . . . . . . . 105

9.2 .4 Conectividade entre vértices . . . . . . . . . . . . . . . . . . . . . . 107

9.2 .5 A Estrutura Graph-Tree . . . . . . . . . . . . . . . . . . . . . 107

9.2.6 Construindo uma Graph-Tree a partir de um grafo . . . . . . . . . . . 108

9.2.7 Visualização no Sistema GMine . . . . . . . . . . . . . . . . . . 111

9.2 .8 Análise do Sistema GMine . . . . . . . . . . . . . . . . . . . 113

9.3 Múltiplas exibições no Sistema VisTree . . . . . . . . . . . . . . . . 115

9.3.1 Filtragem Iterativa . . . . . . . . . . . . . . . . . . . . 116

9.3.2 Definindo uma árvore de visualização . . . . . . . . . . . . . . . . . 117

9.3.3 Análise do Sistema VisTree . . . . . . . . . . . . . . . . . . . 120

9.4 Considerações Gerais . . . . . . . . . . . . . . . . . . . . . . . . 121

10 Conclusão $\quad 123$

10.1 Contribuições . . . . . . . . . . . . . . . . . . . . 123

10.2 Resultados . . . . . . . . . . . . . . . . . . . . . . . . . . . . . . . . . . . . . . . . . . . . . . . .

10.3 Trabalhos Futuros . . . . . . . . . . . . . . . . . 125

$\begin{array}{lr}\text { Bibliografia } & 127\end{array}$ 



\section{Lista de Figuras}

1.1 A integração das frentes de pesquisa da Ciência Analítica Visual. Adaptado para o português do trabalho de Thomas e Cook [Thomas e Cook, 2005]. . . . 11

2.1 O processo de compreensão produzido por meio da prática estruturada da análise de dados. Adaptado do trabalho de Pirolli e Card [Pirolli e Card, 2005]. . . 21

2.2 Modelo geral de visualização adaptado de [Card et al., 1999] e de [Upson et al., 1989]. . . . . . . . . . . . . . . . . 26

3.1 Exemplo de pré-atenção. A contagem da quantidade de símbolos "4" (total de 22) na imagem (a) é mais fácil quando os símbolos estão enfatizados, como na imagem (b). Adaptado de [Ware, 2004] . . . . . . . . . . . . . . . . 32

3.2 Estímulos pré-atentivos. . . . . . . . . . . . . . . . . 32

3.3 O modelo de Kowk-Chu $\mathrm{Ng}$ [Ng, 2000] o qual, além de interação, relaciona processos perceptivos, processos cognitivos e tarefas visuais (observação). . . . 34

3.4 O Processo de Expressividade Visual. . . . . . . . . . . . . . . . . . . 35

3.5 Princípios de Gestalt. . . . . . . . . . . . . . . . . . . . . . 36

4.1 A taxonomia de Shneiderman, tarefas definidas em função do tipo dos dados. . 42

4.2 A taxonomia de Keim, um espaço com dimensões de interação, tipo dos dado e técnica de visualização. . . . . . . . . . . . . . . . . . . . . . . 43

4.3 O espaço de classificação de Bugajska. O Modelo de Classificação de Design Espacial prevê uma apreciação holística das técnicas de VisInfo. Adaptado de [Bugajska, 2005]. . . . . . . . . . . . . . . . 46

4.4 A taxonomia de Tory e Möller que categoriza a VisInfo e a VisC como técnicas contínuas e discretas. Adaptado de [Tory e Möller, 2002] . . . . . . . . . . . . .

4.5 O Modelo de Referência de Estado dos Dados, base da taxonomia proposta por Chi $[$ Chi, 2000]. . . . . . . . . . . . . . . . . . 50

4.6 O espaço de design proposto por Bertin junto com um exemplo ilustrativo. . . . 52

4.7 Adequação dos padrões de percepção visual. Os padrões envoltos em retângulos não se aplicam ao tipo de dado correspondente à coluna. Adaptado do trabalho de Mackinlay [Mackinlay, 1986]. . . . . . . . . . . . . . . . . .

4.8 (a) A tabela de referência proposta por Card e Mackinlay [Card e Mackinlay, 1997], nela os constituintes de uma dada técnica de visualização são anotados para rápida referenciação e comparação com outras técnicas. (b) Um exemplo de notação para uma projeção simples com codificação de cor e forma sem transformação de dados. . . . . . . . . . . . . . 56

5.1 Diferentes níveis de abstração de um carro. . . . . . . . . . . . . . . . . . 62 
5.2 Organização abstrata proposta neste trabalho para sistemas de visualização aplicados à análise visual de dados. . . . . . . . . . . . . . . . . . . . . . . .

6.1 (a) Exposição estrutural via Tree-maps. Posição: arranjo por meio de hierarquia recursiva; forma: correspondência contínua por meio de proporcionalidade de tamanho; cor: diferenciação discreta. (b) Exposição estrutural de um grafo via algoritmo "dirigido por força". Posição: arranjo por meio de proximidade dos relacionamentos; forma: conectividade e significado por meio de setas; cor: diferenciação discreta. . . . . . . . . . . . . . . .

6.2 (a) Seqüenciamento na técnica Pixel Bar Charts - num conjunto de dados hipotético, os pixels mapeiam diferentes transações de vários fabricantes. Posição: correspondência discreta por meio do mapa não ordenado de rótulos de fabricantes, e correspondência contínua por meio do mapa mental declarado em ordem vertical ascendente de tempo; forma: correspondência contínua por meio da largura das colunas; cor: correspondência contínua. (b) Seqüenciamento na técnica Gráfico de Pizza. Posição: correspondência discreta por meio do mapa circular não ordenado de rótulos; forma: correspondência contínua por meio do tamanho da área, significado por meio de texto (composição de formas); cor: diferenciação discreta. . . . . . . . . . . . . . . . .

6.3 (a) Projeção via gráfico funcional 3D. Posição: correspondência contínua por meio do mapa de três eixos ortogonais; arranjo significativo por meio de interpolação de linhas (à esquerda) e de superfície (à direita); forma: não escolhida explicitamente no design; cor: sem expressividade. (b) Projeção via Star Coordinates com oito dimensões. Posição: correspondência contínua por meio do conjunto de eixos; forma: sem expressividade; cor: correspondência discreta por meio das cores dos itens de informação e das cores do eixo $D_{5} \ldots \ldots$. . .

6.4 (a) Reprodução via um conjunto de dados renderizado. Posição: significado por meio da forma criada com interpolação visual dos pontos do espaço; forma: não escolhida explicitamente no design; cor: correspondência contínua. (b) Reprodução via mapa geográfico. Posição: correspondência contínua por meio do mapa visual geográfico, dos pontos e das linhas de marcação; forma: significado por meio dos ícones que identificam aeroportos, e diferenciação por meio da estrela que identifica uma cidade mais importante (ao centro); cor: diferenciação discreta e significado por meio do conhecimento prévio de que água é azul. Imagem (a) reproduzida com permissão de S. G. Eick.

6.5 (a) Projeção de itens classificados. Posição: correspondência contínua por meio do mapa de dois eixos ortogonais; forma: correspondência discreta por meio do mapa de formas na parte inferior, e diferenciação por meio do retângulo de seleção; cor: correspondência discreta, e diferenciação por meio do retângulo de seleção em amarelo. (b) Projeção via Faces de Chernoff. Posição: correspondência contínua por meio do mapa de dois eixos ortogonais, e correspondência discreta por meio do mapa da face humana; forma: correspondência contínua por meio do tamanho e da curvatura dos elementos faciais; cor: sem expressividade. . . . . . . . . . . . . . . . . 
6.6 (a) Reprodução tridimensional sobre um mapa visual do globo terrestre. Posição: correspondência contínua por meio do mapa visual do globo terrestre; forma: correspondência por meio do tamanho dos pilares nos pontos de interesse, e conectividade por meio das linhas curvilíneas unindo diferentes pontos; cor: correspondência discreta. (b) Reprodução de estrutura química. Posição: correspondência contínua por meio do mapa de três eixos ortogonais, e significado por meio da forma criada via interpolação visual dos pontos do espaço; forma: não escolhida explicitamente no design; cor: correspondência contínua. Imagens (a) e (b) reproduzidas com permissão de S. G. Eick. . . . . . . . 79

6.7 Design de um gráfico de pizza. . . . . . . . . . . . . . . . . . . . . 80

6.8 Design da técnica baseada em posicionamento de pixels em espiral. . . . . . . 81

6.9 Design da técnica Coordenadas Paralelas. . . . . . . . . . . . . . . . . 82

6.10 Dois ciclos de espacialização aplicados na concepção de uma visualização. (a) Projeção de Star Glyphs. (b) Foco num glifo em particular. (c) Seqüenciamento dentro do glifo. (d) Informação de atributo como uma correspondência de forma. 83

7.1 Espaços de Design. (a) O Espaço de Design Perceptivo com dimensões de posição, forma e cor cujos domínios são subconjuntos das percepções visuais identificadas. (b) O Espaço de Design Espacial-Perceptivo onde a percepção de posição é ditada por processos de espacialização. (c) O completo Espaço de Design Espacial-Perceptivo que inclui múltiplos ciclos de espacialização.

8.1 O modelo generalizado de design automatizado de visualizações, denominado Máquina de Visualização. . . . . . . . . . . . . . . . . . . . .

9.1 Exemplo de um grafo e sua respectiva representação hierárquica em SuperGrafo. 102

9.2 Matrizes de adjacências em multi-resolução. (a) Matriz de adjacências. (b) Primeiro nível de agregação de vértices e arestas. (c) Segundo nível de agregação de vértices e arestas. . . . . . . . . . . . . . . . . . . . . . . . . . 104

9.3 Exemplo de Graph-Tree. . . . . . . . . . . . . . . . . . . . . . . . . . 108

9.4 Componentes da Graph-Tree. . . . . . . . . . . . . . . . . . . . . . . . . 109

9.5 Particionamento recursivo. A informação é embutida na estrutura Graph-Tree que irá guiar o desenho e a interação com o SuperGrafo. . . . . . . . . . . . 110

9.6 Ilustração do processo de preenchimento da Graph-Tree. De (a) a (c), particionamento hierárquico e criação da árvore vazia. De (d) a (g), ilustração do algoritmo utilizado para preencher a Graph-Tree.

9.7 Ilustração do sistema GMine. (a) Visão geral de um grafo de relacionamentos (mensagens eletrônicas) de funcionários de três empresas hipotéticas. (b) Relacionamentos entre os funcionários de diferentes departamentos de diferentes empresas. (c) Detalhes sob demanda dos relacionamentos entre duas empresas. (d) Resolução mais alta para focar na partição que representa uma empresa em particular. Parametrização das propriedades de forma e cor do grafo que representa um departamento de interesse. . . . . . . . . . . . .

9.8 Espacialização do sistema GMine. Três níveis de particionamento espacial recursivo semelhante a uma R-Tree balanceada e orientada a ângulos de regiões circulares. . . . . . . . . . . . . . . . . . . . . . 114 
9.9 Ilustração do sistema VisTree. O mesmo conjunto de dados pode ser visualmente particionado em diferentes exibições automaticamente integradas. No exemplo a técnica Table Lens dá origem a visualizações baseadas em Star Coordinates. Por sua vez, as Star Coordinates originam Coordenadas Paralelas. Sobre as visualizações pode-se observar interação de filtragem e sumarização estatística explorada por meio de diferenciação de cor e forma. . . . . . . . . . . 115

9.10 Filtragem iterativa. (a) Componentes da filtragem iterativa. (b) Meta funções que a definem. (c) Ciclo da filtragem iterativa, o qual se repete indefinidamente. 116

9.11 Ciclo interativo de filtragem iterativa. . . . . . . . . . . . . . . 118

9.12 Construção da árvore de visualização. (a) Exploração seqüiencial definindo um ramo de análise mais profundo. (b) Exploração paralela definindo um ramo de análise paralelo. (c) Exploração em ramos mais profundos da árvore. . . . . . . .

9.13 Posicionamento de vértices no sistema VisTree. A primeira ilustração no canto superior esquerdo mostra a configuração desejada e a ordem de varredura dos vértices por meio de numeração. Os passo do 1 ao 8 ilustram o posicionamento dos vértice 5 a 8 no intuito de se obter a configuração desejada. Para cada vértice posicionado, seu "primeiro vértice acima" considerado para reposicionamento é destacado com círculos vermelhos. Vértices filhos considerados para reposicionamento são destacados com elipses azuis. . . . . . . . . . . . . . .

9.14 Interação sobre o sistema VisTree. (a) O contexto instantâneo mostra onde na estrutura da árvore está localizado um vértice de interesse. (b) Para árvores grandes, a apresentação normal pode esconder detalhes contextuais. (c) $\mathrm{O}$ foco instantâneo apresenta os detalhes de uma dada exibição aumentando o tamanho da respectiva janela. . . . . . . . . . . . . . . . . . . 121 


\section{Lista de Tabelas}

2.1 Amplificação da cognição possibilitada pelas técnicas de visualização. Adaptado da obra de Card et al [Card et al., 1999]. . . . . . . . . . . . . . . . . . .

4.1 Caracterização de técnicas de externalização. Adaptado do trabalho de Tweedie [Tweedie, 1997]. . . . . . . . . . . . . . . . . . . .

4.2 Marcas-propriedades e possibilidades de apresentação com relação aos níveis organizacionais cognitivos. Adaptado da obra de Bertin [Bertin, 1974] . . . . . . 52

7.1 Exemplos de análise espacial-perceptiva considerando configurações comuns para técnicas de visualização conhecidas. . . . . . . . . . . . . . 88 


\section{Glossário de Termos}

\author{
Análise Visual de Dados
}

Abstração

Análise Confirmativa

Análise Exploratória

Apresentação Analítica

Atividade de Análise

\section{Ciência Analítica Visual}

Cognição

Cognição Externa

Dados Nominais

Dados Ordinais

Dados Quantitativos

Diretrizes de Design estuda as representações visuais de conjuntos de dados e lida com as questões envolvidas no respectivo processo de sistematização. Contexto do presente estudo relacionado tanto à Visualização de Informações quanto à Ciência Analítica Visual, 9

reflexão por meio da qual coisas originalmente unidas podem ser consideradas separadamente, em maiores (análise) ou em menores (generalização) detalhes, 62

investigação analítica para validação de uma hipótese já existente, 19

investigação analítica sem hipótese pré-definida, 19 demonstração de fatos já identificados por meio de análise, 19

refere-se à apreciação (ao exame) de uma questão sob a luz de um propósito decisório num contexto de julgamento, 20

ciência que visa a permitir que as faculdades humanas (percepção visual e cognição) possam ser combinadas com ferramentas computacionais para auxiliar tarefas de análise de dados, 10

aquisição ou o uso de conhecimento, 19

corresponde à totalidade do relacionamento entre representação externa (como as coisas são observadas) e representação interna (como as coisas são imaginadas) considerando a interação entre ambas as representações, 19

dados que não podem ser ordenados nem passar por operações aritméticas, suportam apenas o conceito de igualdade, 26

dados que obedecem a uma relação de ordem, 26 dados passíveis de operações aritméticas, 26 definição de regras e princípios provindos de conhecimento experimental compartilhados na forma de conjuntos de diretrizes, 57 
Escalabilidade

Escalabilidade Visual

Espaço de Design em VisInfo

Espacialização de Dados

Interpretações Cognitivas

Múltiplas Exibições

Mantra da Visualização

Organização analítica

Organização Taxonômica

Percepção

Percepções Visuais Analíticas

Pré-processamento

Princípios de Gestalt

Processamento Atentivo capacidade para lidar com uma quantidade maior de dados, 10

obtenção de representações e de ferramentas visuais capazes de exibir grandes conjuntos de dados de maneira eficaz considerando sua cardinalidade e dimensionalidade, 11

refere-se ao delineamento do universo de possibilidades dentro do qual as representações visuais se encaixam, 12

refere-se à codificação de dados para um formato espacial/visual, 33

conclusões, inferências ou deduções provenientes do auxílio visual da cena de visualização em conjunto com o conhecimento do domínio dos dados sendo analisados, 38

sistemas que usam uma ou mais visualizações para investigar uma única entidade conceitual, 58 descrição sucinta da atividade natural realizada por uma pessoa sobre um objeto de investigação num contexto de visualização, 28

tenta identificar empiricamente os constituintes elementares das visualizações e determinar a relação que existe entre eles, 41

tenta identificar características semelhantes pertencentes a visualizações já existentes com o intuito de propor organizações orientadas a classes, 41

faculdade humana cujo propósito é a detecção de informações, 31

conjunto de fenômenos úteis para análise que são deflagrados por estímulos pré-atentivos, 35

procedimentos que visam converter os dados para um formato adequado ao processo de visualização, 25

teorias de percepção visual, desenvolvidas por psicólogos alemães na década de 1920, que tentam descrever como as pessoas tendem a organizar elementos visuais em grupos, ou em "totalidades unidas", quando certos princípios se aplicam, 36

segunda fase do processo visual, compreende a busca por detalhes da cena de visualização sendo realizada seqüencialmente e mais lentamente do que o processamento pré-atentivo, 31 
Processamento Pré-atentivo

Renderização

Resultados de Análise

Semiótica

Substrato Espacial

Tabela de Dados

VisC

VisInfo

Visualização Científica

Visualização de Informações

Voxels primeira fase do processo visual, diz respeito à extração de propriedades de baixo nível realizada em paralelo pelo sistema visual, 31

uma visão global de como as visualizações produzem conhecimento útil considerando a relação entre processo perceptivo, processo cognitivo e tarefas visuais, 34

técnicas que transformam primitivas espaciais de exibição em uma imagem plana, 27

conclusões referentes a processos de avaliação (compreensão e explicação), de previsão (identificar possibilidades futuras) e de definição de opções (estimar alternativas e suas implicações), tudo no contexto de uma dada configuração a partir da qual as questões foram levantadas, 20

o estudo de símbolos e como eles provêem significado, 13

meio dentro do qual as visualizações são possíveis por meio de marcas e de propriedades gráficas aplicáveis às marcas, 55

um conjunto de tuplas e meta-dados descrevendo relacionamentos entre elas, 25

Visualização Científica, 22

Visualização de Informações, 10

visualizações baseadas em dados que possuem uma representação natural espacial ou física, 24

visualizações baseadas em dados abstratos que carecem de uma representação relacionada a formas conhecidas físicas ou concretas, 24

unidades constituintes de dados volumétricos representados por vetores tri-dimensionais de células cúbicas, 25 


\section{Capítulo 1}

\section{Introdução}

\subsection{Considerações Iniciais}

Esta tese é sobre Análise Visual de Dados Interativa, uma área de pesquisas que estuda as representações visuais de conjuntos de dados e que lida com as questões envolvidas no respectivo processo de sistematização de tais representações. O objetivo desta área de pesquisas é tirar proveito das faculdades perceptivas e cognitivas do ser humano em tarefas analíticas. A análise visual de dados trata da problemática envolvida na apresentação gráfica interativa de conjuntos de dados de maneira que as informações sejam codificadas em imagens, tornando a compreensão mais facilmente assimilada pelo usuário analista.

A ciência de análise visual foi impulsionada pela prática da cartografia, que se baseia na representação visual a partir de abstrações do mundo real. Os seres humanos percebem os objetos à sua volta como um todo ao invés de seus componentes elementares como curvas, arestas, brilho, cor, dentre outras. Isto se deve à capacidade humana de organização perceptiva. Automaticamente e sem esforço, esta capacidade é responsável pela estruturação de pedaços de informação visual de maneira que, dada uma organização espacial adequada, é possível perceber objetos e relacionamentos entre eles [Kimchi, 1998]. O mesmo princípio é aplicado na análise visual de dados auxiliada por computador que envolve a ciência de computação, a computação gráfica, a semiótica e a psicologia no intuito de criar representações visuais válidas de conjuntos de dados. Na ciência de computação, em particular, as principais linhas investigativas envolvidas são as metodologias de projeto (denominadas a partir daqui como design) gráfico, o tratamento da progressão escalar (denominada a partir daqui como escalabilidade) do volume de dados, o pré-processamento de dados, a interação usuário-computador, as percepções visual e sonora e a integração a técnicas de mineração de dados, além de pesquisas em maquinário especializado para tais propósitos. 
Pode-se afirmar que as maiores vantagens oferecidas pela prática da análise visual de dados auxiliada por computador são sua escalabilidade - capacidade para lidar com uma quantidade maior de dados - e sua interatividade. Estas vantagens se tornam claras quando se imagina um gráfico de análise de dados desenhado sobre papel. O papel é estático e, quanto mais dados, mais tempo é necessário para o traçado do gráfico.

Nos últimos 15 anos a análise visual de dados auxiliada por computador tem sido denominada Visualização de Informações (VisInfo) [Keim, 2002]. Nesta conceituação, diversos progressos foram realizados em suas sub-especialidades. Estes progressos foram reunidos em publicações e eventos, como nas revistas ACM Transactions on Applied Perception (http: //www. acm.org/tap) e IEEE Transactions on Computer Graphics, e nas conferências IEEE Symposium on Information Visualization (http://conferences . computer .org/infovis/) e Workshop on Smart Graphics (http://www.smartgraphics.org/). No decorrer deste período a ciência VisInfo convergiu de uma aplicação mais concentrada em design gráfico para se tornar um grupo de especialidades integradas definindo uma maior amplitude. Em trabalhos recentes, surgiu uma nova nomenclatura denominada Visual Analitcs (do inglês, Ciência Analítica Visual) [Thomas e Cook, 2005] [Jern et al., 2006].

A Ciência Analítica Visual, como descrita em publicações recentes, visa a permitir que as faculdades humanas, a percepção visual e a cognição, possam ser combinadas com ferramentas computacionais para auxiliar tarefas de análise de dados. Formalmente, veja a figura 1.1, a Ciência Analítica Visual é constituída pela integração das seguintes áreas de pesquisa: "Raciocínio Analítico", "Representações Visuais e Interação", "Representações e Transformações de Dados", "Produção, Apresentação e Disseminação". Os objetivos vislumbrados incluem: compreensão e síntese de informações, comunicação e avaliação, detecção de padrões (especialmente os não previstos) e, sobretudo, discernimento decisório. Trata-se da possibilidade de diálogo entre dados e seres humanos facilitada por mecanismos interativos desenvolvidos com base em princípios de percepção, design visual e cognição.

Dado o relacionamento entre as conceituações, o termo mais conhecido Visualização de Informações e o mais amplo Ciência Analítica Visual, o presente trabalho foca numa área de pesquisas relacionada a ambos: o Espaço de Design para Representações Visuais Interativas. Assim, ao longo do texto, ora referencia-se a uma conceituação, ora a outra, e de forma geral estabelece-se o termo Análise Visual de Dados para se designar o contexto deste estudo. Com efeito, enquanto a Visualização de Informações é subconjunto da Ciência Analítica Visual, ela também é seu núcleo, o que muitas vezes permite o uso indistinto dos termos. 


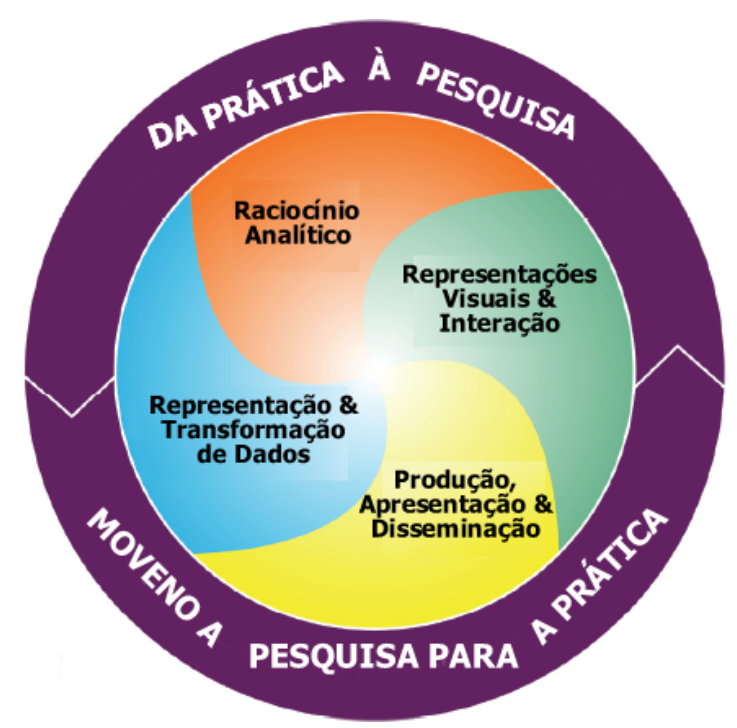

Figura 1.1: A integração das frentes de pesquisa da Ciência Analítica Visual. Adaptado para o português do trabalho de Thomas e Cook [Thomas e Cook, 2005].

\subsection{Motivação}

Estimativas do ano de 2002 apontam para uma produção mundial de dados da ordem de 5 exabytes/ano [Lyman e Varian, 2003], incluindo papel, filme ou mídia eletrônica. No mesmo estudo há uma estimativa de crescimento de $30 \%$ ao ano desta produção, o que aventa a necessidade de maneiras robustas de aproveitamento de dados. São dados que provêm de múltiplas fontes, possuem múltiplas dimensões, variam no tempo e fluem intensamente com potencial latente para auxílio à tomada de decisões. Trata-se de um volume de dados cujos requisitos para seu aproveitamento estão acima da capacidade das técnicas de análise atuais. Há uma lacuna entre a produção de dados e sua utilização.

Segundo este desafio, o objetivo da análise visual de dados é designado como Escalabilidade Visual [Eick e Karr, 2002], isto é, a obtenção de representações e de ferramentas visuais capazes de exibir grandes conjuntos de dados de maneira eficaz, considerando sua cardinalidade e dimensionalidade. Mais do que uma imensidão de números, procura-se discernimento. Para tanto é necessário o desenvolvimento de novas técnicas de visualização acrescidas de mecanismos interativos e de esquemas eficientes de expressividade visual. Esta demanda pode ser suprida pela organização conceitual proposta em um espaço de design. O presente trabalho encaixa-se neste contexto.

\subsection{Objetivos}

Diante dos progressos da análise visual de dados, a literatura recente da área tem apontado seus próximos objetivos de pesquisa. No trabalho de Thomas e Cook [Thomas e Cook, 2005], por 
exemplo, os autores delineiam, na forma de recomendações categóricas, as ações de pesquisa esperadas. Com relação a representações visuais e interação, temas do presente trabalho, suas três primeiras recomendações em ordem de importância são:

- formalizar os espaços de design que capturam diferentes classes de visualização;

- desenvolver um conjunto de princípios científicos baseados em cognição, percepção e design gráfico para mapear informações em representações visuais;

- criar uma nova ciência de interação.

Em outro trabalho, Chen [Chen, 2005] fala dos 10 desafios para o avanço da análise visual de dados. Dentre suas observações, está a necessidade de se entender tarefas elementares cognitivo-perceptivas baseando-se em uma quantidade substancial de evidências empíricas.

Num recente trabalho sobre os desafios da área de visualização, Johnson et al [Johnson et al., 2006] têm, entre suas recomendações de investimento a longo prazo, a necessidade de pesquisas que incluam a caracterização de como e porque as representações visuais funcionam, o desenvolvimento de novos meios de interação, a exploração de novas possibilidades em maquinário de vídeo e a exploração sistemática do espaço de design.

Os objetivos apontados por estes autores determinam o tema de pesquisa cujas conclusões estabelecem a contribuição deste doutoramento. Trata-se do desenvolvimento de um novo modelo de espaço de design e de um estudo taxonômico que aborda os temas de design gráfico e interação considerando fatores cognitivos e perceptivos. Uma sentença pode resumir parte das contribuições deste trabalho:

"A análise visual de dados pode ser compreendida como um conjunto limitado de procedimentos de mapeamento espacial e de padrões visuais pré-atentivos. Tal compreensão deve possibilitar a compreensão analítica das representações visuais interativas."

O objetivo perseguido pode ser concretizado por meio da definição de um espaço de design para técnicas de visualização. Este problema, como tratado neste trabalho, é um tema concernente ao estado-da-arte da pesquisa em análise visual de dados. O termo espaço de design refere-se ao delineamento do universo de possibilidades dentro do qual as representações visuais se encaixam. Analogamente, assim como para o universo físico existe um conjunto de coordenadas único para cada posição, também no universo de design deve haver uma única configuração para cada representação visual. 


\subsection{Desafios}

Dentre os obstáculos para se alcançar efetiva escalabilidade visual está a necessidade de se dominar o espaço de design das representações visuais. A problemática envolvida na definição de tal conceito vem do fato de que representações visuais são constituídas por diversos componentes cuja integração dificulta a observação discreta e, por conseguinte, analítica de suas propriedades. O resultado é uma subjetividade que atravanca o estudo racional da análise visual de dados.

A definição de um novo espaço de design para a análise visual de dados é uma tarefa teórica que requer a análise de outras competências relacionadas ao seu complexo de fatores. Este trabalho inclui ciência de psicologia (estudo de cores e princípios de Gestalt [Koffka, 1935]), semiótica (o estudo de símbolos e como eles provêem significado [Bertin, 1999]), design gráfico [Ware, 2004] e interação [Ward e Yang, 2004a] [Shneiderman e Plaisant, 2005].

A tarefa requer ainda o estudo de outros trabalhos relacionados ao mesmo assunto para se traçar a linha evolutiva da questão. A solução do problema de se definir um espaço de design tem sido perseguida por diversos autores, [Bertin, 1973], [Mackinlay, 1986] [Cleveland e McGill, 1984], [Card et al., 1999], como será detalhado neste trabalho. O conhecimento de investigação adquirido deve ser relacionado para possibilitar reflexão com o intuito de se organizar um modelo teórico coerente.

Também é necessária a validação empírica das inferências durante todo o processo, alterando-se conclusões, traçando-se modelos intermediários, identificando-se falhas e reestruturando-se a linha de raciocínio. Neste processo, devem-se confrontar os avanços pertinentes com relação aos domínios envolvidos, relacionando-se as deduções e observando-se pontos de coesão. Durante a execução deste projeto, uma quantidade significativa de tarefas foi realizada, num processo em que as conclusões foram modeladas gradualmente.

\subsection{Resultados Obtidos}

Os resultados alcançados neste trabalho incluem propostas diretamente decorrentes de seu conteúdo e propostas indiretamente relacionadas aos conceitos introduzidos.

Como serão detalhados no decorrer do texto, os resultados [Rodrigues Jr. et al., 2006c] [Rodrigues Jr. et al., 2007c] diretamente relacionados à proposta incluem: o Processo de Expressividade Visual, uma nova visão descritiva de como técnicas de visualização promovem compreensão; a Taxonomia Espacial-Perceptiva, uma caracterização orientada à percepção visual capaz de classificar as possibilidades das técnicas de visualização; o Espaço de Design Espacial-Perceptivo, uma compreensão inovadora que visa a estimular perspectivas alternativas tanto para técnicas de visualização como para técnicas de interação aplicáveis à análise visual 
de dados; e a Máquina de Visualização, um modelo que descreve uma nova sistematização para o design automatizado de técnicas de visualização. Todas estas contribuições são inter relacionadas e definem a totalidade desta tese.

Também apresentados neste documento, os resultados indiretamente relacionados à proposta incluem duas novas sistematizações para análise visual de dados. Ambas as sistematizações referem-se ao principal componente das técnicas de visualização: o espaço. Este componente, como será examinado, é limitado gerando a necessidade de meios para se expandir tal recurso. Desta forma, também durante este doutoramento foram desenvolvidos o sistema GMine e o sistema VisTree.

O sistema GMine [Rodrigues Jr. et al., 2006a] [Rodrigues Jr. et al., 2006b] [Rodrigues Jr. et al., 2007a] define uma metodologia completa, do pré-processamento à representação estruturada, para a apresentação visual interativa de grafos em multi-resolução. No intuito de ampliação do espaço de projeção, o sistema GMine tem como essência a utilização de uma nova representação de grafos baseada numa hierarquia de particionamentos.

O sistema VisTree [Rodrigues Jr. et al., 2007b] [Rodrigues Jr. et al., 2005], também visando a ampliação do espaço de projeção, descreve uma metodologia de gerenciamento e de inter relacionamento para a exibição de múltiplas cenas de visualização de dados simultaneamente. O sistema proposto compreende operações de refinamento e de composição de cenas de visualização, bem como técnicas de sumarização estatística que auxiliam à interpretação mais ágil das diversas cenas de visualização apresentadas.

\subsection{Organização do Trabalho}

Este trabalho é organizado em três partes. A primeira parte apresenta e introduz novos conceitos necessários para o desenvolvimento da tese, embasamento teórico advindo de trabalhos correlatos encontrados na literatura, e a estratégia de racionalização por meio da qual as técnicas de visualização de dados serão analisadas no decorrer do texto. A segunda parte aprofunda-se no teor da contribuição da tese definindo gradualmente uma nova compreensão para técnicas de visualização. A terceira parte descreve trabalhos de pesquisa e desenvolvimento paralelos à linha principal da tese, além de apresentar a conclusão do trabalho.

A primeira parte deste documento compreende os seguintes capítulos:

O Capítulo 2 revê conceitos básicos a respeito da Análise Visual de Dados no contexto da ciência de análise e de raciocínio analítico.

O capítulo 3 estabelece o embasamento da perspectiva de consideração das técnicas de visualização de dados que será referenciada ao longo de todo o trabalho. 
No capítulo 4 é feita uma extensa revisão de trabalhos correlatos à presente proposta. Esta revisão considera tanto trabalhos pioneiros como trabalhos mais recentes buscando definir o panorama do estado da arte do tema deste trabalho.

O capítulo 5 compila os trabalhos revistos na primeira parte da tese. Estes trabalhos são analisados visando identificar seus pontos fracos e fortes com o objetivo de se definir claramente como as idéias serão desenvolvidas.

A segunda parte do trabalho é composta pelos seguintes capítulos:

$\mathrm{Na}$ forma de uma taxonomia, o capítulo 6 identifica e exemplifica os relacionamentos entre os elementos que foram identificados como constituintes do processo de expressão visual em análise visual de dados.

No capítulo 7, a organização conceitual desenvolvida é colocada na forma de um espaço de compreensão que resume a essência da proposta de doutorado.

No capítulo 8, num primeiro resultado da aplicação das idéias desenvolvidas, todos os conceitos introduzidos na tese são reunidos em um modelo de design automatizado de técnicas de visualização.

A terceira parte da tese apresenta os dois últimos capítulos:

Complementando a compreensão das idéias expostas com relação à prática corrente de análise visual de dados, o capítulo 9 fala sobre as possibilidades de ampliação do espaço de exibição no design de técnicas de visualização.

O capítulo 10 conclui a tese relacionando os resultados alcançados e as possibilidades de pesquisas futuras. 



\section{Parte I}

\section{Conceitos, Embasamento e Estratégia de Racionalização}





\section{Capítulo 2}

\section{Análise Visual Interativa de Dados}

\subsection{Considerações Iniciais}

A Análise Visual de Dados objetiva auxiliar o ser humano a criar um modelo mental de um conjunto de dados e, para tanto, utiliza-se de uma representação gráfica criada a partir do próprio conjunto de dados. O modelo mental deve servir de alicerce para o raciocínio analítico, estimulando a cognição e levando à produção de unidades de informação que elucidem o problema de análise que se tem em mãos. Pesquisas na área de análise visual de dados têm focado no desenvolvimento de métodos que permitam análise exploratória (sem hipótese pré-definida), análise confirmativa (validação de uma hipótese já existente) ou apresentação (demonstração de fatos já identificados) [Keim, 1997]. Tais métodos são denominados Técnicas de Visualização e têm como princípio de funcionamento o processo mental referenciado como "conhecimento no mundo" [Norman, 1990], ou cognição externa [Scaife e Rogers, 1996]. Cognição externa corresponde à totalidade do relacionamento entre representação externa (como as coisas são observadas) e representação interna (como as coisas são imaginadas) considerando a interação entre ambas as representações.

Cognição pode ser definida como a aquisição ou o uso de conhecimento [Card et al., 1999], ao passo que cognição externa é a cognição conseguida com auxílio de estímulos do mundo real, externos ao nosso pensamento. Coisas, objetos e utensílios, mesmo que virtuais, nos fazem mais espertos quando interagimos com eles [Norman, 1993a]. Um exemplo clássico é a tentativa de se realizar operações matemáticas simples, como multiplicação e divisão com números de três dígitos ou mais sem o auxílio de papel e caneta. Trata-se de uma tarefa simples, mas que para muitas pessoas é impossível sem auxílio externo. Da mesma forma, o objetivo das técnicas de visualização é prover auxílio externo para tarefas de análise, definindo a análise visual de dados. 


\subsection{O Processo de Análise}

Baseando-se em cognição, a atividade de análise refere-se à apreciação, ao exame, de uma questão sob a luz de um propósito decisório num contexto de julgamento. Este julgamento é realizado pelo usuário analista da questão e se baseia na consideração de um conjunto de questões menores relacionadas à análise principal. Limites de tempo e restrições com relação à quantidade e qualidade dos dados disponíveis são freqüentes na prática analítica. Os resultados são conclusões referentes a processos de avaliação (compreensão e explicação), de previsão (identificar possibilidades futuras) e de definição de opções (estimar alternativas e suas implicações), tudo no contexto de uma dada configuração a partir da qual as questões foram levantadas [Thomas e Cook, 2005].

Durante a análise de dados, um analista realiza julgamentos partindo de suposições e evidências extraídas de conjuntos de dados. Por meio de raciocínio, suposições são testadas e certificadas com base em evidências e em estruturas de conhecimento conseguidas utilizandose de técnicas de inferência e estimativa. Gradualmente são formadas cadeias de raciocínio para se justificar novas descobertas ou para se articular um dado julgamento que é confirmado ou rejeitado [Chen, 2003]. O resultado da análise deve ser composto pelo raciocínio desenvolvido, as respectivas evidências, o grau de confiabilidade, lacunas e alternativas, de maneira que a análise possa ser compartilhada e revisada [Kees e Rose, 1994].

O processo completo de análise pode se organizar de maneira estruturada, englobando planejamento, definição de questões, obtenção de recursos, abordagem e cronograma. O analista deve se familiarizar com as informações disponíveis, relacionando-as a seu próprio conhecimento para a geração de hipóteses explicativas. Nesta etapa, evidências e suposições extraídas dos dados são matéria-prima para a geração de julgamentos iniciais a respeito das hipóteses levantadas. Iterativamente, as conclusões iniciais podem ser utilizadas para a geração de novas questões e hipóteses, ampliando a visão do analista. Concluindo, o analista prepara relatórios, sumários e apresentações a respeito do que foi produzido na análise [Waltz, 2003]. Esta estrutura é ideal, na prática a análise pode ser simplificada em função da tarefa que se tem em mãos ou mesmo em função de quem solicita a análise. O núcleo essencial do processo é a necessidade de se reunir peças de informação para o raciocínio que suporta o julgamento realizado. Estas peças de informação incluem evidências (quantitativas e qualitativas), suposições (inferências), dados categóricos (fotos, documentos escritos), padrões e estruturas identificadas, estimativas, além das conclusões do próprio analista, entre outras [Heuer, 1999].

Em um trabalho recente [Pirolli e Card, 2005], o processo de análise (ou compreensão) é descrito de maneira sucinta. No diagrama da figura 2.1, os retângulos representam dados e as flechas representam tarefas. O analista filtra as informações geradas, armazenando-as em um repositório do qual peças de informação mais relevantes são extraídas e colocadas num arquivo 
de evidências. A partir das evidências, o analista começa a organizar seu raciocínio ao traduzir as evidências em representações mais manipuláveis, como modelos de esquemas conceituais. A compreensão que se desenrola permite a construção de casos e de hipóteses conclusivas, as quais podem ser apresentadas como resultado final. Como descrito no diagrama, todas as etapas do processo de compreensão podem ser realizados em ciclos com o intuito de se aprofundar na tarefa sendo realizada.

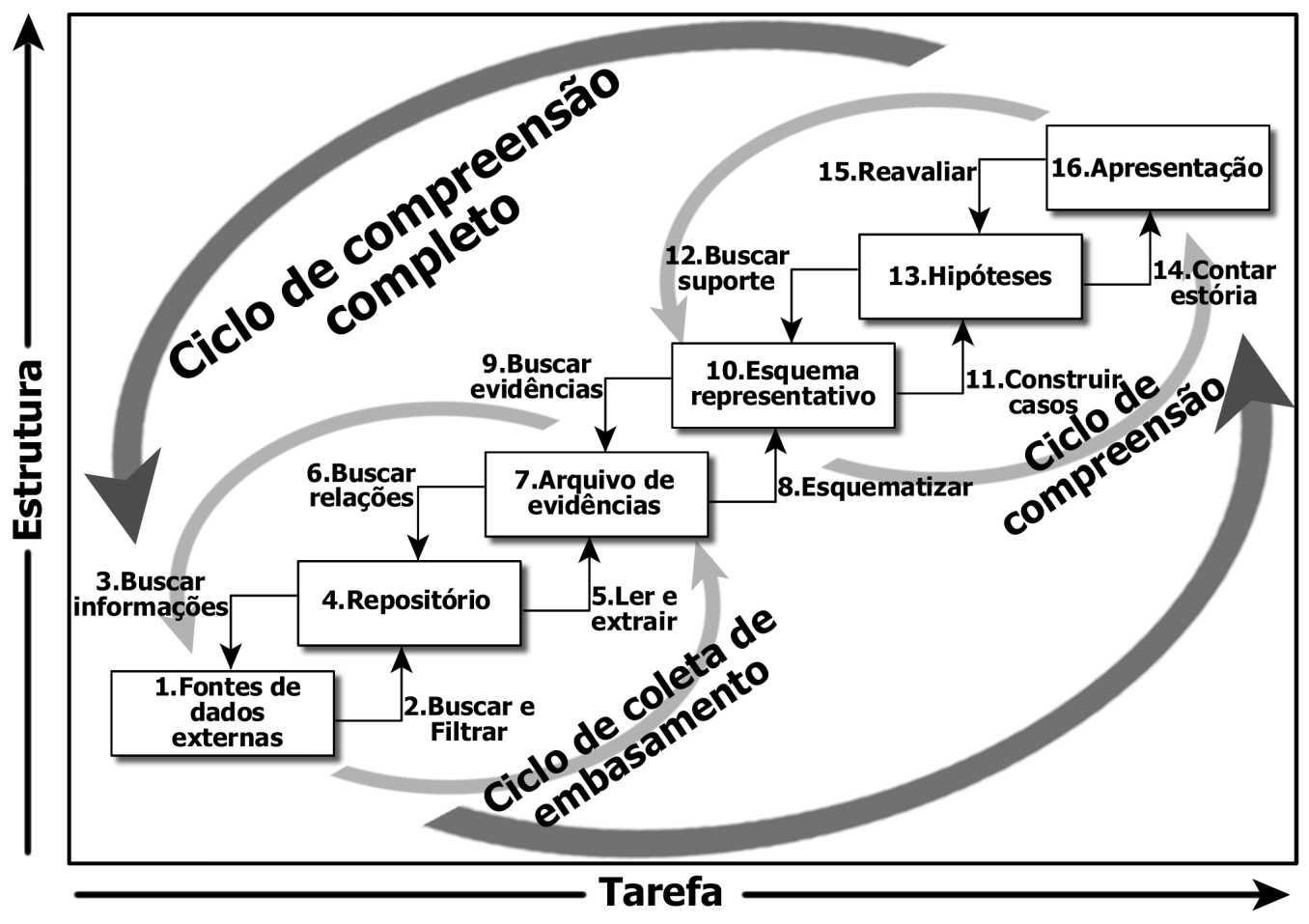

Figura 2.1: O processo de compreensão produzido por meio da prática estruturada da análise de dados. Adaptado do trabalho de Pirolli e Card [Pirolli e Card, 2005].

\subsection{Visualização de Dados e Análise}

A Análise Visual de Dados funciona como a interface entre o usuário analista e o computador, permitindo que um diálogo flua entre o analista e o conjunto de dados. A visualização de dados deve dar suporte às diversas etapas do processo de análise como descrito na seção anterior, apresentando os dados, reunindo e organizando peças de informação, sustentando a evolução iterativa do conhecimento adquirido pelo analista, e apresentando resultados. Obviamente, o suporte deve ser adequado à natureza da configuração de análise e à natureza dos objetivos, seja avaliação, previsão ou definição de opções. Os avanços da análise visual de dados alcançaram estes objetivos em diferentes graus para diversos domínios de aplicação, mas ainda há muito trabalho a ser realizado. 
As virtudes exploradas no intuito se ter a análise de dados auxiliada por técnicas visuais são listadas na tabela 2.1. Uma análise semelhante é feita por Tversky [Tversky, 2001] que aponta as seguintes funções das representações visuais: atrair a atenção e estimular o interesse, registrar informação, facilitar a memorização e o intercâmbio de informações, concretizar modelos (mapas, projetos arquitetônicos), transmitir significado, facilitar descobertas e fazer inferências. Estas capacidades, naturais da análise visual de dados, podem ser combinadas com técnicas de mineração de dados para auxiliar o raciocínio analítico. Técnicas de visualização podem ser utilizadas em qualquer ponto do processo para se alcançar vantagens como mais agilidade em tarefas de busca, leitura, extração e conexão, observação de diagramas, gerenciamento de hipóteses, argumentação estruturada, e apresentação interativa. Em resumo, a análise visual de dados reduz a carga cognitiva ampliando a capacidade perceptiva. Ela também pode contar com suporte de agentes de software em tarefas de busca, filtragem, interpretação, tradução de representações e até raciocínio [Thomas e Cook, 2005]. Estas propriedades definem o conjunto de fatores que interligam procedimentos de análise de dados com técnicas de visualização, determinando sistemas de análise visual de dados.

Sistemas de análise visual de dados contam com rotinas de processamento e interfaces guiadas pelo usuário analista, sendo que as ações realizadas são iniciadas via intervenção direta ou em decorrência de um sistema de monitoramento que reage às mudanças operadas sobre o sistema. Idealmente, estes sistemas são projetados tendo-se em mente as faculdades perceptivas e cognitivas do ser humano. No entanto, a relação entre estas faculdades e a ciência de design gráfico não é óbvia, determinando que o design seja realizado de maneira empírica conforme a necessidade dos analistas desenvolvedores de sistemas específicos.

\subsection{Técnicas de Visualização de Dados}

Na atividade de análise são comuns conjuntos de dados cuja complexidade e tamanho os tornam ininteligíveis, isto é, sua leitura textual provê nenhuma ou quase nenhuma elucidação a respeito de um problema que se tenha em mãos, especialmente em curtos períodos de tempo. Neste panorama é que são utilizadas as técnicas de visualização que beneficiam-se da ampliação cognitiva descrita na tabela 2.1. Informações organizadas de maneira espacial podem ser acessadas, integradas e operadas fácil e rapidamente, especialmente quando a organização espacial reflete organização conceitual [Tversky, 2001]. Com base neste princípio, as técnicas de visualização seguem princípios distintos definindo duas vertentes principais para a prática da análise visual de dados: a Visualização Científica (VisC) e a Visualização de Informações (VisInfo).

A visualização científica compreende dados que possuem uma representação natural espacial ou física como, por exemplo, pontos de tensão sobre as asas de um avião. Para tal repre- 
Tabela 2.1: Amplificação da cognição possibilitada pelas técnicas de visualização. Adaptado da obra de Card et al [Card et al., 1999].

\begin{tabular}{|c|c|}
\hline \multicolumn{2}{|l|}{ 1.Mais recursos } \\
\hline $\begin{array}{l}\text { Interação hierárquica de } \\
\text { banda larga }\end{array}$ & $\begin{array}{l}\text { O olhar móvel humano particiona a capacidade limitada de seu canal para combinar } \\
\text { alta resolução espacial e ampla abertura angular para perceber o ambiente }\end{array}$ \\
\hline $\begin{array}{l}\text { Processamento percep- } \\
\text { tivo paralelo }\end{array}$ & $\begin{array}{l}\text { Comparados à informação textual, alguns atributos da visualização podem ser pro- } \\
\text { cessados em paralelo }\end{array}$ \\
\hline $\begin{array}{l}\text { Transferência de traba- } \\
\text { lho do sistema cogni- } \\
\text { tivo para o perceptivo }\end{array}$ & $\begin{array}{l}\text { Algumas inferências cognitivas podem ser armazenadas utilizando-se de simples } \\
\text { operações perceptivas }\end{array}$ \\
\hline $\begin{array}{l}\text { Expansão da memória } \\
\text { de trabalho }\end{array}$ & $\begin{array}{l}\text { Visualizações podem expandir a memória de trabalho ao guardar as informações } \\
\text { visualmente }\end{array}$ \\
\hline $\begin{array}{l}\text { Expansão da memória } \\
\text { de armazenamento }\end{array}$ & $\begin{array}{l}\text { Grandes quantidades de informação podem ser armazenadas em um formato que } \\
\text { proporciona acesso rápido }\end{array}$ \\
\hline \multicolumn{2}{|l|}{ 2.Busca reduzida } \\
\hline Processamento local & Visualizações agrupam informações utilizadas em conjunto \\
\hline Alta densidade & Representações visuais uma grande quantidade de dados em um pequeno espaço \\
\hline Indexação espacial & Ao agrupar as propriedades de um objeto, não há necessidade de rótulos simbólicos \\
\hline \multicolumn{2}{|c|}{ 3.Melhor reconhecimento de padrões } \\
\hline $\begin{array}{l}\text { Reconhecer ao invés de } \\
\text { recordar }\end{array}$ & $\begin{array}{l}\text { Reconhecer uma informação numa cena de visualização é mais fácil do que se lem- } \\
\text { brar dela }\end{array}$ \\
\hline Abstração e agregação & $\begin{array}{l}\text { Visualizações simplificam e organizam informações, provendo uma maior quanti- } \\
\text { dade de centros de informação agregada utilizando-se de abstração e apresentação } \\
\text { seletiva }\end{array}$ \\
\hline $\begin{array}{l}\text { Esquematização visual } \\
\text { para organização }\end{array}$ & $\begin{array}{l}\text { Organização visual por meio de estruturas de relacionamentos melhora o reconheci- } \\
\text { mento de padrões }\end{array}$ \\
\hline $\begin{array}{l}\text { Valor, relacionamento e } \\
\text { tendência }\end{array}$ & Visualizações podem melhorar a percepção destes três níveis de padrão \\
\hline \multicolumn{2}{|l|}{ 4.Inferência perceptiva } \\
\hline $\begin{array}{l}\text { Alguns problemas se } \\
\text { tornam óbvios }\end{array}$ & $\begin{array}{l}\text { Visualizações suportam um grande número de inferências perceptivas que são extre- } \\
\text { mamente simples para seres humanos }\end{array}$ \\
\hline Computações gráficas & $\begin{array}{l}\text { Visualizações permitem que computações especializadas e complexas sejam execu- } \\
\text { tadas graficamente }\end{array}$ \\
\hline \multicolumn{2}{|c|}{ 5.Monitoramento perceptivo } \\
\hline & $\begin{array}{l}\text { Visualizações podem permitir o monitoramento de um grande número de eventos se } \\
\text { a tela é organizada de maneira que estes eventos fiquem evidenciados por aparência } \\
\text { ou movimento }\end{array}$ \\
\hline \multicolumn{2}{|l|}{ 6.Mídia manipulável } \\
\hline & $\begin{array}{l}\text { Diferente de diagramas estáticos, visualizações podem permitir a exploração de um } \\
\text { espaço de valores de parâmetros e podem ampliar as operações de análise }\end{array}$ \\
\hline
\end{tabular}


sentação seria necessário coletar dados suficientes para se reproduzir a estrutura física do avião, além de dados sensoriais a respeito da tensão incidente às asas. Cada dado coletado teria, $a$ priori, uma posição semântica no espaço. De maneira geral, a visualização científica visa potencializar o sistema sensorial humano utilizando-se da exibição de fenômenos que não sejam visíveis, que sejam muito rápidos (uma explosão, por exemplo) ou muito lentos (erosão do solo, por exemplo), ou que sejam muito grandes ou muito pequenos para que os olhos os percebam (uma estrutura protéica, por exemplo).

A visualização de informações lida com dados abstratos que carecem de uma representação relacionada a formas conhecidas físicas ou concretas [Tversky, 2001] [Shneiderman, 1996]. Por exemplo, bancos de dados multidimensionais, hierarquias complexas e texto. Tais dados não são diretamente representáveis por meio de mapeamentos físicos ou espaciais, ao invés disso é necessário criar uma representação gráfica adequada à percepção espacial e visual. Tal percepção pode se beneficiar da larga experiência humana em avaliar, operar e se mover no espaço [Kuhn e Blumenthal, 1996]. Ainda, a representação criada deve ser capaz de revelar informações interessantes para uma determinada atividade de análise.

A categorização da análise visual de dados em dois ramos distintos é bastante difundida na respectiva comunidade de pesquisa. A separação ajuda a dividir as propostas de pesquisa provendo um mínimo de organização que direciona pesquisadores para um conjunto ou outro. Esta, por exemplo, é a maneira como é realizada a organização das conferências sobre visualização da instituição Institute of Electrical and Electronics Engineers (IEEE). Suas conferências são, respectivamente, IEEE Visualization Conference e IEEE Symposium on Information Visualization. No entanto, a real distinção entre as duas áreas é debatida em diversos trabalhos [Rhyne et al., 2003] [Tory e Möller, 2004] [Duke, 2001]. De fato, a distinção só existe do ponto de visto prático pois, embora a VisC englobe um conjunto de práticas diferentes da VisInfo, em tese elas têm características comuns. Ambas têm o mesmo objetivo, utilizam os mesmos recursos computacionais, são baseadas nos mesmos princípios e utilizam interatividade para impulsionar seus resultados. Em muitos casos é possível, e desejável, a utilização complementar de técnicas de ambas as áreas.

O presente trabalho é de natureza ampla, abrangendo ambas as vertentes da análise visual de dados, embora sem se concentrar especificamente em uma ou em outra. Este trabalho discorre sobre os princípios visuais e cognitivos utilizados nas técnicas de visualização e sobre os processos de formação gráfica utilizados em suas concepções. A discussão é mantida num caráter genérico ainda que citando mais trabalhos da VisInfo pois, sem uma representação espacial intrínseca, suas técnicas abrangem maior amplitude nos domínios do design visual. 


\subsection{O Modelo Geral de Visualização}

De maneira geral, o processo de visualização segue uma seqüência de eventos bem definida. Na figura 2.2 - adaptada do modelo de VisInfo [Card et al., 1999] e do modelo de VisC [Upson et al., 1989] - é apresentado o fluxo desta sequiência a partir dos dados "crus" até a visualização. Considerando esta estrutura, uma técnica de visualização pode ser definida como um conjunto de configurações que definem uma sequiência particular que satisfaz o processo de visualização. Tais sequiências consistem de uma metodologia de pré-processamento, de uma estrutura de objeto, de procedimentos de codificação/transformação, de uma estrutura de objetos visuais e de uma sequiência de projeção/renderização. Cada um destes componentes é descrito a seguir.

\section{Pré-processamento}

Esta etapa como o próprio nome já diz é realizada antes da visualização acontecer, mas não necessariamente antes do processo de visualização ser iniciado. Procedimentos de préprocessamento podem ser disparados respondendo à interação do analista durante uma visualização já em curso. O pré-processamento visa converter os dados para um formato adequado ao próximo passo do processo, sendo possível convertê-los para uma representação que possa ser projetada/renderizada. Pré-processar, além de transformar os dados, implica em selecionar quais dados serão apresentados e quais serão omitidos. Entre as técnicas mais comuns de préprocessamento estão métodos para reduzir o número de itens de dados, seleção de atributos, redução de dimensionalidade, normalização, discretização, sumarização, agregação, redefinição espacial, geometrização, classificação, operações de mineração de dados, entre outros. Em VisC, o pré-processamento cria primitivas espaciais de objetos, na VisInfo, são criados objetos matemáticos.

$\mathrm{Na}$ VisC, as primitivas de dados que constituem os objetos são denominadas voxels. Voxels são unidades constituintes de dados volumétricos representados por vetores tri-dimensionais de células cúbicas. Estas células são abstrações tratadas como dados pontuais, cada uma com propriedades uniformes em toda sua extensão. Na VisInfo, o modelo de dados mais comum é a tabela de dados, amplamente difundida por meio do modelo relacional de bancos de dados - um conjunto de tuplas e meta-dados descrevendo relacionamentos entre elas. Os dados que suportam a VisInfo podem ser categorizados da seguinte forma:

- ordinal: obedece a uma relação de ordem como, por exemplo, as letras do alfabeto;

- quantitativo: passível de operações aritméticas, como o peso de um objeto;

- nominal: não podem ser ordenados nem passar por operações aritméticas. A priori suportam apenas o conceito de igualdade (ou desigualdade), como nomes próprios de indivíduos. 


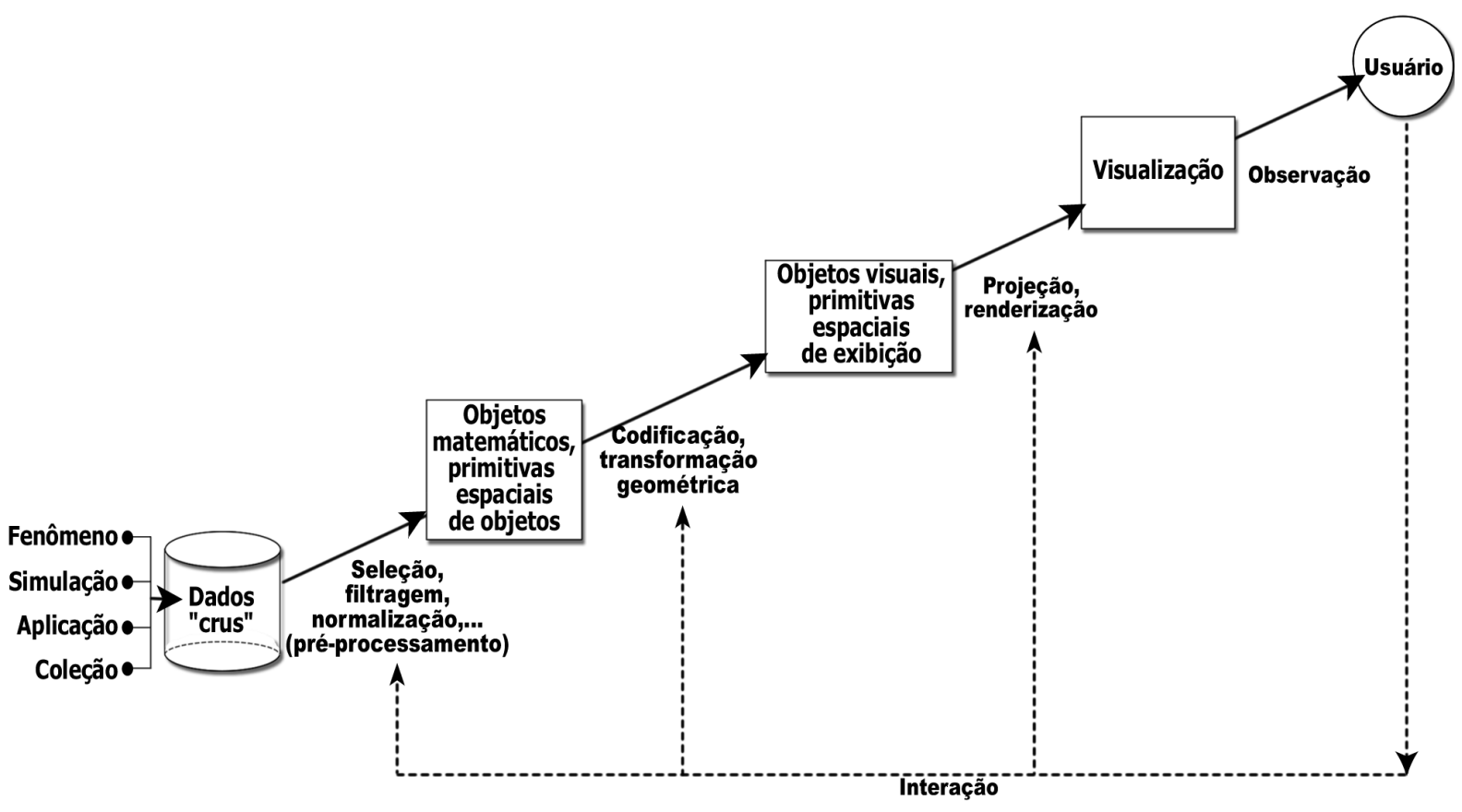

Figura 2.2: Modelo geral de visualização adaptado de [Card et al., 1999] e de [Upson et al., 1989].

\section{Codificação ou Transformação Geométrica}

Nesta etapa os objetos matemáticos, ou as primitivas espaciais de objetos, são submetidos a uma segunda etapa de transformação para gerar objetos visuais adequados à representação dos dados originais. $\mathrm{Na} \mathrm{VisC}$, em sua modalidade mais comum, as primitivas espaciais de objeto são transformadas em primitivas espaciais de exibição por meio de um processo de triangularização que transforma coordenadas espaciais em poliedros. Na VisInfo, a codificação é bastante dependente da aplicação objetivada e dos aspectos que serão enfatizados na apresentação. Esta etapa codifica dados em padrões visuais (objetos visuais) capazes de estimular a percepção visual de diversas maneiras exprimindo, por exemplo, conectividade entre entidades gráficas ou correspondência entre atributo visual e magnitude do dado original.

A codificação a ser realizada é o grande desafio da VisInfo, pois dela depende a funcionalidade da técnica de visualização. Trata-se de um procedimento subjetivo cuja eficácia depende do domínio de dados, do usuário analista e de outros elementos gráficos também presentes na visualização. Em [Mackinlay, 1986], o autor define dois critérios para se avaliar uma dada codificação. O primeiro, a Expressividade, avalia se uma representação gráfica é capaz de expressar a informação desejada. Seu segundo critério, a Efetividade, avalia se uma representação gráfica explora amplamente as capacidades do meio de apresentação e do sistema visual humano. Apesar de serem critérios pouco objetivos, a proposta introduz um esforço pioneiro de avaliação de codificações visuais. 
A tarefa de se definir uma codificação visual refere-se à atividade de design gráfico, que é pertinente à análise visual de dados. Ao passo que na VisC o design conta com menos possibilidades, dado seu mapeamento físico/espacial intrínseco, na VisInfo diversos trabalhos discorrem sobre o espaço de design, como será abordado no capítulo 4. Baseando-se na atividade de design, e desconsiderando-se as peculiaridades de sua prática, a VisC encaixa-se como subconjunto, ou como complemento, da VisInfo. Neste trabalho ambas são abordadas a partir da mesma perspectiva, concentrando-se na pesquisa por um espaço de design alternativo.

\section{Renderização/Projeção}

A última parte do fluxo do processo de visualização é a renderização ou projeção. A renderização visual diz respeito a técnicas que transformam primitivas espaciais de exibição em uma imagem plana. Esta imagem, embora bidimensional, pode carregar informação 3D. Nesta etapa, a imagem renderizada é transmitida diretamente para o frame buffer, quando ela é finalmente exibida. A projeção realiza processo semelhante transformando objetos visuais, listas de objetos OpenGL por exemplo, em uma imagem final exibida para o analista. Uma vez exibida a imagem, a visualização está completa, podendo agora definir um ciclo de re-desenho acionado pelas ações interativas do analista. A possibilidade de alteração da exibição permite a definição de múltiplas visões do conjunto de dados.

\subsection{Interação em Análise Visual de Dados}

A redefinição sob demanda da visualização do conjunto de dados é possibilitada por meio de técnicas de interação. Estas técnicas permitem explorar a dimensão do tempo de maneira que diferentes perspectivas possam ser observadas em diferentes momentos, numa seqüência ou arbitrariamente. Por meio da percepção de movimento que é criada, é possível compreender a estrutura subjacente da cena, resolver ambigüidades visuais como percepção tri-dimensional e definir relações de causa e efeito. Esta é a grande vantagem da análise visual de dados interativa se comparada a diagramas estáticos. Diversos parâmetros da exibição podem ser manipulados, e objetos de dados muito grandes ou muito complexos podem ser mais bem examinados por meio de alteração da exibição. Estas funcionalidades determinam uma relação dinâmica, um diálogo entre o analista e os dados. Este diálogo é o que permite o desenvolvimento da atividade analítica, na qual o analista observa, interpreta e compreende o que vê, prosseguindo com um novo questionamento ao passo que define uma estratégia de análise [Spence, 2000].

Segundo Card et al [Card et al., 1999], a compreensão da efetividade de uma visualização depende da compreensão de fatos da percepção: um conjunto destes fatos refere-se às carac- 
terísticas das diferentes representações visuais; um outro conjunto refere-se a como um dado sistema é funcional em sua capacidade de alterar o foco de atenção. Este segundo conjunto é possibilitado por atividade de interação com técnicas visuais. Um paradigma de interação que é bastante aceito, é definido no trabalho de Schneiderman [Shneiderman, 1996]. Este paradigma define o chamado "mantra da visualização: primeiro visão geral, zoom e filtragem, só então detalhes sob demanda". O autor descreve sucintamente a atividade natural realizada por uma pessoa sobre um objeto de investigação. Segundo o trabalho de Card et al [Card et al., 1999], a interação serve a três propósitos:

- alteração das transformações sobre os dados: atuação direta sobre como e quais dados serão apresentados. Inclui manipulação direta, detalhamento sob demanda e filtragem visual, como no sistema GBDIView [Rodrigues Jr. et al., 2003b];

- alteração do mapeamendo dos dados: permite a definição de diferentes representações de um mesmo conjunto de dados. Como no sistema VisTree [Rodrigues Jr. et al., 2005];

- alteração da visão dos dados: inclui técnicas para se determinar detalhes sob demanda (mais informações numa janela separada), controles de perspectiva (operações espaciais de rotação, translação e escala) [Bederson et al., 1996] e distorção (o espaço de exibição é distorcido de maneira que detalhes permaneçam no foco principal ao mesmo tempo em que uma visão geral permaneça visível) [Furnas, 1986] [Leung e Apperley, 1994] [Walter e Ritter, 2002].

As técnicas de interação são necessárias para dar suporte a processos como comparação e categorização, extração e recombinação, criação e teste de hipóteses, anotação de dados, avaliação de evidências, questionamento de suposições e busca por alternativas [Thomas e Cook, 2005]. Tais técnicas devem ser projetadas com o intuito de ajudar a sobrepujar limitações humanas, dentre elas:

- dificuldade com o excesso de informações: simplificação da carga cognitiva sem comprometer a eficiência do analista ao mesmo tempo em que ajuda a compensar sua memória limitada;

- parcialidade: evitar tendências pessoais que possam atrapalhar a interpretação por meio da enfatização visual de evidências;

- satisfação prematura: fomentar o aprofundamento na análise evitando julgamentos precoces.

Outras formas de interação, além da visual, também são temas de pesquisa. Abordagens baseadas em múltiplos sentidos, tato e som, podem ampliar a capacidade de receber e transmitir 
informação. Sabe-se por exemplo que o uso do som pode aumentar a experiência visual e espacial. Em visualização o uso do som é denominado sonificação, a qual pode proporcionar codificação redundante (além de ver, também ouvir) [Robertson et al., 1998] ou codificação extra (sons informam sobre outros atributos dos dados) [Minghim et al., 2002].

Ainda segundo Thomas e Cook [Thomas e Cook, 2005], não há um espaço de design para técnicas de interação e, portanto, não se sabe se as técnicas criadas para suportar tais operações são as melhores ou as mais apropriadas. Trata-se de uma questão de difícil resolução, especialmente a partir de uma abordagem métrica que seja capaz de quantificar a eficiência das técnicas propostas. Embora não tratando diretamente deste problema, este doutoramento também aborda técnicas de interação, as quais são tratadas a partir da perspectiva do espaço de design que se propõe. Na concepção que será apresentada as técnicas de interação surgem como meios para se alterar os parâmetros que determinam uma dada configuração de design.

\subsection{Considerações Gerais}

Considerando-se a revisão de trabalhos realizada neste capítulo, pode-se dizer que a ciência de Análise Visual de Dados está em seus estágios iniciais. Ainda é necessária a compreensão de princípios básicos relacionados à prática de se expressar, eficientemente, informações por meio de técnicas gráficas. O objetivo geral é o projeto de técnicas de análise visual de dados que possam auxiliar efetivamente ao processo de raciocínio analítico. Neste intuito, alguns trabalhos têm tentado determinar como é possível alcançar este objetivo. No trabalho de Norman [Norman, 1993b], por exemplo, o autor afirma que o primeiro passo para se desenvolver princípios para representações visuais é entender como eles possibilitam a cognição. Tversky et al [Tversky et al., 2002] propõem os seguintes princípios para elaboração de apresentações visuais de dados:

- congruência: a representação visual deve corresponder à estrutura da representação mental desejada representando os conceitos importantes do domínio de interesse;

- grau de aprendizado: uma visualização deve ser prontamente e corretamente percebida e compreendida.

Apesar de existirem diretrizes de design como estas, há uma lacuna entre a compreensão do porquê determinadas práticas propiciam cognição, e entre a compreensão de como novas práticas podem ser determinadas. Com relação aos dois princípios enunciados, por exemplo: como é possível garantir que eles sejam satisfeitos antes de se ter um design visual implementado numa ferramenta? Como averiguar se eles estão sendo satisfeitos de fato? 
Acredita-se que os problemas encontrados na tarefa de se avaliar a eficiência de visualizações decorrem da disparidade entre expressividade concreta e abstrata. A utilização de caracteres e palavras num texto concreto tem enorme amplitude de expressão, podendo representar qualquer idéia, por mais complexa que seja, ao custo de um processo mais lento de assimilação. Já a utilização de abstrações genéricas na forma de representações visuais tem uma amplitude de expressão menos ampla, limitada a idéias mais diretas como correlações e tendências, com a vantagem de ser um processo bastante rápido de assimilação. O processo de avaliação das técnicas de visualização esbarra no fato de que quando se migra do concreto para o abstrato, perde-se expressividade sem se saber precisamente qual foi o ganho em poder de assimilação, o inverso também acontece.

O equacionamento dos fenômenos apontados nos parágrafos acima não é trivial e passa por etapas progressivas de desenvolvimento. Como apresentado na seção 1.3, diversos trabalhos recentes [Thomas e Cook, 2005] [Chen, 2005] [Johnson et al., 2006] apontam como necessária a pesquisa sobre o espaço de design e sobre os mecanismos cognitivo-perceptivos para que a ciência de análise visual de dados possa evoluir. Buscando contribuir com este processo de evolução, e seguindo os rumos apontados na literatura mais recente, o presente estudo aborda o tema da compreensão das técnicas de visualização com relação à capacidade perceptiva e cognitiva do ser humano. No decorrer deste texto, estes assuntos são abordados em conjunto, o intuito é a proposição de uma nova compreensão envolvendo tanto o espaço de possibilidades para o design como os fenômenos cognitivo-perceptivos envolvidos na análise visual. 


\section{Capítulo 3}

\section{Expressividade Visual}

\subsection{Considerações Iniciais}

O propósito da percepção é a detecção de informações [Gibson, 1983]. Uma vez detectada a informação, torna-se possível a cognição e a geração de análises conclusivas. Promovendo a percepção e a posterior cognição, está a visualização que estimula o sistema visual e torna possível a análise visual de dados. O presente trabalho assume este processo perceptivo-cognitivo mediado por visualização, que é natural e intuitivo, como verdadeiro, sendo que esta suposição é central para a teoria que se desenvolve. Nesta seção introduz-se conhecimento básico e definições para o delineamento da relação entre o processo perceptivo-cognitivo e a tese aqui apresentada.

\subsection{Estímulos Pré-atentivos}

Semiótica é a ciência que estuda os símbolos e como eles transmitem significado [Ware, 2004]. De acordo com esta ciência, o processo visual é composto por duas fases. A primeira, chamada de processamento pré-atentivo, diz respeito à extração de propriedades de baixo nível realizada em paralelo pelo sistema visual, veja a figura 3.1. A segunda, chamada de processamento atentivo, compreende a busca por detalhes da cena de visualização, esta etapa é realizada seqüencialmente e mais lentamente pelo sistema visual. A primeira etapa, o processamento pré-atentivo, é de grande importância na promoção do maior benefício da análise visual de dados, isto é, uma compreensão de dados mais rápida e poderosa [Treisman, 1985]. A segunda etapa é utilizada em práticas de leitura convencionais (texto) e colabora pouco para a rápida percepção visual. Ware [Ware, 2004] afirma que a compreensão do que é processado de maneira pré-atentiva, como mostrado na figura 3.2, é provavelmente a mais importante contribuição que a ciência de visão pode trazer à ciência de visualização. 


\begin{tabular}{|c|c|}
\hline 5473456609230982348768162987120 & 5473456609230982348768162987120 \\
\hline 8583487656098348723723423476230 & 8583487656098348723723423476230 \\
\hline 9854096852640937858347534598340 & 9854096852640937858347534598340 \\
\hline 09875686547654 & 9650954953231093409875686547654 \\
\hline 9309348565968568759847156840 & 5459309348565968568759847156840 \\
\hline & \\
\hline
\end{tabular}

Figura 3.1: Exemplo de pré-atenção. A contagem da quantidade de símbolos “4” (total de 22) na imagem (a) é mais fácil quando os símbolos estão enfatizados, como na imagem (b). Adaptado de [Ware, 2004].

O processamento pré-atentivo refere-se a qualquer coisa que seja visualmente identificada por meio de processos inconscientes de percepção. Como tal, este processamento determina quais objetos são instantaneamente e diretamente trazidos à nossa atenção. Ware [Ware, 2004] identifica as categorias das características visuais que são processadas de maneira pré-atentiva. Além de animação, seu estudo considera posição, forma e cor, como mostrado na figura 3.2. De acordo com [Pylyshyn et al., 1994], existem áreas do cérebro especializadas para o processamento de cada uma destas três categorias. De fato, a percepção posição-forma-cor é verdadeira para tudo o que vemos. Num momento específico, para qualquer coisa onde se concentre o olhar, podem-se fazer três questões: onde está isto que estou vendo? qual a sua forma? e qual a sua cor?

Segundo Ware [Ware, 2004], os padrões visuais percebidos de maneira pré-atentiva incluem: posição 1D, 2D, 3D, ponto, linha, área, volume, forma, orientação, comprimento, largura, colinearidade, tamanho, curvatura, sombreamento côncavo e convexo, matiz, saturação, brilho e textura.

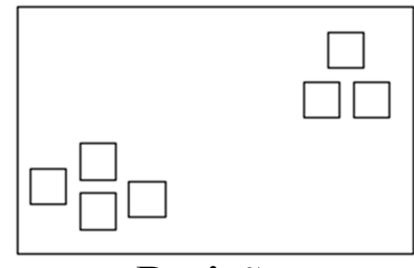

Posição

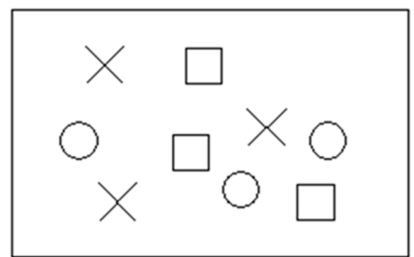

Forma

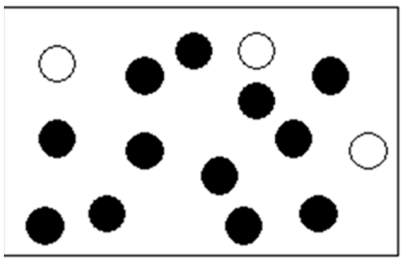

Cor

Figura 3.2: Estímulos pré-atentivos.

Em visualização, a atenção funciona como um mecanismo de seleção da percepção. Para evitar sobrecarga, apenas parte de toda a informação apresentada para um observador é escolhida para processamento posterior. A maneira como a informação é processada define a diferença entre o processamento visual antes e depois da seleção atentiva, primeiro paralelamente (processamento distribuído) e depois seqüencialmente (processamento focado) [Palmer, 1999].

Para que visualizações sejam eficientes, elas precisam ser construídas sobre características pré-atentivas de maneira a maximizar o número de estímulos paralelamente perceptíveis (ou 
just noticeable differences). Segundo Marcus [Marcus, 1995], o design de interfaces de usuário para a comunicação visual deve ser econômica, isto é, deve maximizar a efetividade por meio de um conjunto mínimo de pistas visuais. Assim, ao passo que o processo de visão não é limitado à percepção pré-atentiva, o design de visualizações é orientado a maximizar este tipo de percepção. Neste trabalho assume-se que visualizações são compostas por características que são potencialmente ou desejavelmente pré-atentivas. Segundo esta concepção, a percepção préatentiva varia, apresentando diferentes graus de eficiência, dependendo dos dados e do design utilizado.

\subsection{Percepção Posicional e Espacialização}

Segundo Gattis [Gattis, 2001], para que uma visualização seja eficiente, a organização é um requisito essencial, sendo que o espaço é o principal fenômeno de representação gráfica capaz de promover organização. As habilidades de raciocínio espacial, inatas ao ser humano, nos permitem alternar o foco de concentração segundo nossa vontade. Esta capacidade, que é adequada à atividade de análise, é válida tanto no mundo real quanto em ambientes artificiais permitidos por computação. O raciocínio espacial é crítico na determinação das propriedades de uma cena, seja considerando os objetos visuais distintamente ou um em relação ao outro [Robertson, 1991]. Ao interligar elementos visuais, esquemas espaciais provêem uma organização que realça a memória e que pode determinar uma organização mental, em muitos casos, mais eficiente do que o tempo [Tversky, 2001]. Estes benefícios advém do fato de que a manipulação espacial é uma atividade altamente subconsciente que impõe pouca carga cognitiva, oferecendo funcionalidades poderosas [Kuhn e Blumenthal, 1996].

Dada a importância do espaço na ciência de visualização, a literatura desta área cunhou a expressão espacialização de dados [Kuhn e Blumenthal, 1996]. Espacialização de dados referese à codificação de dados para um formato espacial/visual. Rohrer [Rohrer et al., 1998] afirma que a visualização do que não é visual requer o mapeamento do abstrato para uma forma física. Rhyne et al [Rhyne et al., 2003] diferenciam a Visualização Científica e a Visualização de Informações baseando-se no fato do mecanismo de espacialização ter sido dado ou ter sido escolhido, respectivamente. Naturalmente, é possível concluir que a espacialização de dados é o que promove os processos pré-atentivos de posição.

A espacialização é o elemento fundamental que permite a análise visual de dados ao mesmo tempo em que dita as características para percepção pré-atentiva posicional. De acordo com esta conceituação, a expressividade espacial depende de uma função de mapeamento Espacia$l i z a c ̧ a \tilde{o}($ dados $) \rightarrow R^{3}$ que relaciona elementos de dados a posições no espaço. 


\subsection{O Processo de Expressividade Visual}

Em um trabalho $[\mathrm{Ng}, 2000]$ relevante à presente proposta, o autor Kwok-Chu $\mathrm{Ng}$ identifica e inter-relaciona os componentes envolvidos em VisInfo: a representação gráfica, o processo perceptivo, o processo cognitivo, o processo físico e os controles de interação. Sua proposta descreve bem o sistema definido por estes componentes, os quais constituem a essência da análise visual de dados. Inspirando-se no trabalho do autor $\mathrm{Ng}$ - mostrado na figura 3.3, a primeira contribuição desta tese delineia o Processo de Expressividade Visual, o qual é um modelo que também objetiva sintetizar o decurso da análise visual de dados.

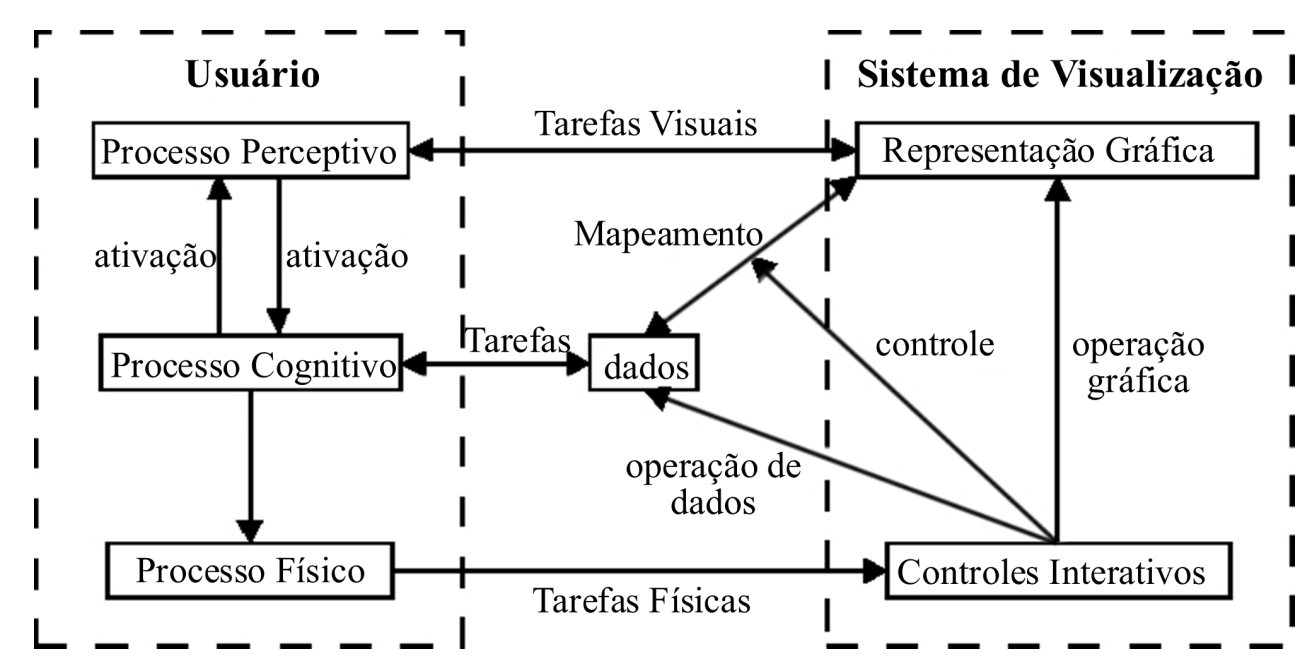

Figura 3.3: O modelo de Kowk-Chu Ng [Ng, 2000] o qual, além de interação, relaciona processos perceptivos, processos cognitivos e tarefas visuais (observação).

O Processo de Expressividade Visual é uma visão global de como as visualizações produzem conhecimento útil. O modelo descrito, conforme a visão aqui proposta, considera especialmente a relação entre processo perceptivo, processo cognitivo e tarefas visuais (observação). Diferentemente da proposta do autor $\mathrm{Ng}$, numa visão mais elaborada, cada componente é destrinchado em um conjunto de fenômenos observáveis e, por simplicidade, a interação não é considerada inicialmente.

O diagrama da figura 3.4 descreve o processo que parte de padrões visuais pré-atentivos - a presença de um conjunto de dados é assumida - e que culmina na interpretação dos dados. Os elementos chave deste processo são: os padrões visuais pré-atentivos utilizados para se conceber visualizações, o conceito de percepção visual analítica, e a atividade de interpretação cognitiva. Esta estrutura é utilizada no delineamento de uma nova estratégia para a análise da ciência de visualização.

A seguir, nesta seção, os componentes do Processo de Expressividade Visual são apresentados um a um com o intuito de elucidar conceitos utilizados ao longo deste trabalho. 


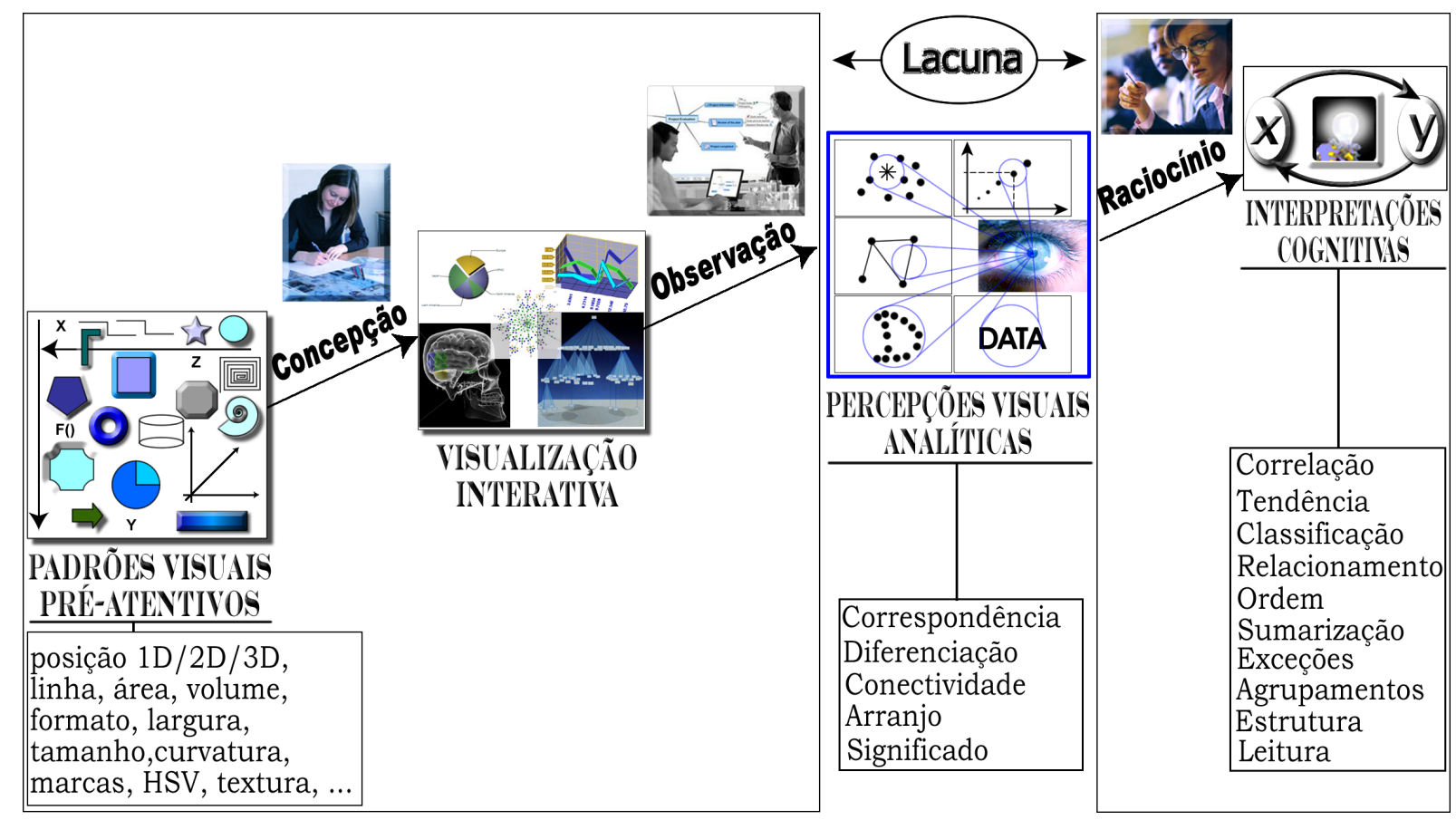

Figura 3.4: O Processo de Expressividade Visual.

\section{Padrões Visuais e Estímulos Pré-atentivos}

A suposição que se faz é que imagens de visualização são compostas pelas três categorias de estímulos pré-atentivos - posição, forma e cor - já apresentados na seção 3.2 e mostrados no início do processo ilustrado na figura 3.4. Para cada categoria, um subconjunto dos padrões visuais pré-atentivos listados na seção 3.2 pode ser utilizado para o design. Os padrões considerados em cada categoria incluem, mas não são limitados a:

- posição: 1D, 2D e 3D;

- forma: ponto, linha, área, volume, forma, orientação, comprimento, largura, profundidade, colinearidade, tamanho, curvatura, sombreamento côncavo e convexo;

- cor: matiz, saturação, brilho e textura.

\section{Percepções Visuais Analíticas}

No processo de expressividade visual, Percepções Visuais Analíticas designam o conjunto de fenômenos úteis para análise que são deflagrados por estímulos pré-atentivos. Formalmente, tais fenômenos são entendidos como o reconhecimento de estímulos visuais auxiliado sobretudo pela memória do usuário analista que observa a cena. Eles são observáveis mesmo que o analista não possua conhecimento sobre os dados subjacentes e, portanto, são um componente inerente à prática de visualização. 
Em análise visual de dados, percepções visuais analíticas parecem ser as características naturais que qualquer usuário analista espera encontrar quando está interpretando uma visualização. Se elas não são encontradas, a cadeia definida na figura 3.4 é quebrada e o processo é interrompido. Neste trabalho, por meio de extenso estudo da literatura da área, foram identificadas as ocorrências de percepções visuais analíticas presentes em análise visual de dados. Um conjunto limitado de percepções pôde ser encontrado e, por observação empírica, verificou-se que este conjunto é recorrente em técnicas de visualização.

A pesquisa por percepções visuais considerou principalmente as propostas de espaços de design introduzidas em trabalhos ligados à ciência de visão e à ciência de visualização. Estes trabalhos são revistos em detalhes no capítulo 4 sobre taxonomias e espaços de design. No trabalho de Bertin [Bertin, 1973], duas ocorrências de percepções visuais podem ser identificadas: correspondência (ou expressão estendida) e diferenciação de marcas - como também observado nos trabalhos de Bowman [Bowman, 1968] e de Card [Card et al., 1999]. Em outro trabalho, Mackinlay [Mackinlay, 1986] afirma que a percepção de relacionamentos advém de padrões visuais que promovem a noção de conectividade, a qual é considerada pelo autor como uma primitiva de design gráfico. Além das percepções visuais de correspondência, diferenciação e conectividade observase ainda as percepções de arranjo, para percepções derivadas de configurações de grupo - os chamados princípios de Gestalt [Koffka, 1935] (veja a figura 3.5); e significado, para percepções baseadas em semelhança a conhecimentos ou habilidades prévias. Em suma as percepções visuais analíticas identificadas são:

\section{Princípios de Gestalt [Koffka, 1935]}

O termo Gestalt vem da psicologia e significa "totalidade unida" (em alemão). Os Princípios de Gestalt se referem às teorias de percepção visual desenvolvidas por psicólogos alemães na década de 1920. As teorias desenvolvidas tentam descrever como as pessoas tendem a organizar elementos visuais em grupos ou em "totalidades unidas" quando certos princípios se aplicam. Tais princípios consideram o fato de que o que se vê não é apenas um fluxo desordenado de estímulos. Ao invés disso itens separados e relacionados formam uma totalidade maior cujo arranjo e divisão são concretos e definidos. Esta observação pode ser explicada pela tendência do sistema visual de procurar a unidade espacial mais econômica [Kepes, 1967]. Os princípios observados são:

Similaridade: varios objetos apresentam semelhança entre si.

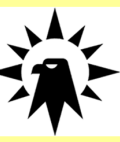
Continuidade: Continuidade ocorre quando os olhos são compelidos a se mover através de um objeto e continuar até outro.

Fechamento: Fechamento ocorre quando um objeto está incompleto Se há informação suficiente a respeito da forma do objeto, as pessoas são capazes de perceber a totalidade preenchendo a informação que falta.

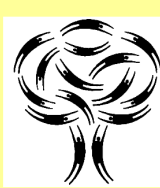

Proximidade:

Proximidade (ou contigüidade) ocorre quando vários objetos são posicionados uns próximos aos outros. Isto gera uma tendência de que eles sejam observados Isto gera uma tende
como um grupo.

Simetria ocorre quando dois ou mais objetosia: percebidos individualmente apesar da totalidade definida por eles indicar uma quantidade diferente de objetos. No exemplo à direita, há três quadriláteros ou dois quadrados sobrepostos?

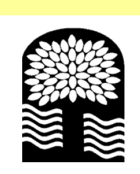

Figura e pano de fundo:

O olho diferencia a forma de um objeto da área que o circunda. Uma forma ou uma silhueta são naturalmente percebidas como figuras (objetos), enquanto a área em volta é percebida como pano de fundo.

Figura 3.5: Princípios de Gestalt. 
- correspondência: cada posição/forma/cor estabelece uma correspondência a um mapa de referência. Assume-se que há a necessidade de um mapa visual explícito ou de um mapa mental implícito. Exemplos de mapas visuais incluem eixos, mapas geográficos, dicionários de forma/cor e intervalos contínuos de variação utilizando posição/forma/cor. Exemplos de mapas mentais incluem ordens previamente conhecidas e metáforas baseadas em forma;

- diferenciação: cada posição/forma/cor discrimina um ou mais itens gráficos. Diferenciação é a forma mais simples de percepção visual e pode ser entendida como um tipo de correspondência em que o analista cria um mapa mental temporário na memória;

- conectividade: formas que informam sobre relacionamentos. Conectividade é uma expressividade decorrente de um padrão visual limítrofe. Formas que indicam conectividade, independente do contexto do domínio de dados, podem ser um componente visual sem significado, ou podem expressar percepção de conectividade de maneira bem específica se aliadas a uma disposição espacial adequada;

- arranjo: características (similaridade, continuidade, fechamento, proximidade, simetria, figura e pano de fundo) que informam sobre propriedades de grupo, como aglomerados e estruturas, segundo os princípios de Gestalt [Koffka, 1935];

- significado: posição/forma/cor cuja interpretação se baseia em conhecimentos ou habilidades prévias. Significado é um tipo de correspondência estabelecida entre entidades visuais e conceitos armazenados na memória de longo prazo do usuário analista. Alguma coisa é percebida como tendo significado se sua capacidade de expressão extrapola o contexto da visualização. Em contraste, os componentes de uma cena de visualização têm significado apenas dentro de seu próprio conjunto.

Outras percepções visuais analíticas poderiam ser identificadas como, por exemplo, rótulos textuais, textura e fechamento [Mackinlay, 1986]. No entanto, texto pode ser considerado como composição de formas que podem expressar percepções como diferenciação e significado. Texturas estão no limiar entre cor (visão homogênea) e forma (visão segregada). Kimchi [Kimchi, 1998] lembra que, na literatura da ciência de visão, texturas têm sido interpretadas como agrupamentos por similaridade dos elementos que compõem a textura. Na prática, uma ou outra expressividade pode ser percebida especialmente para correspondência ou diferenciação. Fechamento é compreendido como um tipo de percepção de arranjo grupal estimulada por diferenciação de forma, assim como já abordado pelos princípios de Gestalt [Koffka, 1935]. 


\section{Interpretações cognitivas}

Interpretações cognitivas referem-se a conclusões, inferências ou deduções provenientes do auxílio visual da cena de visualização em conjunto com o conhecimento do domínio dos dados sendo analisados. Como mostrado na figura 3.4, a interpretação visual ocorre em consequiência da percepção visual, sendo que uma dada visualização pode ser mais ou menos efetiva na tarefa de gerar interpretações. Numa sessão de análise visual de dados, interpretações podem ser geradas ou não, esta capacidade depende dos dados, da técnica de visualização e do analista. Dentre outras possibilidades [Goebel e Gruenwald, 1999] [Fayyad et al., 1996], interpretações cognitivas na análise visual de dados incluem: correlação, tendência, classificação, relacionamento, sumarização, exceção, agrupamento, estrutura e leitura.

\section{O Processo de Expressividade Visual}

A figura 3.4 agrega as observações feitas até agora num único processo, o qual aqui denominase Processo de Expressividade Visual. Três tarefas cognitivas estão envolvidas neste processo: concepção, observação e raciocínio. A concepção de uma visualização requer o estabelecimento de como posição, forma e cor serão empregadas para a estimulação visual; durante a observação, supõe-se que visualizações promovam percepção; por último, o raciocínio baseado nas percepções pode ou não produzir interpretações a respeito dos dados. Acredita-se que, de maneira geral, este processo ocorra subjacente à prática da análise visual de dados. Intuitivamente, pode-se dizer que padrões visuais de posição, forma e cor estão puramente relacionados aos dados "crus" e que, por intermédio de percepção visual, são geradas interpretações cognitivas relacionadas não a dados, mas a informações contextualizadas dentro de um domínio de aplicação. Trata-se da geração de conhecimento.

O processo de expressividade visual estabelece que, uma vez que uma visualização é concebida, dois passos adicionais são necessários para se gerar conhecimento: observação e raciocínio. No entanto, uma lacuna separa as visualizações e as interpretações. Esta lacuna é preenchida pelo conceito de percepção visual promovida por visualizações. As percepções visuais se baseiam na memória do analista para transformar observações em procedimentos relacionados à ciência de análise e a conhecimento. Esta compreensão sustenta o desenvolvimento da teoria do presente trabalho ao responder algumas perguntas chaves para a pesquisa em visualização:

- quais são os constituintes das técnicas de visualização?

- em que sentido tais constituintes podem ser aproveitados para a definição de percepção visual analítica?

- qual é o fator que interliga estímulos visuais e produção de conhecimento? 
Nota-se que os argumentos apresentados se aplicam a observações empíricas relacionadas a processos de visão que objetivam maximizar a percepção para a exploração de dados. Como tal, a priori tais observações são restritas à ciência de visualização, não sendo aplicáveis à teoria da ciência de visão em geral.

\subsection{Considerações Gerais}

Nesta seção, os elementos fundamentais da visualização de dados foram identificados: estímulos pré-atentivos, mapeamento de dados para o espaço (espacialização) e percepção visual. Em seguida, estes elementos foram contextualizados no cenário de expressividade visual. Nos próximos capítulos, estes conceitos serão utilizados no desenvolvimento de uma revisão da ciência de visualização por meio de uma sistematização alternativa.

A observação da análise realizada nesta seção revela que o design de técnicas de visualização requer a consideração de representações gráficas apropriadas, da configuração espacial para os objetos gráficos e do contexto cognitivo, além de uma estrutura de exploração interativa [Bugajska, 2003]. As idéias apresentadas se baseiam em estímulos pré-atentivos, como constituintes naturais das composições visuais; em espacialização, como a essência que possibilita a cognição visual/espacial; e em percepção visual, como o catalisador que age sobre o processo de raciocínio.

No cenário destes conceitos, a compreensão que embasa grande parte da presente tese é de que é possível desenvolver uma teoria taxonômica e analítica orientada a percepções visuais. Esta escolha é justificada pelas seguintes observações relativas às percepções visuais, as quais:

- são presentes (ou necessárias) em qualquer técnica de visualização, em contraste a outros fatores como interação, pré-processamento e interpretações utilizados como critérios em outros trabalhos analíticos (apresentado no capítulo 4);

- não são numerosas, em contraste às inúmeras possibilidades de padrões visuais;

- podem ser categoricamente relacionadas aos estímulos pré-atentivos constituintes das visualizações, possibilitando reconhecimento e associação imediatos;

- constituem um elemento chave para a cognição analítica visual.

Estas propriedades permitem que um estudo orientado à percepção visual seja mais racionalizável do que outras propostas orientadas a características de alto nível ou a padrões visuais. Sua presença natural, seu número reduzido, sua proximidade a faculdades visuais inatas e seu papel no processo analítico tornam a percepção visual em um provável alicerce para a ciência 
de visualização. Uma suposição que se faz é de que é mais fácil saber quais interpretações podem ser alcançadas a partir de uma dada percepção visual do que a partir de um padrão visual. Esta suposição vem do senso de que quando desejam observar dados, os usuários analistas estão mais interessados em compreender de quais percepções visuais eles podem se beneficiar e não nos padrões visuais que eles podem ver. Por exemplo, ao invés de manifestar interesse por um conjunto de eixos e pontos, um analista estaria mais inclinado a querer observar a correspondência presente entre seus dados. Da mesma maneira, Senay e Ignatius [Senay e Ignatius, 1990] defendem que a definição de regras para os componentes das visualizações, ao invés de para as próprias visualizações, permite melhores escolhas durante a composição de técnicas.

No presente estudo, os fatores pré-atentivos, a espacialização e a percepção visual são relacionados com o intuito de se repensar conceitos da ciência de visualização. O trabalho engloba o delineamento de uma organização taxonômica capaz de promover uma perspectiva diferenciada da ciência de visualização. Em seguida, ao longo desta tese, o estudo avança para a concepção de um novo espaço de design e conclui num modelo de projeto de sistemas de visualização que se beneficia das idéias apresentadas. 


\section{Capítulo 4}

\section{Taxonomias e Espaços de Design}

\subsection{Considerações Iniciais}

A Análise Visual de Dados, como qualquer área de pesquisa, pode se beneficiar de um arcabouço conceitual para organizar métodos e técnicas num único espaço de compreensão. Isto é, um espaço delimitado de possibilidades onde é possível navegar através das variáveis constituintes sem perder o referencial. Assim, como visto na seção 1.3, diversos trabalhos recentes apontam para a necessidade de se conduzir pesquisas em busca de um novo espaço de design capaz de incorporar diferentes classes de visualização. As obras encontradas na literatura têm tentado alcançar esta meta, seja a partir de uma perspectiva taxonômica ou a partir de uma perspectiva analítica. Trabalhos taxonômicos tentam identificar características semelhantes pertencentes a visualizações já existentes com o intuito de propor organizações orientadas a classes. Trabalhos analíticos tentam identificar empiricamente os constituintes elementares das visualizações e determinar a relação que existe entre eles. Ambos os tipos de trabalho têm natureza semelhante, apenas diferindo pelo grau de abstração. Em alguns casos a categorização entre taxonomia e espaço de design não é clara.

Neste trabalho aborda-se o tema de se desenvolver um espaço único de compreensão para as técnicas de visualização. A abordagem utilizada é tanto taxonômica quanto analítica, e o resultado é um espaço de design alternativo que engloba técnicas de interação e que define um modelo de projeto de técnicas de visualização. Nesta seção serão revistos os trabalhos correlatos à presente proposta. Faz-se uma extensa revisão a respeito de taxonomias, de espaços de design e de diretrizes de design. O objetivo é descrever o embasamento teórico existente, apontando suas fraquezas e suas contribuições, de maneira que seja possível a compreensão da contribuição da presente proposta como uma evolução fundamentada em pesquisas já ratificadas. 


\subsection{Taxonomias}

Taxonomias são úteis para a definição e a organização de elementos que caracterizam um determinado fenômeno. Elas auxiliam na descoberta de dependências e de relacionamentos entre estes elementos de maneira sistemática e ordenada. Isso acontece pois, caracterizando-se quais são os fenômenos específicos que fazem parte de um dado conjunto de fenômenos, a compreensão do conjunto todo torna-se mais simples. Taxonomias são importantes pois descartam detalhes irrelevantes enquanto identificam e enfatizam as propriedades dos artefatos e das situações mais importantes para o design [Brooks, 1991]. Na prática uma taxonomia permite a comparação e a generalização dos resultados de uma determinada ciência. Nesta seção serão apresentados os trabalhos taxonômicos mais representativos da área de análise visual de dados.

\subsubsection{A Taxonomia de Shneiderman}

O trabalho de Shneiderman [Shneiderman, 1996], denominado Task by Data Type, ou algo como "tarefas definidas em função do tipo dos dados", é um dos mais referenciados trabalhos de classificação na área de visualização. O objetivo da proposta é organizar projetos de design de modo a guiar pesquisadores para novas abordagens de visualização. O trabalho, mostrado na figura 4.1 é fundamentado em sua própria afirmação de que a atividade de design se baseia no "mantra da visualização: primeiro visão geral, zoom e filtragem, só então detalhes sob demanda" já mencionado no capítulo 2. O trabalho de Shneiderman, como frisa o próprio autor, é

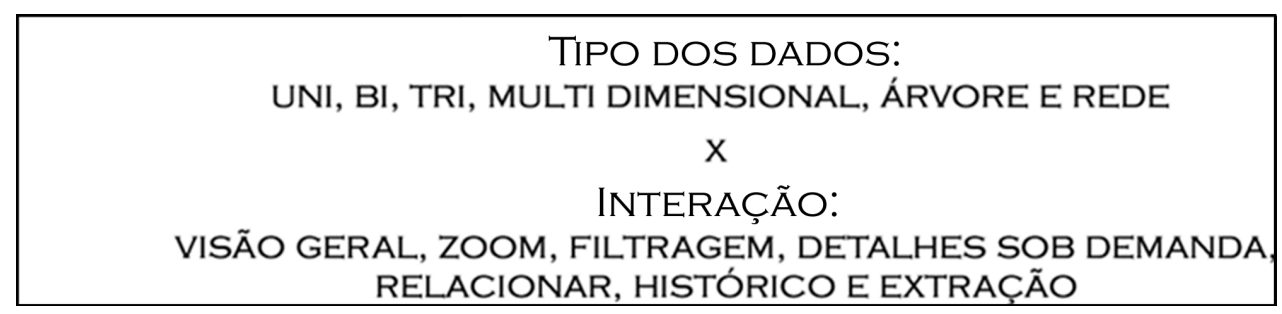

Figura 4.1: A taxonomia de Shneiderman, tarefas definidas em função do tipo dos dados.

apenas um ponto inicial que não explora plenamente o espaço de possibilidades de design para classificar técnicas de visualização. A proposta é apresentada como uma coleção de observações a respeito das características da prática de visualização, quais dados são apresentados (uni, bi, tri, multi dimensionais, árvores e redes) e como se interage com eles (visão geral, zoom, filtragem, detalhes sob demanda, relacionar, histórico e extração), introduzindo uma abordagem analítica de alto nível. Sua contribuição está na análise do que os usuários analistas esperam de uma dada visualização e, conseqüentemente, com o que os projetistas devem se preocupar. A intenção principal do autor é definir um guia para o design não de técnicas de visualização, mas para o design de ambientes de visualização onde o fator de interação (a tarefa) tem grande impacto. 


\subsubsection{A Taxonomia de Keim}

Outra proposta bastante referenciada é o trabalho de Keim [Keim, 2002]. Neste trabalho, o autor não coloca sua taxonomia como contribuição principal, apenas como um exercício de análise. No entanto, suas colocações são utilizadas amplamente em toda a literatura da área de VisInfo. A taxonomia de Keim organiza os sistemas de visualização dentro de um espaço de possibilidades de alto nível. Suas dimensões são interação, tipo dos dados e técnica de visualização, como apresentado na figura 4.2.

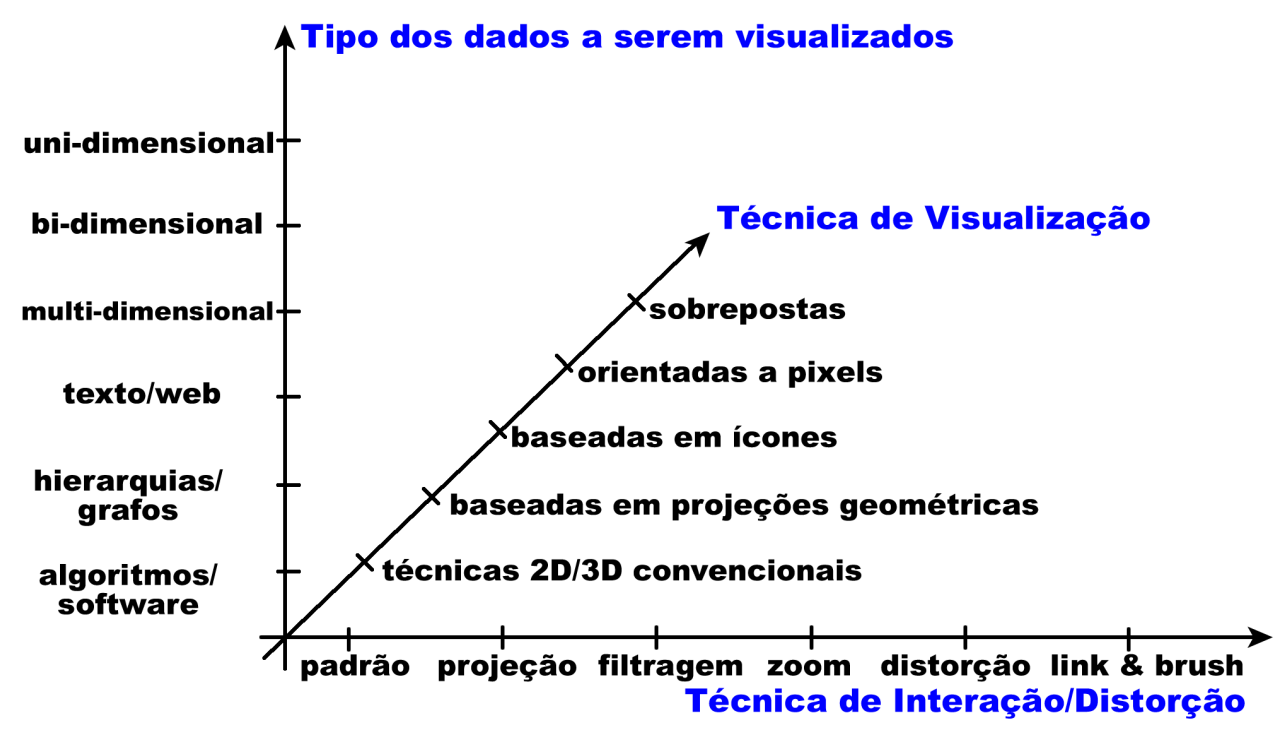

Figura 4.2: A taxonomia de Keim, um espaço com dimensões de interação, tipo dos dado e técnica de visualização.

Os tipos de dados identificados por Keim podem ter uma ou várias dimensões (bases de dados relacionais), podem ser textuais (incluindo hipertexto), podem ser estruturados (como grafos e hierarquias) ou podem ser páginas de código de linguagem de programação.

As técnicas de interação apresentadas incluem:

- projeção interativa: possibilita a redefinição dinâmica da projeção por meio de manipulação direta do analista. Como exemplo, cita-se o trabalho de Wegman e Luo [Wegman e Luo, 1997], com o sistema GrandTour que procura exibir todas as projeções bidimensionais de um conjunto multidimensional por meio de uma série de Scatter Plots [Ward, 1994]; em outro trabalho, Fekete e Plaisant [Fekete e Plaisant, 2002] pesquisam projeção interativa com o intuito de expandir a escalabilidade de técnicas clássicas de visualização;

- filtragem interativa: trata-se da possibilidade de se realizar consultas visuais sobre os dados em análise. $\mathrm{O}$ analista é capaz de focar em porções dos dados que julgar mais interessantes, gerando diferentes visualizações que podem ser comparadas e utilizadas para 
elucidar a relação entre dados selecionados sobre diferentes consultas. Diversos autores utilizam esta técnica, como Rodrigues et al [Rodrigues Jr. et al., 2005], Rundensteiner et al [Rundensteiner et al., 2002] e Martin e Ward [Martin e Ward, 1995] que analisa a idéia minuciosamente;

- zoom interativo: diferentes visões da distribuição dos dados são conseguidas de acordo com o grau de zoom. Isto é possível aplicando-se operações de escala aos elementos de visualização (pixels, linhas, ícones ou qualquer marca gráfica) expandindo-se (detalhando-se) apenas aqueles em que houver interesse. Como exemplo, Nekrasovski et al [Nekrasovski et al., 2006] apresentam um recente trabalho de avaliação do uso de técnicas de zoom que enfatiza o uso de zoom e de manipulação espacial com funcionalidades que mantêem o contexto da visualização;

- distorção interativa: possibilita uma visão global da distribuição dos dados ao mesmo tempo em que uma parte das informações permanece visível em maiores detalhes. Baseiase na deformação dos elementos visuais de maneira que suas propriedades espaciais ainda permaneçam observáveis. Um estudo profundo das técnicas de distorção pode ser encontrado no trabalho de Leung e Apperley em [Leung e Apperley, 1994], exemplos de implementação incluem o trabalho de Mackinlay et al [Mackinlay et al., 1991] com a Perspective Wall, de Sarkar e Brown [Sarkar e Brown, 1994] com a Fish-eye View, e de Walter e Britter [Walter e Ritter, 2002] com o plano hiperbólico;

- link \& brush: ou co-plots [Wegman e Luo, 1997], tendo-se diversas técnicas de visualização apresentando simultaneamente o mesmo conjunto de dados, o princípio é propagar as ações interativas do usuário analista - especialmente filtragem interativa - para todas as representações visuais de maneira a refletir simultaneamente os novos parâmetros de apresentação em todas as cenas de análise visual [Ward, 1997].

As técnicas de visualização enunciadas por Keim incluem:

- projeções $2 D / 3 D$ convencionais: técnicas simples e amplamente utilizadas, como funções matemáticas em planos e espaços, gráficos de barras, pie-charts (gráfico de pizza), line graphs, etc;

- técnicas baseadas em projeções geométricas: têm como princípio o mapeamento de dados multidimensionais para padrões bidimensionais por meio da utilização dos valores presentes na base de dados como parâmetros para a geração de formas geométricas. Estas formas devem ser tais que o conteúdo da informação representada possa ser percebido visualmente nas propriedades gráficas. Como exemplos, as Coordena- 
das Paralelas [Inselberg e Dimsdale, 1990] [Johansson et al., 2005], as Star Coordinates [Kandogan, 2001] e os Scatter Plots;

- técnicas baseadas em ícones: cada item de informação é representado como um ícone, cuja aparência deve ser familiar ao ser humano para que os atributos das entidades gráficas possam ser prontamente associados aos itens de dados em análise. Segundo [Pickett e Grinstein, 1988], cor, forma e textura são características amplamente exploradas no design dos ícones, pois podem ser utilizadas simultaneamente sem perda de informação. Como exemplos, as clássicas Faces de Chernoff [Chernoff, 1973], os Star Glyphs [Chambers et al., 1983] e as Stick Figures [Pickett e Grinstein, 1988];

- técnicas orientadas a pixels: os valores dos atributos de um dado multidimensional são exibidos utilizando-se individualmente os pixels do dispositivo de exibição, um pixel para cada valor de atributo fazendo uso de cores para representar as propriedades dos atributos. Cada dimensão dos dados pode ser apresentada em uma janela individual, além disso a visualização pode ser gerada sobre todos os elementos de dados ou sobre um subconjunto especificado por uma consulta. Nos trabalhos de Keim [Keim et al., 1995] [Keim, 2000] são apresentados os fatores a se considerar na construção de visualizações deste tipo: o arranjo dos pixels nas janelas, o mapeamento da cor, e o formato das janelas. A idéia dos Pixel Bar Charts [Keim et al., 2001] segue esta linha de apresentação;

- técnicas hierárquicas: o espaço k-dimensional é recursivamente subdividido e os subespaços resultantes são apresentados de forma hierárquica de maneira a refletir os ciclos de divisão do espaço. Como exemplos, a técnica Dimensional Stacking [LeBlanc et al., 1990] apresenta bidimensionalmente as dimensões em sucessivos níveis hierárquicos; a técnica Tree-maps [Shneiderman, 1992] organiza os dados hierarquicamente e os apresenta por meio de uma imagem composta de retângulos cujos tamanhos e posições indicam a localização dos dados dentro da hierarquia.

O trabalho de Keim determina classes de alto nível cognitivo. As categorias compreendidas em suas classes personificam apenas a maneira como as técnicas são percebidas, não como elas são construídas ou projetadas. Esta abordagem tem dois lados. A taxonomia é bastante referenciada, sendo uma das mais utilizadas pois se traduz rapidamente em compreensão. Por outro lado a idéia de construção utilizando conceitos discretos não se enquadra diante do alto nível de abstração da proposta. Desta maneira, a taxonomia de Keim é bastante limitada na tarefa de projeto sistemático de técnicas. 


\subsubsection{O trabalho de Bugajska}

Bugajska [Bugajska, 2003] [Bugajska, 2005] apresenta um trabalho de classificação de técnicas de VisInfo orientado a aspectos espaciais. Em sua proposta, o Modelo de Classificação de Design Espacial, a autora foca no suporte ao design de técnicas buscando eficiência. Por esta razão sua classificação é associada a diretrizes de projeto ao mesmo tempo em que apresenta um arcabouço voltado à disseminação estruturada de informações de design.

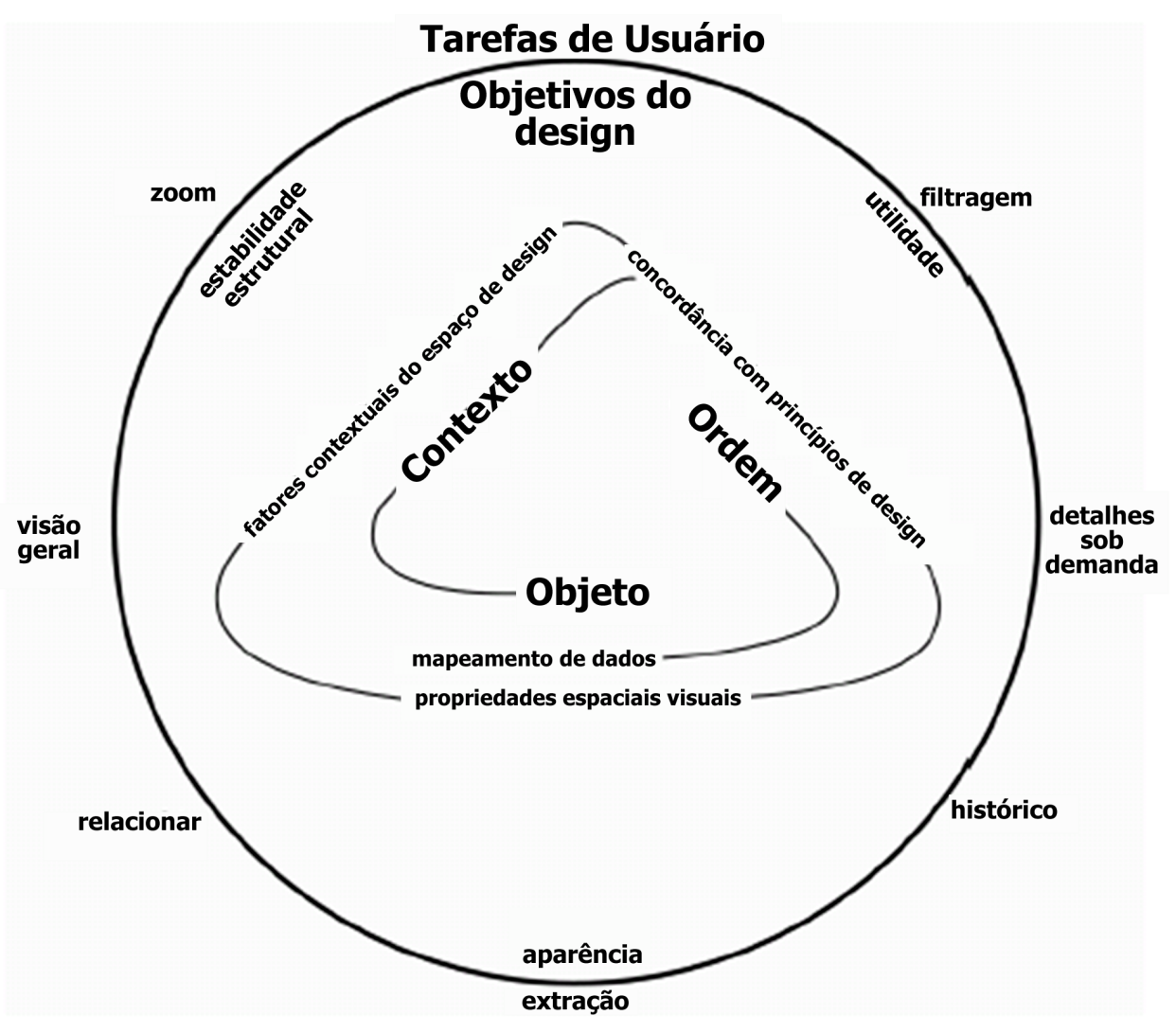

Figura 4.3: O espaço de classificação de Bugajska. O Modelo de Classificação de Design Espacial prevê uma apreciação holística das técnicas de VisInfo. Adaptado de [Bugajska, 2005].

O trabalho proposto considera aspectos interativos, perceptuais, de navegação, organizacionais e metafóricos num modelo interdisciplinar que aborda representações visuais de dados de maneira holística. Os critérios considerados no trabalho de Bugajska são: objeto, contexto, ordem, objetivos de design e tarefas de usuário, como mostrado na figura 4.3. Objeto diz respeito aos elementos gráficos que representam os dados. Contexto se refere ao espaço gráfico utilizado para representar as relações entre os elementos. Ordem se refere ao arranjo espacial dos objetos no contexto. Os objetivos de design se dividem em estabilidade estrutural, utilidade e aparência. As tarefas de usuário correspondem às observações sobre interação do trabalho de Shneiderman, apresentado na seção 4.2.1. 
O trabalho de Bugajska é a mais subjetiva das teorias consideradas nesta tese. Seu espaço de classificação é contínuo e pouco categórico. A consideração de múltiplos aspectos disciplinares torna a análise bastante extensa, dificultando sua utilização a não ser que se utilize de diretrizes de design, assim como colocado pela autora. A contribuição de Bugajska está na integralidade de sua brilhante análise, a qual fornece um panorama bastante coerente a respeito da ciência de visualização a partir de teorias da ciência da visão, percepção e neurociência.

\subsubsection{O trabalho de Tweedie}

Em seu trabalho, Tweedie [Tweedie, 1997] refere-se às técnicas de visualização como técnicas de externalização, sua proposta enfatiza a avaliação e a comparação de técnicas de análise visual. Segundo ela, visualizações podem ser caracterizadas segundo o tipo dos dados sendo representados, a natureza da realimentação promovida pela técnica, as formas de interatividade utilizadas e as informações de entrada e saída suportadas.

A proposta de Tweedie - ilustrada na tabela 4.1 - considera possibilidades de representação visual para dados "crus" e para meta-dados. Dados "crus" incluem: valores dos dados (quantitativos, nominais e ordenados) e estruturas dos dados (hierarquias e relacionamentos em geral). Meta-dados englobam: dados construídos (derivados), quando a forma original do dado é mantida (agregação, por exemplo); e dados convertidos, quando um novo formato é gerado (uma estrutura subjacente, por exemplo). A interação, promovida por manipulação direta (reprodução literal da manipulação realizada no mundo real) ou indireta (por mecanismos artificiais como a barra de rolagem), pode ser manual ou automática, passando por graduações semiautomatizadas. Informações de entrada e saída podem ser combinadas aos pares, por exemplo entrada via controles deslizantes e saída numa visualização com tons de cor variantes, ou saída via mensagem de erro e entrada via elo de conexão até a causa do erro.

Embora referenciada desta maneira, a obra de Tweedie não descreve sistematicamente uma taxonomia e, como a própria autora coloca, seu trabalho apenas sugere um conjunto de recomendações para a atividade de design. Dentre estas recomendações, representar explicitamente a entrada e a saída dos dados para se definir um diálogo de interação; considerar a dimensão do tempo para as atividades interativas; considerar interação colaborativa e novas formas de interação; e desenvolver trabalhos que considerem o contexto da atividade de análise visual de dados. A proposta considera diferentes níveis de abstração e não se preocupa em organizar claramente os limites entre um nível e outro. Sua análise geral é realizada de uma perspectiva bastante voltada à interação sem se preocupar em definir uma sistematização que sintetize amplamente suas idéias. 
Tabela 4.1: Caracterização de técnicas de externalização. Adaptado do trabalho de Tweedie [Tweedie, 1997].

\begin{tabular}{|c|c|c|}
\hline $\begin{array}{l}\text { Meta-dados } \\
\text { (derivados e } \\
\text { convertidos) }\end{array}$ & Spreadplots [Young et al., 1993] & Pad++ [Bederson et al., 1996] \\
\hline \multirow[t]{3}{*}{$\begin{array}{c}\text { Dados } \\
\text { (valores e } \\
\text { estruturas) }\end{array}$} & $\begin{array}{l}\text { Matriz de Scatter Plots [Ward, 1994], } \\
\text { Table Lens [Rao e Card, 1994] }\end{array}$ & $\begin{array}{l}\text { Coordenadas Paralelas } \\
\text { [Inselberg e Dimsdale, 1990], VisDB } \\
\text { [Keim e Kriegel, 1994] }\end{array}$ \\
\hline & Manipulação direta & Manipulação indireta \\
\hline & \multicolumn{2}{|c|}{ Interatividade } \\
\hline
\end{tabular}

\subsubsection{A Taxonomia de Tory e Möller}

Uma taxonomia interessante foi proposta no trabalho de Tory e Möller [Tory e Möller, 2002]. Este trabalho aborda a discussão entre a categorização das técnicas de visualização em VinInfo e VisC que, na taxonomia proposta, correspondem respectivamente a técnicas contínuas e discretas. Sua estrutura geral é apresentada na figura 4.4. A esquerda da figura compreende diversas técnicas e conceitos da VisC [Oliveira e Minghim, 1997], a direita se concentra em técnicas de VisInfo.

Embora coerente em sua simplicidade, a taxonomia tem pouca utilidade prática. A consideração da dimensionalidade das apresentações, assim como em outras propostas, não coopera para a definição de conceitos generalizáveis. A natureza das apresentações não é considerada, o que determina poucas classes com muitos elementos. Esta característica permite, apenas, a definição de conceitos tão amplos quanto as classes propostas, o que restringe a análise mais minuciosa dos constituintes das visualizações. A taxonomia é útil, no entanto, para chamar a atenção para a diferença tênue entre técnicas de VisInfo e VisC.

\subsubsection{A Taxonomina de Chi}

Nesta proposta [Chi, 2000], o autor utiliza o conceito de Modelo de Referência de Estado dos Dados, de sua própria autoria, para analisar as técnicas de visualização. O modelo, apresentado 


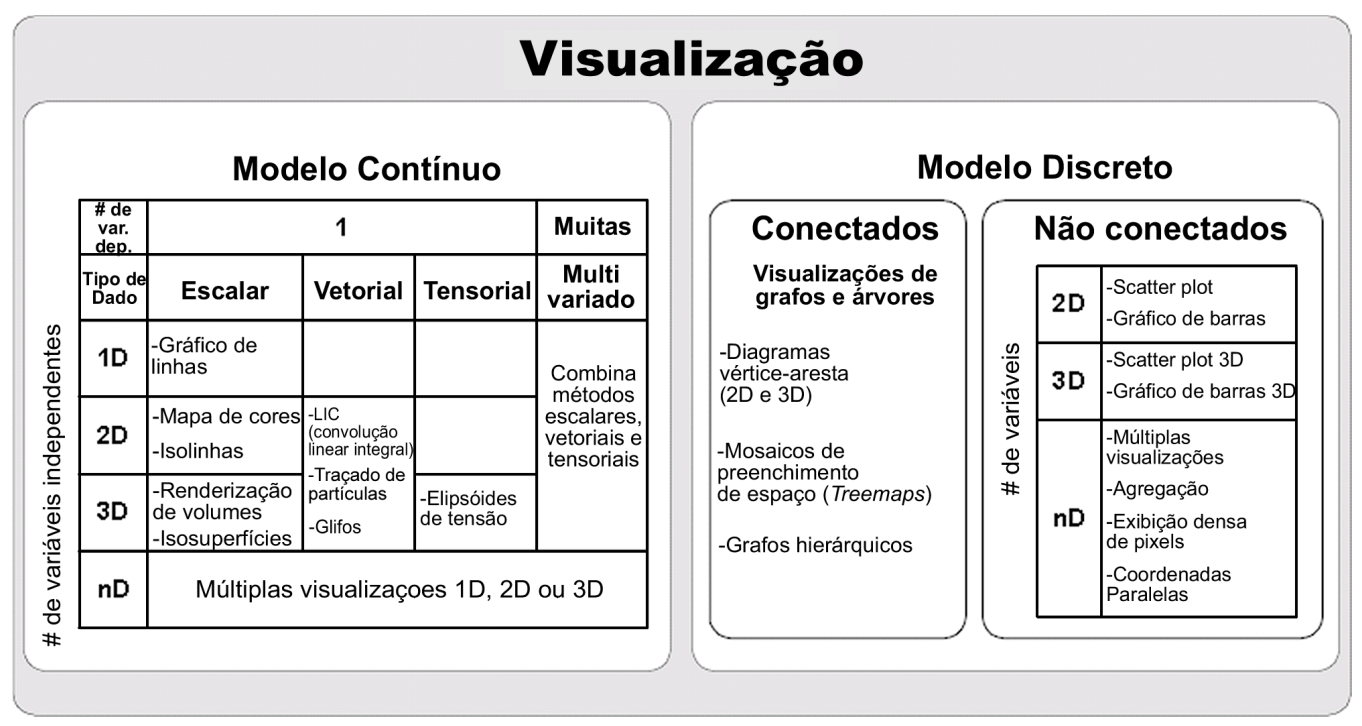

Figura 4.4: A taxonomia de Tory e Möller que categoriza a VisInfo e a VisC como técnicas contínuas e discretas. Adaptado de [Tory e Möller, 2002].

na figura 4.5, quebra as técnicas de visualização em quatro estágios (estados dos dados), três tipos de transformação (mudança de estado) de dados e quatro tipos de operadores. As transformações intermedeiam os estágios e os operadores trabalham sobre os dados de cada estágio sem alterar sua estrutura (ou estado). Por exemplo, para a técnica Coordenadas Paralelas, o estágio valor pode se referir a um conjunto de dados onde diversos campos de informação sem relação explícita são preenchidos por observações de um dado fenômeno. Uma primeira transformação pode colocar os dados em um formato de entidade-relacionamento. Neste estado, um operador de análise pode realizar uma filtragem determinando um subconjunto de informações. Em seguida a transformação de visualização gera dados na forma de pontos geométricos para cada atributo. Estes pontos podem ser utilizados por um operador de visualização que organiza os pontos em linhas e eixos. A última transformação projeta os dados como coordenadas paralelas. Em seu último formato, os dados gráficos podem ser processados por meio de operadores de interação.

Apesar do título de seu trabalho, a proposta de Chi não é rigorosamente uma taxonomia ou ciência de classificação - pois não define classes. Em seu trabalho, uma série de técnicas são analisadas à luz de seu modelo e as descrições resultantes, dos diversos estados e transformações, são a caracterização com a qual o autor delineia suas categorias. A ausência de classes impede que duas técnicas quaisquer pertençam sistematicamente à mesma categoria, embora eventualmente isto possa acontecer. Também como se observa em seu trabalho, as categorizações são prolixas a ponto de se assemelharem a extensas descrições textuais das técnicas em análise. A funcionalidade de sua proposta é restrita, sendo que a maior contribuição do autor é seu modelo, capaz de particionar o processo de concepção de uma dada técnica. 


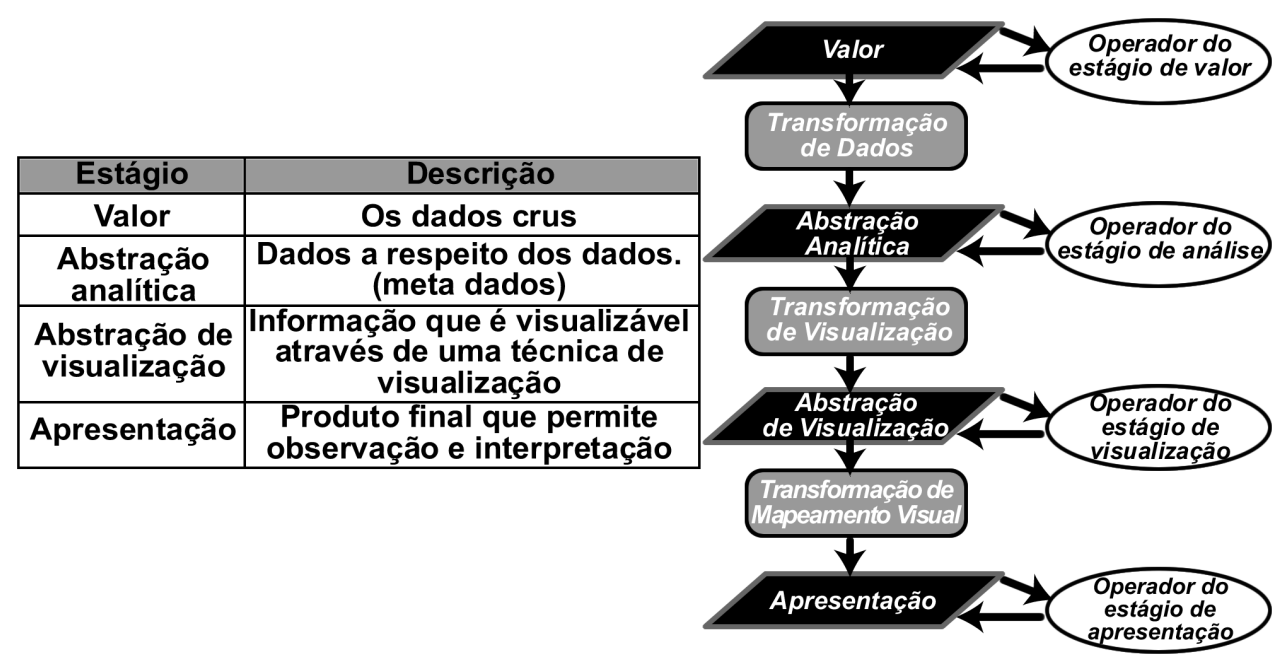

Figura 4.5: O Modelo de Referência de Estado dos Dados, base da taxonomia proposta por Chi [Chi, 2000].

\subsubsection{Outros trabalhos}

Outras taxonomias relevantes incluem:

- o trabalho de Wiss e Carr [Wiss e Carr, 1998] que considera os critérios de atenção (como os itens gráficos são percebidos), abstração (como a estrutura dos dados é personificada) e percepção das possibilidades de interação para analisar cognitivamente técnicas de visualização 3D;

- o trabalho de Grinstein et al [Grinstein e Ward, 2002] descreve um esboço de taxonomia considerando a caracterização das técnicas - geométricas, simbólicas, 2D/3D, estáticas ou dinâmicas - e as interações sobre as visualizações - navegação, amostragem, indireta, associativa e orientada ao sistema. Este trabalho não define formalmente uma classificação mas a discussão desenvolvida levanta aspectos interessantes para guiar um estudo mais refinado a respeito do tópico de taxonomias;

- a proposta de Lohse et al [Lohse et al., 1994] descreve um extenso trabalho de revisão e classificação não apenas de técnicas de visualização, mas de representações visuais em geral. As representações são classificadas segundo as características: espacial ou nãoespacial, temporal ou não-temporal, difícil ou fácil de entender, concreta ou abstrata, contínua ou discreta, atraente ou não-atraente, enfatizando o todo ou as partes, numérica ou não-numérica, estática ou dinâmica, incorporando muita ou pouca informação. 


\subsection{Espaços de Design}

Em análise visual de dados, espaços de design são modelos de organização conceitual que visam determinar quais são os elementos constituintes das técnicas de visualização. Estes elementos são identificados e categorizados definindo uma ordem cuja compreensão pode ser análoga à compreensão dos pontos do espaço físico, isto é, conjuntos de parâmetros (coordenadas) definem pontos dentro do universo de possibilidades. Daí vem a denominação "espaços de design". De característica mais analítica do que taxonomias, espaços de design são orientados a componentes mais elementares. A contribuição destas propostas está, principalmente, na possibilidade de predição de novas possibilidades dentro do domínio da análise visual de dados. Nesta seção serão apresentados os principais espaços de design introduzidos na literatura.

\subsubsection{O Trabalho de Bertin}

A obra de Bertin [Bertin, 1974] é uma referência nas ciências de visão e de visualização. Nela o autor descreve um estudo semiológico a respeito de métodos de representação gráfica. Sua proposta é apresentada na forma de uma teoria na qual as regras que governam sistemas gráficos são relacionadas a mapas, a diagramas bidimensionais e a dados que representam estruturas (retilíneas, circulares, padrões ordenados e não ordenados, e estereogramas). Bertin defende que a representação gráfica a ser utilizada depende do tipo dos dados a serem exibidos, e que duas formas de dados podem ser usadas para se representar qualquer problema: dados de valor e dados de estrutura. Os valores referem-se a atributos numéricos ou categóricos de um dado problema. Estruturas referem-se às relações entre os dados. A partir desta suposição sua teoria conta com os seguintes elementos básicos: componentes, invariantes, correspondências e marcas.

De acordo com a proposta, toda representação gráfica consiste de duas partes primárias denominadas componentes e invariantes. As componentes correspondem a elementos que incorporam o conceito de variação, enquanto as invariantes são usadas para se relacionar as componentes umas às outras. Os relacionamentos definidos são exibidos por meio do mapeamento das componentes a variáveis visuais e por meio de marcas que mostram a correspondência entre as componentes. As marcas descrevem elementos que podem ser apresentados num plano: pontos, linhas ou mesmo áreas. Por exemplo, veja a figura 4.6, num gráfico demonstrando a relação entre peso e idade para uma certa população, as componentes são peso e idade e são mapeadas para os eixos $X$ e $Y$. A invariante é a população de indivíduos. Cada ponto usado para demonstrar a relação entre as componentes que variam é uma marca.

Ainda segundo Bertin, existem dois grupos visuais que descrevem uma marca: planares (em referência ao plano) e retinais (em referência à percepção da retina). Marcas planares 

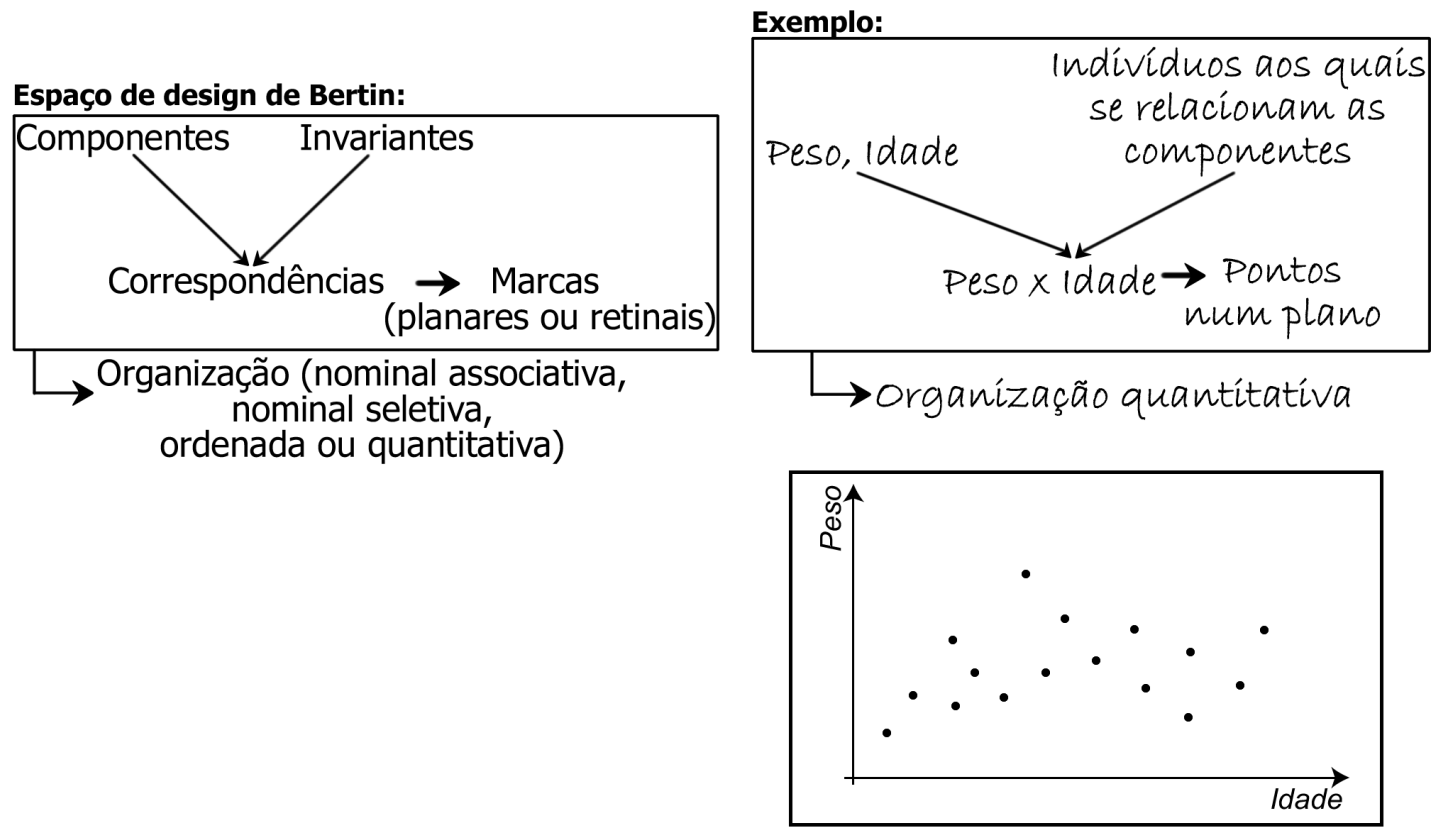

Figura 4.6: O espaço de design proposto por Bertin junto com um exemplo ilustrativo.

representam posições geométricas num plano. Marcas retinais são definidas por seis atributos: tamanho, brilho, textura, cor, orientação e forma. Qualquer propriedade é definida em passos ou categorizações, como incrementos de tamanho por exemplo. Por último, a teoria do autor classifica as marcas planares e retinais em quatro níveis organizacionais de acordo com o tipo de cognição promovida por meio de percepção: nominal associativa, nominal seletiva, ordenada, e quantitativa. A tabela 4.2 relaciona as possibilidades definidas entre os grupos de marcas (planares e retinais) e os níveis de organização (associativo, seletivo, ordenado, e quantitativo).

Tabela 4.2: Marcas-propriedades e possibilidades de apresentação com relação aos níveis organizacionais cognitivos. Adaptado da obra de Bertin [Bertin, 1974].

\begin{tabular}{|l|l|l|l|l|}
\hline $\begin{array}{l}\text { Marca- } \\
\text { propriedade }\end{array}$ & $\begin{array}{l}\text { Nominal } \\
\text { Associativo }\end{array}$ & Nominal Seletivo & Ordenado & Quantitativo \\
\hline \hline Planar & $\operatorname{sim}$ & $\operatorname{sim}$ & $\operatorname{sim}$ & sim \\
\hline Retinal-Tamanho & não & $\operatorname{sim}$ & $\operatorname{sim}$ & sim \\
\hline Retinal-Brilho & não & $\operatorname{sim}$ & $\operatorname{sim}$ & não \\
\hline Retinal-Textura & $\operatorname{sim}$ & $\operatorname{sim}$ & $\operatorname{sim}$ & não \\
\hline Retinal-Cor & $\operatorname{sim}$ & $\operatorname{sim}$ & não & não \\
\hline Retinal-Orientação & $\operatorname{sim}$ & $\operatorname{sim}$ & não & não \\
\hline Retinal-Forma & $\operatorname{sim}$ & não & não & não \\
\hline
\end{tabular}

A organização nominal associativa refere-se à possibilidade de se associar diversas marcas, e seus respectivos dados, de maneira que ocorra percepção de que as marcas definem um grupo, uma categoria. Por exemplo, no gráfico da figura 4.6 que exibe a relação entre peso e idade de indivíduos de uma população, seria possível utilizar-se quadrados para se representar homens e 
círculos para se representar mulheres. A organização nominal seletiva refere-se a uma possibilidade complementar à associativa. Nesta organização, as marcas possuem propriedades capazes de ressaltá-las em detrimento da percepção de outras marcas. Tamanho, por exemplo, define organização seletiva. A organização ordenada permite que as marcas sejam colocadas numa ordem. Por exemplo, é possível observar que uma série de marcas segue a ordem do alfabeto sabendo-se qual o sentido e onde se inicia a ordenação. A organização quantitativa possibilita a extração direta de proporções sem que seja necessário consultar uma legenda. Por exemplo, quando a área de uma marca é duas vezes maior do que a área de outra.

Em sua proposta, Bertin ainda define princípios de design válidos dentro de seu espaço de possibilidades. Seu argumento é de que as propriedades da representação visual devem corresponder às propriedades dos dados. Assim, o uso de cor (matiz) é adequado a dados nominais (não ordenáveis e nem sujeitos à aritmética) pois as cores são naturalmente não ordenadas.

$\mathrm{O}$ trabalho de Bertin foi pioneiro em sua abordagem analítica de como dados podem ser representados graficamente considerando as propriedades dos dados e as possibilidades de percepção visual. Embora o fato de que sua proposta considera uma quantidade limitada de representações visuais e de fenômenos perceptivos, a estrutura de seu trabalho é inspiração para diversas outras obras.

\subsubsection{Cleveland e McGill}

A proposta de Cleveland e McGill [Cleveland e McGill, 1984] desenvolve um trabalho de identificação de componentes (ou códigos) gráficos elementares. Estes códigos são classificados com base em experiências e teorias e, em seguida, são colocados numa ordem. Esta ordem indica a precisão com a qual os dados quantitativos, que foram codificados em padrões visuais, podem ser percebidos. A classificação proposta é realizada para que, durante a tarefa de design, os códigos gráficos sejam escolhidos de maneira a maximizar a escolha por padrões visuais mais eficientes. $\mathrm{O}$ argumento colocado pelos autores é que tal procedimento promove embasamento científico para a tarefa de codificação gráfica. Uma outra contribuição deste trabalho é a argumentação dos autores de que os códigos gráficos são constituintes elementares da percepção gráfica, podendo ser manipulados durante o design de visualizações. Esta perspectiva introduziu grandes contribuições à sua época e foi capaz de abrir novos horizontes de exploração para a pesquisa em análise visual de dados.

Embora o trabalho verse sobre visualizações pouco elaboradas, sobretudo gráficos de funções matemáticas, a proposta insere a prática de design baseada em componentes elementares e introduz a abordagem científica experimental à área de design em análise visual de dados. Apesar da simplicidade do material exposto, estes são pontos de vista bastante válidos que serviram de matéria-prima para outros trabalhos da área. 


\subsubsection{O Trabalho de Mackinlay}

Expandindo o trabalho de Cleveland e McGill [Cleveland e McGill, 1984], Mackinlay [Mackinlay, 1986] propõe um sistema para a construção automática de representações gráficas de dados relacionais. Sua proposta não é ambiciosa e se concentra em possibilidades simples como gráficos de barras, scatter plots e grafos. O autor define uma linguagem gráfica de maneira que diferentes configurações visuais possam ser expressas como sentenças desta linguagem. Para permitir a escolha automática dos parâmetros de design, a obra introduz critérios de expressividade e efetividade - já apresentados na seção 2.5. São considerados dados quantitativos, ordenados e nominais. Os padrões visuais considerados, uma expansão do trabalho de Cleveland e McGill, são avaliados com relação a cada tipo de dado, como apresentado na figura 4.7, sendo que esta avaliação é parte importante da proposta.

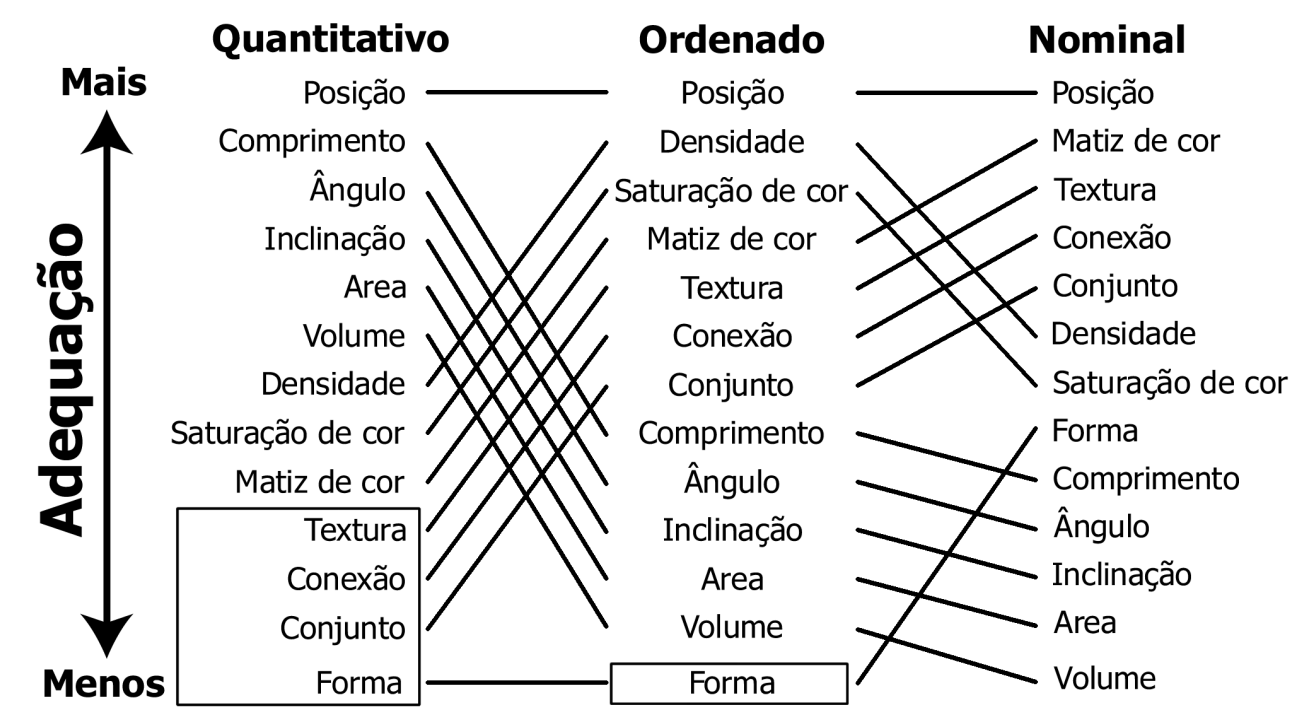

Figura 4.7: Adequação dos padrões de percepção visual. Os padrões envoltos em retângulos não se aplicam ao tipo de dado correspondente à coluna. Adaptado do trabalho de Mackinlay [Mackinlay, 1986].

O autor implementa sua teoria na aplicação denominada A Presentation Tool (APT) que se beneficia da linguagem de programação LISP para interpretar as sentenças de sua linguagem gráfica. Esta interpretação traduz as sentenças da linguagem em expressões de uma álgebra de composição de padrões visuais. Esta álgebra define operadores que são utilizados na combinação das propriedades de cada padrão pré-definido. O trabalho de Mackinlay é uma grande contribuição à análise visual de dados. Apesar de seu domínio limitado a apresentações simples, da baixa cardinalidade de dados assumida na proposta, e da não contemplação de interação, a proposta é inovadora em seu tempo e integral em sua argumentação. Mackinlay mostra que o design automatizado é possível e que tal possibilidade depende de um conjunto de parâmetros bem definidos. Também é demonstrado em sua proposta que a avaliação prévia de padrões 
visuais é necessária para a atividade de design, pois nem todas as configurações gráficas são válidas para o objetivo da análise visual de dados.

\subsubsection{O Trabalho de Card e Mackinlay}

Card e Mackinlay [Card e Mackinlay, 1997] seguem a linha do trabalho de Bertin e do trabalho anterior do próprio Mackinlay. A nova concepção contribui com um novo conceito, o de substrato espacial, o meio dentro do qual as visualizações são possíveis por meio de marcas e de propriedades gráficas aplicáveis às marcas. O autor defende que as propriedades gráficas são muitas, mas apenas um conjunto limitado delas pode ser usado em análise visual. Esta é uma suposição também assumida no presente trabalho. A quantidade de dados que se deseja apresentar numa cena de visualização impede a utilização de todas as possibilidades de percepção visual já identificadas. Por exemplo, o uso de sombra é uma pista bastante utilizada para a percepção tri-dimensional de formas. No entanto, o desenho de sombras requer uma quantidade razoável de espaço, consumindo área que poderia ser destinada a uma quantidade maior de itens de informação visual.

Segundo Card, Mackinlay e Shneiderman [Card et al., 1999] o aspecto fundamental de uma estrutura visual é a utilização do espaço, o qual é dominante em termos de percepção e o qual é a primeira decisão durante o design. De fato, pouca reflexão é necessária para se constatar que visão e percepção espacial são indissociáveis. Os autores analisam o espaço considerando diferentes concepções de eixos que podem ser lineares ou radiais e possuir propriedades em intervalos ou em proporção. Eles observam os seguintes arranjos de eixos: não estruturado (sem eixo), nominal (uma região dividida em sub-regiões), ordinal (a ordem faz sentido) e quantitativo (uma dada região proporciona a idéia de medida). Estas possibilidades podem ser utilizadas diretamente ou por meio de técnicas capazes de expandir o aproveitamento espacial. Segundo os autores, estas técnicas incluem:

- composição: posicionamento ortogonal de eixos definindo espaços 2D ou 3D. Exemplo, traçado de funções matemáticas;

- alinhamento: repetição de um eixo utilizando-se diferentes mapeamentos em posições diferentes no espaço, como nas Coordenadas Paralelas;

- dobramento: continuação de um eixo que se estende paralelamente a outro, definindo uma extensão do mapeamento. Exemplo, a ferramenta de visualização de software Seesoft [Eick et al., 1992];

- recursão: repetida subdivisão do espaço, geralmente definindo uma hierarquia. Exemplo, GMine [Rodrigues Jr. et al., 2007a]; 
- sobrecarga: reuso de um espaço já mapeado para outros mapeamentos, implica em sobreposição de itens gráficos. Como exemplo, Worlds within worlds [Feiner e Beshers, 1990].

Após considerar o espaço, os autores seguem a obra de Bertin considerando as possíveis marcas utilizadas em visualização: pontos, linhas, superfícies, áreas e volumes, as quais podem expressar conexão e fechamento (literalmente em inglês, enclosure) como em hierarquias, árvores e grafos, e as quais podem possuir propriedades retinais. Propriedades retinais estimulam a retina do olho independentemente de sua posição, incluindo: tamanho, brilho, textura, cor, orientação e forma, as quais podem expressar extensão e diferenciação automaticamente. Além disso, é observado que propriedades gráficas que exigem processamento controlado (não são automaticamente percebidas nem interpretadas) também podem compor a visualização, como o uso de rótulos textuais por exemplo. Por fim, os dados (quantitativos, nominais ou ordenados) podem passar por um processo de transformação com o intuito de adequá-los à apresentação. Card e Mackinlay [Card e Mackinlay, 1997] resumem seu arcabouço de design em uma tabela para notação, referenciação e comparação entre técnicas - veja a figura 4.8.

(a)

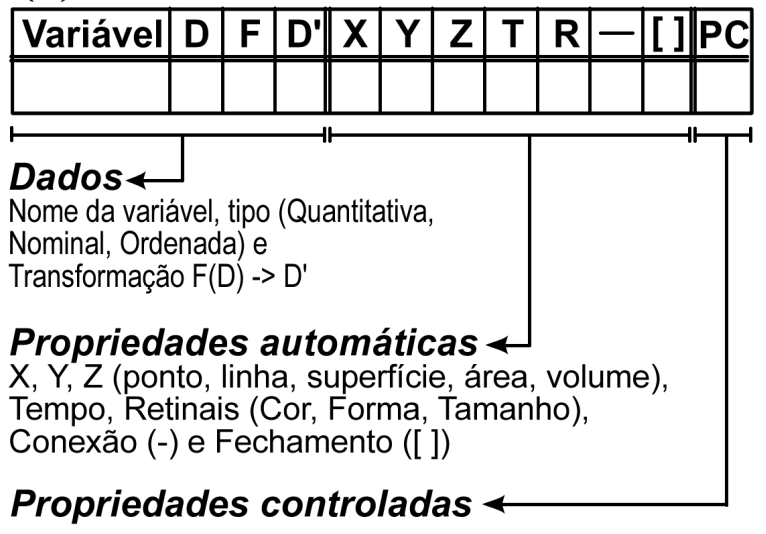

(b)
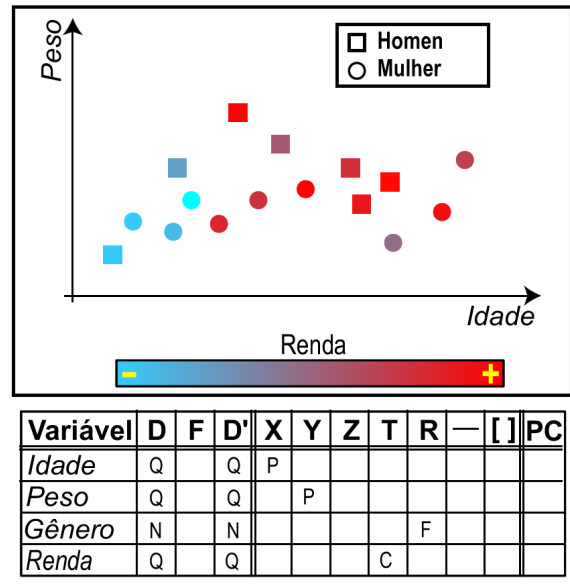

Figura 4.8: (a) A tabela de referência proposta por Card e Mackinlay [Card e Mackinlay, 1997], nela os constituintes de uma dada técnica de visualização são anotados para rápida referenciação e comparação com outras técnicas. (b) Um exemplo de notação para uma projeção simples com codificação de cor e forma sem transformação de dados.

A proposta de espaço de design de Card e Mackinlay é bastante útil ao permitir a anotação dos parâmetros de design das técnicas de visualização. Esta característica é pioneira e foi um ponto de destaque do trabalho. No entanto, algumas limitações podem ser observadas. As propriedades do espaço de design são pouco generalizáveis pois, sem um claro delineamento, o conceito de espaço é tratado junto com o conceito de propriedades visuais. Por exemplo, a caracterização de estruturas que dependem do conceito de conexão (como um grafo) não se relaciona com o aspecto espacial, apenas com o aspecto de como expressar conectividade. 
Não há uma relação direta entre interação e o espaço de possibilidades proposto. A falta de inter-relacionamento conceitual e de delineamento claro das classes constituintes do arcabouço proposto dificulta a racionalização utilizando-se das idéias apresentadas. De fato, a apreciação minuciosa da proposta leva a crer que ela se limita a descrever o conjunto de técnicas de visualização existentes quando de sua publicação. A concepção de novas possibilidades não é abrangida em sua sistematização, mas apenas variações dos parâmetros identificados.

\subsection{Diretrizes de Design}

Uma outra abordagem relacionada à complexidade da atividade de design é o desenvolvimento de diretrizes. Trata-se da definição de regras e princípios provindos de conhecimento experimental compartilhados na forma de conjuntos de diretrizes de design. Diretrizes são utilizadas para auxiliar na busca por designs apropriados, elas definem características que devem ser satisfeitas e práticas que devem ser evitadas. São o resultado de procedimentos heurísticos que refletem conhecimento. Nesta seção são apresentados alguns trabalhos relevantes com o intuito de se caracterizar o panorama dos trabalhos orientados a diretrizes.

\section{Diretrizes para Design Multi Sensorial}

Nesbitt [Nesbitt, 2005] apresenta um trabalho de diretrizes que se baseia numa taxonomia a respeito da exibição de dados utilizando recursos multi sensoriais. Seu conjunto de diretrizes, além de considerar múltiplos sentidos, é organizado em níveis de detalhamento. Diretrizes de alto nível suportam decisões iniciais de design. Em níveis mais baixos, diretrizes de baixo nível provêem suporte para decisões mais específicas. O autor propõe ainda uma sistemática para a definição do design, suas etapas são: análise da tarefa, caracterização dos dados, mapeamento da exibição, prototipação e avaliação. A motivação da proposta são os processos industriais conhecidos como gerência de qualidade total. Segundo o autor, seu processo pode auxiliar orientando procedimentos de design, capturando experiências prévias, provendo conhecimento estruturado, provendo princípios gerais e específicos, mantendo o profissional de design longe do excesso de complexidade, comunicando soluções e possibilitando a avaliação de designs.

\section{Design Automático baseado em Diretrizes}

Senay e Ignatius [Senay e Ignatius, 1990] apresentam um conjunto de regras e princípios para o design de técnicas de análise visual de dados. A intenção dos autores é prover suporte para uma ferramenta de assistência à definição de visualizações, evitando que usuários analistas precisem ser especialistas na utilização de representações gráficas. O material reunido neste trabalho provém de especialistas em visualização e o modelo utilizado é o arcabouço proposto por Mackinlay [Mackinlay, 1986]. 


\section{Diretrizes de Design para Múltiplas Exibições}

Baldonado et al [Baldonado et al., 2000] apresentam diretrizes para a definição de sistemas com múltiplas exibições. Isto é, sistemas que usam uma ou mais visualizações para investigar uma única entidade conceitual. O trabalho propõe um modelo capaz de caracterizar sistemas desta natureza. Este modelo proporciona um arcabouço que permite articular a estrutura de múltiplas exibições, permitindo design e avaliação sistemáticos. As dimensões do modelo proposto são: seleção, identificação das exibições a serem utilizadas; apresentação, escolha de como as exibições serão mostradas; e interação, a integração das exibições selecionadas. As diretrizes propostas sobre estas dimensões são organizadas em dois conjuntos, um ajuda a decidir quando múltiplas exibições são necessárias, o outro ajuda a decidir a respeito da apresentação e da interação das exibições. Por fim, as diretrizes são avaliadas considerando-se seu impacto em fatores de memória, aprendizado, comparação, dispositivo de exibição, carga computacional e alternância de contextos de exibição.

\section{Organização Conceitual}

A empresa IBM também aborda a questão de diretrizes para design em análise visual de dados. Segundo um documento [Team, 2004] publicado pela empresa, as diretrizes representam o nível intermediário na progressão entre princípios abstratos e convenções específicas. A compilação de idéias publicadas neste trabalho promove uma perspectiva geral útil à compreensão de diretrizes. Os conceitos introduzidos neste trabalho incluem:

- princípios: idéias fundamentais e suposições utilizadas na tomada de decisões e na obtenção de resultados globalmente válidos. Como exemplo o trabalho menciona a necessidade de se considerar a experiência prévia do analista;

- diretrizes: decursos de ações que devem suportar um conjunto de princípios específicos para um domínio particular. Por exemplo, utilizar consistentemente os elementos de navegação da rede mundial de computadores;

- convenções: práticas de design específicas e validadas para o suporte de diretrizes e princípios.

\section{Análise do Uso de Diretrizes}

A utilização de diretrizes é bastante válida em domínios muito amplos ou complexos, onde não é possível identificar ou controlar todas as variáveis envolvidas. Esta tem sido uma das práticas utilizadas em visualização, no entanto, conjuntos de diretrizes apresentam algumas inadequações [Bugajska, 2003]. Dada sua proximidade ao exercício empírico de análise, a utilização de 
diretrizes tem caráter bastante prático. Diretrizes tendem a tornar princípios de execução em observações específicas. Esta característica impõe a necessidade de meios de disseminação eficientes para que seja possível aproveitar-se das diretrizes onde elas são aplicáveis. As diretrizes também não são definitivas, pois novas práticas de visualização exigem novas diretrizes e a reciclagem de conceitos acrescenta complexidade. Por último, uma diretriz de design não é válida em todas as circunstâncias, apenas quando uma quantidade de variáveis se alinha determinando a condição em que a diretriz tem significado.

Estes empecilhos tornam inconveniente a utilização de diretrizes. No presente trabalho, embora não se trate fundamentalmente deste aspecto, contribui-se também com a argumentação de que práticas bem sucedidas de design devem contar com um sistema versátil de disseminação. Como será descrito no capítulo 8, seguindo o modelo de design aqui proposto, tal sistema deve ser iterativo e automaticamente replicável.

\subsection{Considerações Gerais}

Um fator importante na construção e projeto de técnicas de qualquer natureza é a possibilidade de se basear no trabalho e na experiência de outros profissionais projetistas. O mesmo acontece na Análise Visual de Dados, o que pode ser conseguido por meio de duas práticas:

- decomposição de processos particulares de visualização em componentes que intermedeiam a compreensão e o uso;

- utilização de metodologias estruturadas para se compartilhar a experiência de projeto.

Estas práticas podem ser esquematizadas com o auxílio da racionalização permitida por meio de sistemas de classificação e de sistemas de análise, como os apresentados nesta seção e como se desenvolve nesta tese. Estes sistemas permitem a compreensão do fenômeno de visualização sendo considerado pois identificam e organizam os elementos envolvidos. A partir desta identificação e organização torna-se possível a transferência de conhecimento heurístico a respeito do design. Para tanto, pode-se utilizar de procedimentos que descrevam, de maneira estruturada, a experiência observada.

O presente trabalho é um esforço de identificação e de organização de elementos relacionados a técnicas de visualização. O objetivo não é propor diretamente metodologias que levem à eficiência em análise visual. Tal eficiência depende de diversos fatores além do método de design, incluindo as características e a organização dos atributos dos dados, a tecnologia de exibição, os objetivos e as tarefas cognitivas do analista. Para se lidar com estes fatores, há a necessidade de se organizar componentes de visualização e de se investigar a inter-relação entre eles. Neste sentido, almeja-se produzir conhecimento capaz de promover orientação no 
projeto de visualizações interativas. Nesta tese, a meta é propor uma discretização que ajude a contornar a subjetividade inerente ao complexo de fatores que determinam as técnicas de visualização. A partir desta discretização, deve ser possível o amadurecimento de métodos de design e de avaliação, promovendo a evolução da ciência de Análise Visual de Dados. 


\section{Capítulo 5}

\section{Uma Nova Organização Abstrata}

\subsection{Considerações Iniciais}

Taxonomias e espaços de design para análise visual de dados determinam organizações que abstraem a constituição das técnicas de visualização. No entanto, de maneira geral, observa-se que trabalhos anteriores não provêem um nível adequado de abstração ou não são capazes de delimitar rigorosamente o nível dentro do qual é feita a análise dos elementos constituintes e o delineamento de seus inter-relacionamentos.

Neste capítulo procura-se elucidar as deficiências encontradas em outros trabalhos. Para isso, analisa-se a organização abstrata de cada proposta. Inicialmente será explicada a linha geral segundo o que se espera de um modelo de raciocínio abstrato. Não se trata da proposição de um método de análise abstrata, mas apenas uma ilustração, por meio de exemplos conhecidos, de como será feita a análise dentro do domínio de visualização. Assim como no exemplo a ser discutido, a orientação é a busca por coerência e clareza na organização das idéias.

\subsection{Raciocínio Abstrato}

Abstração pode ser definida como a reflexão por meio da qual coisas originalmente unidas podem ser consideradas separadamente, em maiores (análise) ou em menores (generalização) detalhes. Este processo pode ser realizado de diferentes maneiras, dependendo do refinamento da análise. Como observam os autores Cleveland e McGill [Cleveland e McGill, 1984], a partícula elementar de um analista pode ser o sistema complexo de outro analista. Como acontece em química, ao passo que o átomo é a partícula elementar para grande parte dos cientistas, para analistas nucleares o átomo é constituído de um grande número de outros elementos. Um outro exemplo elucidativo é a abstração de um carro. Um carro pode ser considerado segundo diversos níveis abstratos, apresentados na figura 5.1. Como um único 
objeto, como um conjunto de sistemas (suspensão, motor, estofamento, lataria e console de comando), como um conjunto de peças (amortecedores, pneus, pistões, velas, bancos, tecido de revestimento, portas, capô, direção e velocímetro) ou como um conjunto de átomos. Dado este exemplo, fazem-se as seguintes observações com relação à organização de uma análise abstrata:

\section{Adequação do nível de abstração}

Quando se analisa uma dada entidade, como o carro, é importante definir-se adequadamente a abstração, e seu nível, com relação à aplicação e aos usuários. Por exemplo, um motorista comum compreenderá a necessidade de recondicionamento de seu sistema de motor, enquanto um mecânico experiente compreenderá a tarefa de troca de pistões e velas, um nível de abstração mais baixo.

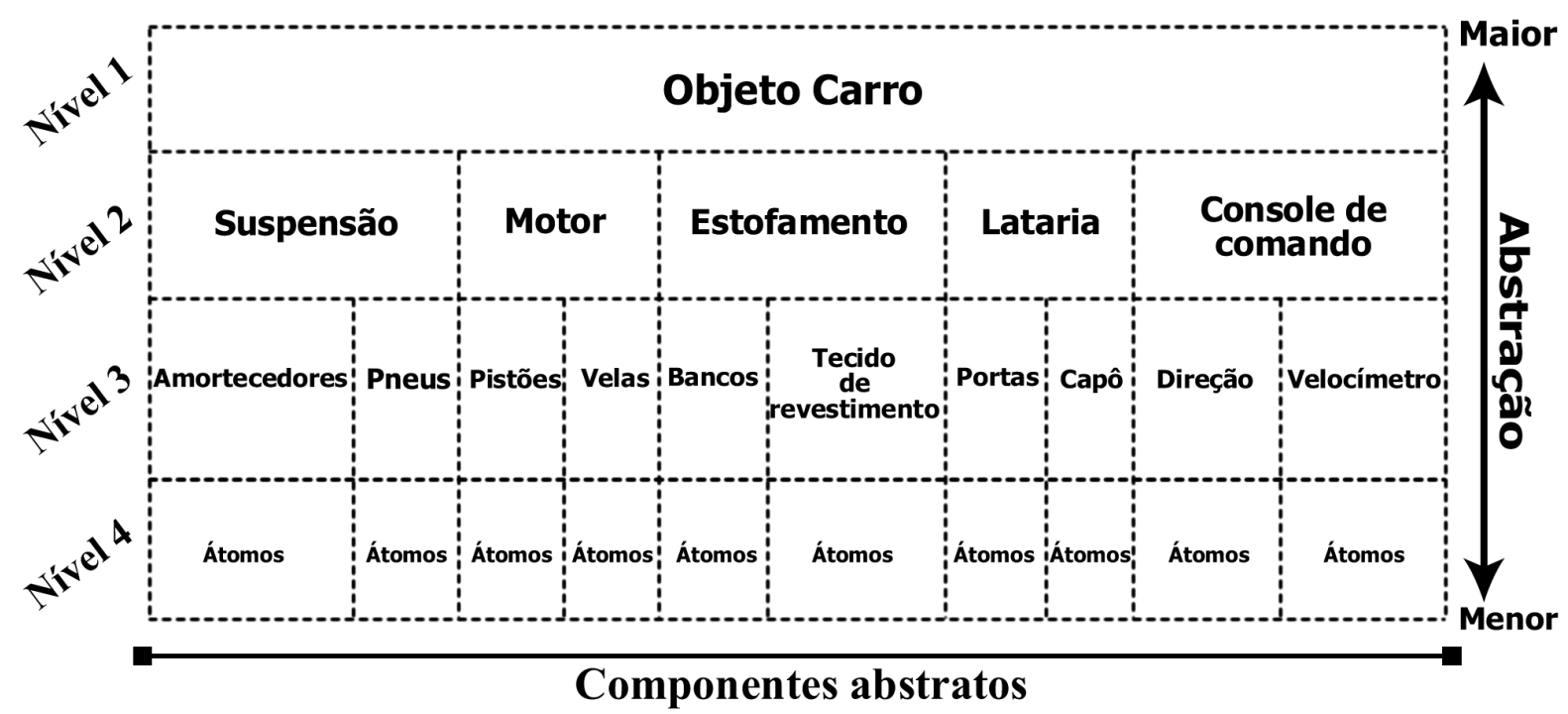

Figura 5.1: Diferentes níveis de abstração de um carro.

\section{Abrangência do nível de abstração}

Do ponto de vista de projeto, diferentes níveis de abstração implicam em diferentes possibilidades de concepção. O nível de abstração que considera o conjunto de sistemas que compõem um carro permite uma quantidade bem menor de combinações do que o nível de abstração que considera o respectivo conjunto de peças. Já o nível mais baixo de abstração, o conjunto de átomos, permite virtualmente infinitas possibilidades. O nível adequado de abstração deve ser escolhido de maneira a oferecer um universo abundante e factível ao projetista.

\section{Definição de relações adequadas entre componentes abstratos}

Também é preciso delimitar o nível de abstração quando na determinação das relações entre componentes sem parentesco hierárquico. Assim, como a suspensão é composta por amorte- 
cedores e pneus, os três conceitos podem se relacionar de maneira direta. Pode-se afirmar "a suspensão depende da qualidade dos amortecedores e dos pneus". Mas, diferentemente, é necessário cautela na definição de relacionamentos entre componentes sem parentesco hierárquico como, por exemplo, "o desempenho do motor depende dos amortecedores". Apesar da aparente coerência de tal afirmação, na verdade o desempenho do motor depende do sistema de suspensão inteiro, da aerodinâmica do sistema definido pela lataria e, também, de seu próprio sistema com pistões e velas. Neste exemplo, onde um relacionamento inadequado é definido entre componentes abstratos, um mecânico menos atento realizaria a troca de todos os amortecedores quando o problema é apenas um pneu murcho.

A organização de idéias em outros campos de compreensão segue estrutura semelhante ao exemplo da figura 5.1, possivelmente com uma hierarquia não tão bem definida. No entanto, outros domínios não são tão familiares e concretos como um carro. Trocar toda a suspensão quando o problema é apenas um pneu murcho pode passar desapercebido mesmo para analistas experientes nos mais variados domínios. Na análise visual de dados, trabalhos anteriores pecaram na escolha do nível abstrato (inadequação, pouco ou excesso de abrangência), na delimitação do nível abstrato escolhido, na definição dos relacionamentos entre entidades abstratas (extrapolação do nível de abstração e relacionamentos incoerentes ou inadequados) e, mesmo, na análise realizada.

\subsection{Abstração em Trabalhos Prévios}

Nesta seção serão analisados os trabalhos revistos no capítulo 4 buscando-se caracterizá-los com base no raciocínio abstrato introduzido nas seções anteriores deste capítulo. Busca-se identificar inadequações, e virtudes, a serem evitadas, ou reproduzidas, no presente trabalho.

\section{Taxonomias}

O trabalho de Shneiderman [Shneiderman, 1996] claramente tenta definir um nível de abstração orientado não ao design de técnicas de visualização, mas ao design de sistemas de visualização. Suas duas classes de componentes são de alto nível abstrato: tipo dos dados e interação. Observa-se, no entanto, que suas classes estão em níveis inadequados de abstração e, por isso, não definem uma coesão direta. Técnicas de interação não podem ser combinadas ou aplicadas a tipos de dados, mas sim a técnicas de visualização. Com relações inadequadas entre seus componentes abstratos, há uma ruptura de racionalização que, embora seja capaz de oferecer um mínimo de perspectiva, tem poder bem limitado para expandir a compreensão do domínio de possibilidades de design. 
O trabalho de Keim [Keim, 2002] combina perfeitamente técnicas de interação e de visualização, mas considera também o tipo dos dados. Neste trabalho também há classes que pertencem a níveis diferentes de abstração. Tipos de dados são componentes rígidos associados aos diferentes designs de visualização e, por esta razão, os eixos que definem o espaço de design da teoria de Keim - figura 4.2 - definem pontos inválidos. Por exemplo, o tipo de dados "algoritmos/software" não pode ser diretamente utilizado com técnicas do tipo projeção, icônicas ou orientadas a pixels. De fato, de maneira geral, as técnicas de visualização de dados podem se adaptar bem a diferentes domínios de dados, mas são bastante vinculadas ao tipo dos dados para o qual foram projetadas.

A proposta de Tweedie [Tweedie, 1997] não se apresenta de fato como uma análise dos constituintes das técnicas de visualização. Na estrutura defendida por Tweedy, os meta-dados são submetidos a um processo de pré-processamento, o qual é apenas um componente de alto nível abstrato que pode ser combinado com técnicas de visualização. Combinações deste tipo objetivam apenas adaptar os dados para o formato esperado pela técnica de visualização. Assim, os meta-dados mencionados pela autora são dados como outros quaisquer e não um conceito individualizado que faz parte da constituição dos sistemas de visualização.

De maneira geral, taxonomias são propostas que enfatizam componentes de alto nível abstrato, como técnicas de visualização, técnicas de interação e técnicas de pré-processamento. Estes trabalhos são orientados apenas a fornecer perspectivas gerais de uso e caracterização, por esse motivo, praticamente todas as propostas consideram o tipo dos dados como uma das classes. Esta característica provê orientação que possibilita a escolha da técnica de visualização em função dos dados que se deseja analisar. Isso também é observado na taxonomia de Tory e Möller [Tory e Möller, 2004] a qual é intensamente centrada no tipo dos dados. Como já mencionado, o tipo dos dados é um constituinte pouco maleável que faz parte da essência das técnicas de visualização. Assim, taxonomias elaboradas desta maneira são pouco flexíveis em análise e predição de novas possibilidades.

\section{Espaços de Design}

O trabalho pioneiro de Bertin [Bertin, 1974] define uma intrincada organização abstrata que mistura análise dos dados e análise do domínio dos dados (componentes e invariantes), análise dos padrões visuais (marcas e suas propriedades) e análise perceptiva (percepção estendida e correspondência). Por esta razão, a compreensão de seu espaço de design acaba por ser não muito direta devido aos diferentes domínios conceituais envolvidos, o que dificulta a construção de um modelo mental de organização. A análise do domínio dos dados, por exemplo, implica que a análise de uma técnica de visualização envolve conhecimento a respeito da aplicação à qual se objetiva a análise visual de dados (a proposta é anterior à disseminação do modelo de dados relacional). Esta implicação dificulta o raciocínio generalizado quando se recorre à 
teoria de Bertin. Recorrendo-se à descrição de sua proposta, na seção 4.3.1, observa-se que ao mencionar correspondência, o autor se utiliza de análise perceptiva. Ao mesmo tempo, no entanto, percepções relacionadas a agrupamento são evocadas quando se menciona organização nominal de marcas. Desta maneira, o conceito de percepção não fica claramente delineado, prejudicando de maneira geral a assimilação de sua teoria. Outras observações semelhantes podem ser feitas com relação ao trabalho de Bertin. O pioneirismo de sua proposta talvez explique algumas dessas inadequações.

Nos trabalhos de Cleveland e McGill [Cleveland e McGill, 1984] e de Mackinlay [Mackinlay, 1986], a orientação é a identificação de padrões visualmente expressivos. Tais padrões passam por um processo de avaliação o qual será o critério para a tomada de decisões na atividade de design. Ambos estes dois trabalhos têm validade justificável devido ao fato de que o espaço, o mais importante componente visual não foi devidamente contemplado na organização abstrata das propostas. O papel do espaço é esquecido pois as visualizações consideradas nas propostas são bastante simples. Esta simplicidade permite assumir que uma dada organização espacial é a única possível em função de dois fatores: o conjunto de padrões visuais escolhidos para o design, e a estrutura dos dados a serem analisados. Esta deficiência é decisiva na determinação de um espaço de design que seja capaz de prever novas possibilidades de concepção. Além disso, as propostas não são capazes de explicar analiticamente técnicas de visualização mais complexas, como as que foram projetadas na última década [Ankerst e Keim, 1996], [Keim, 2000] e [Kandogan, 2001].

O trabalho de Card é o espaço de design mais recente aceito na literatura de análise visual de dados. Fortemente influenciado pelas teorias de Bertin, sua contribuição também considera marcas e propriedades retinais, sendo proposta em dois trabalhos. Na primeira discussão [Card e Mackinlay, 1997], o espaço é mencionado como um componente das técnicas de visualização de maneira semelhante ao trabalho de Bertin. Isto é, pode ser percebido como um componente discreto, mas pouco se fala em como diferentes organizações espaciais podem ser definidas. Na segunda obra de Card [Card et al., 1999] o espaço recebe mais ênfase sendo designado como substrato fundamental. Nesta proposta fala-se do espaço como combinações de eixos cujo aproveitamento pode ser expandido de diferentes maneiras - como apresentado na seção 4.3.4. O trabalho de Card é uma grande contribuição à análise e concepção de técnicas de visualização. Nesta tese, considera-se este e outros trabalhos para se determinar um espaço de design mais compreensível e racionalizável. À proposta de Card, no entanto, fazem-se algumas observações:

- o uso de padrões visuais (propriedades retinais) dificulta a atividade de design. Padrões visuais são bastante numerosos, são por vezes ambíguos e, cada qual, pode expressar múltiplas percepções visuais analíticas (como definidas na seção 3.4). Assim, partir da 
utilização de padrões visuais para se conceber técnicas de visualização pode resultar num exercício não muito intuitivo e nem claro. Neste trabalho, argumenta-se que o usuário analista está mais interessado nas percepções visuais das quais ele poderia se beneficiar do que nos padrões visuais disponíveis para observação. Propõe-se, portanto, centralizar o design não em padrões visuais, mas na compreensão do uso de percepções visuais;

- segundo Card, as funcionalidades do espaço podem ser expandidas por meio de técnicas de composição, alinhamento, dobramento, recursão e sobrecarga. Analisando-se estas técnicas (seção 4.3.4), nota-se que esta visão é uma tentativa de se listar exaustivamente as diferentes maneiras como o espaço é utilizado em análise visual de dados. Falta generalidade nestas observações, o que impede explicar técnicas como as Star Coordinates e a técnica VisImpact [Hao et al., 2006]. Nesta tese, a utilização do espaço é tratada como um procedimento versátil e supostamente simples (a espacialização), mas que pode ser aplicado em vários ciclos enquanto houver espaço disponível;

- técnicas de interação não se encaixam nos conceitos propostos por Card. De fato, a interação é tratada apenas em seu segundo trabalho [Card et al., 1999], no qual a interação é colocada da mesma forma que o espaço, isto é, como uma listagem exaustiva de práticas observáveis. Não há uma relação entre o que se argumenta serem os componentes das visualizações e as práticas identificadas como interação. De maneira mais generalizável, este trabalho defende que técnicas de interação utilizadas em análise visual são mecanismos de alteração dos parâmetros que governam as características pré-atentivas.

\subsection{Proposta de Organização Abstrata}

A figura 5.2 apresenta a proposta deste trabalho para a organização abstrata dos sistemas de visualização aplicados à análise visual de dados. A proposta descrita reflete os conceitos introduzidos no capítulo 3, estímulos pré-atentivos, espacialização e concepção de técnicas de visualização. No nível mais alto de abstração os sistemas de visualização são vistos como unidades. Num nível mais abaixo considera-se a possibilidade de técnicas de pré-processamento e de mineração de dados combinadas com visualização interativa. Este nível contempla configurações que determinam mineração visual de dados, como descrito por Keim [Keim, 2002]. No nível seguinte técnicas de visualização podem ser combinadas a técnicas de interação, trata-se da visualização interativa. No quarto nível combinações de espacialização de dados (posição), forma e cor definem configurações de características pré-atentivas. Estas configurações definem técnicas de visualização, ou determinam conjuntos de parâmetros que caracterizam técnicas de interação - como será abordado em maiores detalhes na seção 7.3. No último nível estão os padrões visuais, a mais alta granularidade da organização abstrata aqui proposta. 


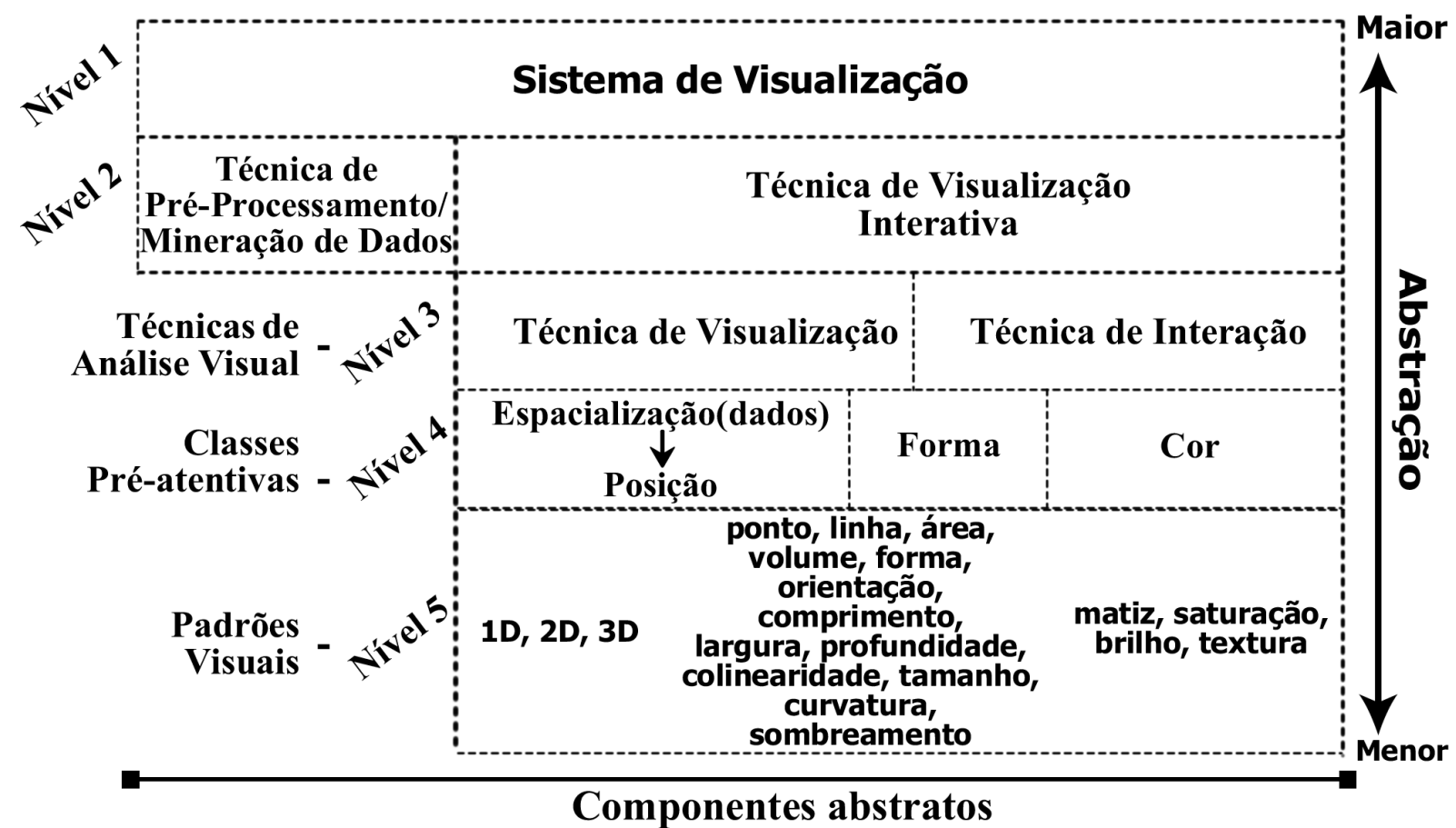

Figura 5.2: Organização abstrata proposta neste trabalho para sistemas de visualização aplicados à análise visual de dados.

Em comparação a trabalhos anteriores, a organização abstrata que se propõe difere nas seguintes características:

- não considera explicitamente o tipo dos dados a serem analisados;

- incorpora técnicas de pré-processamento e mineração de dados, constituintes primordiais em pesquisas recentes de visualização;

- acrescenta o nível das classes pré-atentivas, um nível de menor granularidade intermediário entre as técnicas de visualização e os padrões visuais;

- trata posição não como um padrão visual mas como espacialização de dados, um procedimento de organização espacial;

- coloca técnicas de visualização e técnicas de interação no mesmo nível, abrangendo a possibilidade de livre combinação entre estes dois componentes.

Estas características são os pontos explorados nesta tese no intuito de se propor uma nova perspectiva taxonômica e de espaço de design. No próximo capítulo, considerando-se também o processo de expressividade visual, propõe-se uma taxonomia capaz de classificar práticas de visualização em função da percepção visual analítica promovida. Na seção seguinte, a compreensão estruturada nesta taxonomia guia o trabalho à definição de um novo espaço de possibilidades de design. 


\subsection{Considerações Gerais}

Considerando-se a revisão e a análise realizados sobre trabalhos anteriores, buscou-se desenvolver idéias partindo-se das restrições identificadas e orientando-se a não reproduzir problemas encontrados em outras propostas. Também objetivou-se a consideração de fatores diferenciados levando a hipóteses e conclusões originais. Em continuidade, a organização dos conceitos, como colocada neste capítulo, representa o raciocínio subjacente ao que se propõe na próxima parte desta tese. Trata-se de uma organização abstrata alternativa que, no contexto do Processo de Expressividade Visual, fornece material amplo de desenvolvimento. A partir desta primeira discussão a tese avança para a estruturação de uma metodologia alternativa de compreensão das técnicas de visualização. 


\section{Parte II}

\section{Compreensão Espacial-Perceptiva}





\section{Capítulo 6}

\section{A Taxonomia Espacial-Perceptiva}

\subsection{Considerações Iniciais}

Esta seção descreve a Taxonomia Espacial-Perceptiva, uma contribuição desta tese que visa caracterizar técnicas de visualização. O conteúdo aqui descrito foi apresentado por Rodrigues Jr. em uma versão preliminar [Rodrigues Jr. et al., 2006c] e também em uma versão mais ampla [Rodrigues Jr. et al., 2007c]. A taxonomia que se propõe considera o processo de expressividade visual da seção 3.4 e a organização abstrata proposta na seção 5.4. O processo de expressividade visual colabora proporcionando um modelo de como as técnicas de visualização funcionam. A organização abstrata contribui com um modelo de como as técnicas de visualização são compostas.

Segundo a abstração que se considera, técnicas de visualização interativa podem ser consideradas segundo três diferentes níveis de refinamento, como observado na figura 5.2. Um nível compreende visualizações combinadas a interações. Um nível mais refinado considera combinações de estímulos pré-atentivos: espacialização(dados), forma e cor. O último nível, o que possui maior granularidade, considera combinações de padrões visuais. Como discutido em trabalhos prévios, ao longo do capítulo 4, julga-se que a cardinalidade do último nível de abstração, o dos padrões visuais, dificulta a racionalização durante o exercício de análise e dificulta também o exame exaustivo de como tais padrões podem ser utilizados. No presente trabalho propõe-se considerar um nível de abstração que tenha menor cardinalidade, o das classes préatentivas, para se definir uma nova organização taxonômica das técnicas de visualização. Como será descrito neste trabalho, esta abordagem também auxilia na compreensão da relação entre visualização e técnicas de interação.

Considerando-se o processo de expressividade visual, as percepções visuais analíticas correspondência, diferenciação, conectividade, arranjo e significado - são os elementos que fazem com que as técnicas de visualização sejam efetivas em seu objetivo. As percepções visuais 
são naturalmente presentes, têm número reduzido, são íntimas de faculdades visuais congênitas e são essenciais no processo analítico. Assim, de acordo com a argumentação apresentada nas seções 3.5 e 5.3 e no capítulo 4, acredita-se que a análise orientada a percepções visuais seja uma abordagem mais adequada se comparada com a abordagem de trabalhos prévios.

Neste contexto, a taxonomia proposta combina dois fatores na definição de caracterizações de classificação para técnicas de visualização: o que e como. O que é utilizado na concepção de técnicas de visualização, isto é, espacialização, forma e cor. E como tais fatores contribuem para o processo de descoberta de conhecimento, promovendo percepções visuais de correspondência, diferenciação, conectividade, arranjo e significado.

Portanto, nas próximas seções, espacialização, forma e cor serão empiricamente analisados considerando-se correspondência, diferenciação, conectividade, arranjo e significado. Estes dois grupos de fatores são os elementos que, combinados, definem as caracterizações da taxonomia que se propõe e as dimensões do correspondente espaço de design.

\subsection{Espacialização}

Baseando-se em observações empíricas, pode-se verificar que técnicas de visualização podem ser agrupadas em função de qual processo de espacialização elas utilizam. É importante observar que, diferente do uso de forma e cor, os quais determinam qual percepção visual será expressa, a expressão visual de posição é ditada pelo processo denominado de espacialização. A seguir detalha-se a natureza dos métodos de espacialização observados na literatura:

- Exposição estrutural: os dados podem conter estruturas intrínsecas, tais como hierarquias e conjuntos de relacionamentos (grafos), que compreendem uma parte considerável do significado dos dados. As técnicas de visualização que objetivam expor informações estruturais se baseiam em métodos que ajustam a posição de apresentação dos dados. O objetivo é definir um posicionamento capaz de exibir a estrutura subjacente por meio de percepção visual de arranjo. Exemplos incluem a técnica Tree-maps [Shneiderman, 1992], que define posicionamento hierárquico recursivo como ilustrado na figura 6.1(a); a técnica EncCon [Nguyen e Huang, 2005], que define a visualização estrutural em múltiplos níveis; e esquemas de posicionamento do tipo "dirigidos por força" [Dwyer et al., 2006] [Fruchterman e Reingold, 1991], como ilustrado na figura 6.1(b).

- Seqüenciamento: trata-se do mais simples método de espacialização. Baseia-se no posicionamento dos dados em arranjo seqüencial, de maneira geral, segundo a equação:

$$
\left(x_{i+1}, y_{i+1}, z_{i+1}\right)=f\left(x_{i}, y_{i}, z_{i}\right)
$$




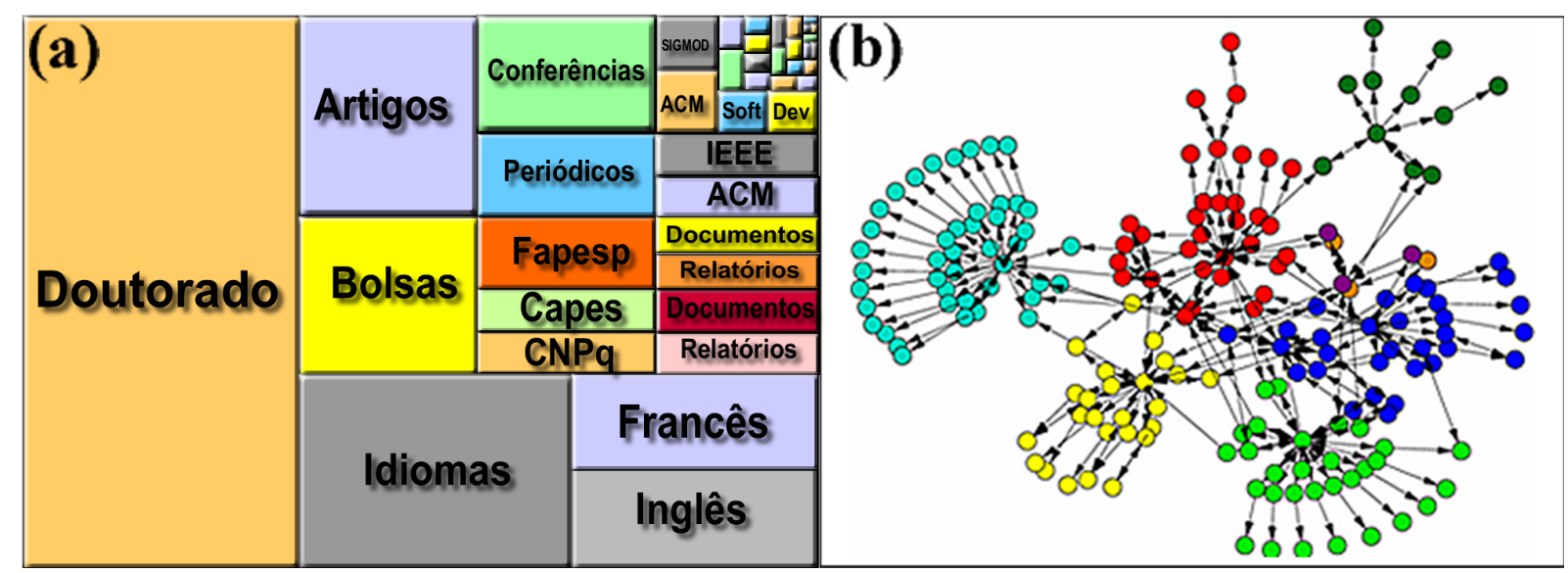

Figura 6.1: (a) Exposição estrutural via Tree-maps. Posição: arranjo por meio de hierarquia recursiva; forma: correspondência contínua por meio de proporcionalidade de tamanho; cor: diferenciação discreta. (b) Exposição estrutural de um grafo via algoritmo "dirigido por força". Posição: arranjo por meio de proximidade dos relacionamentos; forma: conectividade e significado por meio de setas; cor: diferenciação discreta.

A equação 6.1 diz que a posição ocupada por um item de informação em particular depende da posição do item de informação precedente. A espacialização seqüencial adota padrões de posicionamento lineares, circulares ou elaborados, os quais constituem o mapeamento posicional da visualização. Tais arranjos podem provocar percepções visuais do tipo diferenciação ou correspondência. Diferenciação é congenita à percepção espacial, enquanto que correspondência é percebida caso um mapa mental ou visual seja fornecido. Mapas mentais resultam de uma ordem que seja previamente declarada, como ilustrado na figura 6.2(a). Mapas visuais baseiam-se num mapa de posições que explicitamente identifica cada posição, como ilustrado na figura 6.2(b). Técnicas de seqüenciamento tendem a popular totalmente a área do aplicativo de visualização e, por esta razão, muitas destas técnicas são referenciadas como dense pixel displays (do inglês, algo como "exibições com alta densidade de pixels"). As técnicas orientadas a pixels de Keim [Keim, 2000] são exemplos bem conhecidos de posicionamento seqüencial. Elas utilizam apenas a cor, e não a forma, para apresentar os itens de informação. Keim também propõe padrões elaborados de seqüenciamento [Keim et al., 1995] e uma variação, denominada Pixel Bar Charts [Keim et al., 2001], que utiliza mais do que um ciclo de espacialização. Mais recentemente, Blanchard et al [Blanchard et al., 2005] propõem uma nova abordagem que utiliza redução de dimensionalidade do conjunto de dados antes do processo de espacialização. O resultado é uma única imagem capaz de exibir os agrupamentos encontrados em dados multidimensionais.

- Projeção: trata-se de uma exibição de dados delineada por variáveis funcionais. A posição de um item de dados é definida por uma função matemática, explicitamente fornecida 


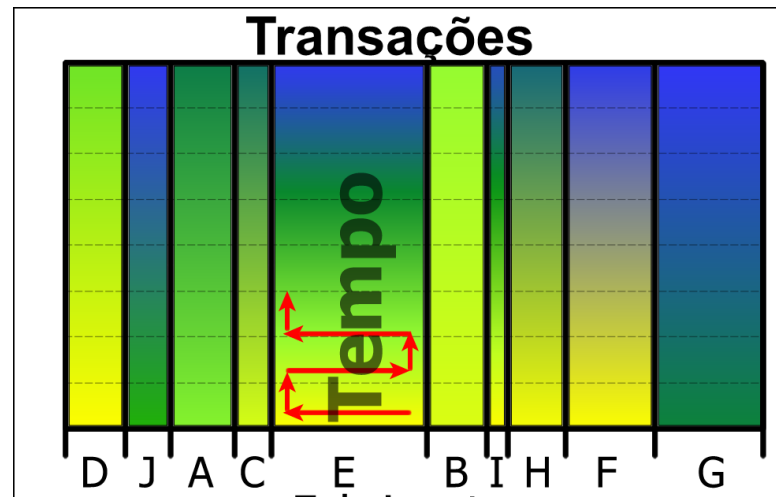

Fabricantes

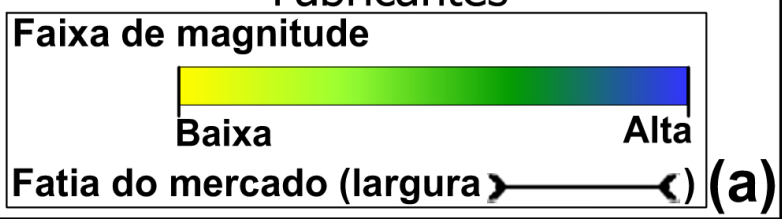

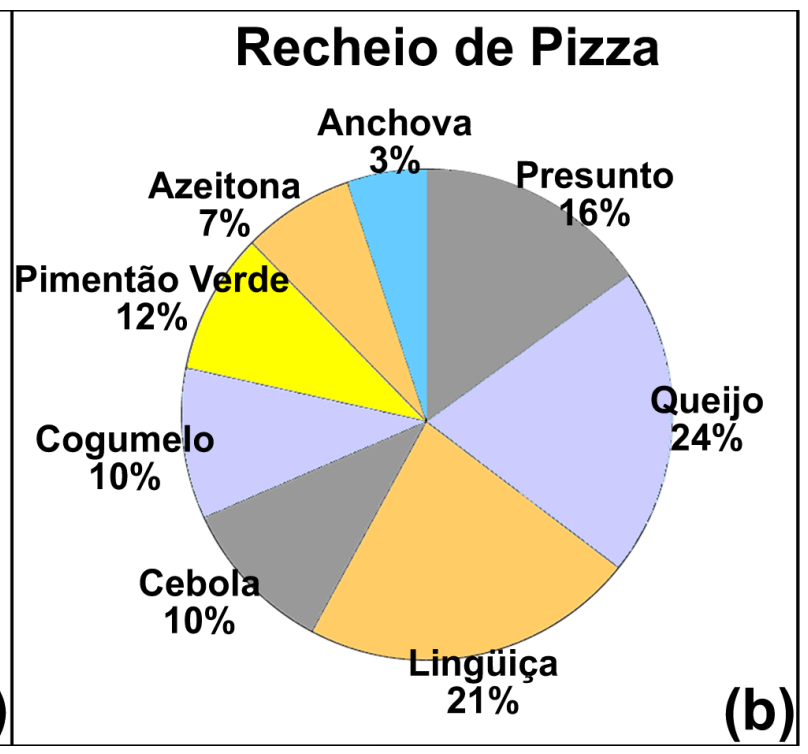

(b)

Figura 6.2: (a) Seqüenciamento na técnica Pixel Bar Charts - num conjunto de dados hipotético, os pixels mapeiam diferentes transações de vários fabricantes. Posição: correspondência discreta por meio do mapa não ordenado de rótulos de fabricantes, e correspondência contínua por meio do mapa mental declarado em ordem vertical ascendente de tempo; forma: correspondência contínua por meio da largura das colunas; cor: correspondência contínua. (b) Seqüenciamento na técnica Gráfico de Pizza. Posição: correspondência discreta por meio do mapa circular não ordenado de rótulos; forma: correspondência contínua por meio do tamanho da área, significado por meio de texto (composição de formas); cor: diferenciação discreta.

ou implicitamente presente nos dados. Esta função gera um conjunto de posições que representam os dados, sendo que um conjunto de eixos é necessário para ser usado como um mapa visual, definindo correspondência. Ao mesmo tempo, o conjunto de posições gerado pela função pode compor, por interpolação implícita ou explícita, linhas, áreas, superfícies ou volumes que podem expressar percepção de arranjo e/ou significado. De maneira geral, projeções obedecem à seguinte equação:

$$
\left(x_{i}, y_{i}, z_{i}\right)=f\left(d_{(i, 0)}, d_{(i, 1)}, \ldots, d_{(i, n-1)}\right)
$$

onde $d_{i, j}$ é o j-ésimo atributo do $i$-ésimo item de informação e $n$ é a dimensionalidade do conjunto de dados. Exemplos incluem as Coordenadas Paralelas com uma projeção por dimensão, gráficos de análise convencionais, e os exemplos das figuras 6.3(a) e 6.3(b).

Há uma fronteira bem definida entre espacializações baseadas em projeção e baseadas em sequienciamento. Ambas utilizam mapas para definir correspondência posicional. No entanto, projeções utilizam mapas visuais, geralmente mais de um, posicionados ortogonalmente e com padrão estritamente reto. Os dados não seguem uma ordem. Seqüenciamentos utilizam um único mapa que é mental e segue padrões mais elaborados. Os 
dados são necessariamente ordenados. Para compensar sua simplicidade, visualizações baseadas em seqüenciamentos utilizam mais de um ciclo de espacialização, como será abordado na seção 6.6.
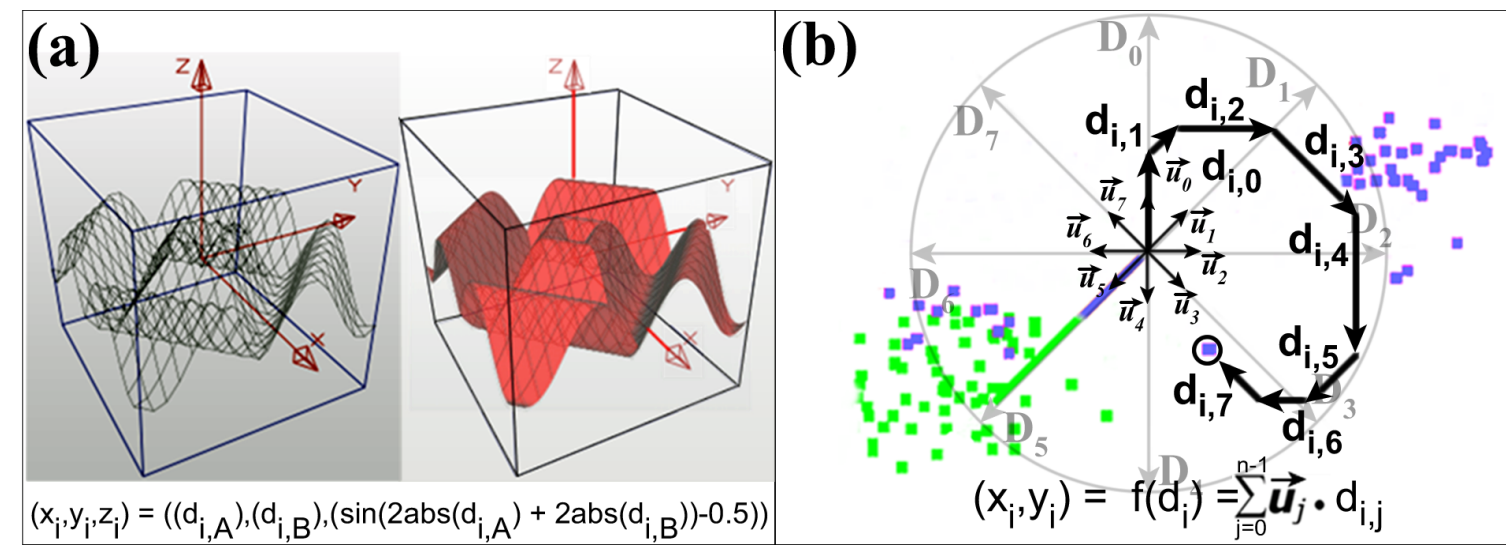

Figura 6.3: (a) Projeção via gráfico funcional 3D. Posição: correspondência contínua por meio do mapa de três eixos ortogonais; arranjo significativo por meio de interpolação de linhas (à esquerda) e de superfície (à direita); forma: não escolhida explicitamente no design; cor: sem expressividade. (b) Projeção via Star Coordinates com oito dimensões. Posição: correspondência contínua por meio do conjunto de eixos; forma: sem expressividade; cor: correspondência discreta por meio das cores dos itens de informação e das cores do eixo $D_{5}$.

- Reprodução: o posicionamento dos dados é conhecido antecipadamente, tendo sido determinado pela espacialização original do sistema/fenômeno que originou os dados. Não de fato, mas idealmente, numa reprodução a visualização e o fenômeno observado devem definir:

$$
\left(x^{\prime}, y^{\prime}, z^{\prime}\right)=P(x, y, z)
$$

onde $P$ é uma função que recebe um conjunto de coordenadas do mundo real e produz coordenadas tridimensionais de projeção. A figura 6.4 ilustra dois exemplos. Usualmente, algoritmos específicos [Elvins, 1992] [Silva et al., 2005] são necessários para se identificar a posição dos dados com base na estrutura implícita das informações. Outros algoritmos podem ser utilizados para simplificar volumes de dados com alta cardinalidade/complexidade, ou para derivar características adicionais mais tarde representadas como glifos ou linhas de fluxo.

Espacialização por meio de reprodução pode ser encarada como um caso especial de projeção, onde a função de projeção é desconhecida ou indeterminável. Ao invés disso, o posicionamento deriva do fenômeno observado. De maneira semelhante à espacialização via projeção, o conjunto de dados mapeado pode compor, via interpolação, linhas, 
áreas, superfícies ou volumes, como se observa comparando-se as figuras 6.3(a) e 6.4(a). Diferentemente das projeções, a referência posicional - mapa de eixos ou mapa geográfico, por exemplo - é opcional, como mostrado na figura 6.4(a). Assume-se que os itens gráficos estão embutidos num ubíquo espaço Euclidiano.

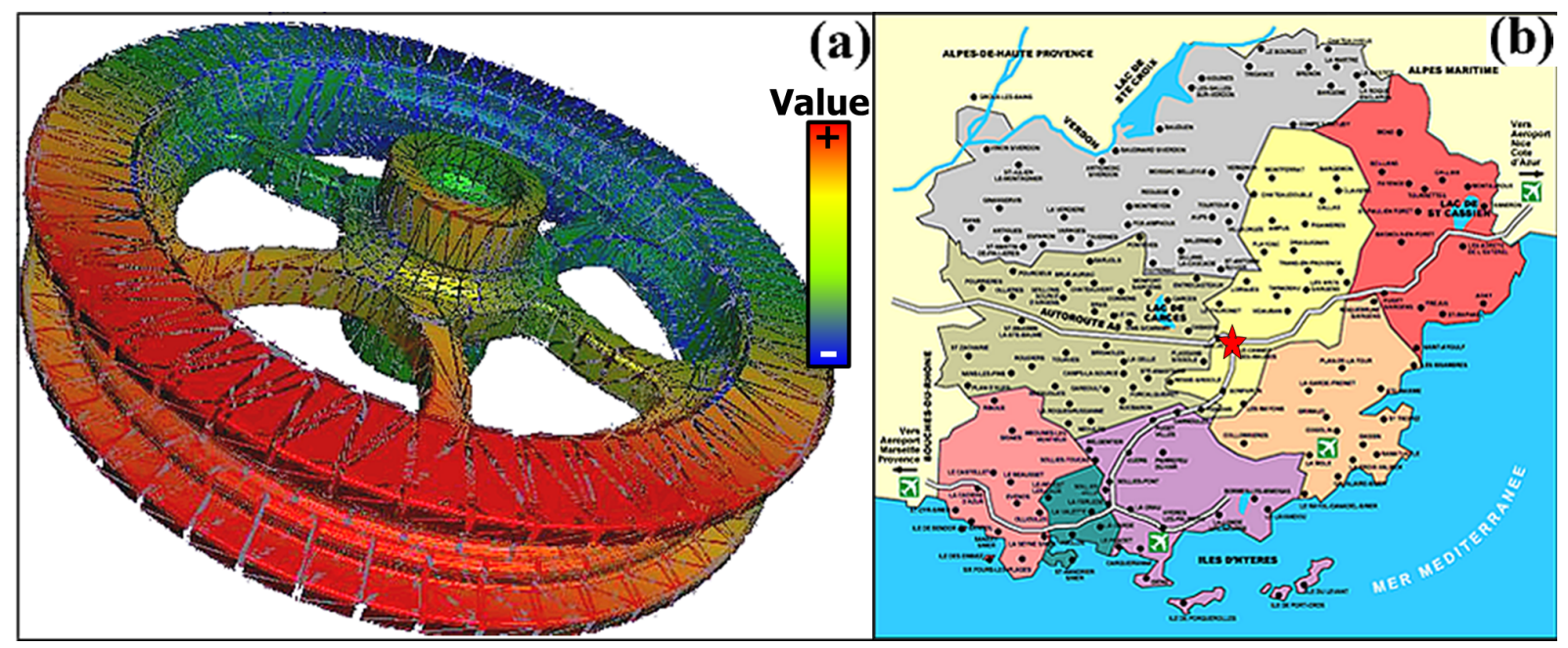

Figura 6.4: (a) Reprodução via um conjunto de dados renderizado. Posição: significado por meio da forma criada com interpolação visual dos pontos do espaço; forma: não escolhida explicitamente no design; cor: correspondência contínua. (b) Reprodução via mapa geográfico. Posição: correspondência contínua por meio do mapa visual geográfico, dos pontos e das linhas de marcação; forma: significado por meio dos ícones que identificam aeroportos, e diferenciação por meio da estrela que identifica uma cidade mais importante (ao centro); cor: diferenciação discreta e significado por meio do conhecimento prévio de que água é azul. Imagem (a) reproduzida com permissão de S. G. Eick.

Espacialização é o fator mais importante da prática de design de técnicas de visualização. Ele é também o mais complexo. Por este motivo, acredita-se que a espacialização seja pouco flexível, isto é, as percepções visuais expressas por um dado método de espacialização são pouco modificáveis. Além disso, nem todas as espacializações podem expressar todos os tipos de percepção. Estes fatores determinam que a etapa de design que decide o posicionamento dos dados não pode ser realizada em função da percepção espacial que se deseja, mas sim em função dos métodos de espacialização dos quais se dispõe.

Do ponto de vista da expressividade visual, a espacialização é o componente que mais contribui com a percepção humana, promovendo organização e economia de memória. Pode-se dizer que espacializações podem expressar percepções direta ou indiretamente, com relação ao fato do tipo de expressividade percebida ter sido escolhido explicitamente ou não. Percepções diretas incluem diferenciação, quando um mapa posicional não é utilizado, e correspondência, quando um mapa é utilizado. De fato, no design de posicionamento, a única decisão disponível, além da escolha do método de espacialização, é o uso ou não de um mapa posicional para estabelecer percepção de correspondência. Percepções indiretas incluem arranjo e/ou significado 
que ocorrem em paralelo a outras percepções. A percepção de arranjo por meio de espacialização de Projeção é a base de visualizações de funções matemáticas. A percepção de significado por meio de espacialização de Reprodução é a base da visualização científica. Em VisC, um conjunto de pontos no espaço define, por interpolação, formas com significado. A compreensão destes fatos é importante em nosso modelo pois define o limite entre expressividade de posição e de forma.

\subsection{Forma}

Até este ponto, argumentou-se que um número limitado de procedimentos de espacialização é o núcleo das técnicas de visualização, e que tais procedimentos ditam como será o estímulo préatentivo de posição. Após a espacialização, ainda é necessário decidir como forma e cor irão compor a visualização. Assim, nesta e na próxima seção, serão investigadas quais percepções visuais analíticas podem ser determinadas por meio de forma e de cor. Especificamente, o estímulo pré-atentivo de forma engloba o maior número de possibilidades para a percepção visual: correspondência, diferenciação, conectividade e significado.

- Correspondência: discreta ou contínua, cada forma perceptível tem uma correspondência específica em um mapa de formas. Se nenhum mapa é fornecido, o mapa intuitivo "maior tamanho, maior magnitude" é tipicamente assumido. A figura 6.5 exemplifica os casos discreto (a) e contínuo (b).

- Diferenciação: as formas exibidas simplesmente discriminam os itens para posterior interpretação, como nas figuras 6.4(b) e 6.5(a).

- Conectividade: segmentos de linha que denotam conectividade entre itens gráficos, como nas Coordenadas Paralelas e em visualizações de grafos, como na figura 6.1(b) e 6.6(a).

- Significado: setas, formas complexas compostas (texto) ou ícones que carregam significado cuja interpretação depende do conhecimento, da experiência e da cultura do usuário analista. Um exemplo é mostrado na figura 6.4(b).

No modelo aqui descrito há uma sutil fronteira entre expressividade por meio de forma e de posição. Observa-se que quando uma forma é explicitamente escolhida para compor o design, trata-se de percepção visual expressa por meio de forma. No entanto, como já discutido, quando uma espacialização define um conjunto de pontos que acabam por definir formas expressivas, trata-se de percepção visual de significado, ou de arranjo, expressa por meio de espacialização do tipo Reprodução ou do tipo Projeção. 


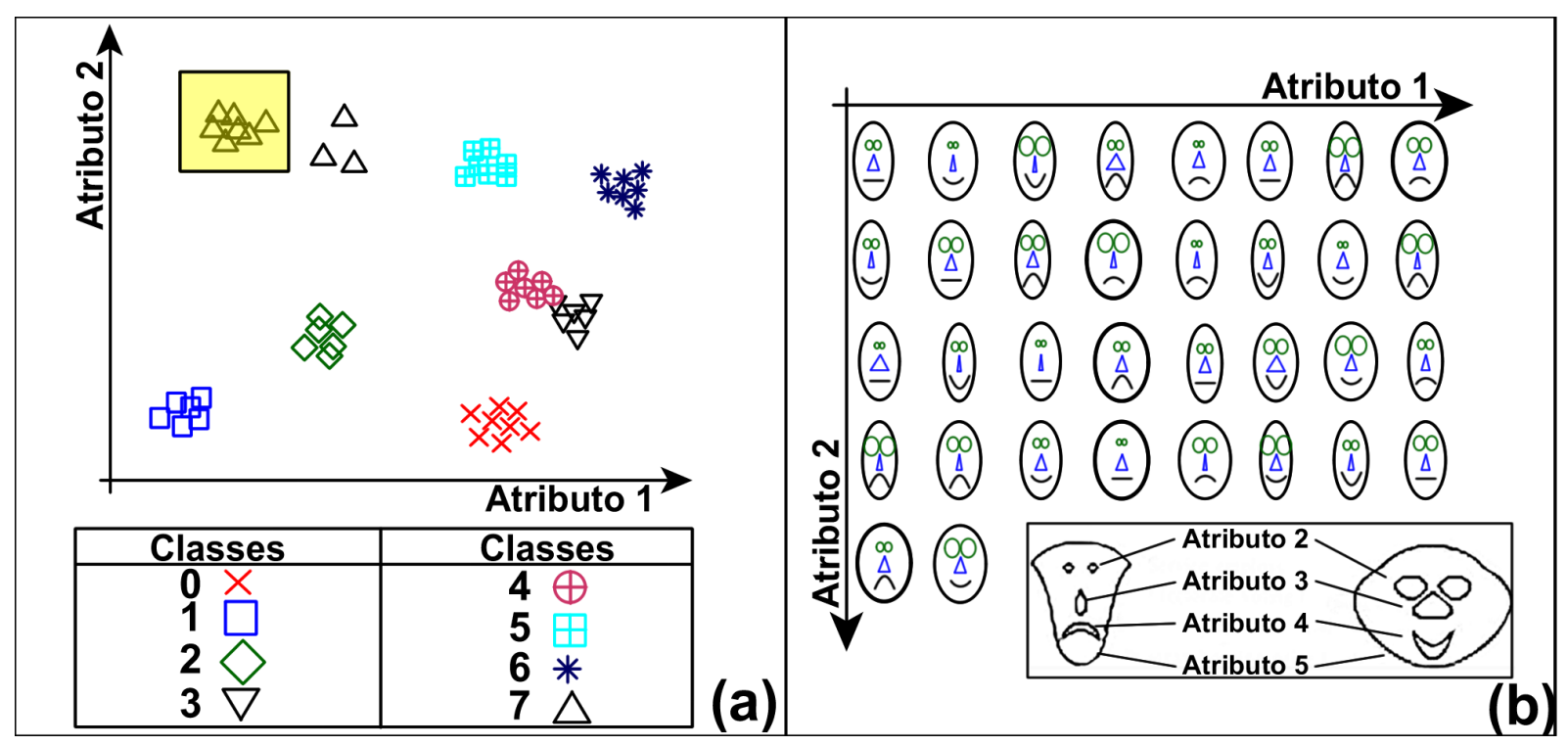

Figura 6.5: (a) Projeção de itens classificados. Posição: correspondência contínua por meio do mapa de dois eixos ortogonais; forma: correspondência discreta por meio do mapa de formas na parte inferior, e diferenciação por meio do retângulo de seleção; cor: correspondência discreta, e diferenciação por meio do retângulo de seleção em amarelo. (b) Projeção via Faces de Chernoff. Posição: correspondência contínua por meio do mapa de dois eixos ortogonais, e correspondência discreta por meio do mapa da face humana; forma: correspondência contínua por meio do tamanho e da curvatura dos elementos faciais; cor: sem expressividade.

\subsection{Cor}

Após a espacialização, que provê pistas espaciais para a percepção de informação, e após a escolha de formas, que proporcionam expressividade adicional, cor é o terceiro estímulo préatentivo a ser definido. Cor é capaz de transmitir informação por meio das percepções visuais de correspondência, diferenciação e significado.

- Correspondência: discreta ou contínua. No caso discreto cada cor perceptível define correspondência a um mapa de cores, como na figura 6.6(a). No caso contínuo, a variação de tons é mapeada para um intervalo contínuo de valores, como mostrado na figura 6.6(b).

- Diferenciação: as cores não possuem correspondência, elas apenas determinam uma idéia de igualdade, ou de desigualdade, entre os itens gráficos. Isto pode ser observado nas figuras $6.2(\mathrm{~b})$ e $6.5(\mathrm{a})$.

- Significado: as cores carregam significado que depende do conhecimento, experiência e cultura do usuário analista. Exemplos incluem cores específicas, como vermelho que em certas circunstâncias indica alerta; e colorações texturizadas, que transmitem a idéia de semelhança a materiais específicos. Exemplificado na figura 6.4(b). 

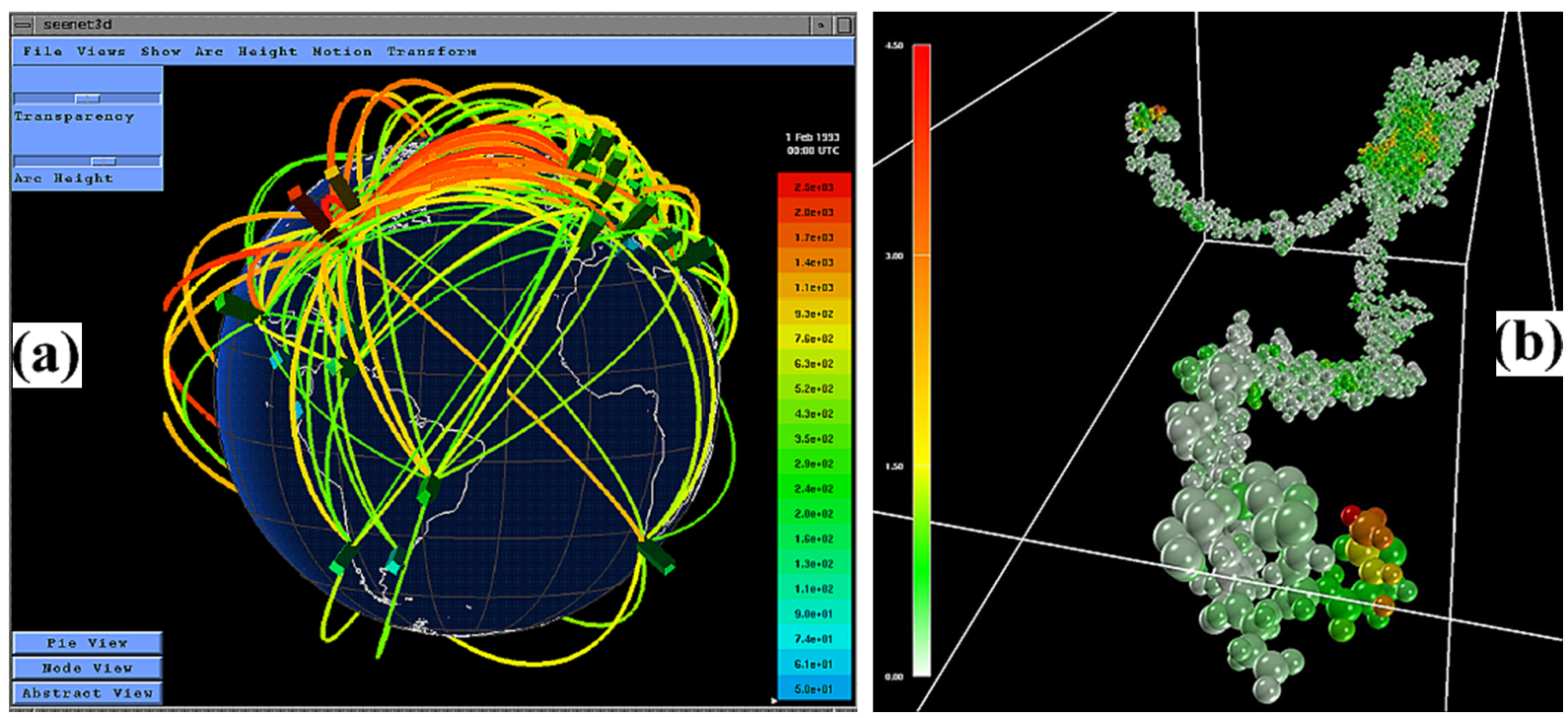

Figura 6.6: (a) Reprodução tridimensional sobre um mapa visual do globo terrestre. Posição: correspondência contínua por meio do mapa visual do globo terrestre; forma: correspondência por meio do tamanho dos pilares nos pontos de interesse, e conectividade por meio das linhas curvilíneas unindo diferentes pontos; cor: correspondência discreta. (b) Reprodução de estrutura química. Posição: correspondência contínua por meio do mapa de três eixos ortogonais, e significado por meio da forma criada via interpolação visual dos pontos do espaço; forma: não escolhida explicitamente no design; cor: correspondência contínua. Imagens (a) e (b) reproduzidas com permissão de S. G. Eick.

\subsection{Exemplos Analíticos}

Nesta seção a taxonomia apresentada é ilustrada utilizando-se de exemplos de análise guiados pela organização conceitual proposta.

\section{Gráfico de Pizza}

Num primeiro exemplo, considera-se a visualização clássica, denominada Gráfico de Pizza. No exemplo, mostrado na figura 6.7 junto com um pequeno conjunto de dados hipotéticos, o design da visualização começa com uma espacialização seqüencial circular. Numa segunda etapa, os dados já espacializados são acrescidos de rótulos textuais (forma). Em seguida, determina-se uma segunda codificação de forma utilizando-se correspondência por meio de tamanho de área, obtendo-se fatias de tamanho proporcional ao atributo $X$. Na última etapa do design, utiliza-se codificação discreta de cor para se obter percepção de diferenciação entre as fatias.

O design do gráfico de pizza é um exemplo bastante intuitivo e direto. Por esta mesma razão, tende-se a enxergá-lo como uma visualização monolítica, sem se perceber seus elementos constituintes. A identificação de tais componentes pode servir de inspiração para variações do gráfico de pizza ou para novos designs. 


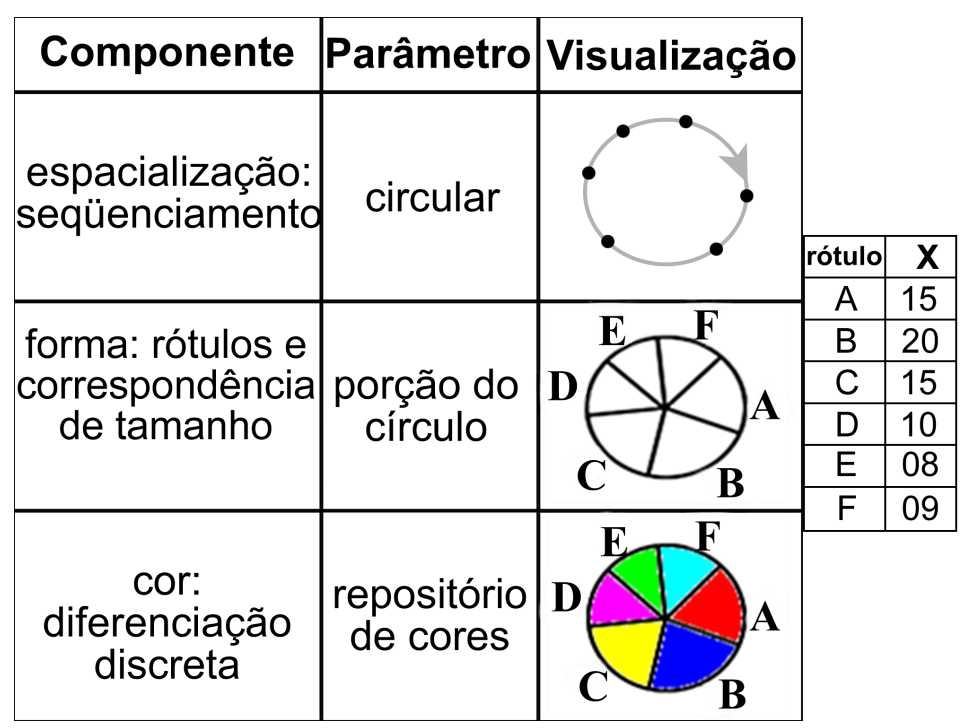

Figura 6.7: Design de um gráfico de pizza.

\section{Visualização via Posicionamento de Pixels em Espiral}

Num segundo exemplo, também acompanhado de um conjunto de dados hipotéticos, faz-se a análise do design baseado no posicionamento de pixels em espiral. Esta técnica é originalmente denominada em inglês como Spiral Pixel Display. A concepção do design inicia-se pela adoção de uma espacialização seqüencial em espiral ordenada pelo atributo $X$. Esta etapa é ilustrada na parte superior direita da figura 6.8. Nesta técnica de visualização, o estímulo de posição irá definir correspondência a um mapeamento mental segundo a ordem do atributo $X$. Na segunda parte do design, opta-se por não se utilizar de codificação de forma. Esta decisão visa maximizar a utilização da área de exibição pois cada item é representado por um pixel, uma representação minimalista. Na terceira etapa, a cor é a terceira decisão do design. Estabelece-se uma correspondência contínua entre os valores do atributo $X$ e um intervalo de cores variando do branco ao vermelho saturado.

Analisando-se esta técnica, percebe-se que ela pode ser considerada uma variação da técnica de visualização do tipo gráfico de pizza. A maior diferença é a decisão por não se utilizar codificação de forma, apenas de cor. Este design resulta numa técnica que suporta um número maior de itens de dados. O custo desta escolha é o fato de que a densidade de itens, um por pixel, previne o uso de mapas de forma. Desta maneira, a determinação de qual posição corresponde a qual dado, só é possível utilizando-se de funcionalidades adicionais de interação.

\section{Coordenadas Paralelas}

Neste terceiro exemplo, mostrado na figura 6.9, a técnica das coordenadas paralelas ilustra a aplicação de múltiplos procedimentos de espacialização. Trata-se de um conceito importante no desenvolvimento do espaço de design proposto nesta tese. Para o exemplo, considera-se 


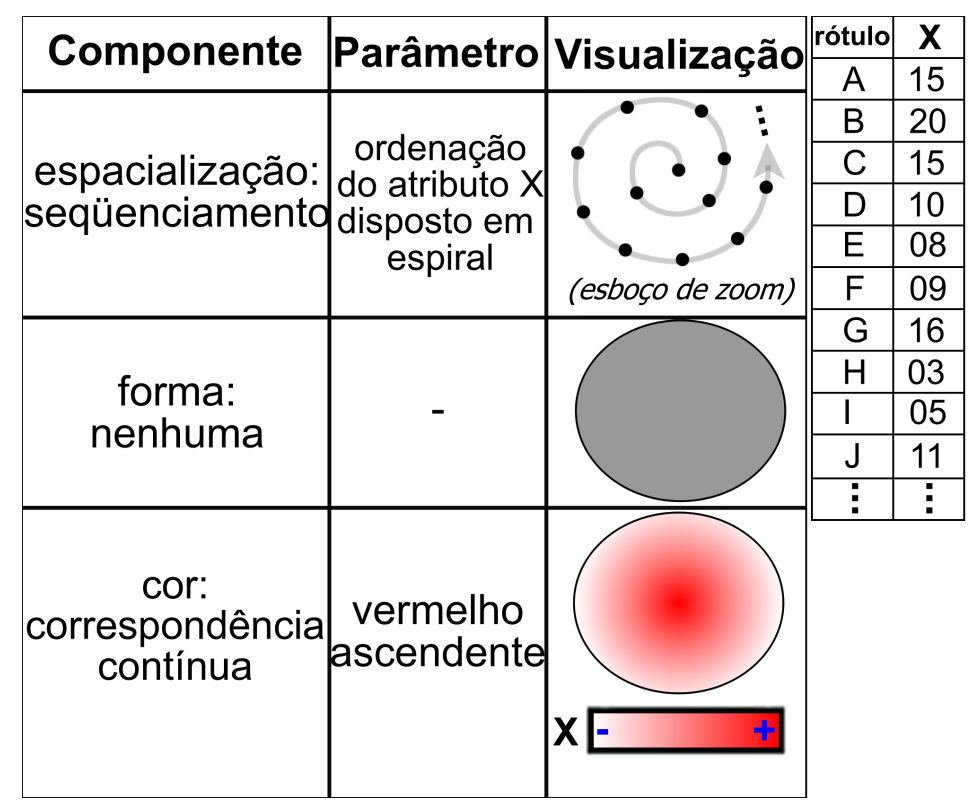

Figura 6.8: Design da técnica baseada em posicionamento de pixels em espiral.

um conjunto de dados hipotético com quatro atributos ( $W, X, Y$ e $Z$, onde $Y$ determina a classe dos itens de dados. Na primeira etapa de design, utiliza-se um posicionamento seqüencial para os atributos, os quais são acrescidos de codificação de forma (nomes dos atributos). A pouca dimensionalidade permite ter-se um mapa posicional composto pelo nome de todos os atributos sem que o espaço horizontal disponível seja extrapolado. Cada posição horizontal definirá correspondência a uma dimensão dos dados. Na segunda etapa, os valores de cada atributo são projetados verticalmente nos respectivos eixos que servem de mapas de posição. Esta segunda espacialização beneficia-se do espaço não utilizado durante a primeira espacialização. Percebese que as duas espacializações são integradas de maneira que os itens dispostos na primeira espacialização (nomes dos atributos) se tornam referência para a segunda espacialização (valores dos atributos). Na próxima etapa de design, formas (segmentos de linha) são utilizadas para estabelecer expressão de conectividade. Esta decisão visa identificar quais valores de atributos estão interconectados refletindo os itens de dados multidimensionais do conjunto de dados. A última etapa do design utiliza codificação de cor para estabelecer expressão de correspondência ao atributo de classificação $Y$, que se torna o mapa de cores da visualização.

\subsection{Espacializações Múltiplas}

Como exemplificado na análise da figura 6.9, visualizações podem utilizar regiões disjuntas do espaço, cada qual preenchida segundo uma diferente estratégia de espacialização. Em outro exemplo, mostrado na figura 6.10, é mostrada uma grade dentro da qual glifos compostos de segmentos de reta são espacializados de acordo com uma projeção de dois atributos. Na figura 


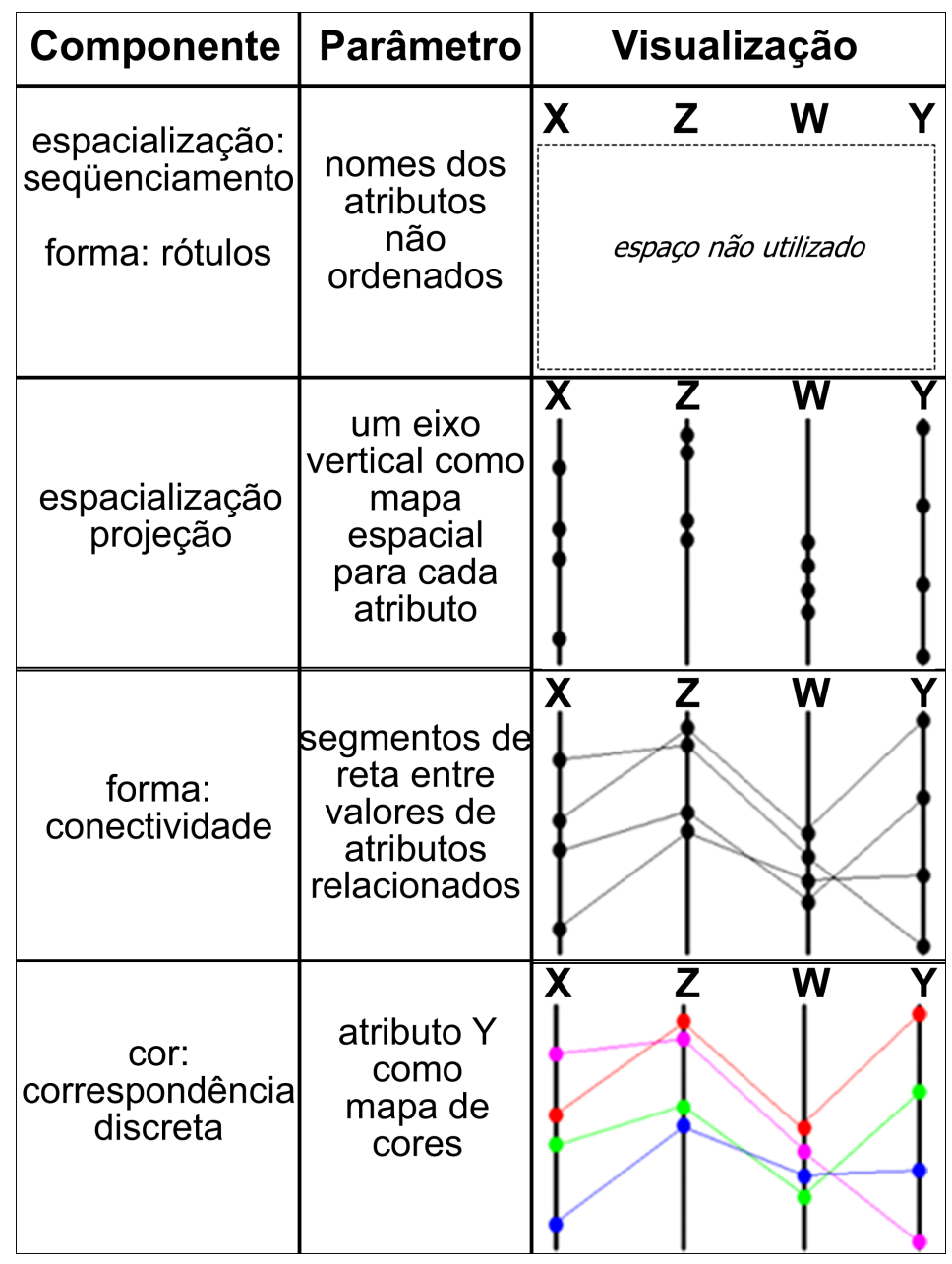

Figura 6.9: Design da técnica Coordenadas Paralelas.

6.10(b), um dos glifos da figura 6.10(a) é focado de maneira a exibir o espaço disponível dentro do glifo. A figura 6.10(c) mostra que dentro de cada glifo, os atributos que ainda não foram codificados podem ser posicionados segundo uma espacialização seqüencial circular. Finalmente, a figura 6.10(d) foca em um dos segmentos de reta do glifo em análise para mostrar que o tamanho do segmento corresponde à magnitude do terceiro atributo do j-ésimo dado hipotético.

De maneira semelhante aos exemplos das figuras 6.9 e 6.10, a prática de múltiplos ciclos de espacialização é aplicada em técnicas como Dimensional Stacking [LeBlanc et al., 1990], Worlds-within-Worlds [Feiner e Beshers, 1990], Circle Segments [Ankerst e Keim, 1996], Pixel Bar Charts [Keim et al., 2001] e em muitas das chamadas técnicas que utilizam ícones, dentre outras.

A utilização de múltiplas espacializações define abordagens híbridas, uma prática presente em grande parte das técnicas encontradas na literatura de visualização. Este fato foi, de diferentes maneiras, observado por outros autores. Card et al [Card et al., 1999], por exemplo, apontam técnicas de recursão e sobrecarga de eixos espaciais; e Bowman [Bowman, 1968] observa a utilização de espaços planos, contínuos e múltiplos na definição de comunicação gráfica. Mais 


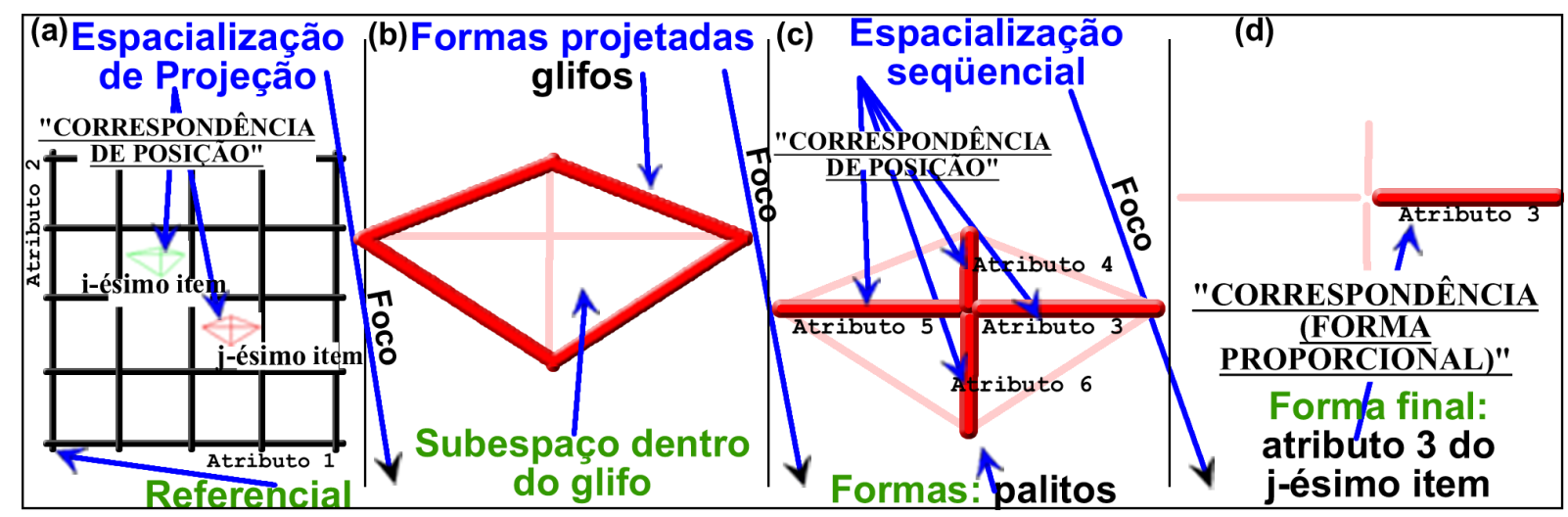

Figura 6.10: Dois ciclos de espacialização aplicados na concepção de uma visualização. (a) Projeção de Star Glyphs. (b) Foco num glifo em particular. (c) Seqüenciamento dentro do glifo. (d) Informação de atributo como uma correspondência de forma.

especificamente, seguindo a descrição deste trabalho, em designs que se beneficiam de espacializações múltiplas a pré-atenção depende de como o analista foca na visualização, permitindo que diferentes níveis de observação e detalhamento sejam explorados simultaneamente. O uso de múltiplos ciclos de espacialização é o fator chave para a diversidade encontrada no design de visualizações. Ciclos de espacialização integrados permitem um uso mais eficiente do espaço e resultam em técnicas mais complexas de apresentação. Nas próximas seções, mostra-se que tal compreensão, em combinação com a taxonomia proposta, pode prover uma valiosa orientação para a exploração de novas possibilidades em visualização.

\subsection{Considerações Gerais}

A taxonomia descrita nesta seção utiliza três componentes para classificar as técnicas de visualização. Estas três componentes possuem uma quantidade limitada de categorias, sendo que classes são definidas como combinações das categorias de cada componente. Diferente de outras propostas, a taxonomia procurou utilizar um conjunto menor tanto de componentes quanto de categorias. O objetivo é a definição de um universo amplo, compreensível e, ao mesmo tempo, factível para utilização. Estruturada desta maneira, a taxonomia abrange um amplo espaço de possibilidades. Embora não tão adequada a usuários finais, os quais esperam preferencialmente um único componente, acredita-se que a taxonomia possa ser útil para usuários projetistas e pesquisadores.

Como descrito por Rodrigues Jr. [Rodrigues Jr. et al., 2006c], o objetivo da taxonomia proposta é a identificação dos elementos das técnicas de visualização colocados num sistema de classificação capaz de servir adequadamente à pesquisa em design. Classificações desta natureza servem como instrumento para o desenvolvimento estruturado de princípios, um mapa de soluções que pode revelar quais áreas ainda não foram exploradas [Bugajska, 2003]. No pró- 
ximo capítulo, as idéias colocadas pela organização taxonômica proposta serão utilizadas para se conceber uma estrutura compreensiva na forma de um espaço de possibilidades. Este espaço de possibilidades pode ser encarado como uma representação visual das idéias desenvolvidas neste trabalho. 


\section{Capítulo 7}

\section{Um Novo Espaço de Design}

\subsection{Considerações Iniciais}

Espaços de design são organizações conceituais capazes de guiar a identificação dos elementos constituintes de um dado fenômeno. Estes espaços determinam uma abordagem não holística, com refinamento abstrato, que serve de base para compreensão das razões que levaram a uma determinada configuração de fatores. A partir desta compreensão torna-se possível o projeto de novas configurações fundamentando-se na reprodução das propriedades e princípios descobertos, bem como na experimentação guiada pelo conhecimento adquirido.

O espaço de design aqui proposto reflete o conhecimento reunido ao longo deste documento. Ele engloba as teorias e os conceitos definidos e pesquisados, pondera sobre a revisão analítica de inúmeras outras propostas e considera deficiências e virtudes predecessoras. Ao mesmo tempo, seguindo uma estratégia alternativa decorrente de uma nova organização abstrata, o espaço de design proposto objetiva simplicidade e fácil assimilação. A simplicidade advém de sua estruturação análoga a um espaço Euclidiano; a assimilação advém de seus componentes intuitivos e pouco numerosos.

\subsection{Design Espacial-Perceptivo}

Seguindo-se os conceitos propostos no capítulo 3, sobre expressividade visual, é possível conceber um espaço de design denominado Espaço de Design Perceptivo. Ilustrado na figura 7.1(a), o Espaço de Design Perceptivo é capaz de descrever como as técnicas de visualização podem ser concebidas buscando-se expressividade visual. Os eixos deste espaço de possibilidades correspondem aos constituintes básicos das técnicas de visualização. Desta maneira, qualquer técnica pode ser definida dentro do Espaço de Design Perceptivo em termos de configurações de estímulos pré-atentivos de posição, forma e cor, cada qual moldado segundo um subconjunto das percepções visuais de correspondência, diferenciação, conectividade, arranjo e significado. 
A essência do Espaço de Design Perceptivo é explorada na definição da Taxonomia Espacial-Perceptiva descrita no capítulo 6, onde se estuda a relação entre as técnicas de visualização, seus constituintes pré-atentivos e as percepções visuais expressas pelas técnicas. Nesta taxonomia, no entanto, verificou-se que o componente de espaço não pode ser definido em termos da expressividade desejada. Assim, estendendo-se a idéia do Espaço de Design Perceptivo (técnicas de visualização em função da expressão visual), e considerando-se a análise realizada na Taxonomia Espacial-Perceptiva, é possível conceber um espaço de design mais completo: o Espaço de Design Espacial-Perceptivo. Ilustrado na figura 7.1(b), o Espaço de Design EspacialPerceptivo assume que a percepção espacial é ditada pelo processo de espacialização.

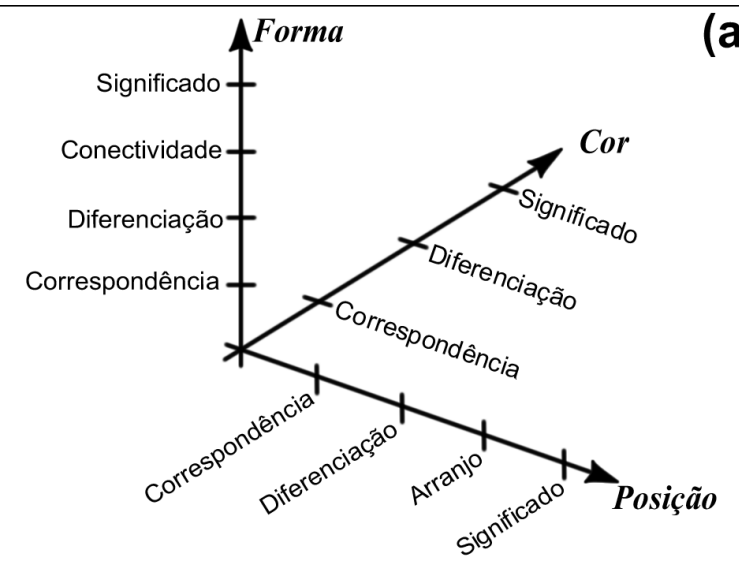

Espaço de Design Perceptivo (a)

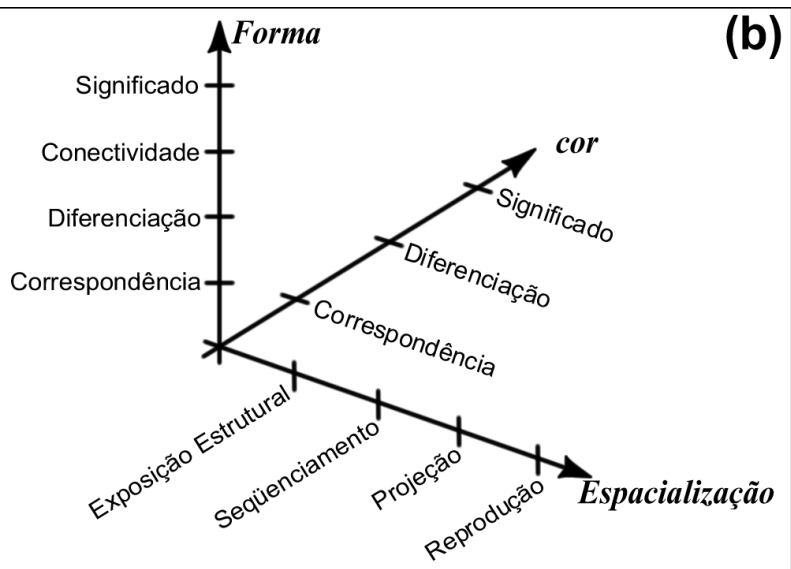

Espaço de Design Espacial Perceptivo

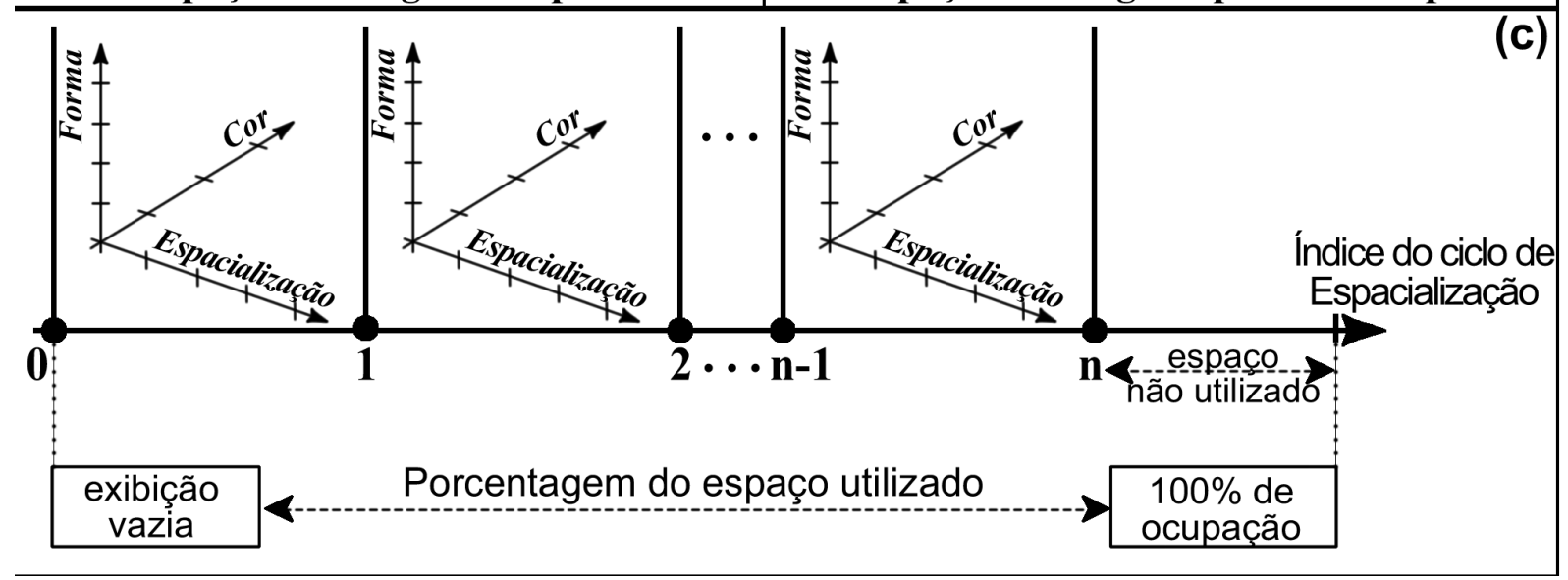

Figura 7.1: Espaços de Design. (a) O Espaço de Design Perceptivo com dimensões de posição, forma e cor cujos domínios são subconjuntos das percepções visuais identificadas. (b) O Espaço de Design Espacial-Perceptivo onde a percepção de posição é ditada por processos de espacialização. (c) O completo Espaço de Design Espacial-Perceptivo que inclui múltiplos ciclos de espacialização.

Neste segundo espaço de design, a dimensão de posição torna-se a dimensão de espacialização. Refletindo a pouca flexibilidade do principal componente das técnicas de visualização, a dimensão de espacialização admite um pequeno conjunto de metodologias de posicionamento espacial. Estas metodologias determinarão diferentes fenômenos de expressividade de acordo 
com suas propriedades. Nas dimensões de forma e cor, as possibilidades giram em torno da expressão visual prevista pelos objetivos de um dado design.

Ainda estendendo as idéias descritas ao longo desta tese, considera-se também o fato de que técnicas de visualização podem, e são, compostas por mais de um ciclo de espacialização, como descrito na seção 6.6. Desta maneira, o Espaço de Design Espacial-Perceptivo pode ser mais elaborado definindo um espaço de possibilidades mais amplo, como ilustrado na figura 7.1(c). Segundo esta organização, o projeto de técnicas de visualização é visto como uma seqüência de ciclos de preenchimento de espaço, cada qual obedecendo às possibilidades de design EspacialPerceptivo. Os ciclos de preenchimento de espaço são utilizados até que o espaço disponível para desenho tenha se esgotado ou até que seja pequeno demais para ser aproveitado, como descrito na figura 7.1(c).

A tabela 7.1 apresenta um conjunto de análises que seguem o espaço de design proposto. Cada análise define uma classificação segundo a Taxonomia Espacial-Perceptiva do capítulo 6. Algumas das visualizações mais referenciadas na literatura são apresentadas.

\subsection{Design Espacial-Perceptivo e Interação}

Interação é um componente fundamental dos sistemas de análise visual de dados. No entanto, diferente de outras propostas, este trabalho não considera as técnicas de interação como parte das técnicas de visualização, mas sim como parte dos sistemas de visualização. Segundo a organização abstrata apresentada na seção 5.4, sistemas de visualização são compostos pela combinação de técnicas de visualização com técnicas de interação, além de técnicas de préprocessamento. Técnicas de interação, de fato, podem ser combinadas com qualquer aplicação computacional, mesmo que a interação ocorra por meio de um terminal de texto.

Na organização de conceitos do Espaço de Design Espacial-Perceptivo, interação pode ser encarada como um produto que surge da possibilidade de se alterar os parâmetros dos componentes de uma dada técnica de visualização. Jensen [Jensen, 2000] afirma que a interatividade pode ser medida como a habilidade potencial de uma mídia na tarefa de permitir que o analista influencie a forma ou o conteúdo da informação sendo mediada. Este autor também afirma que tal noção está relacionada a mídias que, além de promoverem saída de informações, também abrem possibilidades para transferir diferentes graus e tipos de entradas de dados partindo do usuário analista para o sistema. Neste contexto, esta seção procura clarificar o papel das técnicas de interação sob a luz das idéias propostas. A análise que se faz se sustenta nas seguintes condições: 
Tabela 7.1: Exemplos de análise espacial-perceptiva considerando configurações comuns para técnicas de visualização conhecidas.

\begin{tabular}{|c|c|c|c|c|}
\hline Técnica de Visualização & Espacialização & Forma & Cor & $\begin{array}{l}\text { Interação } \\
\text { Prospectiva }\end{array}$ \\
\hline $\begin{array}{lcc}\text { Faces } & \text { de } & \text { Chernoff } \\
\text { [Chernoff, 1973] } & \\
\end{array}$ & Projeção, Seqüenc. & $\begin{array}{l}\text { Diferenciação, } \\
\text { Correspond. }\end{array}$ & - & Filtragem \\
\hline $\begin{array}{l}\text { Dimensional Stacking } \\
\text { [LeBlanc et al., 1990] }\end{array}$ & Múltiplas Projeções & - & Diferenciação & Filtragem \\
\hline $\begin{array}{l}\text { Coordenadas } \\
\text { [Inselberg e Dimsdale, 1990] }\end{array}$ & $\begin{array}{l}\text { Seqüenc., } \\
\text { Múltiplas Projeções }\end{array}$ & Conectividade & Diferenciação & Filtragem \\
\hline Scatter Plots [Cleveland, 1993] & Múltiplas Projeções & - & Diferenciação & Filtragem \\
\hline $\begin{array}{ll}\text { Star } & \text { Coordinates } \\
{[\text { Kandogan, 2001] }} & \\
\end{array}$ & Projeção & - & Diferenciação & $\begin{array}{l}\text { Filtragem, } \\
\text { Transf. espacial }\end{array}$ \\
\hline $\begin{array}{l}\text { Stick Figures } \\
\text { [Pickett e Grinstein, 1988] }\end{array}$ & $\begin{array}{l}\text { Projeção, } \\
\text { Múltiplos Seqüenc. }\end{array}$ & $\begin{array}{l}\text { Diferenciação, } \\
\text { Correspond. }\end{array}$ & Diferenciação & Filtragem \\
\hline $\begin{array}{l}\text { Worlds-within-Worlds } \\
\text { [Feiner e Beshers, 1990] }\end{array}$ & Múltiplas Projeções & - & Diferenciação & Transf. espacial \\
\hline $\begin{array}{l}\text { Coordenadas Paralelas com Star } \\
\text { Glyphs [Fanea et al., 2005] }\end{array}$ & $\begin{array}{l}\text { Múltiplos Seqüenc., } \\
\text { Múltiplas Projeções }\end{array}$ & Conectividade & Correspond. & $\begin{array}{l}\text { Filtragem, } \\
\text { paramétrico }\end{array}$ \\
\hline $\begin{array}{lcc}\text { Flow } & \text { Map } & \text { Layout } \\
\text { [Phan et al., 2005] } & \\
\end{array}$ & Projeção & $\begin{array}{l}\text { Correspond., } \\
\text { Conectividade }\end{array}$ & Correspond. & Detalhamento \\
\hline $\begin{array}{lcc}\text { Pixel } \quad \text { Bar } & \text { Charts } \\
\text { [Keim et al., 2002] } & \\
\end{array}$ & $\begin{array}{l}\text { Projeção, } \\
\text { Múltiplos Seqüenc. }\end{array}$ & Correspond. & Correspond. & $\begin{array}{l}\text { Filtragem, } \\
\text { paramétrico }\end{array}$ \\
\hline $\begin{array}{l}\text { Técnicas orientadas a pixels } \\
{[\text { Keim, 2000] }}\end{array}$ & Múltiplos Seqüenc. & - & Correspond. & $\begin{array}{l}\text { Filtragem, } \\
\text { paramétrico, } \\
\text { Detalhamento }\end{array}$ \\
\hline Gráfico de Pizza & Seqüenc. & Correspond. & Diferenciação & $\begin{array}{l}\text { Filtragem, } \\
\text { paramétrico }\end{array}$ \\
\hline Table Lens [Rao e Card, 1994] & $\begin{array}{l}\text { Seqüenc., } \\
\text { Múltiplos Seqüenc. }\end{array}$ & Correspond. & Diferenciação & $\begin{array}{l}\text { Filtragem, } \\
\text { Detalhamento }\end{array}$ \\
\hline InterRing [Yang et al., 2002] & $\begin{array}{l}\text { Exposição } \\
\text { Estrutural }\end{array}$ & Correspond. & Correspond. & $\begin{array}{l}\text { Transf. espacial, } \\
\text { Detalhamento }\end{array}$ \\
\hline $\begin{array}{l}\text { Árvore Hiperbólica } \\
\text { [Lamping et al., 1995] }\end{array}$ & $\begin{array}{l}\text { Exposição } \\
\text { Estrutural }\end{array}$ & Conectividade & Diferenciação & $\begin{array}{l}\text { Transf. espacial, } \\
\text { Detalhamento }\end{array}$ \\
\hline $\begin{array}{l}\text { Voronoi Tree-maps } \\
\text { [Balzer e Deussen, 2005] }\end{array}$ & $\begin{array}{l}\text { Exposição } \\
\text { Estrutural }\end{array}$ & Correspond. & Correspond. & $\begin{array}{l}\text { Filtragem, } \\
\text { Detalhamento }\end{array}$ \\
\hline Mapas geográficos & $\begin{array}{l}\text { Reprodução com } \\
\text { mapa visual }\end{array}$ & $\begin{array}{l}\text { Diferenciação, } \\
\text { Significado }\end{array}$ & $\begin{array}{l}\text { Diferenciação, } \\
\text { Correspond. }\end{array}$ & $\begin{array}{l}\text { Transf. espacial, } \\
\text { Detalhamento }\end{array}$ \\
\hline Visualização de Vetores & Reprodução & $\begin{array}{l}\text { Significado, } \\
\text { Correspond. }\end{array}$ & Correspond. & Transf. espacial \\
\hline $\begin{array}{l}\text { Renderização de Volumes } \\
\text { [Wilhelms e Gelder, 1991] }\end{array}$ & Reprodução & $\begin{array}{l}\text { Não escolhido } \\
\text { / definido }\end{array}$ & - & Transf. espacial \\
\hline
\end{tabular}


1. uma técnica de interação deve permitir que o usuário analista seja capaz de definir/redefinir uma visualização por meio da alteração de seus estímulos pré-atentivos;

2. uma técnica de interação, com adaptações apropriadas, deve ser aplicável a qualquer técnica de visualização, sendo que o resultado da combinação das técnicas pode ser eficiente ou não.

A primeira condição é conseqüência direta da suposição de que técnicas de interação objetivam alterar o estado de uma dada aplicação computacional. No caso de uma cena de visualização, seus componentes básicos (estímulos pré-atentivos) refletem as alterações. A segunda condição deriva da necessidade de se ter uma conceituação bem definida e ao mesmo tempo universal. Assim, técnicas de interação devem ser aplicáveis a qualquer técnica de visualização, mesmo que tal utilização não seja eficiente. A partir destas considerações, identificam-se os seguintes paradigmas de interação:

- parametrização: a visualização é redefinida visualmente (barra de rolagem, por exemplo) ou textualmente (digitação, por exemplo), alterando-se parâmetros de posição, forma ou cor. Por exemplo, o mecanismo denominado Hierarchical Brushing, descrito por Fua et al [Fua et al., 1999];

- transformação espacial: interação baseada na manipulação direta de parâmetros de forma (tamanho) e posição dos elementos de um cena de visualização por meio de escala, rotação, translação e/ou zoom, como na ferramenta FastmapDB utilizada no trabalho de Rodrigues Jr. [Rodrigues Jr. et al., 2003a];

- filtragem: o analista pode selecionar visualmente um subconjunto de itens que, instantaneamente, serão diferenciados para estimular sua percepção. Baseia-se na alteração das propriedades de cor (brushing, ou pintura) e de forma (contorno de seleção). Estudos detalhados são apresentados por Ward e Yang [Ward e Yang, 2004b];

- detalhes sob demanda: informações detalhadas a respeito dos dados sendo apresentados podem ser recuperadas e exibidas prontamente. Estes tipos de interação permitem recuperar os dados que originaram um item gráfico em particular e exibi-los utilizando-se padrões visuais de texto (composição de formas). Como exemplo, a interação utilizada na técnica Table Lens;

- distorção: permite que visualizações sejam projetadas de maneira que diferentes perspectivas de posição possam ser observadas e definidas simultaneamente. Exemplos clássicos incluem a técnica Fish-eye View [Sarkar e Brown, 1994] e o plano hiperbólico [Walter e Ritter, 2002]; 
Observa-se ainda que a conhecida técnica denominada por Wegman e Luo [Wegman e Luo, 1997] como co-plots e denominada por Keim [Keim, 2002] como Link \& Brush é considerada neste trabalho apenas como uma automação dependente de design, não sendo considerada uma técnica de interação. A automação da técnica Link \& Brush se baseia na possibilidade de se integrar múltiplas visualizações de maneira que a interação de filtragem aplicada a uma das espacializações se reflita nas outras. Analisando-se a técnica Link \& Brush, vê-se que, contrariando os critérios aqui colocados, ela não implica propriamente na alteração de propriedades pré-atentivas, mas apenas na propagação do que a interação de filtragem definiu. Além disso, ela não pode ser aplicada a uma técnica de visualização, mas apenas a sistemas de visualização com múltiplas exibições. Pode-se generalizar o princípio da técnica Link \& Brush (ou algo como Relacionar \& Pintar) e definir-se técnicas semelhantes como Relacionar \& Transformar (transformação espacial sincronizada), Relacionar \& Parametrizar (propagação de parâmetros), Relacionar \& Distorcer (modificação perspectiva simultânea), e assim por diante. Tais técnicas são citadas na literatura por meio do termo Coordenação de Múltiplas Visualizações.

\subsection{Considerações Gerais}

Acredita-se que a maior contribuição do espaço de design proposto seja a maneira como as técnicas de visualização são encaradas. Numa abordagem não holística é possível ver os diversos componentes das técnicas e traçar a relação entre eles [Bugajska, 2003]. Esta compreensão permite vislumbrar novas possibilidades combinando-se os componentes identificados. Os conceitos de múltiplas espacializações e de ampliação do espaço de visualização completam a idéia permitindo uma liberdade ainda maior de criação. A organização conceitual aqui definida é original e, acredita-se, pode contribuir para o desenvolvimento da análise visual de dados. 


\section{Capítulo 8}

\section{Design Automatizado de Visualizações}

\subsection{Considerações Iniciais}

Pode-se dizer que parte da motivação do presente trabalho é a possibilidade de se conhecer o poder de expressão de diferentes métodos de posição, forma e cor e, conseqüentemente, ser capaz de conscientemente manipular tais métodos. Esta possibilidade permite a obtenção dos efeitos desejados e também o desenvolvimento de novos paradigmas. Um fator importante relacionado a este objetivo está na efetividade em se capturar e se comunicar os elementos essenciais em designs de interesse. Algumas das abordagens que focam nesta meta são o estudo de exemplos, a prática orientada por especialistas (consultores), a coleta de princípios de design e o desenvolvimento de pacotes de software que incorporam princípios de design conhecidos.

Outra possibilidade é a proposição de mecanismos que possibilitem o design automatizado de técnicas/sistemas de análise visual de dados. Os trabalhos de Card et al [Card et al., 1999] e de Chuah [Chuah e Roth, 1996] sugerem que o processo de design automatizado de visualizações requer as seguintes realizações:

- determinar os elementos (técnicas, propriedades ou características) que influenciam uma porção específica do espaço de design;

- criar um arcabouço para os elementos identificados;

- identificar os relacionamentos entre os elementos do arcabouço;

- desenvolver uma abstração que incorpore os elementos e as relações entre eles.

Os fatores mencionados na lista acima refletem o trabalho apresentado nesta tese. No capítulo 3, sobre expressividade visual, são identificados os elementos que influenciam o design das técnicas de visualização. No mesmo capítulo, o Processo de Expressividade Visual define um arcabouço para os elementos identificados. Em seguida, a organização abstrata do capítulo 5 
e a Taxonomia Espacial-Perceptiva do capítulo 6 formalmente identificam os relacionamentos entre os elementos do arcabouço de expressividade. Por último, o Espaço de Design EspacialPerceptivo do capítulo 7 define uma abstração que incorpora os elementos identificados e as relações entre eles. Tendo este conjunto de embasamento concretizado, este capítulo prossegue com a proposição de um mecanismo de design automatizado de técnicas de visualização. A proposta descrita é denominada Máquina de Visualização e pode ser considerada como resultado da aplicação das idéias desenvolvidas.

\subsection{A Máquina de Visualização}

Abordando-se as visualizações a partir da perspectiva da teoria proposta torna-se possível a concepção de um mecanismo ideal e generalizado de visualização. Ilustrado na figura 8.1 e denominado Máquina de Visualização, o modelo proposto integra os conceitos descritos até aqui numa única sistematização.

\section{Um Modelo Iterativo}

O modelo estabelece que uma visualização pode ser conseguida por meio de uma sequiência de passos que começa com a espacialização de um conjunto de itens de dados. Esta espacialização inicial passa então por codificação de forma e cor e pode ser seguida de outros ciclos de espacialização. No modelo ilustrado na figura 8.1, cada passo do design de visualização define um ponto de decisão (pontos pretos da figura) que irão iterativamente resultar numa visualização que se adapta às escolhas do projetista. Uma análise atenta revela que a Máquina de Visualização é um modelo que suporta a navegação do usuário projetista através do espaço definido pelo Espaço de Design Espacial-Perceptivo apresentado na seção 7.2.

Seguindo a organização abstrata da seção 5.4, o processo de design de visualizações é complementado pela adição do componente de pré-processamento. Desta maneira, antes da definição do método de espacialização, os dados são usualmente processados para permitir o mapeamento e o melhor gerenciamento de acordo com a espacialização pretendida. Esta etapa conta com o suporte de um sistema de armazenamento de dados e inclui metodologias para reduzir o número de itens de dados, seleção de atributos, redução da dimensionalidade, computação de agregação, redefinição espacial, classificação dos itens de dados, aplicação de operações de mineração de dados, dentre outras. Em muitos domínios, o pré-processamento de dados é essencial para que a visualização seja possível. 


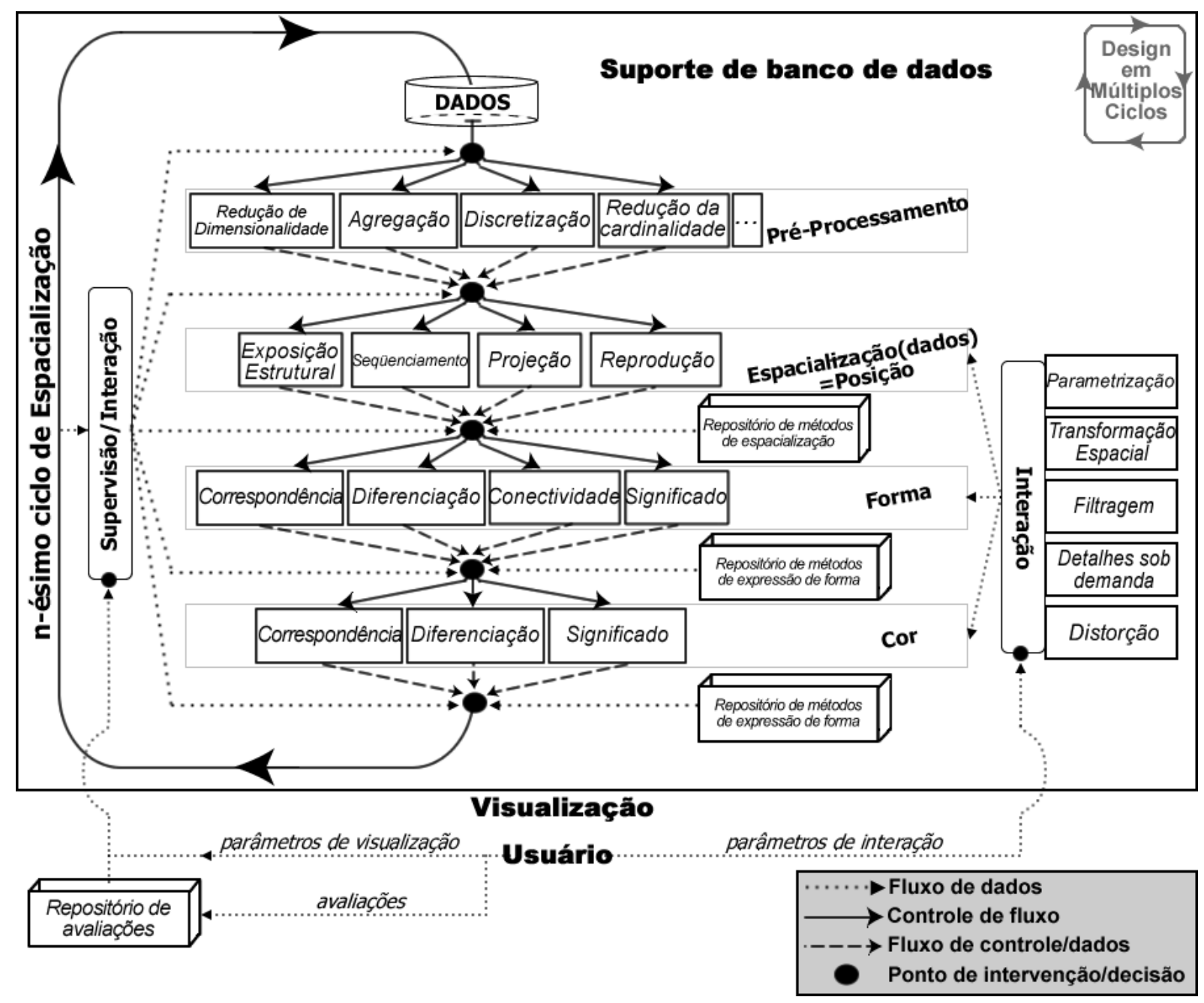

Figura 8.1: O modelo generalizado de design automatizado de visualizações, denominado Máquina de Visualização.

\section{Repositórios de Parâmetros}

Na sistematização proposta, os passos para se codificar espacialização, forma e cor são assistidos, respectivamente, por repositórios de métodos de espacialização, repositórios de métodos de expressão de forma e por repositórios de métodos de expressão de cor. Estes repositórios representam conjuntos de métodos conhecidos que podem ser utilizados na concepção de composições de visualização. Segundo a concepção da Máquina de Visualização, a intervenção do projetista deve permitir o uso dos repositórios com o intuito de se definir parâmetros para cada um dos passos, de pré-processamento à definição de cores, permitindo que o projetista escolha os procedimentos e os padrões que melhor satisfazem suas necessidades. Ao longo do texto foram revistos diversos exemplos de designs que definem algumas das técnicas mais conhecidas de visualização. Os constituintes destes designs exemplificam o repertório de elementos dos repositórios de parâmetros, como se propõe nesta tese. 


\section{Supervisão/Intervenção}

A escolha de parâmetros por meio de intervenção do projetista requer supervisão, tanto automática quanto do próprio usuário. A supervisão que se propõe é representada como um módulo de supervisão no lado esquerdo do esquema mostrado na figura 8.1. Prevê-se supervisão com o intuito de se validar e de se verificar os parâmetros escolhidos em cada passo do processo de design. O objetivo é determinar quais são as escolhas que podem ser aplicadas na etapa de design que está em curso e também na etapa que irá se seguir.

$\mathrm{Na}$ etapa de design em curso, a supervisão deve considerar a escolha do projetista com o objetivo de selecionar quais são os métodos do repositório os quais podem ser apropriadamente utilizados no design sendo definido. Na etapa de design que irá se seguir, a supevisão deve considerar o último parâmetro de design para filtar as opções do repositório as quais podem levar a designs ruins ou inadequados. Por exemplo, em vista do espaço limitado dos dispositivos de exibição convencionais, não é razoável escolher uma espacialização seqüêncial de um conjunto de dados com um milhão de itens e, na próxima etapa, escolher correspondência de forma.

Além dessa função de afunilamento de opções, o módulo de supervisão também é responsável por coletar dados a respeito dos ciclos de espacialização. Esta função é necessária para se manter o controle do espaço de projeção ainda disponível para ser utilizado por outros ciclos de espacialização e para se detectar e oferecer possibilidades de integração de múltiplos ciclos de espacialização. Tal integração é essencial para a concepção de técnicas mais complexas que se beneficiem de múltiplas espacializações. Por exemplo, a integração dos ciclos de espacialização pode definir espacializações coordenadas de maneira que diferentes áreas de projeção sigam a mesma ordenação; ou pode promover automações baseadas no inter-relacionamento de diferentes espacializações de maneira que os parâmetros de interação sejam propagados entre as espacializações.

\section{Interação}

A definição de interação introduzida na seção 7.3 estabelece que qualquer técnica de interação deve ser adaptável a qualquer técnica de visualização. Conseqüentemente, qualquer técnica de interação deve ser prontamente utilizável no modelo da Máquina de Visualização. Obviamente, a disponibilidade e adaptação de cada paradigma de interação refletirá os parâmetros específicos de posição, forma e cor que foram escolhidos para um design em particular. A eficiência da interação será definida pela integração dos components selecionados para o design.

\section{Avaliação}

O modelo de design automatizado da Máquina de Visualização assegura um alto grau de liberdade na combinação dos componentes das visualizações. Tais combinações podem ser eficientes ou totalmente inadequadas, dependendo dos objetivos do analista que utiliza o 
design. Por esta razão, o modelo também incopora um repositório de avaliações, representado ao lado inferior esquerdo do diagrama. Uma vez que o analista aplica uma configuração de visualização e é capaz de usá-la, ele pode avaliar a correspondente visualização de acordo com seus objetivos. Segundo o modelo que se propõe, cada avaliação pode ser armazenada no repositório de avaliações o qual deve integrar informações do conjunto de dados sendo analisado, das técnicas de interação sendo aplicadas e dos parâmetros que definem a visualização. Estas informações tornam-se disponíveis para o módulo de supervisão que deve utilizá-las para assistir ao projetista por meio da validação de suas escolhas, e para a definição automática de parâmetros na utilização subseqüente do sistema.

\section{Um Sistema Incremental}

A Máquina de Visualização é estruturada como um sistema que pode criar visualizações baseadas em conjuntos de parâmetros de design. Trata-se de um ambiente que disponibiliza e manipula aspectos da ciência de visualização. Segundo esta perspectiva, a pesquisa em visualização poderia ser encarada como uma disciplina que trabalha com a descoberta e a avaliação empírica de métodos de espacialização e de métodos de expressão de forma e de cor. Assumindo a utilização e a evolução da Máquina de Visualização, estes métodos seriam incrementalmente incorporados e estabelecidos no modelo de design automatizado, especificamente nos repositórios de métodos. Neste cenário, torna-se possível pensar em um ambiente de visualização que se desenvolve de maneira incremental. Em tal concepção os usuários analistas utilizariam parâmetros previamente concebidos por especialistas projetistas. Observa-se um contraste com o paradigma atual, segundo o qual as visualizações são limitadas a programas específicos que seguem designs rigidamente definidos. A característica de auto avaliação do modelo proposto faz com que ele seja um sistema de aprendizado, nos moldes de um sistema especialista, que se adapta a diferentes perfis de uso ou que converge em direção a uma ferramenta universal de visualização. Observa-se que, a despeito do fato de que a natureza ideal da Máquina de Visualização esconde inúmeras complexidades, sua completitude e coerência provêem um ponto inicial para o estabelecimento de tal sistema.

\subsection{Considerações Gerais}

A utilização de diretrizes de design na ciência de Análise Visual de Dados resulta num universo difuso de possibilidades, dificultando a prática do design. Diferentemente, este trabalho propõe um modelo que ao invés de se guiar por heurísticas derivadas de experiência, propõe um ambiente universal de possibilidades de design que se molda perante o fornecimento de um perfil exploratório já previamente validado. Isto é, ao invés de se fixar um design de sucesso numa 
ferramenta estática, as experiências de sucesso de uma ferramenta dinâmica são fixadas em perfis estáticos na forma de registros. Tais perfis podem então alimentar a Máquina de Visualização restabelecendo uma configuração de sucesso.

A Máquina de Visualização e suas implicações, resultados da teoria desenvolvida, são a contribuição conclusiva desta tese. De acordo com a abordagem descrita, acredita-se que o tratamento da ciência de análise visual de dados, segundo a organização de conceitos desenvolvida neste trabalho, pode prover uma nova linha de pesquisa e desenvolvimento na área. Esta nova linha orienta-se para o desenvolvimento de um ambiente flexível, um gerador de visualizações, ao invés de implementações rígidas sem versatilidade. Este ambiente deve ser capaz de registrar e restaurar configurações de sucesso que reflitam os tipos dos dados analisados e os objetivos dos analistas. No conjunto destas novas concepções, a pesquisa em técnicas de visualização passará a ser a busca por novas configurações (perfis) de design capazes de satisfazer às diversas necessidades de análise de diferentes domínios de aplicação. 


\section{Parte III}

\section{Outras Contribuições e Conclusão}





\section{Capítulo 9}

\section{Ampliação do Espaço de Visualização}

\subsection{Considerações Iniciais}

Uma importante compreensão a respeito do design de técnicas de visualização é que os limites de preenchimento de espaço, assim como utilizados na prática de análise visual de dados, podem ser ampliados por meio de técnicas específicas. Estas técnicas objetivam prover a sensação de espaço aumentado, permitindo uma maior quantidade de itens gráficos exibidos não simultaneamente. Para tanto, tais técnicas contam com mecanismos de interação que permitem alterar os parâmetros espaciais de uma dada visualização. Desta maneira, foco, manipulação espacial, alteração da resolução de projeção e imersão dimensional auxiliam na definição de mais opções para a exibição visual de dados. Dentre as técnicas mais utilizadas de ampliação do espaço, pode-se citar projeção tri-dimensional, multi-resolução e manipulação espacial sobre múltiplas exibições, além da distorção espacial já mencionada na seção 7.3.

A projeção tri-dimensional requer meios adequados para se navegar através dos diversos planos definidos ao longo da profundidade de projeção. Esta noção pode ser percebida comparando-se as clássicas Coordenadas Paralelas [Inselberg e Dimsdale, 1990] e as Coordenadas Paralelas combinadas com Star Glyphs [Fanea et al., 2005]. Nesta segunda obra as Coordenadas Paralelas são projetadas no espaço 3D e os eixos de projeção são substituídos por planos que se estendem para dentro do dispositivo de exibição. Estes planos são utilizados para espacialização seqüencial de forma semelhante ao que é realizado com a técnica Star Glyphs, acrescentando um componente extra de informação visual.

Uma outra técnica de ampliação do espaço, a multi-resolução, trabalha com o fator de resolução considerando o espaço como possuindo resolução alta (idealmente infinita) e variável. Nesta abordagem, uma pequena região de interesse do espaço bidimensional de projeção pode encerrar um espaço de projeção maior do que a própria região de interesse. Neste cenário não é possível a observação de ambas as regiões simultaneamente, sendo preciso meios de interação 
que permitam alternar entre uma região ou outra por meio de diferentes resoluções de exibição. $\mathrm{O}$ processo é semelhante à utilização de um microscópio para se analisar uma gota de água. $\mathrm{O}$ microscópio amplia a gota de água de maneira que o campo de visão dentro da gota se torne tão grande quanto o campo de visão convencional. Técnicas desta natureza são denominadas de técnicas multi-resolução, como apresentado por Rodrigues Jr. et al [Rodrigues Jr. et al., 2006a] no sistema GMine, detalhado na seção 9.2.

Outra maneira de se expandir o espaço de visualização é por meio de manipulação espacial sobre múltiplas exibições. Uma exibição neste contexto é entendida como um ambiente de trabalho individualizado, uma janela, que engloba um conjunto de técnicas de visualização e de interação. Ao se utilizar um sistema de visualização com múltiplas exibições, assumindose a possibilidade de se focar em uma exibição de interesse, pode-se multiplicar o número de representações visuais interativas disponíveis no ambiente de análise visual de dados. Este paradigma pode ser ainda mais bem aproveitado definindo-se elos entre as diferentes exibições. Como explorado por Rodrigues Jr. et al [Rodrigues Jr. et al., 2005] no sistema VisTree, esta possibilidade permite o intercâmbio de dados entre diferentes exibições, a alternância do foco de análise, a combinação de inferências visuais provindas de diferentes exibições, dentre outras possibilidades, como detalhado na seção 9.3.

\subsection{Multi-resolução no Sistema GMine}

Aplicações recentes têm produzido dados representados como grafos na ordem de centenas de milhares de vértices e milhões de arestas. Para que tais grafos possam oferecer vantagens, o analista precisa ser capaz de encontrar padrões, exceções e comunidades, preferencialmente em um ambiente visual e interativo, no qual a percepção do analista pode guiá-lo para a descoberta de conhecimento. No entanto, a visualização interativa de grandes grafos apresenta dois desafios: os altos requisitos de poder de processamento impedem a interatividade, e o excessivo número de itens gráficos sobrecarregam o usuário durante a análise visual.

Em trabalhos prévios, o problema de se visualizar grandes grafos é tratado por meio de hierarquias de partições do grafo. Esta metodologia determina que um grafo seja recursivamente particionado de modo a definir uma hierarquia de partições (subgrupos de vértices relacionados). No entanto, trabalhos anteriores falham na tarefa de integrar os grupos que constituem os níveis da hierarquia. Nestes trabalhos, a hierarquia de grafo está "morta" e não pode responder a questões como Qual a relação entre um dado grupo de vértices e outro grupo de vértices? Quantas arestas conectam estes dois grupos? Quais são elas? Quais os vértices pertencentes a outros grupos de vértices que se conectam a um vértice de interesse? Estas questões se traduzem na possibilidade de se usar a informação original do grafo concomitantemente com sua versão hierárquica, beneficiando-se de ambas as estruturas em cooperação. 
Para se tratar desta problemática propôs-se o sistema GMine [Rodrigues Jr. et al., 2006a], [Rodrigues Jr. et al., 2006b] e [Rodrigues Jr. et al., 2007a], uma proposta formal para o uso de hierarquias de partições de grafos. O sistema GMine implementa um esquema baseado na representação de partições de grafos (SuperGrafos) em um ambiente bastante interativo. A contribuição da proposta inclui escalabilidade por meio de uma representação visual em multi-resolução, além de funcionalidades inovadoras para hierarquias de partições de um grafo promovidas por uma estrutura de dados original.

O sistema GMine é capaz de particionar recursivamente e de maneira automática um conjunto de dados representado como um grafo. As partições definidas, organizadas em uma hierarquia, podem então ser visualizadas em múltiplas resoluções, sendo que cada nível da hierarquia corresponde a uma resolução diferente. Funcionalidades interativas são integradas ao sistema proporcionando detalhes sob demanda, transformação espacial e parametrização das propriedades de exibição do grafo.

\subsubsection{Terminologia}

O sistema GMine utiliza uma hierarquia de partições de um grafo denominada aqui de SuperGrafo. A informação subjacente de um SuperGrafo é um grafo $G=\{V, E\}$, com $|V|$ vértices e $|E|$ arestas. No entanto, se comparado com um grafo, um SuperGrafo apresenta uma estrutura abstrata diferente, pois SuperGrafos se beneficiam do fato de que as entidades do grafo $G$ podem ser agrupadas de acordo com os relacionamentos que elas definem. Em um SuperGrafo, cada grupo de vértices definido é considerado um subgrafo. Tal conceituação permite trabalhar com um grafo como um conjunto de partições definidas hierarquicamente. A seguir definem-se os constituintes de um SuperGrafo junto com um exemplo ilustrativo apresentado na figura 9.1 .

Definição 9.2.1 [SuperGrafo] - Dado um grafo finito não direcionado $G=\{V, E\}$, sem laços nem arestas múltiplas, um SuperGrafo é um conjunto $\bar{G}=\left\{\bar{V}, \overline{V_{l}}, \bar{E}\right\}$. Mais especificamente, um SuperGrafo é composto de um conjunto $\bar{V}$ de SuperVértices $\bar{v}$, um conjunto $\overline{V_{l}}$ de SuperVérticesFolha $\overline{v_{l}}$ e de um conjunto $\bar{E}$ de SuperArestas $\bar{e}$.

A seguir são definidos os conceitos de SuperVérticeFolha, SuperVértice e SuperAresta.

Definição 9.2.2 [SuperVérticesFolha] - Dado um subconjunto $V^{\prime} \subset V$, um SuperVérticeFolha $\overline{v_{l}}$ será o subgrafo $G \mid V^{\prime}$ induzido por $V^{\prime}$. Isto é, $G \mid V^{\prime}=\overline{v_{l}}=G^{\prime}=\left\{V^{\prime}, E^{\prime}\right\}, E^{\prime} \subset E$. 


\begin{tabular}{|c|c|c|}
\hline Grafo $G$ & $\begin{array}{l}G=\{ \\
\quad V=\{1,2 \\
\quad E=\{(1, \\
(2,4),(5,\end{array}$ & $\begin{array}{l}3,4,5,6,7,8\} \\
(3,4),(5,6),(7,8),(2,3) \\
(6,8),(1,5),(1,7),(4,7)\}\end{array}$ \\
\hline 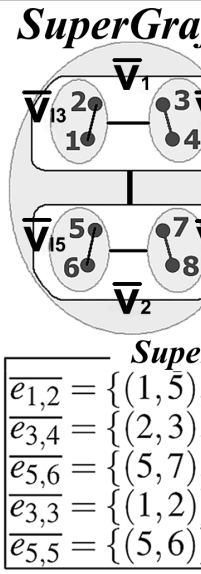 & 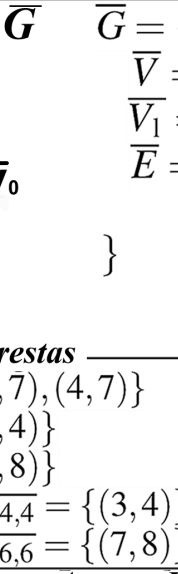 & $\begin{aligned} &=\left\{\overline{v_{0}}, \overline{v_{1}}, \overline{v_{2}},\right\}, \\
&=\left\{\overline{v_{13}}, \overline{v_{14}}, \overline{v_{15}}, \overline{v_{16}}\right\}, \\
&=\left\{\overline{e_{1,2}}, \overline{e_{3,4}}, \overline{e_{5,6}}, \overline{e_{3,3}},\right. \\
&\left.\overline{e_{4,4}}, \overline{e_{5,5}}, \overline{e_{6,6}},\right\} \\
& \text { Super Vértices } \\
& \overline{\overline{v_{0}}}=\left\{\left\{\overline{v_{1}}, \overline{v_{2}}\right\},\left\{\overline{e_{1,2}}\right\}\right\} \\
& \overline{v_{1}}=\left\{\left\{\overline{v_{3}}, \overline{v_{4}}\right\},\left\{\overline{e_{3,4}}\right\}\right\} \\
& \overline{v_{2}}=\left\{\left\{\overline{v_{5}}, \overline{v_{6}}\right\},\left\{\overline{e_{5,6}}\right\}\right\} \\
& \overline{\overline{v_{l 3}}}=\left\{\{1,2\},\left\{\overline{\bar{e}_{3,3}}\right\}\right\} \\
& \overline{v_{l 4}}=\left\{\{3,4\},\left\{\overline{e_{4,4}}\right\}\right\} \\
& \overline{v_{l 5}}=\left\{\{5,6\},\left\{\overline{e_{5,5}}\right\}\right\} \\
& \overline{v_{l 6}}=\left\{\{7,8\},\left\{\overline{e_{6,6}}\right\}\right\}\end{aligned}$ \\
\hline $\begin{array}{l}\text { Arestas Internas } \\
\text { Arestas Internas } \\
\text { Arestas Internas } \\
\text { Arestas Internas } \\
\text { Arestas Internas }\end{array}$ & $\begin{aligned} & \text { Arestas I } \\
= & \{(1,2)\} A \\
= & \{(3,4)\} A \\
= & \{(1,2),(3, \\
= & \{(5,6),(7, \\
= & \{\text { Arestas Int } \\
& (1,5),(1,\end{aligned}$ & $\begin{array}{l}\text { nternas } \\
\text { estas Internas }\left(\overline{v_{l 5}}\right)=\{(5,6)\} \\
\text { restas Internas }\left(\overline{v_{l 6}}\right)=\{(7,8)\} \\
4),(2,3),(2,4)\} \\
8),(5,7),(6,8)\} \\
\text { ernas }\left(\overline{v_{1}}\right), \text { Arestas Internas }\left(\overline{v_{2}}\right) \\
7),(4,7)\}=E\end{array}$ \\
\hline $\begin{array}{l}\text { Arestas Externa } \\
\text { Arestas Externa } \\
\text { Arestas Externa } \\
\text { Arestas Externa } \\
\text { Arestas Externa } \\
\text { Arestas Externa } \\
\text { Arestas Externa }\end{array}$ & $\begin{array}{l}\overline{\text { Arestas }} \\
\overline{3})=\{(2,3),( \\
\overline{4})=\{(3,2),( \\
\overline{5})=\{(6,8),( \\
\overline{6})=\{(8,6),( \\
)=\{(1,5),(1 \\
=\{((5,1),( \\
=\{\}\end{array}$ & $\begin{array}{l}\text { Externas },(1,5)\} \\
, 4),(1,7),(1,5),(4,7)\} \\
\{, 7),(5,1)\} \\
, 5),(7,1),(7,4)\} \\
, 7),(4,7)\} \\
7,1),(7,4)\}\end{array}$ \\
\hline $\begin{array}{l}\text { Vértices Abertos }\left(\overline{v_{l}}\right) \\
\text { Vértices Abertos }\left(\overline{v_{l}}\right) \\
\text { Vértices Abertos }\left(\overline{v_{l}}\right. \\
\text { Vértices Abertos }\left(\overline{v_{l}}\right.\end{array}$ & $\begin{aligned} & \text { Vértices } \\
= & \{1,2\} \text { Vértices } \\
= & \{3,4\} \text { Vértices } \\
= & \{5,6\} \text { Vértices } \\
= & \{7,8\}\end{aligned}$ & $\begin{array}{l}\operatorname{1bertos} \\
\operatorname{Abertas}\left(\overline{v_{1}}\right)=\{1,4\} \\
\operatorname{Abertas}\left(\overline{v_{2}}\right)=\{5,7\} \\
\text { Abertas }\left(\overline{v_{0}}\right)=\{\}\end{array}$ \\
\hline
\end{tabular}

Figura 9.1: Exemplo de um grafo e sua respectiva representação hierárquica em SuperGrafo.

O conjunto de SuperVérticesFolha é totalmente disjunto:

$$
\bigcap V_{i}^{\prime}=\emptyset, \text { para } V_{i}^{\prime} \in \overline{v_{l i}}=\left\{V_{i}^{\prime}, E_{i}^{\prime}\right\} e \overline{v_{l i}} \in \overline{V_{l}}
$$

A união dos vértices de todos os SuperVérticesFolha é igual ao conjunto de vértices $V$. Este fato é ilustrado na lista de SuperVértices da figura 9.1 e definido como:

$$
\bigcup V_{i}^{\prime}=V, \text { para } V_{i}^{\prime} \in \overline{v_{l i}}=\left\{V_{i}^{\prime}, E_{i}^{\prime}\right\} e \overline{v_{l i}} \in \overline{V_{l}}
$$

Definição 9.2.3 [SuperVértice] - Um SuperVértice v é composto por um conjunto de SuperArestas $\bar{e}$ e, recursivamente, por um conjunto de SuperVértices $\bar{v}$. Como se segue:

$$
\bar{v}=\left\{\overline{V^{\prime}}=\left\{\overline{v_{0}}, \overline{v_{1}}, \ldots, \overline{v_{\left(\left|\overline{v^{\prime}}\right|-1\right)}}\right\}, \overline{E^{\prime}}=\left\{\overline{e_{i j}} \mid\left\{\overline{v_{i}}, \overline{v_{j}}\right\} \subset \overline{V^{\prime}}\right\}\right\}
$$


Onde $\overline{v_{i}}$ pode ser tanto um SuperVértice como um SuperVérticeFolha. O conceito de SuperAresta, $\bar{e}$, é definido mais adiante nesta seção.

Definição 9.2.4 [Fechamento de um SuperVértice] - Em um SuperGrafo, o fechamento de um SuperVértice, ou SuperVérticeFolha, v equivale ao conjunto de todos os vértices $v \in V$ que, em última instância, pertencem ao SuperVértice $\bar{v}$.

Ou seja, dado um SuperVértice $\bar{v}=\left\{\overline{V^{\prime}}, \overline{E^{\prime}}\right\}$, o fechamento $\bar{v}$ é dado pela definição recursiva:

$$
\text { Fechamento }(\bar{v})=\left\{\begin{array}{l}
V^{\prime}, \text { caso } \bar{v}=\left\{V^{\prime}, E^{\prime}\right\} \text { seja um SuperVerticeFolha } \\
\bigcup \text { Fechamento }\left(\overline{v_{i}}\right), \text { para } \overline{v_{i}} \in \bar{v}, \text { para todos os outros casos }
\end{array}\right.
$$

Por exemplo, na figura 9.1, tem-se Fechamento $\left(\overline{v_{2}}\right)=\operatorname{Fechamento}\left(\overline{v_{l 5}}\right) \cup$ Fechamento $\left(\overline{v_{l 6}}\right)=\{5,6\} \cup\{7,8\}=\{5,6,7,8\} . \quad$ Ainda no grafo da figura 9.1, Fechamento $\left(\overline{v_{0}}\right)=V$. Esta última igualdade vale para qualquer SuperGrafo. O fechamento de um SuperVértice corresponde aos vértices que compreendem sua comunidade. Dessa forma, no nível mais baixo da árvore (em suas folhas) uma comunidade é considerada um subgrafo. No nível mais alto da árvore (na raíz) a comunidade é o grafo inteiro. Intuitivamente, refere-se ao pai de um SuperVértice $\bar{w}$ como $\operatorname{pai}(\bar{w})=\bar{v}$ se $\bar{w} \in \overline{V^{\prime}}, \overline{V^{\prime}} \in \overline{v^{\prime}}=\left\{\overline{V^{\prime}}, \overline{E^{\prime}}\right\}$. Da mesma forma, refere-se ao conjunto de todos os ancestrais de um SuperVértice $\bar{w}$ como sendo o conjunto pais $(\bar{w})=\{\bar{v} \mid \bar{w} \in$ Fechamento $(\bar{v}) e \bar{v} \in \bar{V}\}$.

Definição 9.2.5 $[$ SuperAresta $]$ - Uma SuperAresta $\overline{e_{i j}}$ corresponde à SuperAresta para os SuperVértices $\overline{v_{i}} e \overline{v_{j}}$. Esta SuperAresta contém as arestas $e \in E$ que conectam os vértices do SuperVértice $\overline{v_{i}}$ aos vértices do SuperVértice $\overline{v_{j}}$. Uma SuperAresta $\overline{e_{k k}}$ corresponde à SuperAresta para o SuperVérticeFolha $v_{l k}$. Esta SuperAresta contém as arestas que interconectam os vértices do SuperVérticeFolha $v_{l k}$ e corresponde a $E_{k}^{\prime}$. Isto é, $\overline{e_{k k}}=E_{k}^{\prime}$ para $\overline{v_{l k}}=\left\{V_{k}^{\prime}, E_{k}^{\prime}\right\}$.

Ainda, para uma SuperAresta $\bar{e}, \operatorname{peso}(\bar{e})=|\bar{e}|$; para uma aresta $e=\left\{v_{p}, v_{q}\right\}$, $\operatorname{origem}(e)=v_{p}$ e destino $(e)=v_{q}$ (embora estejamos assumindo grafos não direcionados). Formalmente, uma SuperAresta é definida como:

$$
\begin{gathered}
\qquad \overline{e_{i j}}=\{e \mid e \in E \\
\left.\operatorname{origem}(e) \in \text { Fechamento }\left(v_{i}\right) \text { e destino }(e) \in \operatorname{Fechamento}\left(v_{j}\right)\right\}
\end{gathered}
$$

A união das SuperArestas de todos os SuperVértices junto com a união das SuperArestas de todos os SuperVérticesFolha equivale ao conjunto de arestas $E$, como segue: 


$$
\begin{gathered}
\left(\left(\bigcup \overline{e_{i j}}\right) \cup\left(\bigcup \overline{e_{k k}}\right)\right)=E, \\
\text { para }\left\{\overline{v_{i}}, \overline{v_{j}}\right\} \subset \bar{V} e \overline{v_{l k}} \in \overline{V_{l}}
\end{gathered}
$$

\section{Uma estrutura de grafos em multi-resolução}

Na figura 9.2(a) é apresentada a matriz de adjacências para o grafo mostrado na figura 9.1. De acordo com o conceito de SuperGrafo, a matriz de adjacências é a mais alta resolução para a representação de um grafo. Ela contém e suporta toda a informação do grafo. Na figura 9.2(b) é apresentada a camada de SuperVérticesFolha para este mesmo grafo. Os SuperVérticesFolha definem o primeiro nível de agregação para o grafo e resulta em uma representação com menor granularidade. Neste exemplo, cada SuperVérticeFolha abstrai dois vértices do grafo. Na figura 9.2(c) é apresentado o segundo nível de agregação do grafo (primeira camada de SuperVértices). Neste ponto, cada SuperVértice abstrai quatro vértices do grafo. A resolução da representação do grafo permite a sumarização das informações a partir de uma perspectiva geral ou detalhada. $\mathrm{Na}$ figura, os números representam o total de arestas conectando os vértices dos fechamentos dos respectivos SuperVértices.

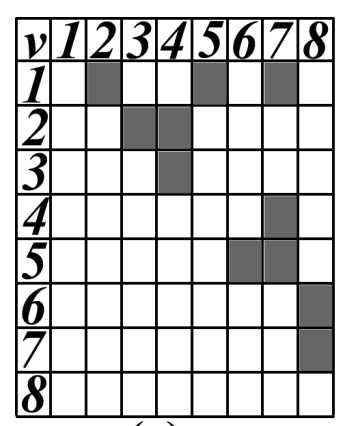

(a)

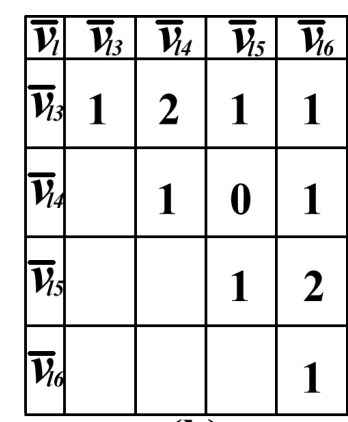

(b)

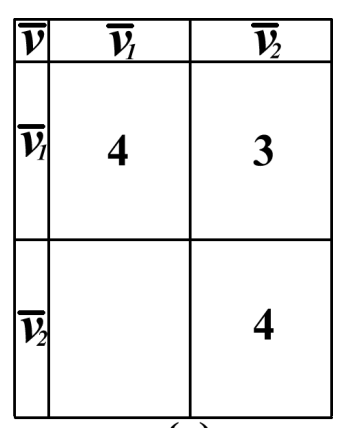

(c)

Figura 9.2: Matrizes de adjacências em multi-resolução. (a) Matriz de adjacências. (b) Primeiro nível de agregação de vértices e arestas. (c) Segundo nível de agregação de vértices e arestas.

O conceito de SuperGrafo permite a representação hierárquica das partições de um grafo. Seu princípio é a utilização de uma organização comunidades-dentro-de-comunidades, a qual permite determinar as relações entre os grupos (comunidades) de vértices. Baseando-se na estrutura de SuperGrafo, um grande grafo pode ser utilizado e visualizado a partir de diferentes resoluções permitindo análise e computação compartimentadas. Estas características permitem o desenvolvimento de uma estrutura de dados original denominada Graph-Tree, a qual é a base para a ferramenta de visualização denominada GMine. 


\subsubsection{Estendendo o conceito de SuperGrafo}

O conceito de SuperGrafo é uma representação sucinta para uma hierarquia de partições de um grafo. No entanto, hierarquias de partições de grafos não carregam a estrutura original do grafo, a qual é inevitavelmente perdida quando a representação hierárquica é usada. Nesta seção serão definidos conceitos mais avançados para que se possa estender as possibilidades de utilização de um SuperGrafo.

Definição 9.2.6 [Aresta Interna] - Dado um SuperVértice, ou SuperVérticeFolha, $\bar{v}$, uma aresta e é denominada uma aresta interna de $\bar{v} \operatorname{se} \operatorname{origem}(e) \in \operatorname{Fechamento}(\bar{v})$ e destino $(e) \in$ Fechamento $(\bar{v})$. Nesta situação, diz-se que "a aresta e pode ser resolvida dentro do fechamento de $\bar{v}$ ". Defini-se o conjunto de todas as arestas internas de um SuperVértice $\bar{v}$ como $\operatorname{ArestasInternas}(\bar{v})$.

Definição 9.2.7 [Aresta Externa] - Uma aresta e é denominada aresta externa de $\bar{v}$ se $\operatorname{origem}(e) \in$ Fechamento $(\bar{v})$ e destino $(e) \notin$ Fechamento $(\bar{v})$. Assim, diz-se que "a aresta e não pode ser resolvida dentro do fechamento de $\bar{v}$. Defini-se o conjunto de todas as arestas externas de um SuperVértice $\bar{v}$ como ArestasExternas $(\bar{v})$.

Definição 9.2.8 [Vértice Aberto] - Um vértice v, v $\in$ Fechamento $(\bar{v})$, é um vértice aberto de $\bar{v}$ se existe uma aresta externa e, $e \in \operatorname{ArestasExternas}(\bar{v})$, tal que origem $(e)=v$. Defini-se o conjunto de todos os vértices abertos de um SuperVértice $\bar{v}$ como VerticesAbertos $(\bar{v})$.

Nas próximas subseções é explicado como utilizar estas definições para se ampliar as informações que um SuperGrafo pode prover.

\subsubsection{Conectividade entre SuperVértices}

A informação que define as conexões (arestas) entre grupos de vértices de uma hierarquia de grafo é denominada conectividade. Ou seja, a conectividade entre um par de SuperVértices corresponde às arestas do grafo que conectam os SuperVértices em questão. Formalmente, a conectividade corresponde à equação 9.5. De acordo com a formalização de SuperGrafo, a conectividade para comunidades (grupos de vértices) irmãs já está disponibilizada como parte do SuperGrafo, em suas SuperArestas. Para comunidades que não são irmãs, ou que estão em diferentes níveis da hierarquia, a conectividade precisa ser calculada.

O desafio aqui está em como calcular a conectividade entre SuperVértices arbitrários sem ter que cruzar os dados da hierarquia de partições com os dados do grafo subjacente (não mais disponível). Ao contrário, procura-se por uma maneira mais escalonável e eficiente (viável) para 
grandes grafos. Para realizar esta tarefa, propõe-se utilizar a informação acima denominada de vértices abertos.

Os vértices abertos especificam todos os vértices de um SuperVértice que se conectam a vértices de outros SuperVértices.

Proposição 1: dado qualquer par de SuperVértices $\overline{v_{i}}$ e $\overline{v_{j}}$, o conjunto de todos as possíveis arestas conectando $\overline{v_{i}}$ a $\overline{v_{j}}$ é dado pelo Produto Cartesiando $\operatorname{VerticesAbertos}\left(\overline{v_{i}}\right) X$ VerticesAbertos $\left(\overline{v_{j}}\right)$.

Das equações 9.3 e 9.5 segue que dado um SuperVértice $\overline{v_{f}}=\left\{\overline{V^{\prime}}, \overline{E^{\prime}}\right\}$, para um par qualquer de SuperVértices irmãos $\left\{\overline{v_{g}}, \overline{v_{h}}\right\},\left\{\overline{v_{g}}, \overline{v_{h}}\right\} \subset \overline{V^{\prime}}$, o SuperVértice $\overline{v_{f}}$ é o único SuperVértice que contém as arestas que conectam qualquer par de SuperVértices $\left\{\overline{v_{i}}, \overline{v_{j}}\right\},\left\{\overline{v_{i}}, \overline{v_{j}}\right\} \subset\left\{\right.$ Fechamento $\left(\overline{v_{g}}\right) x$ Fechamento $\left.\left(\overline{v_{h}}\right)\right\}$.

Proposição 2: o conjunto de arestas que, de fato, conecta um par qualquer de SuperVértices $\overline{v_{i}}$ e $\overline{v_{j}}$ é um subconjunto da única SuperAresta $\overline{e_{g h}}$, a qual satisfaz $\overline{v_{i}} \in \operatorname{Fechamento}\left(\overline{v_{g}}\right) \mathrm{e}$ $\overline{v_{j}} \in$ Fechamento $\left(\overline{v_{h}}\right) \mid\left\{\overline{v_{g}}, \overline{v_{h}}\right\} \subset \overline{v_{f}}$. Intuitivamente, $\overline{v_{f}}$ é o primeiro ancestral comum entre $\overline{v_{i}}$ $\mathrm{e} \overline{v_{j}}$.

Para se determinar o conjunto de arestas que conectam um par qualquer de SuperVértices $\overline{v_{i}}$ e $\overline{v_{j}}$, tem-se que computar a intersecção entre o conjunto de todos as possíveis arestas entre $\overline{v_{i}} \mathrm{e}$ $\overline{v_{j}}$ (proposição 1) e o conjunto que contém, de fato (mas não somente), as arestas entre $\overline{v_{i}}$ e $\overline{v_{j}}$ (proposição 2). Ou seja:

$$
\text { Conectividade }\left(\overline{v_{i}}, \overline{v_{j}}\right)=\left\{\begin{array}{c}
\left\{\text { VerticesAbertos }\left(\overline{v_{i}}\right) X\right. \\
\text { VerticesAbertos } \left.\left(\overline{v_{j}}\right)\right\} \\
\cap \\
\left\{\overline{e_{g h}} \mid \overline{v_{i}} \in \operatorname{Fechamento}\left(\overline{v_{g}}\right),\right. \\
\left.\overline{v_{j}} \in \operatorname{Fechamento}\left(\overline{v_{h}}\right)\right\}
\end{array}\right\}
$$

A conectividade de SuperVértices expressa a relação entre um par de SuperVértices de maneira que é possível determinar o número e quais são, exatamente, os vértices que determinam a conectividade. Esta possibilidade estende a análise para partições de grafos pois, mesmo que estejam em diferentes níveis hierárquicos, os SuperVértices podem ser inspecionados como entidades isoladas ou como grupos de entidades que descendem do grafo subjacente. 


\subsubsection{Conectividade entre vértices}

Uma hierarquia de grafo utiliza os relacionamentos entre os vértices para definir grupos de vértices relacionados. Mas os relacionamentos entre vértices do grafo original que pertencem a diferentes grupos de vértices da hierarquia não fazem parte da informação contida em um SuperGrafo. Isto é, o grafo original é perdido pois a informação de arestas externas não é mantida, apenas a informação dos vértices externos.

Em um SuperGrafo, com a ajuda da informação de vértices abertos, é possível determinar o conjunto completo de arestas externas relativas a um vértice qualquer de interesse.

Da equação 9.5 e da definição 3, segue que dado um vértice $v$, para qualquer SuperVértice $\bar{v} \mid v \in \operatorname{VerticesAbertos}(\bar{v})$, existe um ou mais vértices $e=\{v, w\} \mid e \in \bar{e}, e \bar{e} \in \operatorname{pais}(\bar{v})$.

Proposição 3: se um vértice $v$ é um vértice aberto de um SuperVértice $\bar{v}$, então o conjunto de ancestrais pais $(\bar{v})$ possui todas as SuperArestas que contêm as arestas que se conectam a $v$.

Assim, conhecendo-se os ancestrais e o conjunto de vértices abertos de um SuperVértice, pode-se determinar as arestas externas de qualquer vértice $v \in \operatorname{VerticesAbertos}(\bar{v})$. Para tanto, a referência ao primeiro SuperVértice ancestral (o pai) é suficiente para se definir um procedimento recursivo que pode identificar as arestas externas para qualquer vértice de interesse. Portanto, enquanto o vértice de interesse estiver no conjunto VerticesAbertos do SuperVértice sendo inspecionado por um algoritmo de varredura, ainda existem arestas externas para serem verificadas. É necessário apenas proceder acima na hierarquia.

A conectividade de um vértice restabelece a informação que define o grafo original. Desta maneira, em uma visualização com um milhão de arestas, o analista é guiado através da hierarquia de partições e pode inspecionar um vértice em particular, ao invés de ser sobrepujado por uma imensidão de entidades gráficas apresentadas simultaneamente.

\subsubsection{A Estrutura Graph-Tree}

A abstração de SuperGrafo e a informação de vértices abertos podem ser utilizadas para se definir uma nova estrutura de dados para grafos. Tal estrutura, denominada Graph-Tree provê uma representação computacional adequada para a realização das operações definidas nas seções 9.2.3 e 9.2.4. Nesta seção, a estrutura Graph-Tree será apresentada explicando-se como se dá sua construção ao mesmo tempo em que se reune a informação necessária do grafo subjacente.

A estrutura Graph-Tree foi projetada para representar um SuperGrafo com funcionalidades estendidas. Esta representação pode ser considerada uma nova estrutura de dados para grafos. Diferente de estruturas de dados clássicas para grafos, como listas e matrizes de adjacências, a Graph-Tree gerencia um grafo como sendo uma hierarquia de partições. Esta característica 


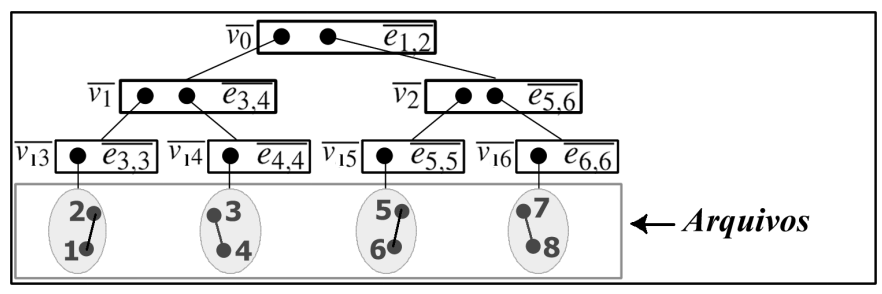

Figura 9.3: Exemplo de Graph-Tree.

é explorada para o processamento e a visualização de grandes grafos. A figura 9.3 mostra a Graph-Tree correspondente ao exemplo da figura 9.1. A estrutura é composta de SuperVértices que são conjuntos de SuperVértices, e de SuperVérticesFolha que são conjuntos de vértices. Os SuperVérticesFolha guardam referências para arquivos que armazenam as informações dos subgrafos, um arquivo para cada SuperVérticeFolha. Estes subgrafos são carregados para a memória apenas quando necessário, seguindo as ações do usuário, possibilitando apresentação e processamento compartmentados.

Ainda na figura 9.3, é possível observar como a árvore se ajusta aos SuperVértices refletindo o arranjo hierárquico. Por exemplo, o SuperVértice $\overline{v_{2}}=\left\{\overline{v_{l 5}}, \overline{v_{l 6}}\right\}$ se torna pai dos SuperVértices $\overline{v_{l 5}}$ e $\overline{v_{l 6}}$. As SuperArestas são armazenadas no pai dos SuperVértices que contém referencias para os respectivos SuperVértices. Neste caso, o SuperVértice $\overline{v_{2}}$ possui referências para os SuperVérticeFolhas $\overline{v_{l 5}}$ e $\overline{v_{l 6}}$, consequentemente, ele armazena a SuperAresta $\overline{e_{5,6}}$. Na parte inferior da árvore ficam os subgrafos e seus respectivos vértices e arestas.

\section{Componentes da estrutura}

Para armazenar um SuperGrafo, a Graph-Tree utiliza sub estruturas para representar os conceitos apresentados na seção 9.2.1: vértice aberto (openNode), aresta (edge), SuperAresta ( $s E d g e$ ), SuperVérticeFolha (lNode) e SuperVértice (sNode). A primeira destas sub estruturas, openNode é apenas uma aliás para um vértice, ela refere-se a um vértice pertencente um dado SuperVértice. A estrutura edge é utilizada para abstrair uma relação (aresta) entre dois vértices. A estrutura $s E d g e$ é usada para abstrair um conjunto de arestas entre dois SuperVértices. A estrutura $l$ Node representa um SuperVérticeFolha e a estrutura $s$ Node representa um SuperVértice. A figura 9.4 detalha e exemplifica cada uma destas estruturas.

\subsubsection{Construindo uma Graph-Tree a partir de um grafo}

Nesta seção será descrito como construir uma Graph-Tree a partir de um grafo previamente particionado, com cada uma de suas partições armazenadas em um arquivo separado. Serão ilustrados todos os passos para explicar o processo e para elucidar a estrutura, seu arranjo e a informação que ela gerencia. 


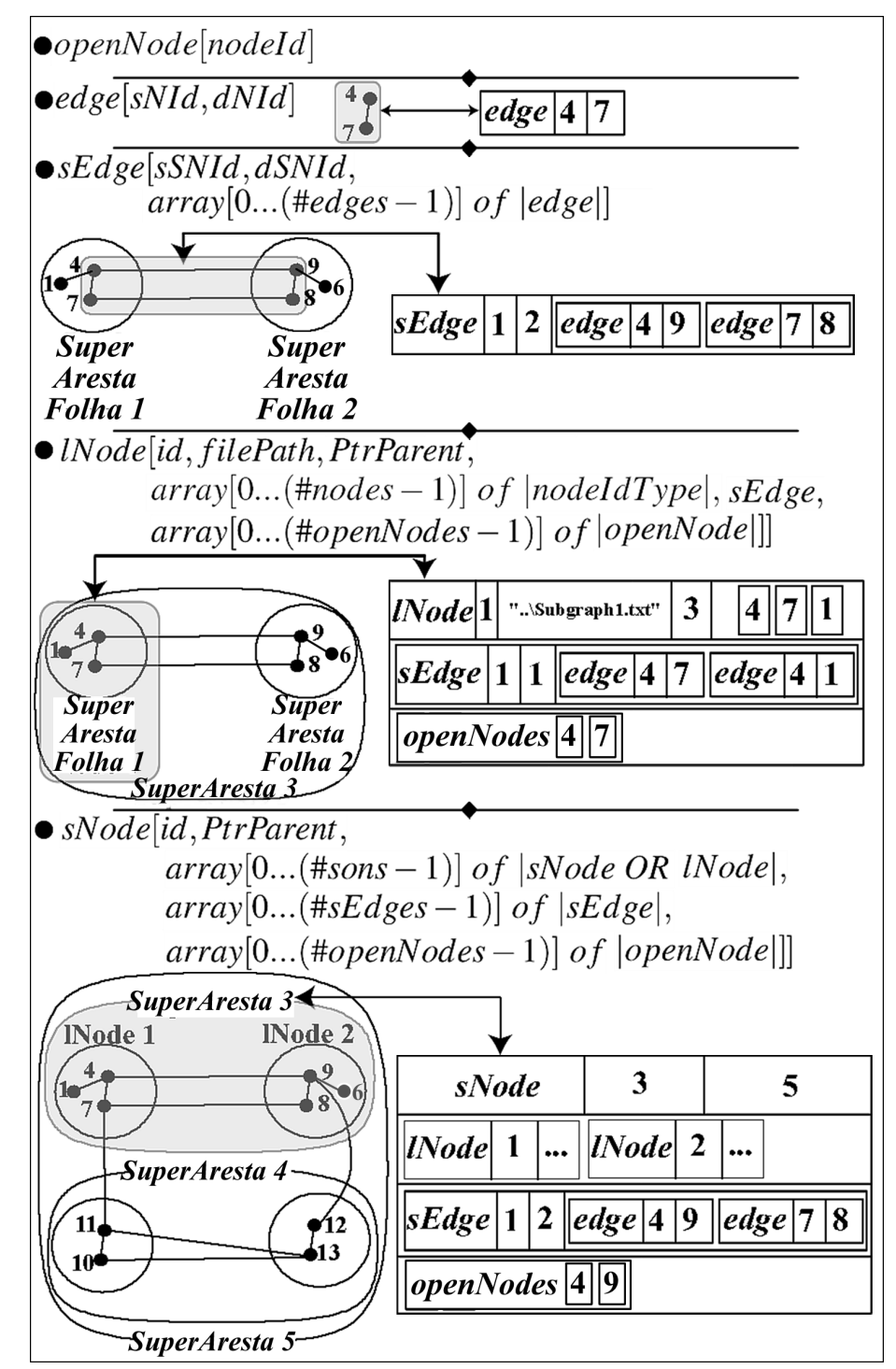

Figura 9.4: Componentes da Graph-Tree.

\section{Construção da hierarquia}

Dado um grafo $\mathrm{G}=\{\mathrm{V}, \mathrm{E}\}$, aplica-se o particionamento recursivo $k$-way [Karypis e Kumar, 1995]. Realiza-se uma seqüência de particionamentos recursivamente para se alcançar uma hierarquia de partições. Como ilustrado na figura 9.5, a cada recursão, cada partição é submetida ao particionamento $k$-way que irá criar outro conjunto de $k$ partições. Estas partições são propagadas para o nível acima da árvore e o processo se repete até que se tenha o número de níveis hierárquicos pré-definido pelo analista, $h$. Para cada novo conjunto de partições, uma nova sub árvore é embutida na estrutura da Graph-Tree e as referências para os vértices do grafo são mantidas na parte inferior da árvore. 


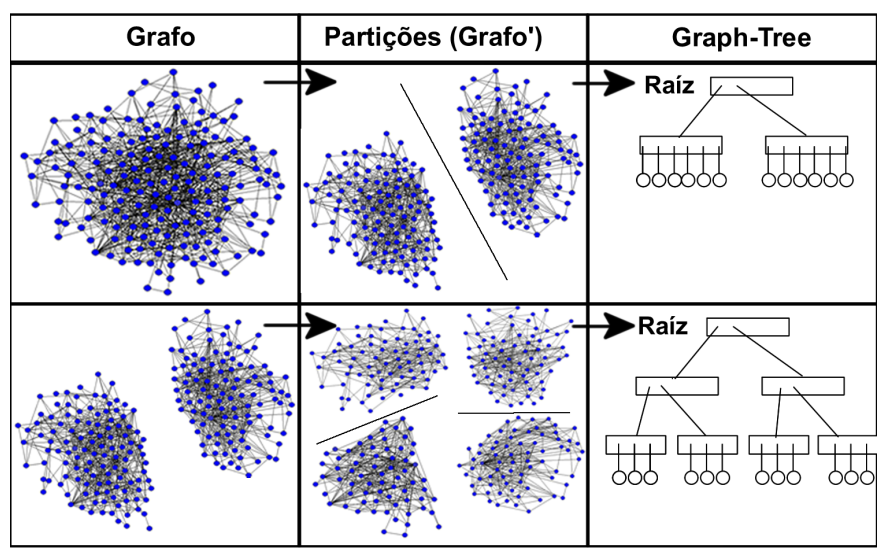

Figura 9.5: Particionamento recursivo. A informação é embutida na estrutura Graph-Tree que irá guiar o desenho e a interação com o SuperGrafo.

\section{Preenchendo a Graph-Tree}

Após a construção da árvore baseando-se no particionamento recursivo, é necessário preencher os SuperVértices da árvore com as informações das SuperArestas e dos vértices abertos. No algoritmo 1 é utilizada a estrutura recursiva da Graph-Tree para se varrer os níveis da árvore de baixo para cima. Inicialmente os SuperVérticesFolha são preenchidos com informações produzidas pelo procedimento de particionamento. Em seguida, prossegue-se para os níveis acima onde os SuperVértices usam as informações das arestas externas propagadas a partir do nv́eis mais abaixo na árvore.

A figura 9.6 ilustra o processo que inicia-se com o grafo $G$, o qual é particionado para se criar a Graph-Tree com SuperVértices vazios (figuras 9.6(a), 9.6(b) and 9.6(c)). O processo recursivo de baixo para cima inicia-se nas folhas, como ilustrado na figura 9.6(d). Nesta ilustração, e na figura 9.6(e), cruzamentos entre arestas externas são indicados em negrito enquanto que arestas externas cinzas indicam arestas externas não resolvidas. Vértices sublinhados indicam vértices abertos e a flechas diagonais indicam arestas externas propagadas acima na árvore. Ainda na figura 9.6(d), é possível ver a informação propagada dos vértices $\overline{v_{l 3}}$ e $\overline{v_{l 4}}$, a qual será usada no passo 11 do algoritmo 1 para encontrar cruzamentos entre arestas externas não resolvidas. A figura 9.6(e) ilustra o resultado do cruzamento da informação propagada dos níveis abaixo na árvore, o que determinou os cruzamentos $(2,3)-(3,2)$ e $(2,4)-(4,2)$ armazenados na SuperAresta $\overline{e_{3,4}}$. A figura 9.6(e) também mostra as primeiras SuperArestas entre irmãos $\left(\overline{e_{3,4}}\right.$ e $\overline{e_{5,6}}$ ) e outra propagação de dados vinda de níveis abaixo na árvore. A figura 9.6(f) mostra a última SuperAresta que armazena o último conjunto de arestas entre SuperVértices irmãos. A figura 9.6(g) mostra o fim do processo, quando nenhuma informação resta para ser processada. 


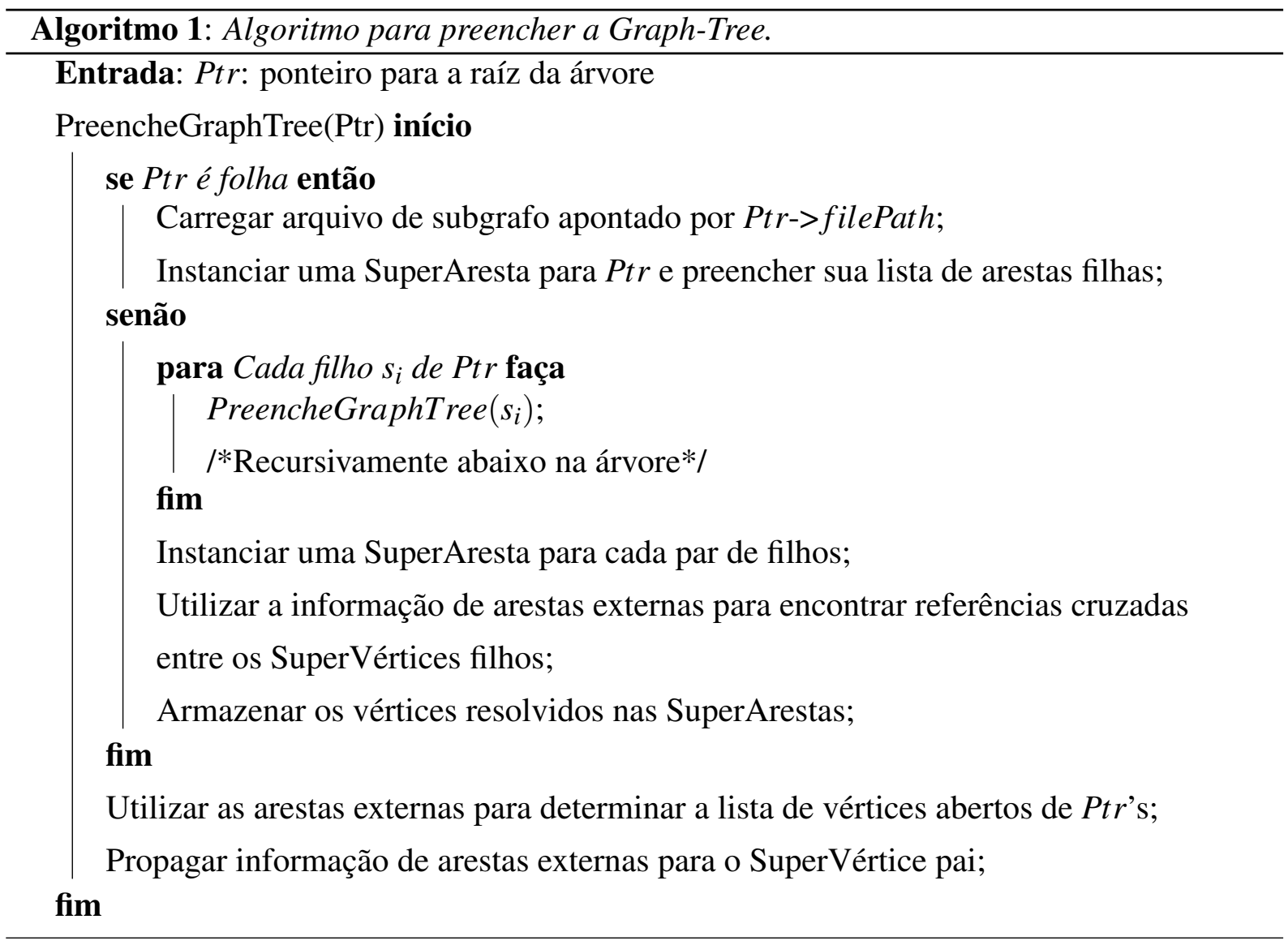

\subsubsection{Visualização no Sistema GMine}

O sistema GMine utiliza a estrutura de dados Graph-Tree e suporta um conjunto de tarefas de interação para permitir a mineração visual de um SuperGrafo. Nesta seção, serão ilustradas as funcionalidades do sistema GMine utilizando-se um conjunto de dados sintético.

O conjunto de dados utilizado é intencionalmente pequeno e com bastante conteúdo semântico, tendo sido definido manualmente com o intuito de ilustrar as características do sistema GMine. O conjunto possui 81 vértices e 341 arestas. Cada vértice representa um empregado que pertence a um departamento de uma companhia hipotética. No primeiro nível, os empregados estão agrupados de acordo com a companhia a qual pertencem, no segundo nível eles estão agrupados de acordo com os respectivos departamentos, veja a figura 9.7. Cada aresta não direcionada representa uma mensagem eletrônica transmitida entre dois empregados, o peso indica o número de mensagens.

A interpretação visual deste grafo objetiva apresentar o inter relacionamento entre os indivíduos, entre os departamentos e/ou entre as companhias. Primeiramente ilustram-se os relacionamentos entre SuperVértices na figura 9.7(a). Nesta ilustração são apresentadas SuperArestas entre as companhias e entre os departamentos de uma mesma companhia. Utilizando-se a equação 9.7 e segundo requisição do usuário analista, pode-se calcular os relacionamentos entre 


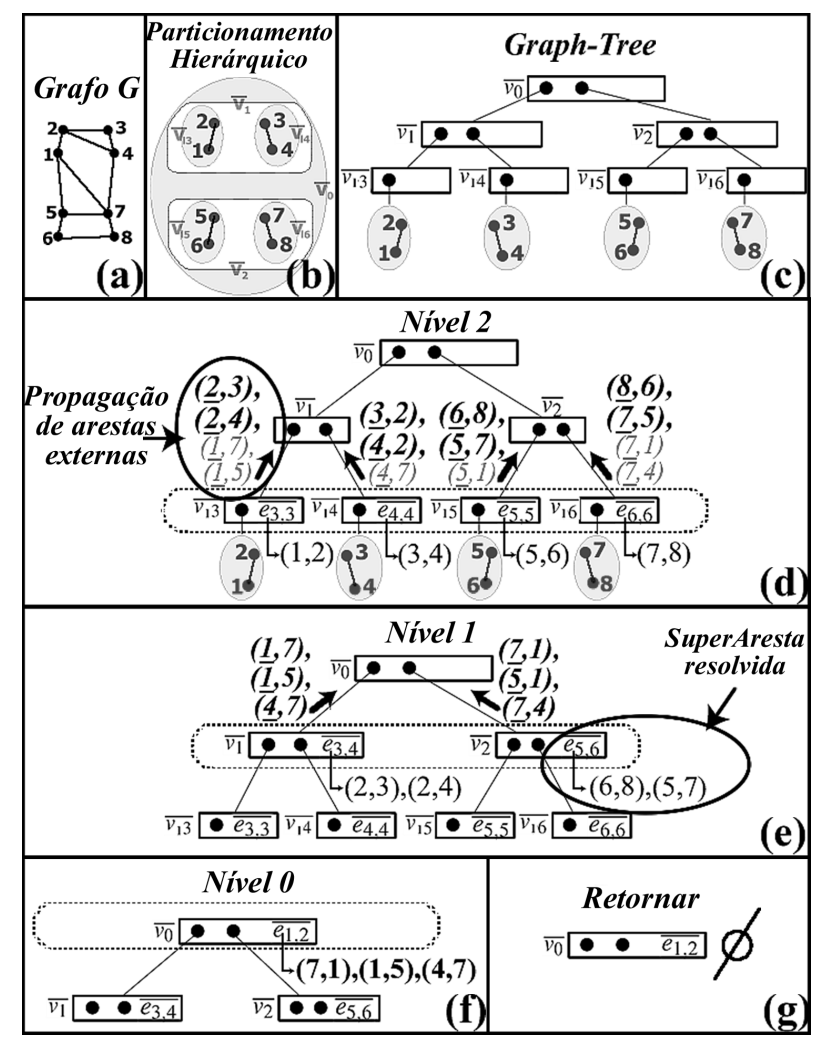

Figura 9.6: Ilustração do processo de preenchimento da Graph-Tree. De (a) a (c), particionamento hierárquico e criação da árvore vazia. De (d) a (g), ilustração do algoritmo utilizado para preencher a Graph-Tree.

departamentos de diferentes companhias, como mostrado na figura 9.7(b). Sobre a estrutura Graph-Tree, o sistema GMine pode também rastrear vértices individuais do grafo original, os quais representam empregados que trocam mensagens com empregados de outros departamentos de outras empresas. Com um simples clique duplo do mouse, o sistema apresenta quais são estes indivíduos por meio da geração da visualização de um grafo bipartido mostrado numa janela separada, como ilustrado na figura 9.7(c). No sistema GMine, cada subgrafo (SuperVérticeFolha) pode ser processado de maneira totalmente independente do resto da visualização, incluindo um conjunto de tarefas de gerenciamento de grafos (amostragem, particionamento, posicionamento espacial), cálculos sobre grafos (distribuição dos pesos das arestas e sumário de componentes) e interação. A figura 9.7(d) mostra como o sistema permite aprofundar-se na hierarquia do SuperGrafo e explorar uma comunidade específica de vértices como um subgrafo separado, tudo no contexto do SuperGrafo sendo visualizado. 


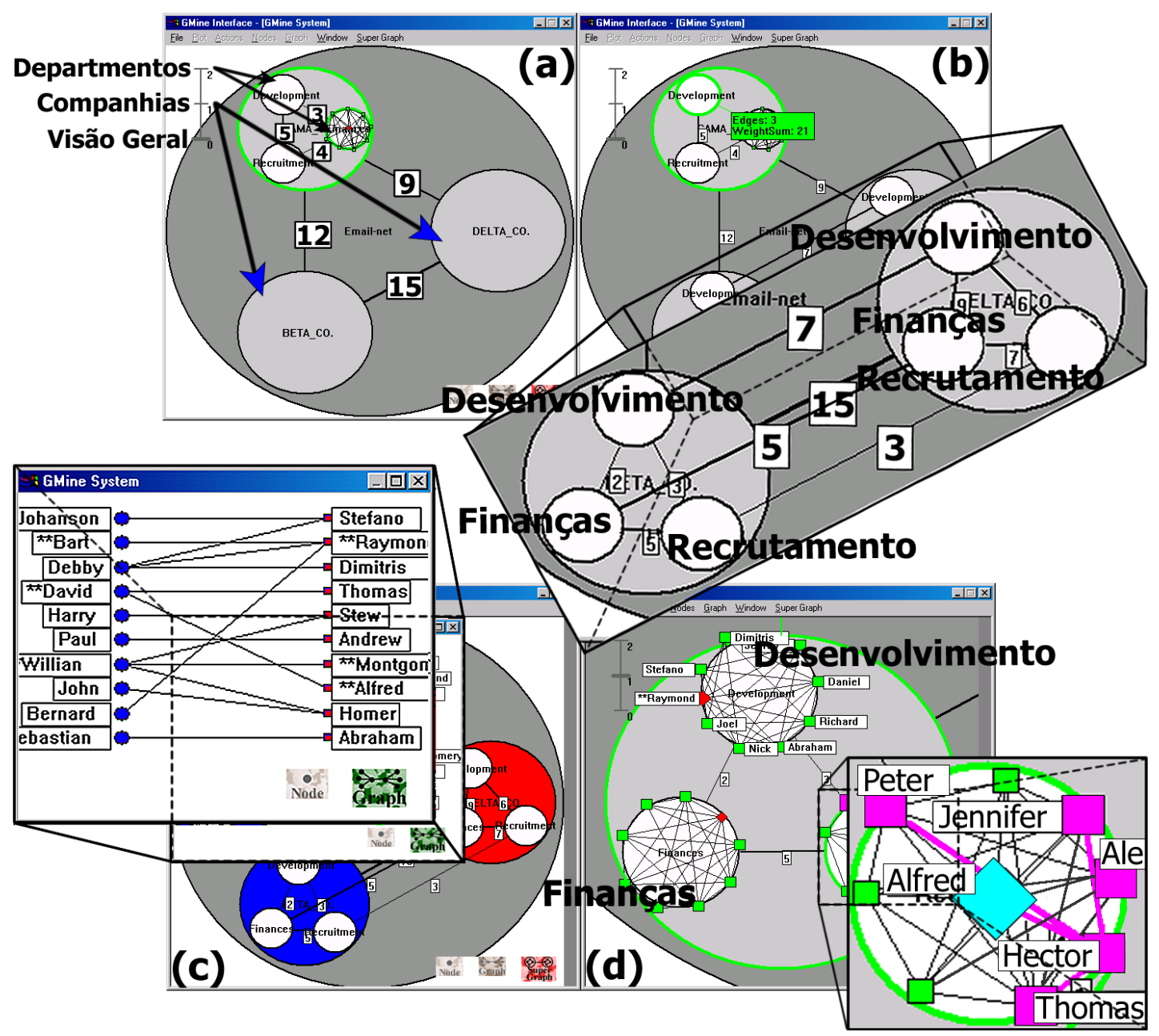

Figura 9.7: Ilustração do sistema GMine. (a) Visão geral de um grafo de relacionamentos (mensagens eletrônicas) de funcionários de três empresas hipotéticas. (b) Relacionamentos entre os funcionários de diferentes departamentos de diferentes empresas. (c) Detalhes sob demanda dos relacionamentos entre duas empresas. (d) Resolução mais alta para focar na partição que representa uma empresa em particular. Parametrização das propriedades de forma e cor do grafo que representa um departamento de interesse.

\subsubsection{Análise do Sistema GMine}

A análise do sistema GMine do ponto de vista da teoria desenvolvida requer a apreciação a partir de duas perspectivas: a técnica de visualização definida e a completa sistematização alcançada.

\section{Design da Técnica de Visualização}

A representação visual no sistema GMine utiliza duas espacializações de Exposição Estrutural. Numa primeira espacialização os níveis da árvore, gerada a partir do pré-processamento hierárquico, são distribuídos no plano de exibição segundo particionamentos recursivos do espaço. Tal particionamento segue de maneira semelhante a uma árvore de indexação espacial 
$R$-Tree balanceada e baseada em ângulos de subregiões circulares. O método de espacialização utilizado assume um espaço virtualmente infinito. Neste espaço os filhos de cada nó da árvore, refletindo a estrutura hierárquica, distribuem-se em uma partição do espaço de mapeamento ao redor do respectivo nó pai. Este primeiro ciclo aplica Diferenciação de forma com o objetivo de se expressar, para cada nó, quem são seus filhos. Aplica-se Conectividade de forma aos nós irmãos da árvore para se estabelecer suas relações de SuperAresta. Numa segunda espacialização, o design utiliza Exposição Estrutural por meio de algoritmo dirigido por força em cada subgrafo dos nós folhas da árvore (SuperVérticesFolha). Este ciclo é seguido por Conectividade de forma para se estabelecer as relações entre os vértices de cada subgrafo.

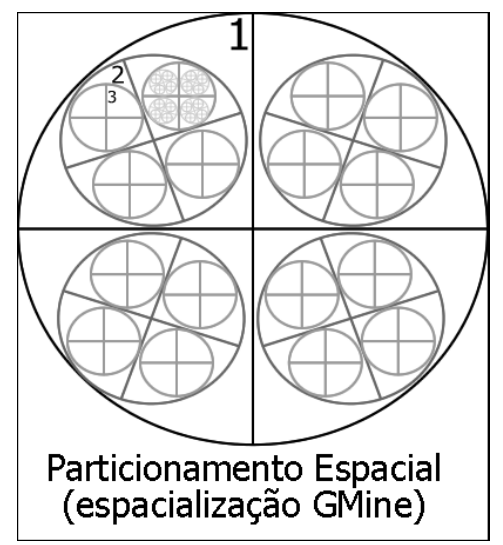

Figura 9.8: Espacialização do sistema GMine. Três níveis de particionamento espacial recursivo semelhante a uma R-Tree balanceada e orientada a ângulos de regiões circulares.

\section{Sistematização}

A espacialização principal do sistema GMine, sem sobreposição de itens gráficos e sobre um espaço de exibição virtualmente infinito, implica na necessidade de um meio para se alterar os parâmetros espaciais da exibição. No trabalho proposto, denominou-se tal meio como interação multi-resolução. Isto é, por meios interativos pode-se alterar a resolução da exibição (unidades espaciais/pixel) com o objetivo de se ter uma quantidade maior de itens gráficos visíveis. Para se guiar tal processo, a interação é orientada a alterar os parâmetros espaciais da exibição segundo os níveis da árvore e segundo os SuperVértices do SuperGrafo. Assim, tendo-se conhecimento da estrutura subjacente à visualização, a tarefa de se navegar o SuperGrafo torna-se intuitiva.

Em conclusão, a complexidade do sistema GMine engloba três níveis da organização abstrata introduzida no capítulo 5: sistema de visualização, pré-processamento e visualização interativa, e visualização e interação. Em resumo, o Sistema de Visualização GMine é estabelecido pela combinação de Pré-processamento de particionamento hierárquico de grafo junto à Visualização Interativa de SuperGrafo. Tal visualização interativa é definida pelo design de Técnica de Visualização descrito nesta seção combinado com a Técnica de Interação espacial orientada à estrutura Graph-Tree. 


\subsection{Múltiplas exibições no Sistema VisTree}

Conjuntos de dados de diversas naturezas apresentam estruturas hierárquicas definidas intrínseca ou explicitamente. De acordo com Nguyen e Huang [Nguyen e Huang, 2005] estruturas hierárquicas podem ser encontradas em muitas aplicações, desde sistemas de arquivos a taxonomias da biologia. Trata-se de uma organização conceitual bastante intuitiva e de rápida assimilação para o ser humano. Arranjos hierárquicos comunicam informação topológica ao mesmo tempo em que elucidam a inter-relação entre as entidades sendo representadas. Por esta razão, mesmo para domínios não hierárquicos, é desejável que os dados possam ser particionados e organizados numa estrutura hierárquica de maneira que o analista possa considerar conjuntos menores de dados um de cada vez. Segundo Derthick e Roth [Derthick e Roth, 2001] retroceder (backtrack) e investigar cenários alternativos são partes integrantes da análise visual de dados. No entanto, muitos dos sistemas atuais de visualização são limitados em sua capacidade de representar caminhos alternativos de exploração. Tais sistemas apresentam um único estado de configuração de cada vez, levando o usuário analista a se basear em sua memória para a tarefa de comparação de cenários.

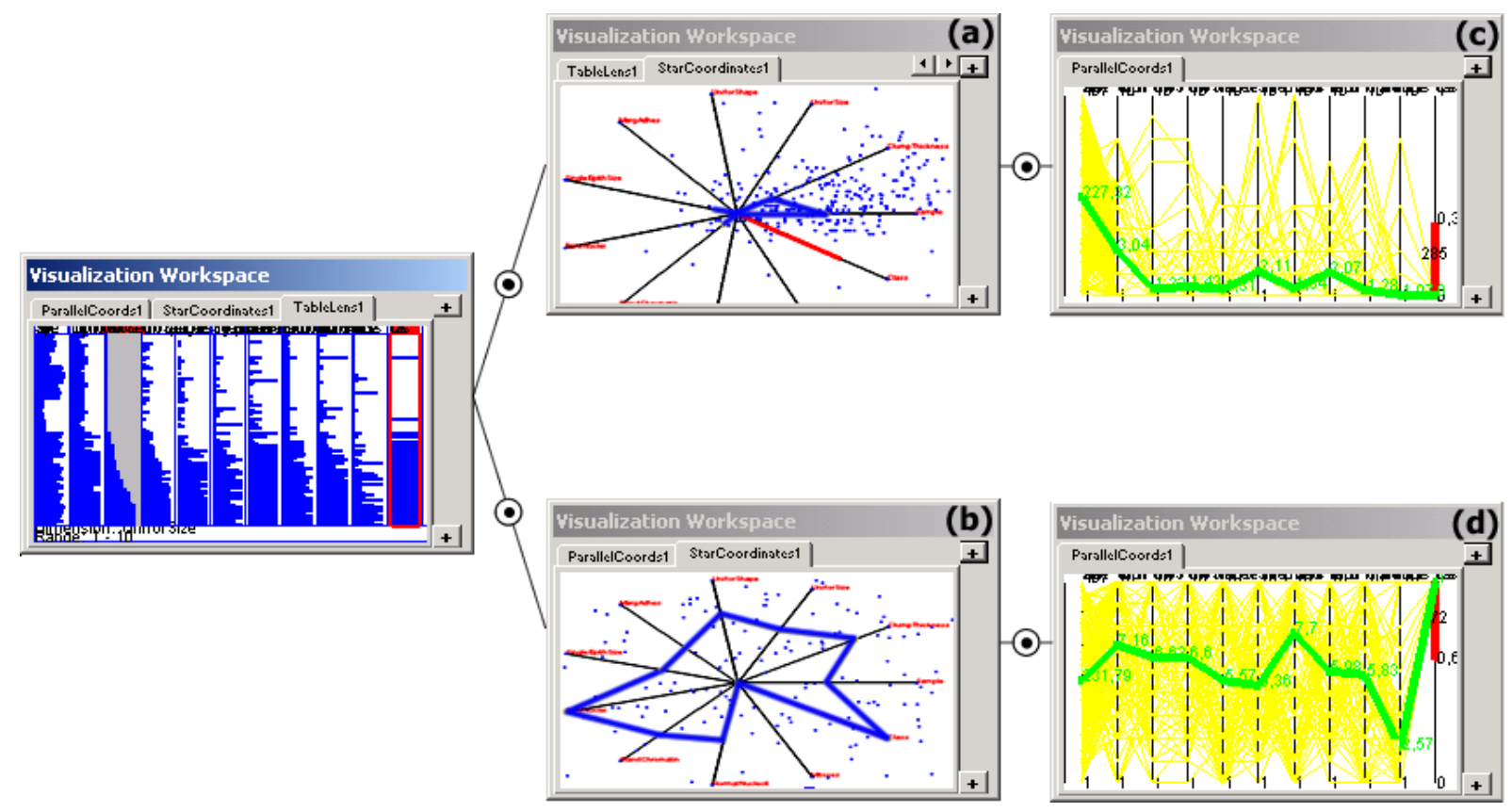

Figura 9.9: Ilustração do sistema VisTree. O mesmo conjunto de dados pode ser visualmente particionado em diferentes exibições automaticamente integradas. No exemplo a técnica Table Lens dá origem a visualizações baseadas em Star Coordinates. Por sua vez, as Star Coordinates originam Coordenadas Paralelas. Sobre as visualizações pode-se observar interação de filtragem e sumarização estatística explorada por meio de diferenciação de cor e forma. 
Por estas razões propôs-se o sistema VisTree [Rodrigues Jr. et al., 2007b] [Rodrigues Jr. et al., 2005], ilustrado na figura 9.9, um ambiente interativo capaz de exibir simultaneamente múltiplas técnicas de visualização. No sistema proposto as exibições de dados, criadas por intervenção do analista, são automaticamente relacionadas e gerenciadas por meio de uma estrutura de árvore. A apresentação desenvolvida possibilita a observação de múltiplos cenários ao mesmo tempo, permitindo ao analista retroceder em suas decisões de análise ou considerá-las comparativamente sem se basear em sua memória.

\subsubsection{Filtragem Iterativa}

Uma solução direta para o particionamento de um conjunto de dados é por meio de consultas como as que são definidas pela álgebra relacional (popularmente difundidas pela linguagem declarativa SQL). Sobre cenas de visualização, consultas deste tipo correspondem à filtragem interativa. No sistema VisTree, a filtragem interativa é utilizada segundo uma sistematização iterativa para a definição de consultas. Esta sistematização é denominada Filtragem Iterativa. A filtragem iterativa combina seleção interativa de itens gráficos e refinamento progressivo das cenas de visualização para permitir o particionamento de um único conjunto de dados.

A filtragem iterativa, apresentada na figura 9.10, é composta por um conjunto de dados $D$, uma visualização $V$, uma função de visualização $v$, uma função de filtragem $f(D) \rightarrow V$ e uma função reversa $\Lambda(V) \rightarrow D$.
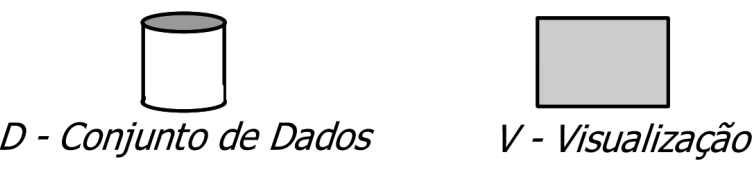

\section{(a)}
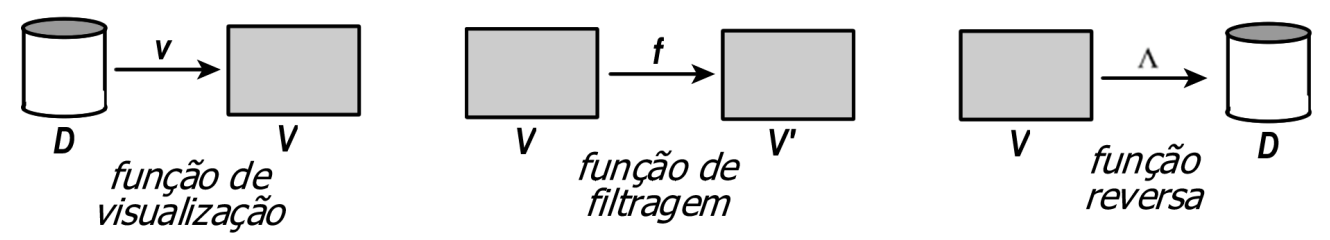

(b)

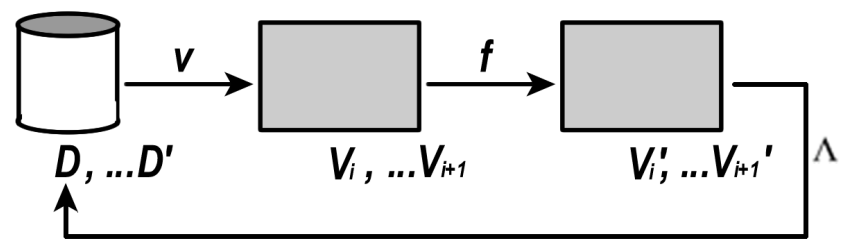

(c)

ciclo da filtragem iterativa

Figura 9.10: Filtragem iterativa. (a) Componentes da filtragem iterativa. (b) Meta funções que a definem. (c) Ciclo da filtragem iterativa, o qual se repete indefinidamente. 
Na figura 9.10, a função de visualização $v: D \rightarrow V$ é uma função que recebe dados e produz uma representação visual. A função de filtragem $f: V \rightarrow V^{\prime}$ é um $\operatorname{par}(d, e)$ onde $d$ é um conjunto de dimensões (atributos) dos dados e $e$ é um conjunto de expressões booleanas que se aplicam a $d$ com o intuito de se definir a seleção da filtragem interativa. A filtragem interativa produz uma alteração $V^{\prime}$ na visualização $V$. A função $\Lambda: V \rightarrow D$ recebe uma visualização, $V^{\prime}$ por exemplo, e desfaz a operação da função $v$ retornando o conjunto de dados subjacente à visualização. A figura 9.10 também apresenta o ciclo de interação que caracteriza a filtragem iterativa. De acordo com este ciclo, um conjunto de dados $D$ é usado para criar uma visualização $V_{i}$ por meio da função $v$. Esta visualização então é filtrada por meio da função $f$ para determinar uma nova configuração da visualização, denominada $V_{i}^{\prime}$. A seguir, os dados que estão sendo apresentados em $V_{i}^{\prime}$ são extraídos utilizando-se a função $\Lambda$. Com os dados extraídos, representados por $D^{\prime}$, uma nova visualização $V_{i+1}$ pode ser criada. Este processo se repete iterativamente segundo as definições do usuário analista.

A figura 9.11 ilustra a filtragem iterativa como ela é realizada no sistema VisTree de acordo com o ciclo apresentado na figura 9.10. Duas seqüências de operações são utilizadas, na primeira, todo o conjunto de dados $D$ é carregado em um novo ambiente de visualização (uma nova exibição). Esta exibição permite escolher uma dentre cinco técnicas de visualização. Ao se escolher uma delas, a correspondente função $v$ é acionada para gerar a visualização $V_{1}$. Sobre $V_{1}$ o analista pode interativamente determinar parâmetros para a função de filtragem $f$. Uma nova configuração da visualização $V_{1}$ é criada, $V_{1}^{\prime}$, na qual os parâmetros de filtragem são enfatizados por meio de cor e forma. Um novo comando de usuário aciona a função $\Lambda$ que retorna os dados sendo exibidos em $V_{1}^{\prime}$, isto é, $D^{\prime}$. Estes dados são enviados (canalizados) para a criação da visualização $V_{2}$ por meio de $v$. Definindo um segundo ciclo de iteração, $V_{2}$ é criada por meio de $f$ e de novos parâmetros de filtragem. E assim por diante através de diversos ciclos.

\subsubsection{Definindo uma árvore de visualização}

A filtragem iterativa permite que o analista defina várias exibições, cada uma carregando um subconjunto de dados considerado interessante para a análise. Para tanto, o analista começa observando a exibição original do conjunto de dados completo e, interativamente, define parâmetros de filtragem na forma de expressões booleanas. Quando uma configuração de visualização interessante é gerada, o analista pode determinar que seus elementos de dados fluam para uma nova exibição. Este processo pode se repetir para a nova exibição ou para a exibição original. Se uma nova exibição é criada a partir da nova exibição, define-se um ramo de análise seqüencial mais profundo, como mostrado na figura 9.12(a). Se uma nova exibição é criada a partir da exibição original, define-se um ramo de análise paralelo, como mostrado na figura 9.12(b). O mesmo pode ser feito em outros níveis da árvore, como demonstrado na 


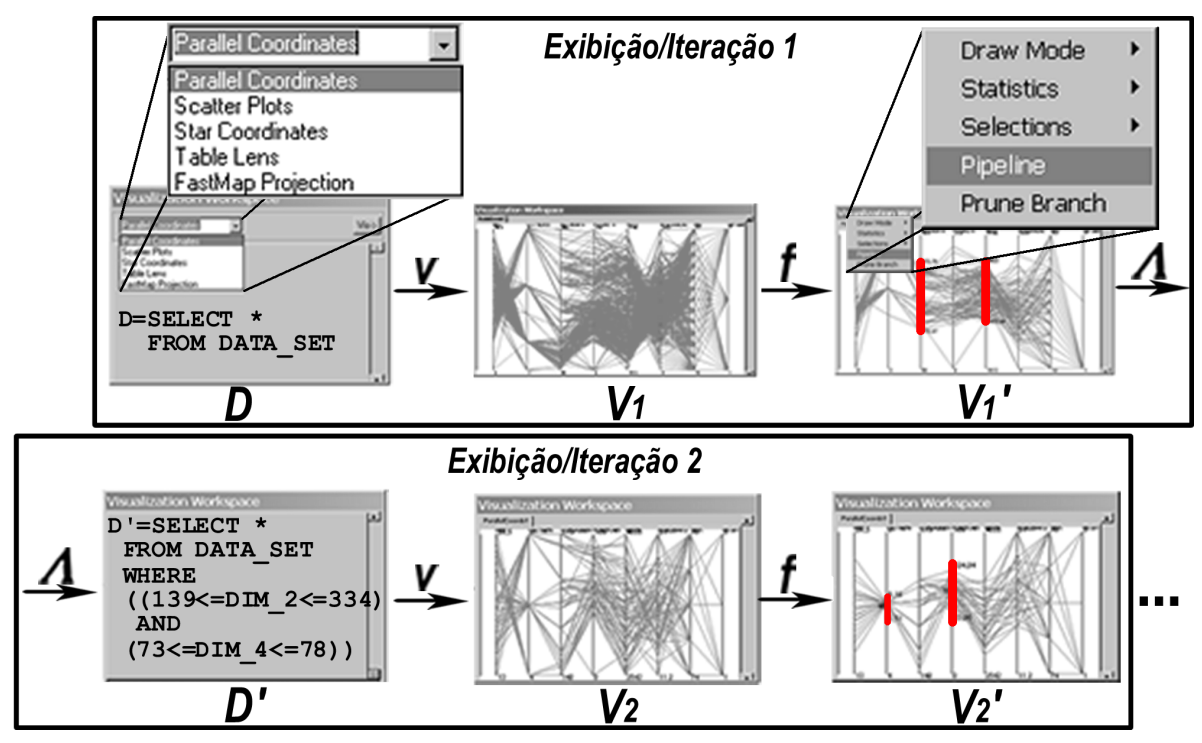

Figura 9.11: Ciclo interativo de filtragem iterativa.

figura 9.12 (c). Ao longo do processo interativo de iteração, o sistema VisTree é responsável por gerenciar as exibições criadas e apresentá-las numa estrutura de árvore.

\section{Gerenciamento da Árvore}

Ao passo que o analista cria novas exibições e a estrutura da árvore se desenvolve, é necessário gerenciar sua estrutura para que a utilização do espaço possa ser maximizada e para que se tenha uma representação adequada em forma de árvore.

No sistema VisTree, para um dado vértice, o posicionamento horizontal é diretamente conseguido utilizando-se a informação do nível do vértice, o qual corresponde a quão profundo o espaço de exibição está posicionado na árvore, como ilustrado na figura 9.13. Já o posicionamento vertical é um pouco mais complicado, pois os vértices menos profundos estão posicionados em função dos vértices mais profundos. Por esta razão, o arranjo da árvore deve se iniciar pelas folhas. A figura 9.13 ilustra o processo de arranjo. Na ilustração, para todos os vértices de exemplo (em amarelo), o posicionamento vertical inicial é apresentado na parte inferior da tela. Nos passos 1 a 3 da figura 9.13, os vértices 5 e 6 ilustram o caso para vértices sem filhos segundo o algoritmo: inicialmente posição do fundo, procure pelo "primeiro vértice acima" (círculo vermelho) e reposicionamento. Nos passos 4 a 8 da figura, os vértices 7 e 8 ilustram o caso para vértices com filhos. Estendendo o caso para vértices sem filhos, após o primeiro reposicionamento é necessário realizar um segundo reposicionamento de acordo com os vértices filhos (elipses). Por razões estéticas, o segundo reposicionamento coloca o vértice pai numa posição onde tanto a soma quanto a variação das distâncias para todos os vértices filhos são minimizadas. Isto é, o vértice pai é posicionado na altura média definida entre seu filho mais acima e seu filho mais abaixo. 
(a)
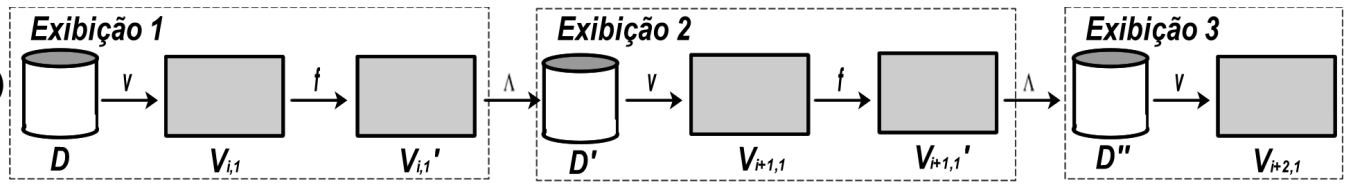

\section{Exibição 2}

(b)
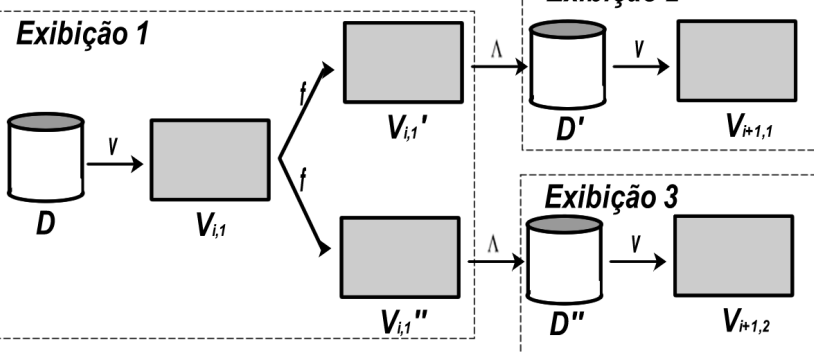

(c)
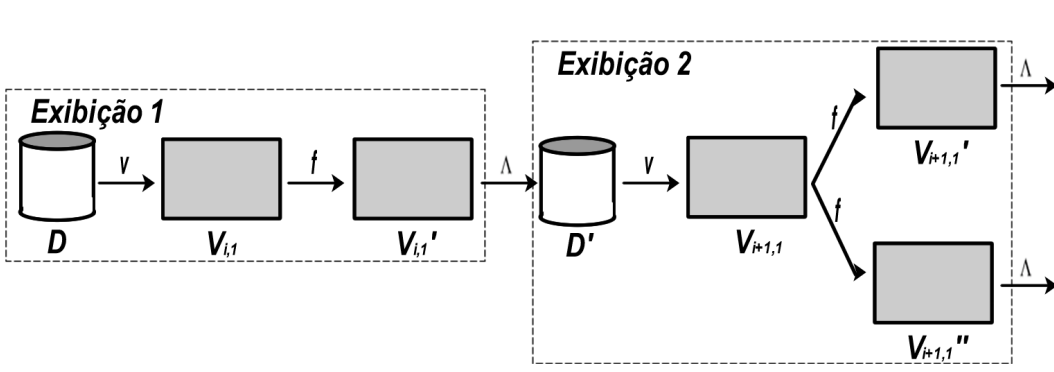

Exibição 3
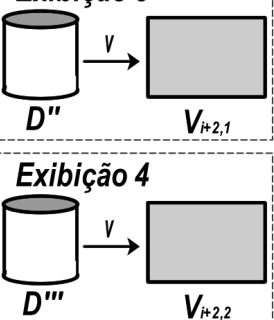

Figura 9.12: Construção da árvore de visualização. (a) Exploração seqüencial definindo um ramo de análise mais profundo. (b) Exploração paralela definindo um ramo de análise paralelo. (c) Exploração em ramos mais profundos da árvore.

\section{Interação}

A estratégia utilizada é combinar mecanismos de interação automáticos e manuais para se poder navegar no ambiente de múltiplas exibições. Desta maneira, quando a árvore não mais cabe dentro do espaço de exibição e um novo vértice é criado, prossegue-se determinando o arranjo da árvore, que fica fora da tela, ao mesmo tempo em que a árvore é transladada e o novo vértice é posicionado no centro. O intuito é prover contexto e sensação de controle ao usuário que vê a última exibição em destaque rodeada dos vértices que determinam o contexto da árvore de análise.

Ao prover espaço de projeção sem limites, a árvore, que já não cabe na tela, requer meios adequados de navegação. Este problema é tratado por meio de zoom convencional e transformação espacial (translação) sobre a árvore. Além disso, para navegação mais ágil, também se utilizam mecanismos de interação de forma e de espaço denominados contexto instantâneo e foco instantâneo. O contexto instantâneo procura exibir a completa estrutura da árvore dentro da tela, não interessando quão pequenos seus vértices se tornem. O foco instantâneo permite que o analista tenha uma exibição em particular imediatamente ocupando toda a tela. Estas duas funcionalidades são ilustradas na figura 9.14 


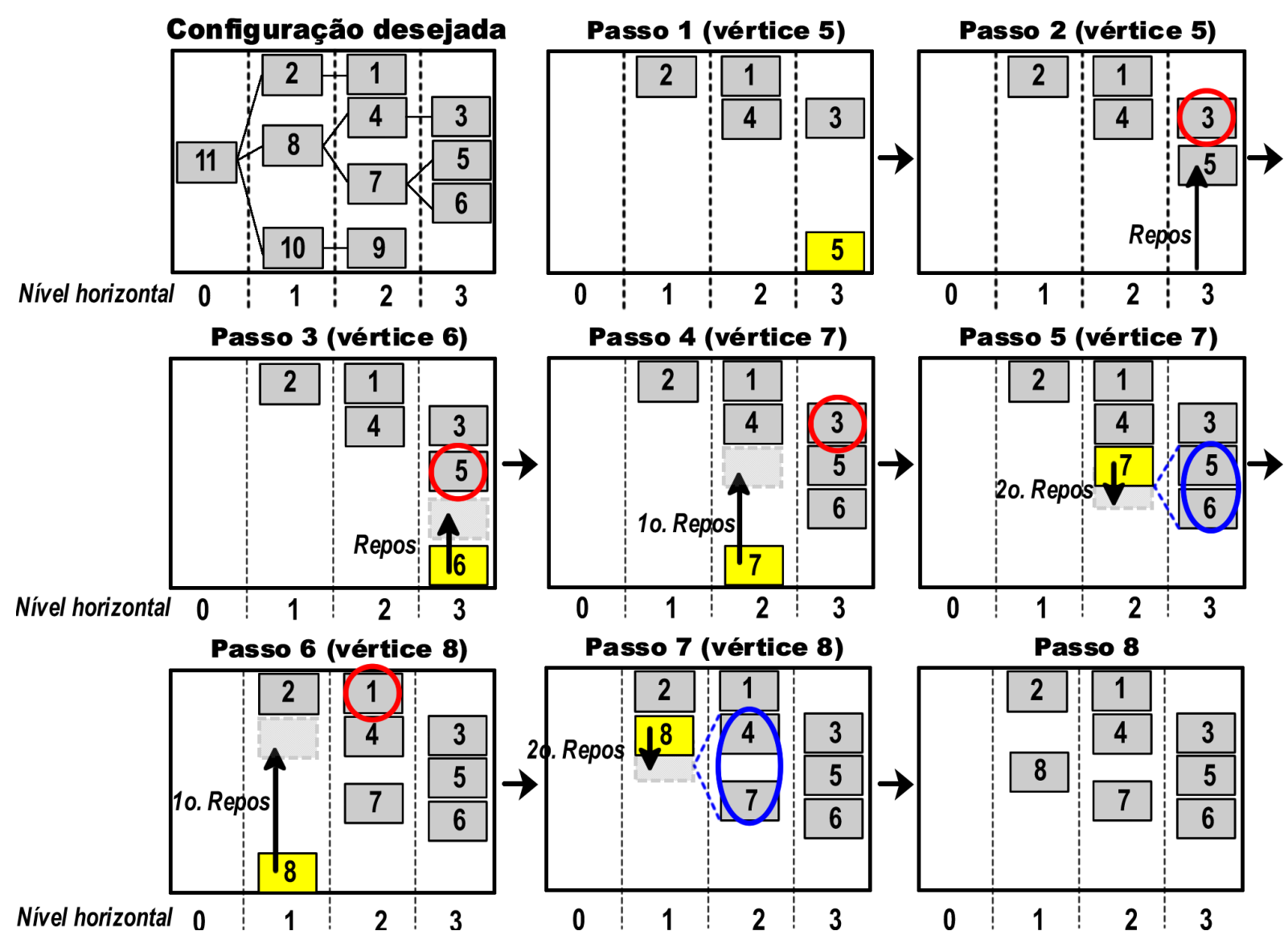

Figura 9.13: Posicionamento de vértices no sistema VisTree. A primeira ilustração no canto superior esquerdo mostra a configuração desejada e a ordem de varredura dos vértices por meio de numeração. Os passo do 1 ao 8 ilustram o posicionamento dos vértice 5 a 8 no intuito de se obter a configuração desejada. Para cada vértice posicionado, seu "primeiro vértice acima" considerado para reposicionamento é destacado com círculos vermelhos. Vértices filhos considerados para reposicionamento são destacados com elipses azuis.

\subsubsection{Análise do Sistema VisTree}

A análise do sistema VisTree segundo a teoria desenvolvida não abrange o nível de design de Técnica de Visualização ou de Interação. O sistema VisTree utiliza um conjunto de técnicas de visualização já conhecidas (Coordenadas Paralelas, Scatter Plots, Coordenadas Estelares e Table Lens), não introduzindo nenhum novo design visual para apresentação de dados. A contribuição do sistema VisTree vem de sua sistematização.

No sistema VisTree, cada janela de análise é um ambiente completo de visualização composto por múltiplas técnicas interativas integradas e acrescidas de processamento estatístico pré-visualização. A proposta VisTree apresenta design em um nível acima da generalização de Sistema de Visualização, o qual fica acima da mais alta generalização abrangida neste trabalho. Esta generalização, especificamente, tem sido tratada numa subárea de pesquisas da Análise Visual de Dados denominada Coordenação de Múltiplas Visualizações. Esta constatação intro- 


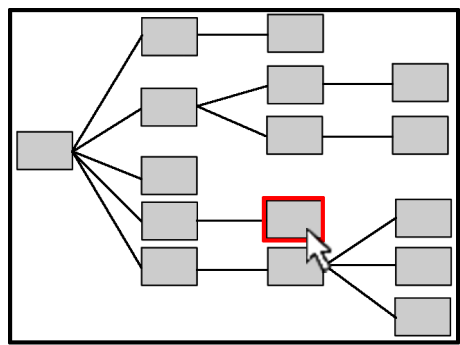

(a) Contexto instantâneo

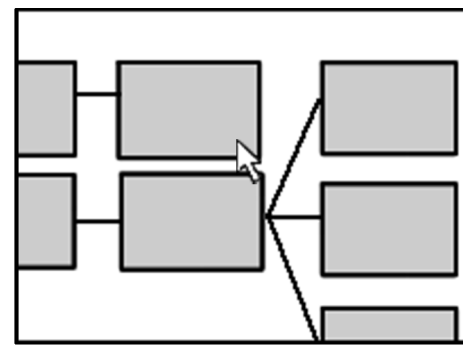

(b) Apresentação normal

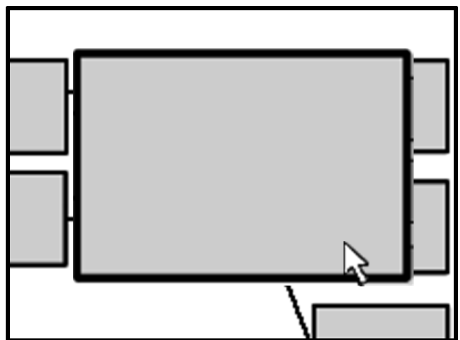

(c) Foco instantâneo

Figura 9.14: Interação sobre o sistema VisTree. (a) O contexto instantâneo mostra onde na estrutura da árvore está localizado um vértice de interesse. (b) Para árvores grandes, a apresentação normal pode esconder detalhes contextuais. (c) $\mathrm{O}$ foco instantâneo apresenta os detalhes de uma dada exibição aumentando o tamanho da respectiva janela.

duz um novo nível na organização abstrata do capítulo 5, o qual poderia denominar-se Sistemas Complexos de Visualização.

No presente desenvolvimento conceitual, Sistemas Complexos de Visualização definiriam uma nova ordem de organização abrangendo sistemas complexos compostos por mais de um sistema de visualização. Esta organização define claramente um campo de estudo que demanda sua própria teoria e prática de design, como brevemente abordado na seção 4.4. Portanto percebe-se que, ao se considerar a organização abstrata e o sistema VisTree, conclui-se que há necessidade de mais um nível de organização: Sistemas Complexos de Visualização. O fato deste nível de organização derivar das observações colocadas no presente trabalho, ao mesmo tempo em que se encaixa na ciência existente de Coordenação de Múltiplas Visualizações, corrobora para a constatação da validade dos princípios apresentados quando justapostos a compreensões já aceitas. Observa-se aqui, então, o potencial do presente trabalho para contribuir com a ciência de Análise Visual de Dados, em sua teoria e desejavelmente em sua prática.

\subsection{Considerações Gerais}

As três abordagens apresentadas para ampliação do espaço de projeção são dependentes da técnica de espacialização utilizada. A utilização do espaço 3D requer capacidades de renderização específicas como a projeção perspectiva implementada em equipamentos gráficos de nova geração e acessíveis por bibliotecas gráficas como a OpenGL e a DirectX. Técnicas multi-resolução como a descrita equivalem à projeção em um espaço de endereçamento contínuo (virtualmente infinito). Técnicas assim requerem gerenciamento dos diferentes níveis de resolução para rápida alternância entre as perspectivas de observação. Já técnicas baseadas em múltiplas exibições equivalem a um espaço de projeção sem limites, mas particionado em diversas sub-imagens exclusivas e, preferencialmente, integradas. 
De acordo com o estudo desenvolvido nesta tese, a ampliação do espaço de visualização é um recurso amplamente aplicado para o design de técnicas de análise visual de dados. Tratase também de um recurso que demanda técnicas de espacialização mais sofisticadas e maior integração dos ciclos de espacialização. Parte do doutorado compreendido nesta tese dedicou-se à exploração de sistematizações inovadoras que buscassem o objetivo de se ampliar o espaço de visualização. Os sistemas GMine e VisTree são os resultados que refletem estas linhas paralelas de trabalho e que complementam o conjunto da contribuição do presente doutorado. 


\section{Capítulo 10}

\section{Conclusão}

\subsection{Contribuições}

Este trabalho introduziu uma nova perspectiva de compreensão para o design de visualizações. Segundo a compreensão desenvolvida, o design de técnicas de visualização requer, além da consideração do contexto cognitivo, a consideração da configuração espacial dos itens de dados, da representação gráfica para os itens gráficos e da estrutura exploratória de interação. Para o desenvolvimento da proposta, inicialmente definiu-se o Processo de Expressividade Visual com o intuito de se examinar e se delinear uma nova estratégia para análise de técnicas de visualização. Esta observação orientou o trabalho a se concentrar no processo de expressividade das visualizações objetivando identificar seus constituintes. Tais constituintes, juntamente com uma extensa revisão de trabalhos prévios, foram base para a concepção da Taxonomia EspacialPerceptiva, a qual considera visualizações como conjuntos de componentes que promovem um número limitado de percepções visuais. Esta investigação avançou para a definição do Espaço de Design Espacial-Perceptivo, o qual agrega as idéias apresentadas numa única concepção e o qual considera a possibilidade de múltiplos ciclos de visualização.

Técnicas de interação também foram analisadas à luz da organização conceitual proposta e a conclusão foi a de que técnicas de interação se manifestam como possibilidades de alteração dos parâmetros de uma dada configuração de visualização. Num primeiro resultado decorrente deste trabalho, a taxonomia desenvolvida e o espaço de design foram integrados em um modelo de design automatizado denominado Máquina de Visualização. Ao longo do texto, para validar as observações propostas, foi realizada uma revisão analítica de diversas configurações de design seguindo os conceitos apresentados.

O trabalho proposto é centrado em como os usuários analistas percebem as visualizações ao invés de ser orientado a quais padrões visuais são usados para se construir visualizações. Diferente de abordagens anteriores que partem de um conjunto de padrões visuais, este trabalho 
se alicerça em um conjunto de percepções visuais com o intuito de escolher métodos para a codificação de posição, forma e cor. Esta orientação traz os projetistas para mais perto das características expressivas das composições visuais. Desta maneira, acredita-se que a teorização apresentada possa promover uma compreensão mais intuitiva e clara do processo de design, fomentando pesquisas futuras em busca de um espaço de design mais preciso e compreensivo no âmbito da análise visual de dados.

\subsection{Resultados}

Nesta seção, complementando a apresentação das conclusões iniciada na seção de contribuições, apresentam-se objetivamente os resultados alcançados. Além de se listar os resultados advindos da espinha dorsal da contribuição da tese - o Design Espacial-Perceptivo - também listam-se os resultados provindos das linhas paralelas de pesquisa. Estas linhas paralelas, os sistemas GMine e VisTree desenvolvidos no decorrer do doutorado, são importantes atividades de pesquisa e desenvolvimento que alcançaram reconhecimento junto à comunidade científica da área.

Com relação ao Design Espacial-Perceptivo [Rodrigues Jr. et al., 2006c] [Rodrigues Jr. et al., 2007c], listam-se os seguintes resultados originais:

- o Processo de Expressividade Visual, o qual fornece uma visão analítica de como visualizações transformam-se em interpretações por meio de percepção visual;

- a Taxonomia Espacial-Perceptiva que classifica técnicas de visualização de dados segundo a função de seus componentes básicos no intuito de produzir interpretações cognitivas;

- o Espaço de Design Espacial-Perceptivo, o qual define uma abstração análoga ao espaço Euclidiano para a percepção de quais são as possibilidades de design em análise visual de dados;

- interpretações para composição espacial (múltipla) e para interação (derivada da compreensão Espacial-Perceptiva), as quais são utilizadas no design de visualizações;

- a Máquina de Visualização, um modelo de desenvolvimento que parte de uma perspectiva universal para a elaboração de técnicas de estimulação visual voltadas à análise de dados;

- um ponto de vista alternativo sobre a ciência de análise visual de dados que deve contribuir com novos caminhos de pesquisa e desenvolvimento visando o amadurecimento pleno desta ciência. 
Em referência ao sistema GMine [Rodrigues Jr. et al., 2006a] [Rodrigues Jr. et al., 2006b] [Rodrigues Jr. et al., 2007a], observam-se os seguintes resultados:

- formalização do conceito de SuperGrafo acrescido de extensões funcionais para cálculo de conectividade entre vértices do grafo e entre grupos de vértices da hierarquia de partições;

- concepção da estrutura de dados Graph-Tree capaz de armazenar, ao mesmo tempo, uma hierarquia de partições de um grafo e o grafo original;

- um sistema completo de análise visual de dados do tipo grafo, escalonável, interativo e multi-resolução.

Por fim, o sistema VisTree [Rodrigues Jr. et al., 2007b] [Rodrigues Jr. et al., 2005] compreende os seguintes desenvolvimentos:

- um sistema automatizado de gerenciamento e manipulação de múltiplas exibições de dados integradas em uma estrutura de árvore visando escalabilidade;

- a sistematização de funcionalidades de refinamento de diferentes visualizações possibilitando a ampliação das possibilidades de exploração visual.

\subsection{Trabalhos Futuros}

Inicialmente, como trabalho futuro, pode-se pensar no desenvolvimento do projeto da Máquina de Visualização descrita no capítulo 8. A Máquina de Visualização descreve a visão geral de um grande conjunto de problemas. É necessário definir-se uma modelagem de implementação que possibilite encaixar diferentes metodologias de pré-processamento, espacialização, definição de forma e de cor. Conseqüentemente também seria necessária a definição de padrões que regulamentassem a implementação de módulos adequados ao modelo proposto. O mesmo seria necessário para técnicas de interação, definindo uma abordagem parametrizável objetivando manter a versatilidade do sistema. Em parceria com estas funcionalidades é necessário um formato de padronização capaz de incorporar os parâmetros que descrevem uma dada técnica de visualização, isto é, um descritor de técnicas que possibilite configurar os fatores da Máquina de Visualização. Este formato de padronização deve ser adequado à avaliação das técnicas de visualização (conjuntos de parâmetros) considerando tanto o tipo dos dados quanto os objetivos de análise. O conjunto destes fatores definiria perfis de visualização, em substituição às chamadas técnicas de visualização, um avanço desejável para a ciência de análise visual de dados.

Um outro trabalho a ser desenvolvido na linha da tese apresentada é o estudo da animação. Animação é o quarto fator pré-atentivo juntamente com posição, forma e cor. No entanto, o 
fator de animação não foi considerado neste trabalho pois trata-se de uma dimensão de design ainda pouco explorada em análise visual de dados. Este fato dificulta o estudo empírico dos fenômenos visuais, assim como foi a abordagem deste trabalho. Também se considera o fato de que a dimensão de animação é relacionada às outras três dimensões, podendo-se ter animação de posição, forma e, até mesmo, cor. Desta maneira, animação em análise visual de dados incorpora complexidade suficiente para um trabalho dedicado apenas a este fator, devendo ser um trabalho futuro.

Pode-se também pensar na expansão do escopo de estudo considerando-se as dimensões não visuais de som (sonificação) e tato, já estudadas na literatura mas não abrangidas por este primeiro trabalho. Estas novas dimensões culminariam na redefinição do Espaço de Design Espacial-Perceptivo e da Máquina de Visualização. Ainda abrangendo o domínio considerado na presente proposta, deve-se ampliar a organização abstrata colocada no capítulo 5 introduzindo-se o nível de Sistemas Complexos de Visualização. Tal nível já é objeto de estudo segundo a denominação de Coordenação de Múltiplas Visualizações, mas não tem uma correspondente análise espacial e perceptual.

O sistema GMine também levanta possibilidades de mais contribuições. Sua sistematização atual é híbrida, com um dado SuperGrafo sendo parcialmente armazenado em memória (Graph-Tree) e parcialmente armazenado em disco (subgrafos dos nós folhas). Uma continuação complementar do trabalho é seu desenvolvimento exclusivamente em disco, buscando-se um sistema de armazenagem e indexação eficientes. 


\section{Referências Bibliográficas}

[Ankerst e Keim, 1996] Ankerst, M. e Keim, D. (1996). Circle segments: A technique for visually exploring large multidimensional data sets. In Proceedings of the IEEE Visualization - Hot Topic Session, San Francisco, CA, EUA. IEEE Computer Society Press.

[Baldonado et al., 2000] Baldonado, M. Q. W., Woodruff, A., e Kuchinsky, A. (2000). Guidelines for using multiple views in information visualization. In Proceedings of the working conference on Advanced visual interfaces, páginas 110-119.

[Balzer e Deussen, 2005] Balzer, M. e Deussen, O. (2005). Voronoi treemaps. In IEEE Symposium on Information Visualization, páginas 7-14, Minneapolis, MN, EUA. IEEE Computer Society.

[Bederson et al., 1996] Bederson, B., Hollan, J. D., Perlin, K., Meyer, J., Bacon, D., e Furnas, G. (1996). Pad++: a zoomable graphical sketchpad for exploring alternate interface physics. Elsevier Science. Journal of Visual Languages and Computing, 7(1):3-31.

[Bertin, 1973] Bertin, J. (1973). Sémiologie graphique : les diagrammes, les réseaux, les cartes. Paris: Mouton, 431 pp. - FFLCH /511.5^B544s^2.ed.

[Bertin, 1974] Bertin, J. (1974). Graphische Semiologie, Diagramme, Netze, Karten. ISBN 978-3110036602. Berlin:Walter de Gruyter, 430 pp.

[Bertin, 1999] Bertin, J. (1999). Readings in information visualization: using vision to think Capítulo Graphics and Graphic Information-Processing. The Morgan Kaufmann series in interactive technologies. ISBN 1-55860-533-9. Morgan Kaufmann Publishers Inc., ICMSC /68U15.05^C266ri^e.1.

[Blanchard et al., 2005] Blanchard, F., Herbin, M., e Lucas, L. (2005). A new pixel-oriented visualization technique through color image. Palgrave. Information Visualization Journal, 4(4):257-265.

[Bowman, 1968] Bowman, W. J. (1968). Graphic Communication. Wiley Series on Human Communication. ISBN 978-0471092902. New York: John Wiley \& Sons, Inc., 222 pp.

[Brooks, 1991] Brooks, R. (1991). Comparative Task Analysis: An Alternative Direction for Human-Computer Interaction Science, páginas 50-59. - Designing interaction: psychology at the human-computer interface - John M. Carroll, editor, New York:Cambridge University Press.

[Bugajska, 2003] Bugajska, M. (2003). Spatial Visualization of Abstract Information. PhD thesis, ETH Zurich. 197 pages. 
[Bugajska, 2005] Bugajska, M. (2005). Framework for spatial visual design of abstract information. In Proceedings of the International Conference on Information Visualisation, páginas 713-723, Los Alamitos, CA, USA. IEEE Computer Society.

[Card et al., 1999] Card, S., Mackinlay, J., e Shneiderman, B. (1999). Readings in Information Visualization: Using Vision to Think. The Morgan Kaufmann series in interactive technologies. ISBN 978-1558605336. San Francisco, CA, EUA: Morgan Kaufmann Publishers, 712 pp. - ICMSC /68U15.05^C266ri^e.1.

[Card e Mackinlay, 1997] Card, S. K. e Mackinlay, J. (1997). The structure of the information visualization design space. In IEEE Symposium on Information Visualization, páginas 9299, Phoenix, AZ, EUA. IEEE Computer Society.

[Chambers et al., 1983] Chambers, J. M., Cleveland, W. S., e Tukey, P. A. (1983). Graphical Methods for Data Analysis. The Wadsworth statistics/probability series. ISBN 9780534980528. Duxbury Press, 395 pp. - ESALQ-BC /519.5^C444g^64727.

[Chen, 2003] Chen, C. (2003). Mapping Scientific Frontiers: The Quest for Knowledge Visualization. London:Springer-Verlag, 256 pp.

[Chen, 2005] Chen, C. (2005). Top 10 unsolved information visualization problems. IEEE Computer Society. IEEE Computer Graphics and Applications Journal, 25(4):12-16.

[Chernoff, 1973] Chernoff, H. (1973). The use of faces to represent points in k-dimensional space graphically. JSTOR. Journal of the American Statistical Association, 68(342):361368 .

[Chi, 2000] Chi, E. H. (2000). A taxonomy of visualization techniques using the data state reference model. In IEEE Symposium on Information Visualization, páginas 69-75, Salt Lake City, UT, EUA. IEEE Computer Society Press.

[Chuah e Roth, 1996] Chuah, M. C. e Roth, S. F. (1996). On the semantics of interactive visualizations. In IEEE Symposium on Information Visualization, páginas 29-36, Washington, DC, EUA. IEEE Computer Society. online: http://www.cs.cmu.edu/s̃age/Papers/semanticsInfoViz96/semantics-InfoViz96.html.

[Cleveland, 1993] Cleveland, W. S. (1993). Visualizing Data. ISBN 978-0963488404. Hobart Press, $360 \mathrm{pp}$.

[Cleveland e McGill, 1984] Cleveland, W. S. e McGill, R. (1984). Graphical perception: Theory, experimentation and application to the development of graphical methods. JSTOR. Journal of the American Statistical Association, 150(3):192-229.

[Derthick e Roth, 2001] Derthick, M. e Roth, S. F. (2001). Enhancing data exploration with a branching history of user operations. Elsevier Science. Knowledge Based Systems Journal, 14(1-2):65-74.

[Duke, 2001] Duke, D. (2001). Modular techniques in information visualization. In Proceedings of the Asia-Pacific symposium on Information visualization, páginas 11-18, Sydney, Australia. Australian Computer Society, Inc. 
[Dwyer et al., 2006] Dwyer, T., Marriott, K., e Wybrow, M. (2006). Integrating edge routing into force-directed layout. In Graph Drawing Conference - Series Lecture Notes in Computer Science, LNCS 4372, páginas 8-19, Karlsruhe, Alemanha. Springer-Verlag.

[Eick et al., 1992] Eick, S., Steffen, J., e Summer, E. (1992). A tool for visualizing line oriented software statistics. IEEE Computer Society. IEEE Transactions on Software Engineering Journal, 18:957-968.

[Eick e Karr, 2002] Eick, S. G. e Karr, A. F. (2002). Visual scalability (managing massive datasets). JSTOR. Journal of Computational \& Graphical Statistics, 11(1):22-43.

[Elvins, 1992] Elvins, T. T. (1992). A survey of algorithms for volume visualization. ACM Press. ACM SIGGRAPH Computer Graphics Quarterly Journal, 26(3):194-201.

[Fanea et al., 2005] Fanea, E., Carpendale, S., e Isenberg, T. (2005). An interactive 3d integration of parallel coordinates and star glyphs. In IEEE Symposium on Information Visualization, páginas 20-27, Minneapolis, MN, EUA. IEEE Computer Society.

[Fayyad et al., 1996] Fayyad, U., Piatetsky-Shapiro, G., e Smyth, P. (1996). From data mining to knowledge discovery in databases. AAAI Press. AI Magazine Journal, 17(3):37-54.

[Feiner e Beshers, 1990] Feiner, S. K. e Beshers, C. (1990). Worlds within worlds: Metaphors for exploring n-dimensional virtual worlds. In Conference on User Interface Software and Technology, páginas 76-83, New York, EUA. Acm Press.

[Fekete e Plaisant, 2002] Fekete, J.-D. e Plaisant, C. (2002). Interactive information visualization of a million items. In IEEE Symposium on Information Visualization, páginas 117-124, Boston, MA, EUA. IEEE Computer Society.

[Fruchterman e Reingold, 1991] Fruchterman, T. M. J. e Reingold, E. M. (1991). Graph drawing by force-directed placement. Wiley InterScience. Software - Practice and Experience Journal, 21(11):1129-1164.

[Fua et al., 1999] Fua, Y.-H., Ward, M. O., e Rundensteiner, E. A. (1999). Hierarchical parallel coordinates for exploration of large datasets. In IEEE Visualization '99, páginas 43-50, San Francisco, CA, EUA. IEEE Computer Society Press.

[Furnas, 1986] Furnas, G. W. (1986). Generalized fisheye views. In ACM Conference on Human Factors in Computing Systems, páginas 16-23, Boston, Massachusetts, EUA. ACM Press.

[Gattis, 2001] Gattis, M. (2001). Article - Spatial Schemas and Abstract Thought, páginas 2-12. - Space as a Basis for Abstract Thought, ISBN 0262072130. Cambridge, Massachusetts:The MIT Press.

[Gibson, 1983] Gibson, J. J. (1983). The Senses Considered as Perceptual Systems. ISBN 978-0313239618. Greenwood Press Reprint.

[Goebel e Gruenwald, 1999] Goebel, M. e Gruenwald, L. (1999). A survey of data mining software tools. ACM Press. SIGKDD Explorations - Newsletter of the Special Interest Group on Knowledge Discovery \& Data Mining, 1(1):20-33. 
[Grinstein e Ward, 2002] Grinstein, G. G. e Ward, M. O. (2002). Artigo - Introduction to Data Visualization, páginas 21-45. - Information Visualization in Data Mining and Knowledge Discovery, ISBN 1558606890. Morgan Kaufmann Publishers, ICMSC /68U15.05^I43^e.1.

[Hao et al., 2006] Hao, M. C., Keim, D. A., Dyal, U., e Shneidewind, J. (2006). Business process impact visualization and anomaly detection. Palgrave. Information Visualization Journal, 5(1):15-17.

[Heuer, 1999] Heuer, R. (1999). Psychology of Intelligence Analysis. ISBN 978-0160590351. Washington, D.C.:U.S. Government Printing Office, 210 pp.

[Inselberg e Dimsdale, 1990] Inselberg, A. e Dimsdale, B. (1990). Parallel coordinates: A tool for visualizing multi-dimensional geometry. In IEEE Conference on Visualization, páginas 361-378. IEEE Computer Society Press.

[Jensen, 2000] Jensen, J. F. (2000). Capítulo - Virtual inhabited 3D Worlds: Interactivity and Interaction Between Avatars, Autonomous Agents and Users. ISBN 1852333316. London: Springer-Verlag.

[Jern et al., 2006] Jern, M., Banissi, E., Andreinko, G., Müller, W., e Keim, D. (2006). European research forum panel session envisioning research challenges in visual analytics. In International Conference on Information Visualization, páginas 5-8, Londres, UK. IEEE Computer Society Press.

[Johansson et al., 2005] Johansson, J., Ljung, P., Jern, M., e Cooper, M. (2005). Revealing structure within clustered parallel coordinates displays. In International Conference on Information Visualization, páginas 125-132, Londres, UK. IEEE Computer Society Press.

[Johnson et al., 2006] Johnson, C., Moorhead, R., Munzner, T., Pfister, H., Rheingans, P., e Yoo, T. S. (2006). NIH/NSF Visualization Research Challenges. ISBN 0-7695-2733-7. Los Alamitos, CA, EUA: IEEE Computer Society Press, online: http://tab.computer.org/vgtc/vrc/NIH-NSF-VRC-Report-Final.pdf.

[Kandogan, 2001] Kandogan, E. (2001). Visualizing multi-dimensional clusters, trends, and outliers using star coordinates. In ACM SIGKDD International Conference on Knowledge Discovery and Data Mining, páginas 107-116, San Francisco, CA, EUA. ACM Press.

[Karypis e Kumar, 1995] Karypis, G. e Kumar, V. (1995). Multilevel graph partitioning schemes. In IEEE/ACM Int. Conference on Parallel Processing, páginas 113-122, UrbanaChampain, Illinois, EUA. CRC Press.

[Kees e Rose, 1994] Kees, T. S. e Rose, R. R. (1994). Advanced information processing and analysis steering group: intelligence community. SPIE. Proceedings of the The International Society for Optical Engineering - Coupling Technology to National Need, 2102:115-121.

[Keim, 1997] Keim, D. A. (1997). Visual database exploration techniques. In Tutorial at the International Conference on Knowledge Discovery and Data Mining, California, EUA. AAAI Press. 60 slides.

[Keim, 2000] Keim, D. A. (2000). Designing pixel-oriented visualization techniques: Theory and applications. IEEE Computer Society. IEEE Transactions on Visualization and Computer Graphics Journal, 6(1):59-78. 
[Keim, 2002] Keim, D. A. (2002). Information visualization and visual data mining. IEEE Computer Society. IEEE Transactions on Visualization and Computer Graphics Journal, 8(1):1-8.

[Keim et al., 1995] Keim, D. A., Ankerst, M., e Kriegel, H.-P. (1995). Recursive pattern: A technique for visualizing very large amounts of data. In IEEE Conference on Visualization, páginas 279-286, Washington, DC, EUA. IEEE Computer Society.

[Keim et al., 2002] Keim, D. A., Hao, M. C., e Dayal, U. (2002). Hierarchical pixel bar charts. IEEE Computer Society. IEEE Transactions on Visualization and Computer Graphics Journal, 08(3):255-269.

[Keim et al., 2001] Keim, D. A., Hao, M. C., Dayal, U., Hsu, M., e Dayal, U. (2001). Pixel bar charts: A new technique for visualizing large multi-attribute data sets without aggregation. In IEEE Symposium on Information Visualization, páginas 113-122, San Diego, California, EUA. IEEE Computer Society.

[Keim e Kriegel, 1994] Keim, D. A. e Kriegel, H.-P. (1994). Visdb: Database exploration using multidimensional visualization. IEEE Computer Society Press. IEEE Computer Graphics and Applications Journal, 14(5):40-49.

[Kimchi, 1998] Kimchi, R. (1998). Uniform connectedness and grouping in the perceptual organization of hierarchical patterns. American Psychological Association. Journal of Experimental Psychology: Human Perception and Performance, 24:1105-1118.

[Koffka, 1935] Koffka, K. (1935). Principles of Gestalt psychology. International library of psychology, philosophy and scientific method. ISBN 978-0156744607. New York : Harcourt, Brace and Company, 720 pp. - online: http://gestalttheory.net/ - FFLCH /150.19^K78p^e.1.

[Kuhn e Blumenthal, 1996] Kuhn, W. e Blumenthal, B. (1996). Spatialization: Spatial metaphors for user interfaces. In Conference companion on Human factors in computing systems, páginas 346-347, New York, NY, EUA. ACM Press.

[Lamping et al., 1995] Lamping, J., Rao, R., e Pirolli, P. (1995). A focus+context technique based on hyperbolic geometry for visualizing large hierarchies. In ACM SIGCHI conference on Human factors in computing systems, páginas 401-408, Denver, Colorado, EUA. ACM/Addison-Wesley.

[LeBlanc et al., 1990] LeBlanc, J., Ward, M. O., e Wittels, N. (1990). Exploring n-dimensional databases. In IEEE Conference on Visualization, páginas 230-237, San Francisco, California, EUA. IEEE Computer Society Press.

[Leung e Apperley, 1994] Leung, Y. K. e Apperley, M. D. (1994). A review and taxonomy of distortion-oriented presentation techniques. ACM Press. Transactions on Computer-Human Interaction Journal, 1(2):126-160.

[Lohse et al., 1994] Lohse, G. L., Biolsi, K., Walker, N., e Rueter, H. H. (1994). A classification of visual representations. ACM Press. Communication of ACM Journal, 37(12):36-49. 
[Lyman e Varian, 2003] Lyman, P. e Varian, H. (2003). How much information? In Online research. SIMS, University of California at Berkeley, CA, US. online: http://www.sims.berkeley.edu/how-much-info-2003. Aix-en-Provence, France.

[Mackinlay, 1986] Mackinlay, J. (1986). Automating the design of graphical presentations of relational information. ACM Press. Transactions on Graphics Journal, 5(2):110-141.

[Mackinlay et al., 1991] Mackinlay, J. D., Robertson, G. G., e Card, S. K. (1991). The perspective wall: detail and context smoothly integrated. In SIGCHI conference on Human factors in computing systems, páginas 173-176, New Orleans, Louisiana, EUA. ACM Press.

[Marcus, 1995] Marcus, A. (1995). Artigo - Principles of Effective Visual Communication for Graphical User Interface Design, páginas 425-435. - Readings in Human-Computer Interaction. Towards the Year 2000, ISBN 1558602461. San Francisco:Morgan Kaufmann, ICMSC /68U25.01^R287.2^e.1.

[Martin e Ward, 1995] Martin, A. R. e Ward, M. O. (1995). High dimensional brushing for interactive exploration of multivariate data. In IEEE Conference on Visualization, páginas 271-278, Washington, DC, EUA. IEEE Computer Society.

[Minghim et al., 2002] Minghim, R., Salvador, V. C. L., Freitas, B. S., Oliveira, M. C. F., Nonato, L. G., e Mun, S. K. (2002). Distributed sound for volumes: data analysis using distributed visualization and sonification. SPIE. Proceedins of The International Society for Optical Engineering, 4665:379-390.

[Nekrasovski et al., 2006] Nekrasovski, D., Bodnar, A., McGrenere, J., Guimbreti\&\#232;re, F., e Munzner, T. (2006). An evaluation of pan \& zoom and rubber sheet navigation with and without an overview. In Proceedings of the SIGCHI conference on Human Factors in computing systems, páginas 11-20, Montr\&\#233;al, Qu\&\#233;bec, Canada. ACM Press.

[Nesbitt, 2005] Nesbitt, K. V. (2005). Using guidelines to assist in the visualization design process. In Proceedings of the Asia-Pacific symposium on Information visualization, páginas 115-123, Sydney, Australia. Australian Computer Society, Inc.

[Ng, 2000] Ng, K.-C. (2000). Interactive Visualization techniques for Ontology Development. $\mathrm{PhD}$ thesis, Department of Computer Science. University of Manchester, UK. $273 \mathrm{pp}$.

[Nguyen e Huang, 2005] Nguyen, Q. V. e Huang, M. L. (2005). Enccon: an approach to constructing interactive visualization of large hierarchical data. Palgrave. Information Visualization Journal, 4:1-21.

[Norman, 1990] Norman, D. A. (1990). The design of everyday things. ISBN 0385267746. New York:Basic Books, ICMSC /00-00^N842de^e.1.

[Norman, 1993a] Norman, D. A. (1993a). Cognition in the head and in the world: An introduction to the special issue on situated action. Cognitive Science Society, Inc. Cognitive Science Journal, 17(1):1-6.

[Norman, 1993b] Norman, D. A. (1993b). Things that make us smart: defending human attributes in the age of the machine. ISBN 0201626950. Reading, Mass : Perseus Books, 290 pp. - ICMSC /68U25.01^N842tt^e.1. 
[Oliveira e Minghim, 1997] Oliveira, M. C. F. e Minghim, R. (1997). Cap. 3 - Uma Introdução à Visualização Computacional, páginas 85-131. - Curso JAI-03, XVII Congresso da SBC, Brasilia, Brazil.

[Palmer, 1999] Palmer, S. E. (1999). Vision Science - Photons to Phenomenology. ISBN 9780262161831. Cambridge, Massachusetts:The MIT Press.

[Phan et al., 2005] Phan, D., Xiao, L., Yeh, R., Hanrahan, P., e Winograd, T. (2005). Flow map layout. In IEEE Symposium on Information Visualization, páginas 29-34, Minneapolis, MN, EUA. IEEE Computer Society.

[Pickett e Grinstein, 1988] Pickett, R. M. e Grinstein, G. G. (1988). Iconographic displays for visualizing multidimensional data. In IEEE Conference on Systems, Man and Cybernetics, volume 1, páginas 514-519.

[Pirolli e Card, 2005] Pirolli, P. e Card, S. (2005). The sensemaking process and leverage points for analyst technology as identified through cognitive task analysis. In International Conference on Intelligence Analysis. 2-4.

[Pylyshyn et al., 1994] Pylyshyn, Z., .Burkell, J., Fisher, B., Sears, C., Schmidt, W., e Trick, L. (1994). Multiple parallel access in visual attention. Canadian Psychological Association. Canadian Journal of Experimental Psychology, 48(2):260-283.

[Rao e Card, 1994] Rao, R. e Card, S. K. (1994). The table lens: Merging graphical and symbolic representation in an interactive focus+context visualization for tabular information. In Conference on Human Factors in Computing Systems, páginas 318-322, Boston, Massachusetts, EUA. ACM Press.

[Rhyne et al., 2003] Rhyne, T.-M., Tory, M., Munzner, T., Ward, M., Johnson, C., e Laidlaw, D. H. (2003). Information and scientific visualization: Separate but equal or happy together at last. In IEEE Visualization, página 115, Washington, DC, EUA. IEEE Computer Society.

[Robertson et al., 1998] Robertson, G., Czerwinski, M., Larson, K., Robbins, D. C., Thiel, D., e van Dantzich, M. (1998). Data mountain: Using spatial memory for document management. In ACM Symposium on User Interface Software and Technology, páginas 153-162, San Francisco, CA, EUA. ACM Press.

[Robertson, 1991] Robertson, P. K. (1991). A methodology for choosing data representations. IEEE Computer Society Press. IEEE Computer Graphics and Applications Journal, 11(3):56-67.

[Rodrigues Jr. et al., 2003a] Rodrigues Jr., J. F., Castañón, C. A. B., Traina, A. J. M., e Traina Jr., C. (2003a). Using efficient visual exploration techniques to evaluate features for content-based image retrieval. In Oliveira, M. C. F. e Cesar Jr., R. M., editores, Simpósio Brasileiro de Computação Gráfica e Processamento de Imagens, volume 1, páginas 183-190, São Carlos - SP. São Carlos, SP, Brasil.

[Rodrigues Jr. et al., 2007a] Rodrigues Jr., J. F., Tong, H., Traina, A. J. M., e Faloutsos, C. (2007a). Large graph visualization with gmine. ACM Press. Transactions on Applied Perception Journal. Artigo completo submetido em 04/2007 - 28 pp. 
[Rodrigues Jr. et al., 2006a] Rodrigues Jr., J. F., Tong, H., Traina, A. J. M., Faloutsos, C., e Leskovec, J. (2006a). GMine: A system for scalable, interactive graph visualization and mining. In The 32nd International Conference on Very Large Data Bases, páginas 11951198, Seul, Coréia do Sul. ACM Press.

[Rodrigues Jr. et al., 2006b] Rodrigues Jr., J. F., Traina, A. J. M., Faloutsos, C., e Traina Jr., C. (2006b). Supergraph visualization. In The 8th IEEE International Symposium on Multimedia, páginas 227-234, San Diego, CA, EUA. IEEE Press.

[Rodrigues Jr. et al., 2003b] Rodrigues Jr., J. F., Traina, A. J. M., e Traina Jr., C. (2003b). Enhancing data visualization techniques. In Simoff, S. J., Noirhomme-Fraiture, M., e Böhlen, M. H., editores, Third IEEE Intl. Workshop on Visual Data Mining - VDM@ICDM'03, volume 1, páginas 97-112, Melbourne, CA, EUA. IEEE CS.

[Rodrigues Jr. et al., 2005] Rodrigues Jr., J. F., Traina, A. J. M., e Traina Jr., C. (2005). Visualization tree, multiple linked analytical decisions. In The 5th International Symposium on Smart Graphics - Series Lecture Notes in Computer Science, LNCS 3638, páginas 65-76, Munique, Alemanha. Berlin Heidelberg:Springer-Verlag.

[Rodrigues Jr. et al., 2007b] Rodrigues Jr., J. F., Traina, A. J. M., e Traina Jr., C. (2007b). Capítulo de livro - Mining Patterns for Visual Interpretation in a Multiple Views Environment, chapter Artigo completo aguardando publicação - 19 pp. - Visual Data Mining: Theory, Techniques and Tools, Simeon Simoff, editor, Springer-Verlag.

[Rodrigues Jr. et al., 2006c] Rodrigues Jr., J. F., Traina, A. J. M., Oliveira, M. C. F., e Traina Jr., C. (2006c). Reviewing data visualization: an analytical taxonomical study. In The 10th International Conference on Information Visualization, páginas 713-720, Londres, UK. IEEE Computer Society Press.

[Rodrigues Jr. et al., 2007c] Rodrigues Jr., J. F., Traina, A. J. M., Oliveira, M. C. F., e Traina Jr., C. (2007c). The spatial/perceptual design space: a new comprehension for data visualization. Palgrave. Information Visualization Journal. Artigo completo submetido em 12/2006 - 40 pp.

[Rohrer et al., 1998] Rohrer, R. M., Sibert, J. L., e Ebert, D. S. (1998). The shape of shakespeare: Visualizing text using implicit surfaces. In IEEE Symposium on Information Visualization, páginas 121-129, North Carolina, EUA. IEEE Computer Society.

[Rundensteiner et al., 2002] Rundensteiner, E. A., Ward, M. O., Yang, J., e Doshi, P. R. (2002). Xmdvtool: visual interactive data exploration and trend discovery of high-dimensional data sets. In ACM SIGMOD International Conference on Management of Data, página 631, Madison, Wisconsin, EUA. ACM Press.

[Sarkar e Brown, 1994] Sarkar, M. e Brown, M. H. (1994). Graphical fisheye views. ACM Press. Communications of the ACM Journal, 37(12):73-83.

[Scaife e Rogers, 1996] Scaife, M. e Rogers, Y. (1996). External cognition: How do graphical representations work? Elsevier Science. International Journal of Human-Computer Studies, 45(2):185-213. 
[Senay e Ignatius, 1990] Senay, H. e Ignatius, E. (1990). Rules and principles of scientific data visualization. In Paper presented at the State of the art in data visualization (ACM) SIGGRAPH Course Notes. ACM Press. online: http://www.siggraph.org/education/materials/HyperVis/percept/visrules.htm.

[Shneiderman, 1992] Shneiderman, B. (1992). Tree visualization with tree-maps: 2-d spacefilling approach. ACM Press. Transactions on Graphics Journal, 11(1):92-99.

[Shneiderman, 1996] Shneiderman, B. (1996). The eyes have it: A task by data type taxonomy of information visualizations. In IEEE Symposium on Visual Languages, páginas 336-343, Colorado, EUA. IEEE Computer Society.

[Shneiderman e Plaisant, 2005] Shneiderman, B. e Plaisant, C. (2005). Designing the User Interface: Strategies for Effective Human-Computer Interaction. ISBN 0321197852. AddisonWesley Publishing, 652 pp. - ICMSC /68U25.10^S358d.4^e.1.

[Silva et al., 2005] Silva, C. T., ao L. D. Comba, J., Bernardon, F. F., e Callahan, S. P. (2005). A survey of gpu-based volume rendering of unstructured grids. Instituto de Informática da Universidade Federal do Rio Grande do Sul. Revista de Informática Teórica e Aplicada, 12-2:9-29.

[Spence, 2000] Spence, R. (2000). Information Visualization. ISBN 0201596261. Harlow : Addison-Wesley, 206 pp. - ICMSC /68U15.05^S744iv^e.1.

[Team, 2004] Team, I. U. E. (2004). User engineering - version 1.10. In IBM Ease of Use. online: http://www-03.ibm.com/easy/page/1996.

[Thomas e Cook, 2005] Thomas, J. J. e Cook, K. A., editores (2005). Illuminating the Path: The Research and Development Agenda for Visual Analytics. ISBN 0-7695-2323-4. IEEE Press, 184 pp. - online: http://nvac.pnl.gov/agenda.stm.

[Tory e Möller, 2002] Tory, M. e Möller, T. (2002). A model-based visualization taxonomy. Relatório Técnico SFU-CMPT-TR2002-06, Computing Science Dept., Simon Fraser University. 4 pp.

[Tory e Möller, 2004] Tory, M. e Möller, T. (2004). Rethinking visualization: A high-level taxonomy. In IEEE Information Visualization, páginas 151-158, Austin, Texas, EUA. IEEE Computer Society.

[Treisman, 1985] Treisman, A. (1985). Preattentive processing in vision. Elsevier Science. Computer Vision, Graphics and Image Processing Journal, 31(2):156-177.

[Tversky, 2001] Tversky, B. (2001). Spatial Schemas in Depictions, páginas 79-111. - Spatial Schemas and Abstract Thought - M. Gattis, editor, Cambridge, Massachusetts: The MIT Press.

[Tversky et al., 2002] Tversky, B., Morrison, J. B., e Betrancourt, M. (2002). Animation: can it facilitate? Minnesota:Academic Press Inc. International Journal of Human-Computer Studies, 57:274-262.

[Tweedie, 1997] Tweedie, L. (1997). Characterizing interactive externalizations. In ACM SIGCHI conference on Human factors in computing systems, páginas 375-382, Atlanta, Georgia, EUA. ACM Press. online: http://acm.org/sigchi/chi97/proceedings/paper/lt.htm\#U11. 
[Upson et al., 1989] Upson, C., Faulhaber Jr., T., Kamins, D., Laidlaw, D. H., Schlegel, D., Vroom, J., Gurwitz, R., e van Dam, A. (1989). The application visualization system: A computational environment for scientific visualization. IEEE Computer Society Press. IEEE Computer Graphics and Applications Journal, 9(4):30-42.

[Walter e Ritter, 2002] Walter, J. A. e Ritter, H. (2002). On interactive visualization of highdimensional data using the hyperbolic plane. In ACM International Conference on Knowledge Discovery and Data Mining, páginas 123-132, Edmonton, Alberta, Canada. ACM Press.

[Waltz, 2003] Waltz, E. (2003). Knowledge Management in the Intelligence Enterprise. Artech House Information Warfare Library. ISBN 978-1580534949. Boston:Artech House, 512 pp.

[Ward, 1997] Ward, M. (1997). Creating and manipulating n-dimensional brushes. In Proceedings of the Joint Statistical Meeting, páginas 6-14.

[Ward, 1994] Ward, M. O. (1994). Xmdvtool: Integrating multiple methods for visualizing multivariate data. In IEEE Conference on Visualization, páginas 326-333, Washinton, D.C., EUA. IEEE Computer Society Press.

[Ward e Yang, 2004a] Ward, M. O. e Yang, J. (2004a). Interaction spaces in data and information visualization. In Eurographics/IEEE TCVG Symposium on Visualization, páginas 137-145, Konstanz, Alemanha. Eurographics Association.

[Ward e Yang, 2004b] Ward, M. O. e Yang, J. (2004b). Interaction spaces in data and information visualization. In Joint Eurographics - IEEE TCVG Symposium on Visualization, páginas 137-145, Konstanz, Alemanha. Eurographics Association.

[Ware, 2004] Ware, C. (2004). Information Visualization: Perception for design. ISBN 1558608192. San Francisco, CA: Morgan Kaufman, 486 pp. - ICMSC /68U15.05^W267i.2^e.1.

[Wegman e Luo, 1997] Wegman, E. J. e Luo, Q. (1997). High dimensional clustering using parallel coordinates and the grand tour. The American Statistical Association. Computing Science and Statistics Journal, 28:352-360.

[Wilhelms e Gelder, 1991] Wilhelms, J. e Gelder, A. V. (1991). A coherent projection approach for direct volume rendering. ACM Press. SIGGRAPH Computer Graphics Journal, 25(4):275-284.

[Wiss e Carr, 1998] Wiss, U. e Carr, D. (1998). A cognitive classification framework for 3dimensional information visualization. Relatório Técnico LTU-TR-1998/4-SE, Lulea, University of Technology: Computer Science and Electrical Engineering / Software Engineering. $17 \mathrm{pp}$.

[Yang et al., 2002] Yang, J., Ward, M. O., e Rundensteiner, E. A. (2002). Interring: An interactive tool for visually navigating and manipulating hierarchical structures. In IEEE Symposium on Information Visualization, páginas 77-84, Boston, MA, EUA. IEEE Computer Society.

[Young et al., 1993] Young, F. W., Faldowski, R. A., e McFarlane, M. M. (1993). Multivariate Statistical Visualization, - páginas 959-998. Elsevier Science. 